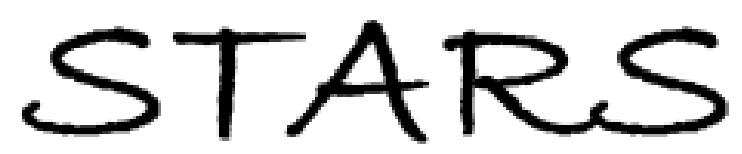

University of Central Florida

STARS

\title{
Treatment of Leachate Organic Matter through Sunlight Driven Processes
}

Duncan Lozinski

University of Central Florida

\section{Part of the Environmental Engineering Commons}

Find similar works at: https://stars.library.ucf.edu/etd

University of Central Florida Libraries http://library.ucf.edu

This Masters Thesis (Open Access) is brought to you for free and open access by STARS. It has been accepted for inclusion in Electronic Theses and Dissertations by an authorized administrator of STARS. For more information, please contact STARS@ucf.edu.

\section{STARS Citation}

Lozinski, Duncan, "Treatment of Leachate Organic Matter through Sunlight Driven Processes" (2018). Electronic Theses and Dissertations. 5780.

https://stars.library.ucf.edu/etd/5780

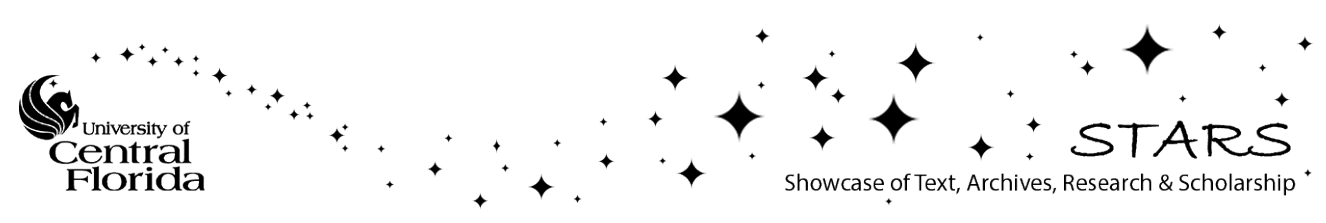


TREATMENT OF LEACHATE ORGANIC MATTER THROUGH SUNLIGHT DRIVEN PROCESSES

by

DUNCAN JOSEPH LOZINSKI, EI

B.S. University of Central Florida, 2016

A thesis submitted in partial fulfillment of the requirements for the degree of Master of Science

in the Department of Civil, Environmental, and Construction Engineering

in the College of Engineering and Computer Science at the University of Central Florida Orlando, Florida

Spring Term

2018

Major Professor: Debra R. Reinhart 
(C)2018 Duncan Joseph Lozinski, EI 


\begin{abstract}
The ability to manage leachate during post-closure care (PCC) of a landfill may be increasingly difficult as leachate organic matter (LOM) becomes recalcitrant when a landfill ages, requiring advanced and costly treatment technologies. This research investigated the ability to treat LOM through sunlight driven processes, with a focus on photolysis, to provide insight to landfill owners and operators on the potential of wetlands treatment as a means for reducing long-term risks and costs associated with leachate treatment during PCC.

The study was completed in eight batch tests, where leachate was exposed to natural sunlight in central Florida for a period of 90 days. It was hypothesized that through photolytic reactions, in particular photolysis, high molecular weight recalcitrant LOM would be degraded to labile, low molecular weight material. To identify the treatment mechanisms, transformation processes were measured using ultraviolet-visible (UV-Vis) spectroscopy, fluorescence excitation-emission matrix spectroscopy (EEMs), size-exclusion chromatography (SEC), and chemical oxygen demand (COD) from the beginning to the end of the test period. Additionally, the ability for nitrogen species to become bioavailable when exposed to sunlight was evaluated for two of the leachate samples using solid-phase extraction (SPE) to fractionate recalcitrant dissolved organic nitrogen (rDON) and bioavailable dissolved organic nitrogen (bDON).

Results suggest that treatment of LOM through sunlight driven processes is possible. Treatment is dependent upon the dilution of leachate and characteristics of the LOM. Dilution must be high enough to allow sunlight to penetrate the depth of the liquid. UV-Vis, EEMs, and SEC show that high molecular weight recalcitrant material is undergoing transformation into lower molecular weight material as a result of photolytic and likely biological reactions promoted by
\end{abstract}


sunlight. The ability for nitrogen to become bioavailable when exposed to sunlight was shown to be dependent upon nitrogen concentrations in the sample. 
In dedication to my grandfather Colonel Robert Ernest Spiller

December 25, 1928 - January 13, 2018 


\section{TABLE OF CONTENTS}

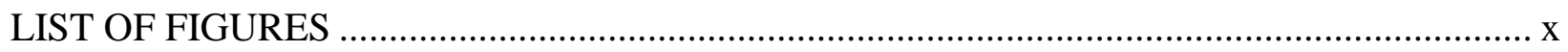

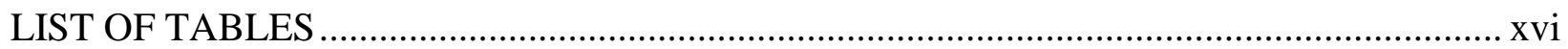

LIST OF ACRONYMS/ABREVIATIONS ...................................................................... xviii

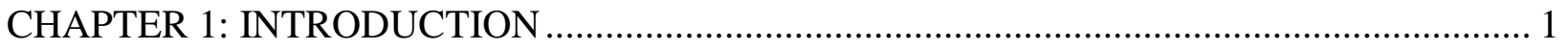

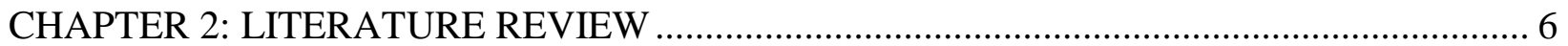

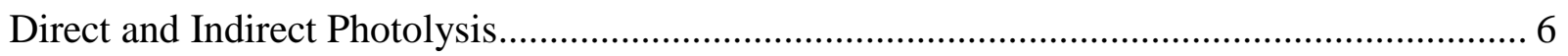

Photochemical Reactions with Dissolved Organic Matter ............................................... 7

Photochemical Reactions with Nitrogen .................................................................... 9

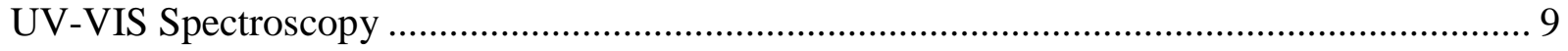

Fluorescence Excitation Emission Matrix Spectroscopy................................................ 11

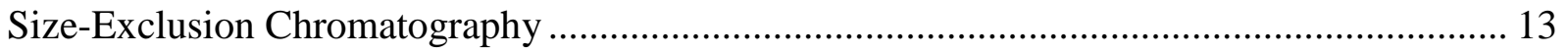

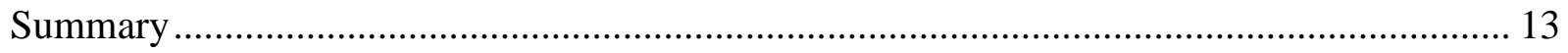

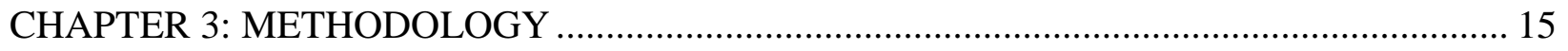

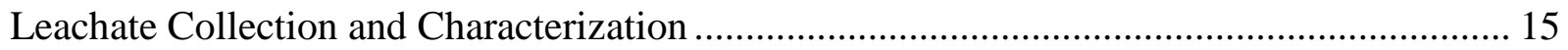

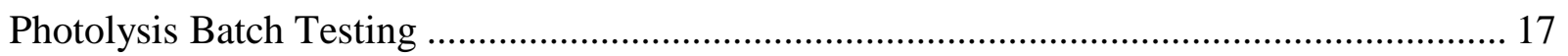

Evaluation of Dissolved Organic Nitrogen Bioavailability of Leachate .............................. 18

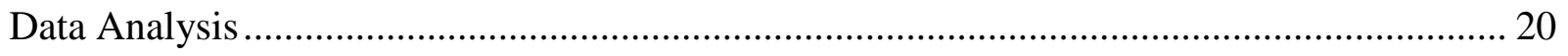

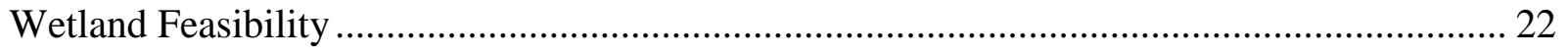

CHAPTER 4: TREATMENT OF LEACHATE ORGANIC MATTER THROUGH SUNLIGHT

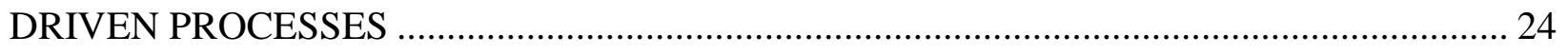

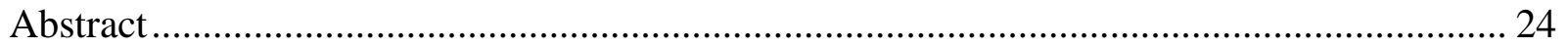

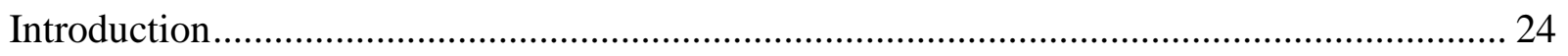




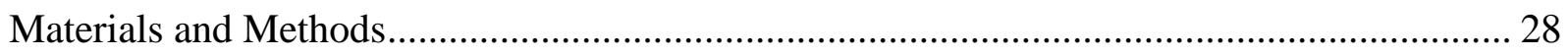

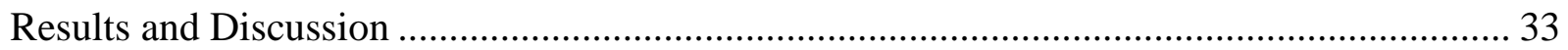

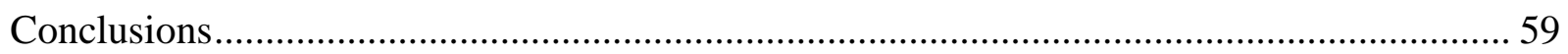

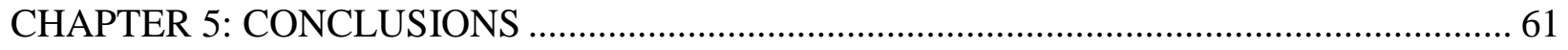

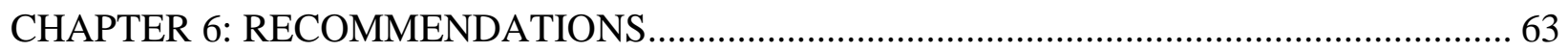

APPENDIX A: RAW LEACHATE SAMPLE CHARACTERISTICS .......................................... 65

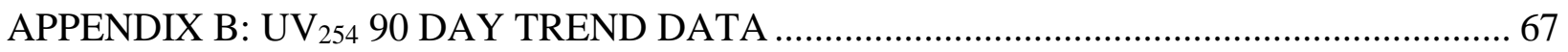

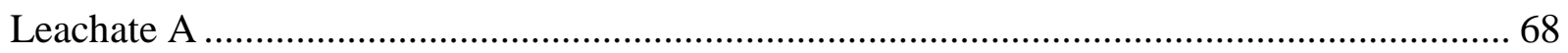

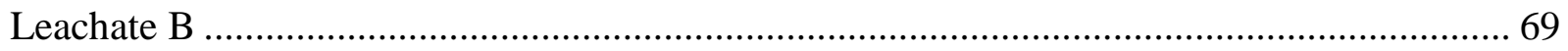

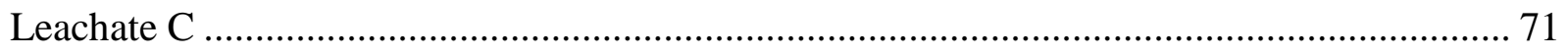

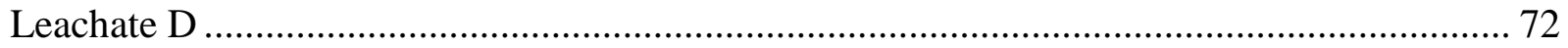

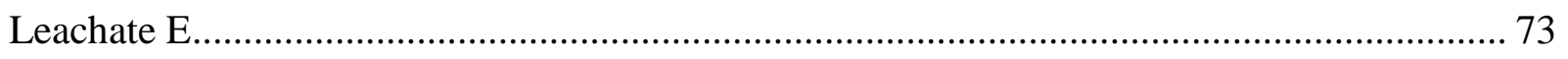

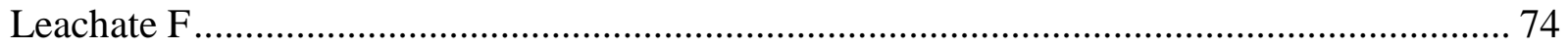

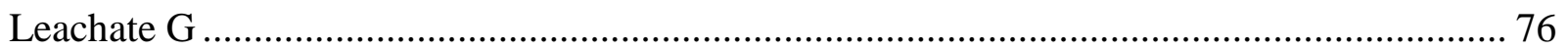

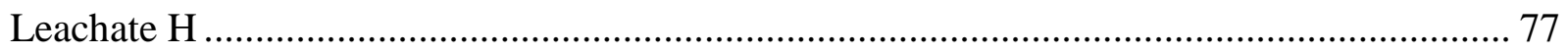

APPENDIX C: DAY 0 AND DAY 90 UV-VIS SCANS.......................................................... 79

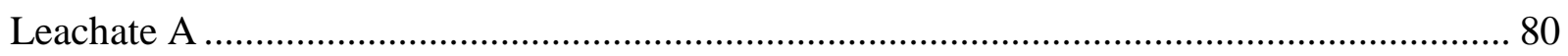

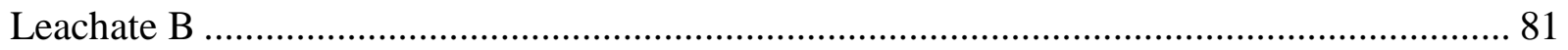

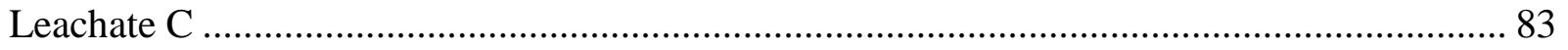

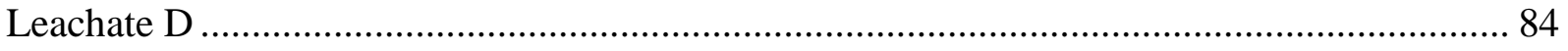

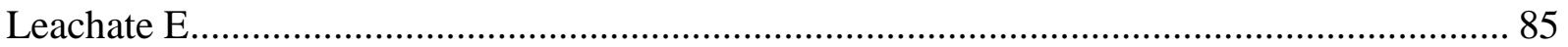

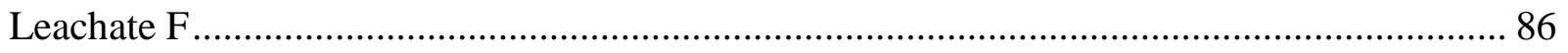

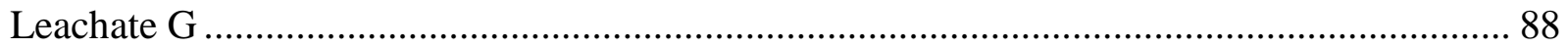




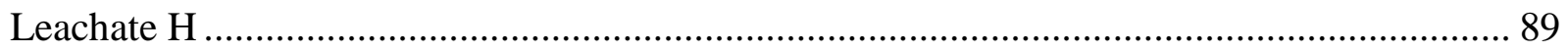

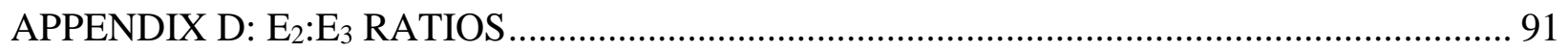

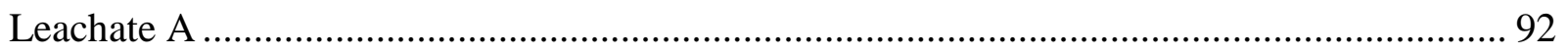

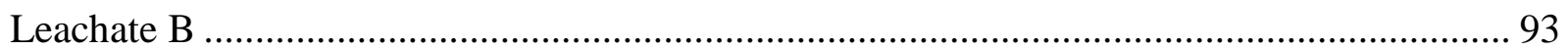

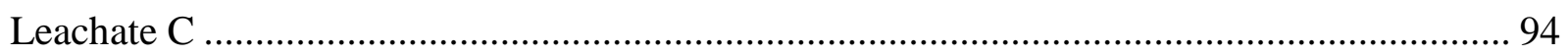

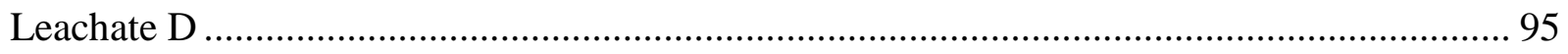

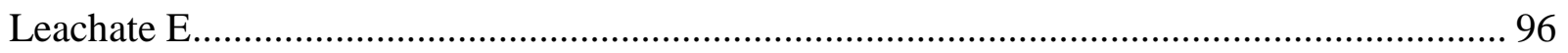

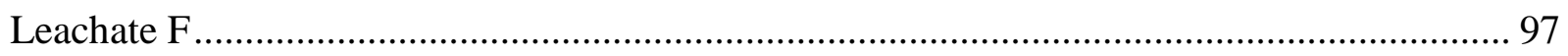

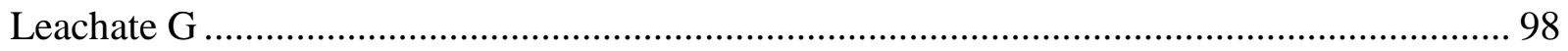

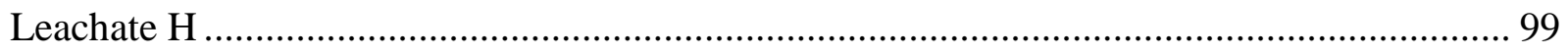

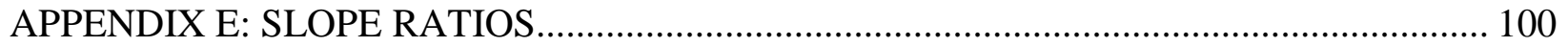

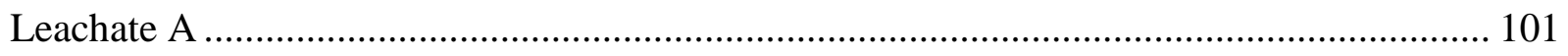

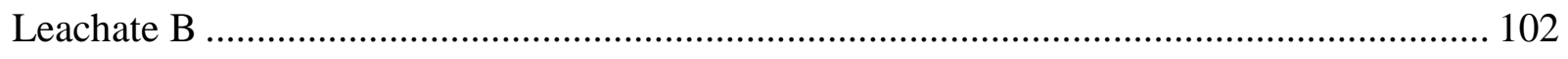

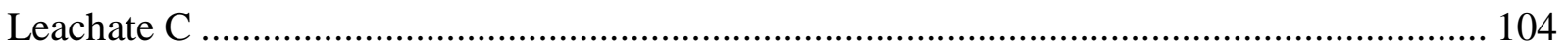

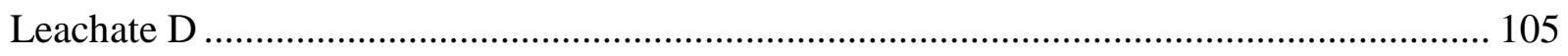

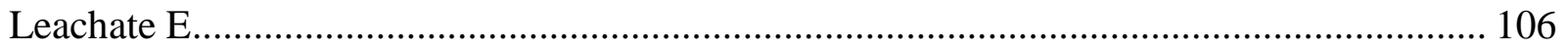

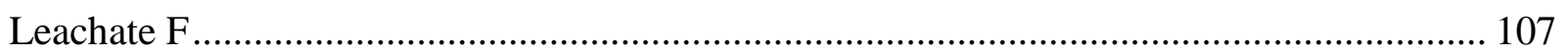

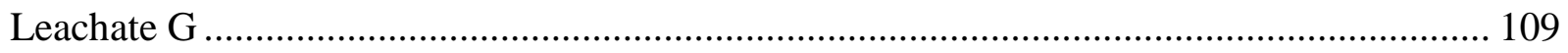

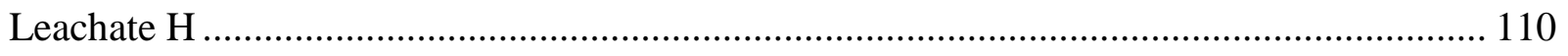

APPENDIX F: FLUORESCENCE EXCITATION EMISSION MATRIX SPECTROSCOPY

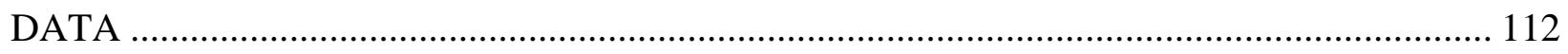

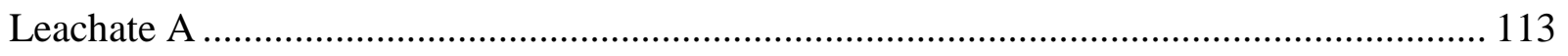

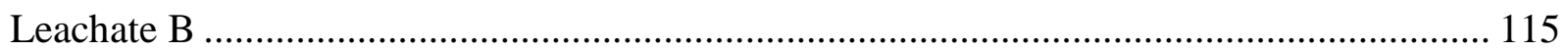




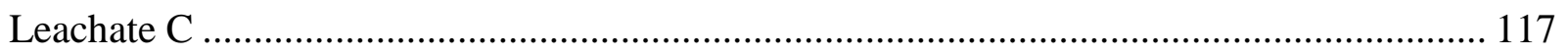

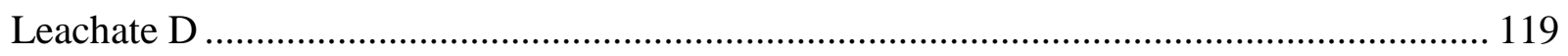

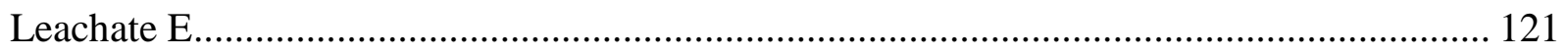

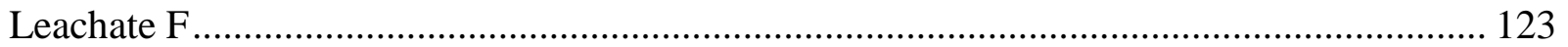

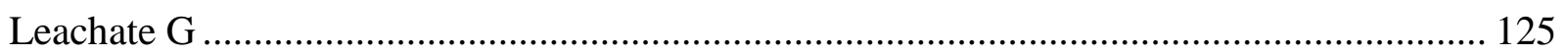

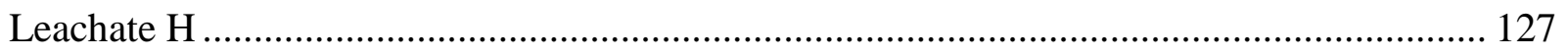

APPENDIX G: SIZE-EXCLUSION CHROMATOGRAPHY DATA ................................... 129

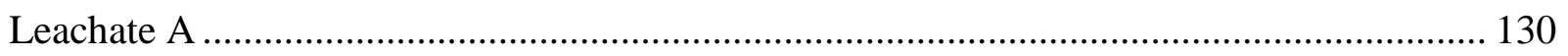

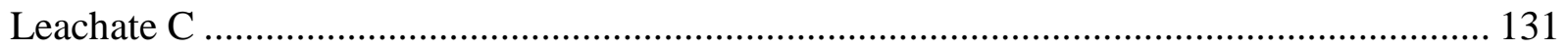

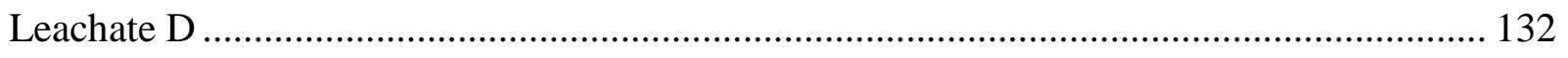

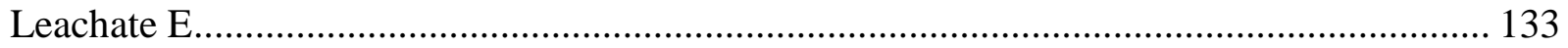

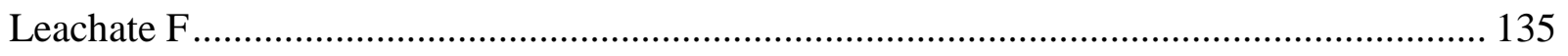

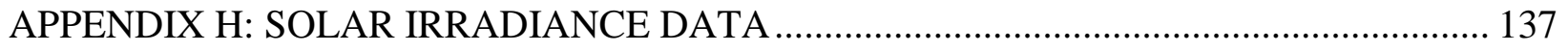

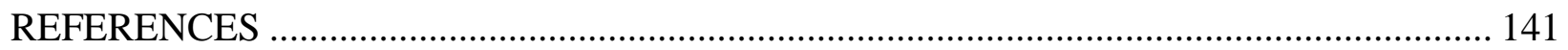




\section{LIST OF FIGURES}

Figure 1-1: Process Schematic of Leachate Organic Matter Treatment through Sunlight Driven

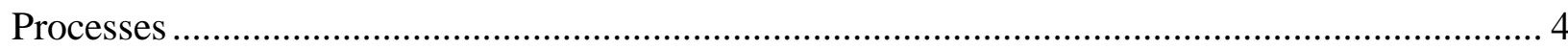

Figure 2-1: Fluorescence Excitation Emission Matrix (EEMs) Output Image........................... 12

Figure 3-1: Empty 2.0 Liter Tedlar Bags Used for Photolysis Testing ................................... 17

Figure 4-1: Percent Reduction of $\mathrm{UV}_{254}$ versus Initial Absorbance ....................................... 35

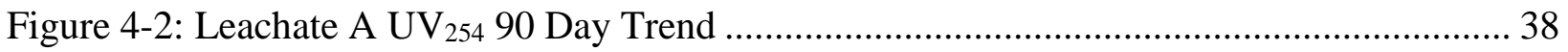

Figure 4-3: Leachate A No Dilution Day 0 and Day 90 UV-Vis Scans .................................. 39

Figure 4-4: Leachate A 1:10 Dilution Day 0 and Day 90 UV-Vis Scans ................................ 39

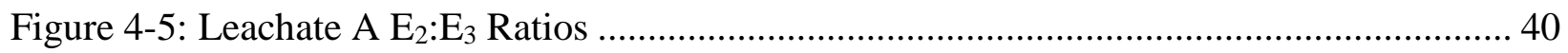

Figure 4-6: Leachate A No Dilution Day 0 and Day 90 Slope Ratios..................................... 42

Figure 4-7: Leachate A 1:10 Dilution Day 0 and Day 90 Slope Ratios .................................. 42

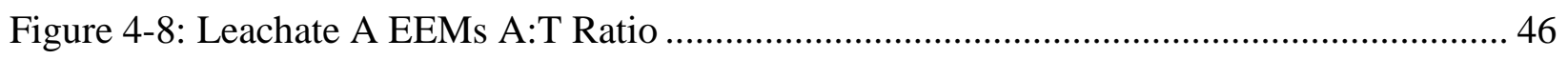

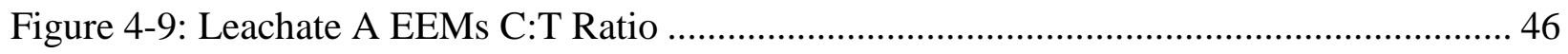

Figure 4-10: Leachate A 1:100 Dilution SEC Normalized Peak Areas.................................... 49

Figure 4-11: Leachate H 1:10 Dilution $\mathrm{UV}_{254}$ Trend Over 90 Days ....................................... 50

Figure 4-12: Leachate H 1:50 Dilution UV 254 Trend Over 90 Days ....................................... 51

Figure 4-13: Leachate H 1:10 No Dilution Day 0 and Day 90 UV-Vis Scans.......................... 51

Figure 4-14: Leachate H 1:50 Dilution Day 0 and Day 90 UV-Vis Scans............................... 52

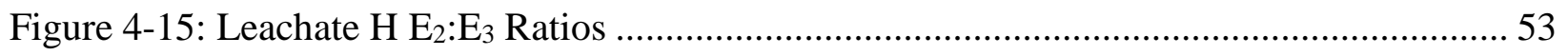

Figure 4-16: Leachate H 1:10 Dilution Day 0 and Day 90 Slope Ratios ................................. 54

Figure 4-17: Leachate H 1:50 Dilution Day 0 and Day 90 Slope Ratios .................................. 54 
Figure 4-18: Leachate H EEMs A:T Ratio …………….............................................................. 55

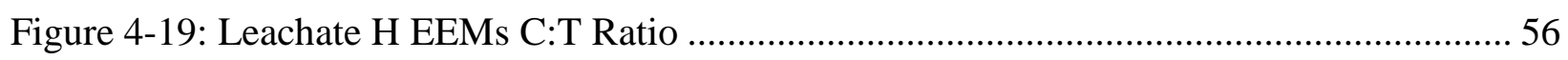

Figure 4-20: Leachates E and F Bioavailability of Dissolved Organic Nitrogen ........................... 57

Figure B-1: Leachate A No Dilution $\mathrm{UV}_{254}$ Trend Over 90 Days ................................................. 68

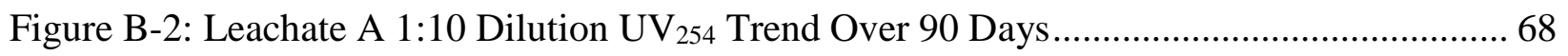

Figure B-3: Leachate A 1:100 Dilution UV $_{254}$ Trend Over 90 Days............................................... 69

Figure B-4: Leachate B No Dilution $\mathrm{UV}_{254}$ Trend Over 90 Days ................................................. 69

Figure B-5: Leachate B 1:10 Dilution $\mathrm{UV}_{254}$ Trend Over 90 Days ............................................. 70

Figure B-6: Leachate B 1:100 Dilution $\mathrm{UV}_{254}$ Trend Over 90 Days ............................................ 70

Figure B-7: Leachate C 1:4.1 Dilution $\mathrm{UV}_{254}$ Trend Over 90 Days .............................................. 71

Figure B-8: Leachate C 1:31 Dilution $\mathrm{UV}_{254}$ Trend Over 90 Days .............................................. 71

Figure B-9: Leachate D 1:2.4 Dilution $\mathrm{UV}_{254}$ Trend Over 90 Days.............................................. 72

Figure B-10: Leachate D 1:16 Dilution $\mathrm{UV}_{254}$ Trend Over 90 Days......................................... 72

Figure B-11: Leachate E No Dilution UV 254 Trend Over 90 Days ................................................ 73

Figure B-12: Leachate E 1:10 Dilution $\mathrm{UV}_{254}$ Trend Over 90 Days .............................................. 73

Figure B-13: Leachate E 1:50 Dilution $\mathrm{UV}_{254}$ Trend Over 90 Days ............................................. 74

Figure B-14: Leachate F No Dilution UV 254 Trend Over 90 Days................................................. 74

Figure B-15: Leachate F 1:10 Dilution UV 254 Trend Over 90 Days ............................................ 75

Figure B-16: Leachate F 1:50 Dilution $\mathrm{UV}_{254}$ Trend Over 90 Days ............................................. 75

Figure B-17: Leachate G No Dilution UV 254 Trend Over 90 Days ................................................ 76

Figure B-18: Leachate G 1:10 Dilution $\mathrm{UV}_{254}$ Trend Over 90 Days............................................. 76

Figure B-19: Leachate G 1:50 Dilution UV 254 Trend Over 90 Days............................................. 77

Figure B-20: Leachate H No Dilution UV 254 Trend Over 90 Days............................................... 77 
Figure B-21: Leachate H 1:10 Dilution $\mathrm{UV}_{254}$ Trend Over 90 Days............................................ 78

Figure B-22: Leachate H 1:50 Dilution $\mathrm{UV}_{254}$ Trend Over 90 Days............................................ 78

Figure C-1: Leachate A No Dilution Day 0 and Day 90 UV-Vis Scans ........................................ 80

Figure C-2: Leachate A 1:10 Dilution Day 0 and Day 90 UV-Vis Scans .................................... 80

Figure C-3: Leachate A 1:100 Dilution Day 0 and Day 90 UV-Vis Scans ................................... 81

Figure C-4: Leachate B No Dilution Day 0 and Day 90 UV-Vis Scans......................................... 81

Figure C-5: Leachate B 1:10 Dilution Day 0 and Day 90 UV-Vis Scans .................................... 82

Figure C-6: Leachate B 1:100 Dilution Day 0 and Day 90 UV-Vis Scans ................................... 82

Figure C-7: Leachate C 1:4.1 Dilution Day 0 and Day 90 UV-Vis Scans ................................... 83

Figure C-8: Leachate C 1:31 Dilution Day 0 and Day 90 UV-Vis Scans ..................................... 83

Figure C-9: Leachate D 1:2.4 Dilution Day 0 and Day 90 UV-Vis Scans ..................................... 84

Figure C-10: Leachate D 1:16 Dilution Day 0 and Day 90 UV-Vis Scans .................................... 84

Figure C-11: Leachate E No Dilution Day 0 and Day 90 UV-Vis Scans..................................... 85

Figure C-12: Leachate E 1:10 Dilution Day 0 and Day 90 UV-Vis Scans.................................... 85

Figure C-13: Leachate E 1:40 Dilution Day 0 and Day 90 UV-Vis Scans.................................... 86

Figure C-14: Leachate F No Dilution Day 0 and Day 90 UV-Vis Scans ...................................... 86

Figure C-15: Leachate F 1:10 Dilution Day 0 and Day 90 UV-Vis Scans..................................... 87

Figure C-16: Leachate F 1:40 Dilution Day 0 and Day 90 UV-Vis Scans.................................... 87

Figure C-17: Leachate G No Dilution Day 0 and Day 90 UV-Vis Scans ..................................... 88

Figure C-18: Leachate G 1:10 Dilution Day 0 and Day 90 UV-Vis Scans .................................... 88

Figure C-19: Leachate G 1:50 Dilution Day 0 and Day 90 UV-Vis Scans ................................... 89

Figure C-20: Leachate H No Dilution Day 0 and Day 90 UV-Vis Scans ...................................... 89

Figure C-21: Leachate H 1:10 No Dilution Day 0 and Day 90 UV-Vis Scans .............................. 90 
Figure C-22: Leachate H 1:50 Dilution Day 0 and Day 90 UV-Vis Scans ............................... 90

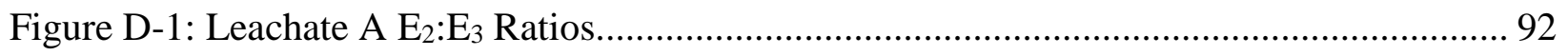

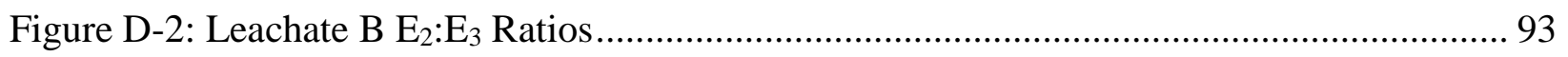

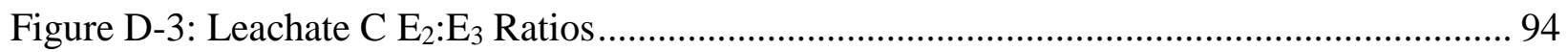

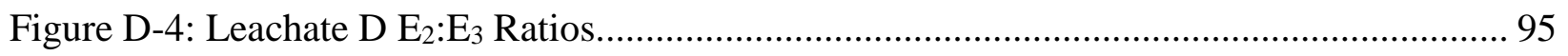

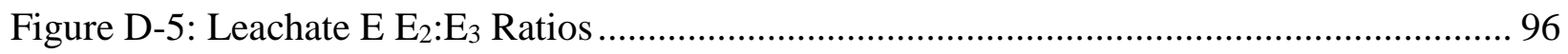

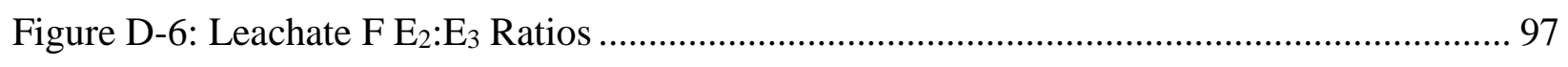

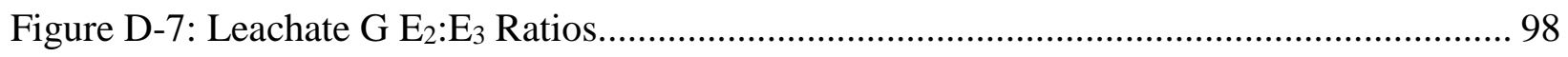

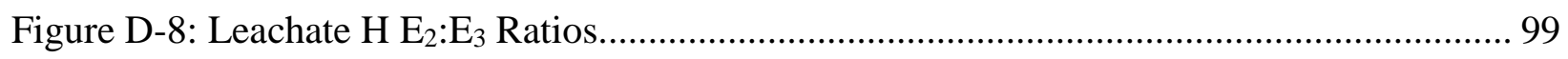

Figure E-1: Leachate A No Dilution Day 0 and Day 90 Slope Ratios ................................... 101

Figure E-2: Leachate A 1:10 Dilution Day 0 and Day 90 Slope Ratios ................................. 101

Figure E-3: Leachate A 1:100 Dilution Day 0 and Day 90 Slope Ratios ................................ 102

Figure E-4: Leachate B No Dilution Day 0 and Day 90 Slope Ratios .................................. 102

Figure E-5: Leachate B 1:10 Dilution Day 0 and Day 90 Slope Ratios ................................. 103

Figure E-6: Leachate B 1:100 Dilution Day 0 and Day 90 Slope Ratios ............................... 103

Figure E-7: Leachate C 1:4.1 Dilution Day 0 and Day 90 Slope Ratios ................................ 104

Figure E-8: Leachate C 1:31 Dilution Day 0 and Day 90 Slope Ratios .................................. 104

Figure E-9: Leachate D 1:2.4 Dilution Day 0 and Day 90 Slope Ratios ................................ 105

Figure E-10: Leachate D 1:16 Dilution Day 0 and Day 90 Slope Ratios ................................ 105

Figure E-11: Leachate E No Dilution Day 0 and Day 90 Slope Ratios.................................. 106

Figure E-12: Leachate E 1:10 Dilution Day 0 and Day 90 Slope Ratios ................................ 106

Figure E-13: Leachate E 1:40 Dilution Day 0 and Day 90 Slope Ratios ............................... 107

Figure E-14: Leachate F No Dilution Day 0 and Day 90 Slope Ratios .................................. 107 
Figure E-15: Leachate F 1:10 Dilution Day 0 and Day 90 Slope Ratios..................................... 108

Figure E-16: Leachate F 1:40 Dilution Day 0 and Day 90 Slope Ratios...................................... 108

Figure E-17: Leachate G No Dilution Day 0 and Day 90 Slope Ratios ........................................ 109

Figure E-18: Leachate G 1:10 No Dilution Day 0 and Day 90 Slope Ratios .............................. 109

Figure E-19: Leachate G 1:50 Dilution Day 0 and Day 90 Slope Ratios ..................................... 110

Figure E-20: Leachate H No Dilution Day 0 and Day 90 Slope Ratios ....................................... 110

Figure E-21: Leachate H 1:10 Dilution Day 0 and Day 90 Slope Ratios .................................... 111

Figure E-22: Leachate H 1:50 Dilution Day 0 and Day 90 Slope Ratios ..................................... 111

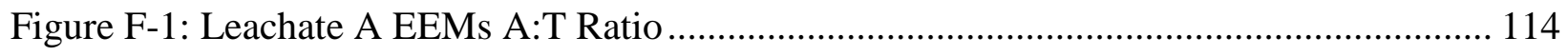

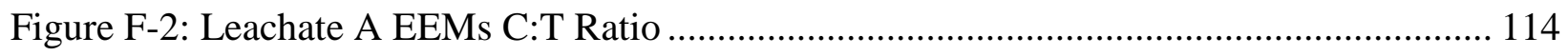

Figure F-3: Leachate B EEMs A:T Ratio ………................................................................. 116

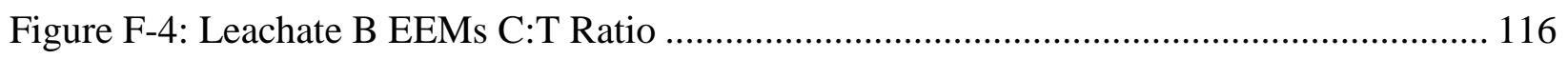

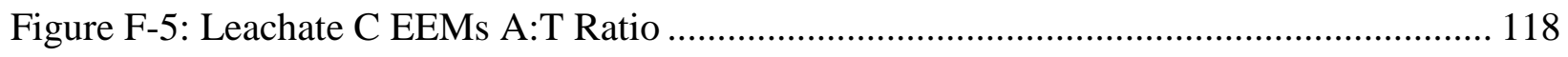

Figure F-6: Leachate C EEMs C:T Ratio …………………................................................. 118

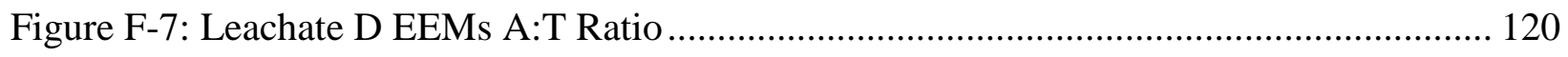

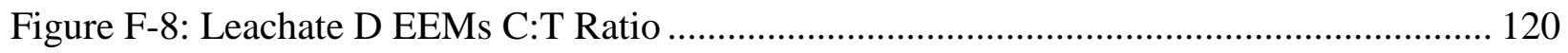

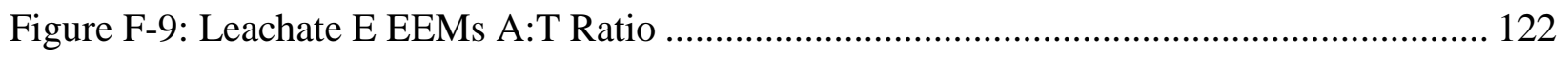

Figure F-10: Leachate E EEMs C:T Ratio............................................................................ 122

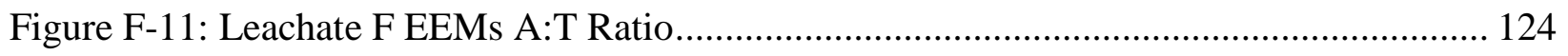

Figure F-12: Leachate F EEMs C:T Ratio........................................................................... 124

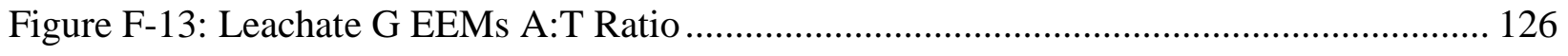

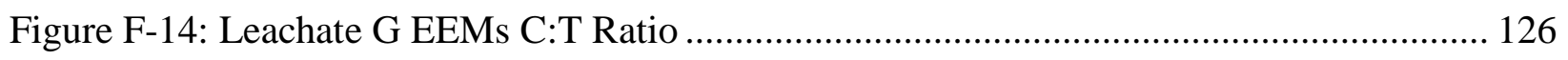

Figure F-15: Leachate H EEMs A:T Ratio …………….......................................................... 128

$$
\text { xiv }
$$


Figure F-16: Leachate H EEMs C:T Ratio 128

Figure G-1: Leachate A 1:100 Dilution SEC Normalized Peak Areas........................................ 130

Figure G-2: Leachate C 1:4.1 Dilution SEC Normalized Peak Areas ........................................... 131

Figure G-3: Leachate C 1:31 Dilution SEC Normalized Peak Areas ......................................... 131

Figure G-4: Leachate D 1:2.4 Dilution SEC Normalized Peak Areas........................................... 132

Figure G-5: Leachate E No Dilution SEC Normalized Peak Areas ............................................. 133

Figure G-6: Leachate E 1:10 Dilution SEC Normalized Peak Areas .......................................... 133

Figure G-7: Leachate E 1:40 Dilution SEC Normalized Peak Areas ........................................... 134

Figure G-8: Leachate F No Dilution SEC Normalized Peak Areas............................................. 135

Figure G-9: Leachate F 1:10 Dilution SEC Normalized Peak Areas .......................................... 135

Figure G-10: Leachate F 1:40 Dilution SEC Normalized Peak Areas ....................................... 136

Figure H-1: Solar Irradiance Data from Batch Test 1 (Leachate A)............................................. 138

Figure H-2: Solar Irradiance Data from Batch Test 2 (Leachate B)........................................... 138

Figure H-3: Solar Irradiance Data from Batch Tests 3 and 4 (Leachates C \& D) ....................... 139

Figure H-4: Solar Irradiance Data from Batch Tests 5 and 6 (Leachates E \& F)........................ 139

Figure H-5: Solar Irradiance Data from Batch Tests 7 and 8 (Leachates G \& H)...................... 140 


\section{LIST OF TABLES}

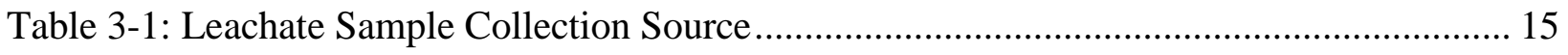

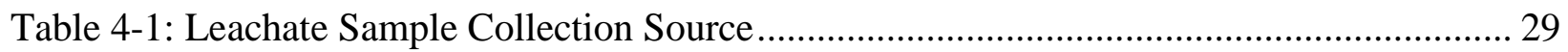

Table 4-2: Raw Leachate Sample Characteristics ....................................................................... 34

Table 4-3: First-Order Rate Constant (k) for the Reduction of UV254 over 90 Day Test Period.. 37

Table 4-4: Percent Reduction of Apparent Color over 90 Day Test Period ................................... 43

Table 4-5: Percent Reduction of COD over 90 Day Test Period..................................................... 45

Table 4-6: SEC Percent Reduction of Area ................................................................................. 48

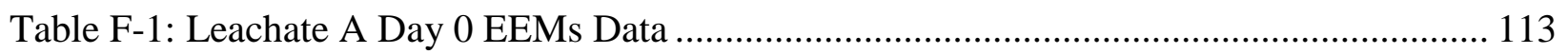

Table F-2: Leachate A Day 90 EEMs Data ........................................................................... 113

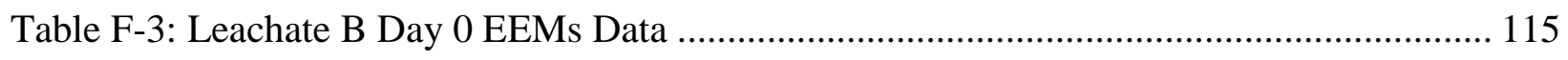

Table F-4: Leachate B Day 90 EEMs Data .......................................................................... 115

Table F-5: Leachate C Day 0 EEMs Data ................................................................................ 117

Table F-6: Leachate C Day 90 EEMs Data ............................................................................ 117

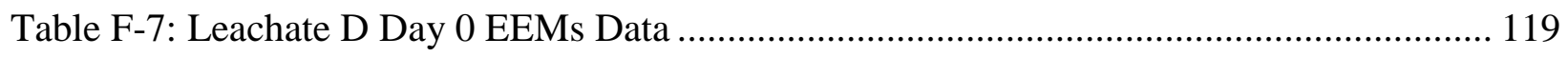

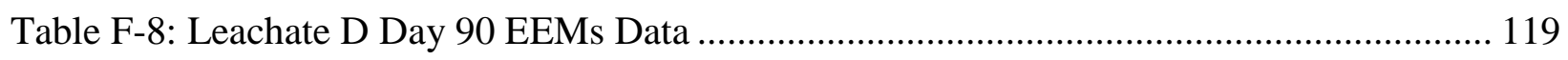

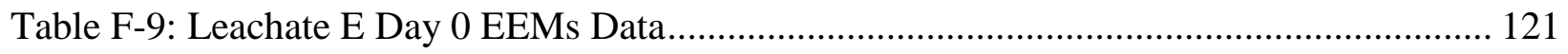

Table F-10: Leachate E Day 90 EEMs Data............................................................................... 121

Table F-11: Leachate F Day 0 EEMs Data ........................................................................... 123

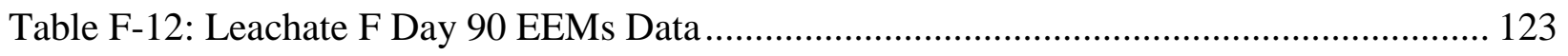

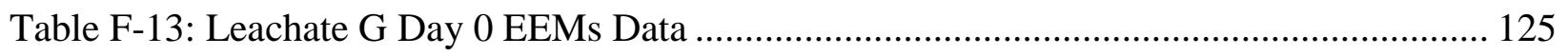

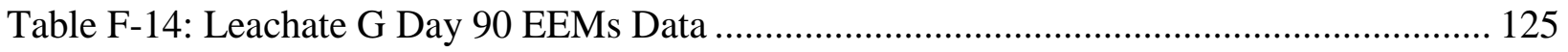


Table F-15: Leachate H Day 0 EEMs Data .................................................................... 127

Table F-16: Leachate H Day 90 EEMs Data ................................................................. 127 


\section{LIST OF ACRONYMS/ABREVIATIONS}

\begin{tabular}{|c|c|}
\hline abs & absorbance \\
\hline avg & average \\
\hline bDON & bioavailable dissolved organic nitrogen \\
\hline $\mathrm{BOD}_{5}$ & 5-day biochemical oxygen demand \\
\hline${ }^{\circ} \mathrm{C}$ & degrees Celsius \\
\hline COD & chemical oxygen demand \\
\hline $\mathrm{C}_{2} \mathrm{H}_{7} \mathrm{NO}_{2}$ & ammonium acetate \\
\hline CDOM & chromophoric dissolved organic matter \\
\hline $\mathrm{CH}_{3} \mathrm{OH}$ & methanol \\
\hline $\mathrm{cm}$ & centimeter \\
\hline $\mathrm{CO}_{2}$ & carbon dioxide \\
\hline $\mathrm{Da}$ & Dalton \\
\hline DBPs & disinfection byproducts \\
\hline DI & deionized \\
\hline DIC & dissolved inorganic carbon \\
\hline DO & Dissolved oxygen \\
\hline DOM & dissolved organic matter \\
\hline DON & dissolved organic nitrogen \\
\hline $\mathrm{E}_{2}: \mathrm{E}_{3}$ & ratio of UV absorption at $250 \mathrm{~nm}$ to $365 \mathrm{~nm}$ \\
\hline $\mathrm{E}_{4}: \mathrm{E}_{6}$ & ratio of UV absorption at $465 \mathrm{~nm}$ to $665 \mathrm{~nm}$ \\
\hline
\end{tabular}

xviii 


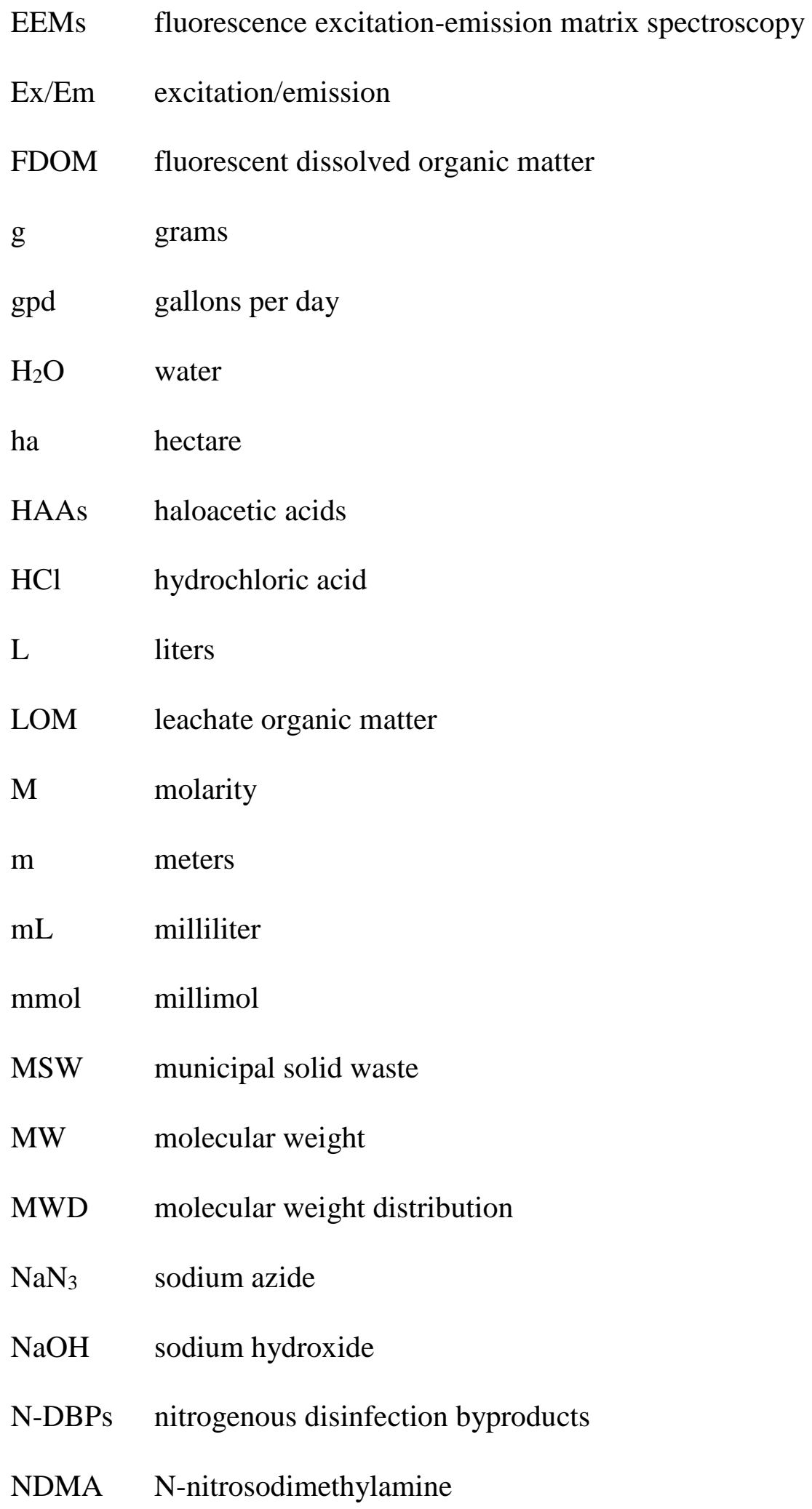




\begin{tabular}{|c|c|}
\hline $\mathrm{NH}_{3}-\mathrm{N}$ & ammonia-nitrogen \\
\hline $\mathrm{NH}_{4}^{+}$ & ammonium \\
\hline $\mathrm{nm}$ & nanometer \\
\hline $\mathrm{NO}_{2}^{-}$ & nitrite \\
\hline $\mathrm{NO}_{3}^{-}$ & nitrate \\
\hline NOM & natural organic matter \\
\hline $\mathrm{NO}_{\mathrm{x}}$ & nitrite + nitrate \\
\hline$\cdot \mathrm{OH}$ & hydroxyl radical \\
\hline PCC & post-closure care \\
\hline Pt-Co & platinum-cobalt color units \\
\hline QSE & quinine sulfate equivalents \\
\hline $\mathrm{R}^{2}$ & coefficient of determination \\
\hline rDON & recalcitrant dissolved organic nitrogen \\
\hline ROS & reactive oxygenated species \\
\hline $\mathrm{S}_{275-295}$ & spectral slope from log transformed UV region of 275-295 nm \\
\hline $\mathrm{S}_{350-400}$ & spectral slope from log transformed UV region of $350-400 \mathrm{~nm}$ \\
\hline SEC & size-exclusion chromatography \\
\hline SPE & solid-phase extraction \\
\hline $\mathrm{S}_{\mathrm{R}}$ & slope ratio \\
\hline std. dev. & standard deviation \\
\hline THMs & trihalomethanes \\
\hline TKN & total Kjeldahl nitrogen \\
\hline
\end{tabular}




$\begin{array}{ll}\text { TN } & \text { total nitrogen } \\ \mathrm{TP} & \text { total phosphorus } \\ \mu \mathrm{m} & \text { micrometer } \\ \mathrm{UV} & \text { ultraviolet } \\ \mathrm{UV}_{254} & \text { absorbance at } 254 \mathrm{~nm} \\ \mathrm{UV}-\mathrm{Vis} & \text { ultraviolet-visible } \\ \mathrm{W} / \mathrm{m}^{2} & \text { watts per square meter }\end{array}$




\section{CHAPTER 1: INTRODUCTION}

Landfilling is one of the most widespread methods of disposal of municipal solid waste (MSW) (Greedy, 2016). Despite efforts to divert waste from landfills by composting, recycling, or energy conversion, the practice of landfilling is the most frequently used method for refuse disposal in the United States (Powell et al., 2016). The composition of MSW from one community to another is dependent upon socio-economic, geographic, and climatic factors, but all landfills have in common the production of biogas and leachate (Zairi et al., 2014). Effective management of these two byproducts of landfilling is required to maintain compliance with regulatory agencies and to prevent pollution of the environment.

Leachate is generated as water percolates through a landfill and comes into contact with the waste. Physical (particulate), chemical, and microbial pollutants transfer into the water forming what is termed 'leachate' (Kjeldsen et al., 2002). The quantity of leachate generated is a function of the moisture content of the waste, as well as the amount of precipitation (Zairi et al., 2014). Modern landfills are designed with engineered systems to collect leachate. Low permeable liners and collection systems at the bottom of the landfill prevent leachate from contaminating the soil and groundwater (Stibinger, 2017).

The composition and quality of leachate is a function of the waste composition, age of the waste, and the landfill technology used (Kjeldsen et al., 2002). Leachate from mature, stabilized landfills is highly recalcitrant, characterized by a five-day biochemical oxygen demand to chemical oxygen demand (BOD $/ \mathrm{COD}$ ) ratio less than 0.1 (Comstock et al., 2010). A large portion of the recalcitrant organic matter is from humic substances, complex poorly defined organic matter (Stedmon et al., 2003), with other contributions from aliphatic, aromatic, phenolic, and alicyclic 
compounds (Monje-Ramirez et al., 2004) many of which have high molecular weights (Chian et al., 1977). At low $\mathrm{BOD}_{5} / \mathrm{COD}$ ratios, biological treatment is less favorable due to low concentrations of biodegradable organic material. Physical/chemical treatments, such as coagulation and chemical oxidation, are recommended for treating mature leachates (MonjeRamirez et al., 2004) however, recalcitrant organic matter exerts a significant chemical demand, thus increasing operating costs and complexity of treatment (Pernet-coudrier et al., 2008). Young or fresh leachates with high $\mathrm{BOD}_{5} / \mathrm{COD}$ ratios (i.e. $\mathrm{BOD}_{5} / \mathrm{COD}>0.5$ ) have less recalcitrant organic matter and biological treatment is appropriate (Comstock et al., 2010).

The recalcitrant organic matter in leachate is comparable to dissolved organic matter (DOM) that is found in natural aquatic systems (Comstock et al., 2010). This thesis will refer to organic matter that has been derived from leachate, as leachate organic matter (LOM). DOM is commonly defined as the fraction of natural organic matter (NOM) that passes through a filter with a pore size ranging from less than $0.1 \mu \mathrm{m}$ to $0.46 \mu \mathrm{m}$ (Chin et al., 1998). DOM has been shown to significantly contribute to the total carbon, total nitrogen (TN), and total phosphorus (TP) found in aquatic systems (Knudsen-Leerbeck et al., 2017). While essential for life in aquatic systems, excess nutrients can lead to eutrophication. LOM is generally recalcitrant and may not lead to eutrophication initially. However, possibilities exist for LOM to transform in sun-lit systems, releasing carbon, nitrogen, and phosphorus for use by microbial organisms (Aiken et al., 2011). Additionally, DOM in aquatic environments has been shown to impact metal speciation, alter charges of particles, influence mineral precipitation/dissolution reactions, and drive photochemical and redox reactions (Aiken et al., 2011). For these reasons, proper management of LOM is essential for landfill operators to minimize adverse impacts associated with discharging leachate to natural waters, although COD is rarely regulated at present. 
Mature leachates also have high concentrations of nitrogen-containing compounds which must be managed during post-closure care (PCC) of a landfill, particularly where nitrogen emissions are tightly restricted. Dissolved organic nitrogen (DON) in leachate has low molecular weight and is difficult to remove through biological treatment (Bolyard et al., 2017). DON photochemical reactions have been shown to release amino acids, free ammonium, and urea in aquatic systems (Karen et al., 1999). Once bioavailable, these excess nutrients may lead to eutrophication of aquatic systems.

In instances where LOM impacted waters are used to produce drinking water, there exist possibilities for disinfection byproduct (DBP) formation from the reactions between chlorine/chloramines with LOM and nitrogen species. DBPs of concern include trihalomethanes (THMs) and haloacetic acids (HAAs). Of more concern are emerging nitrogenous disinfection byproducts (N-DBPs), such as N-nitrosodimethylamine (NDMA), as they are believed to be more carcinogenic than other regulated DBPs (Dotson et al., 2009).

Issues arise during PCC when landfill operators must continue to manage leachate beyond the design life of the landfill. Landfill operators who employed biological treatment may be unable to continue to do so as the $\mathrm{BOD}_{5} / \mathrm{COD}$ ratio decreases. Costs associated with implementing physical/chemical treatment options may be beyond what the landfill owners can afford during PCC.

This research focuses on the behavior and fate of LOM in aquatic sun-lit systems. This thesis specifically addresses the extent and mechanisms of LOM photodegradation by exposing leachate to natural sunlight. The ultimate goals are to understand the fate of LOM exposed to natural sunlight in aquatic systems and to provide insight on the use of manmade wetlands treatment, designed to allow sunlight to penetrate sufficiently to promote photolysis. Figure 1-1 
shows a process schematic of the treatment of LOM through sunlight driven processes where LOM is collected from a landfill and attenuated in a manmade wetlands system. After adequate detention time for treatment, LOM derivatives are discharged to a natural body of water. This technology can be implemented at a fraction of the cost of alternatives used for treating LOM in mature, stabilized leachates. This research will provide a first time investigation of the potential of wetlands treatment as a means for reducing long-term risks and costs associated with LOM treatment during PCC.

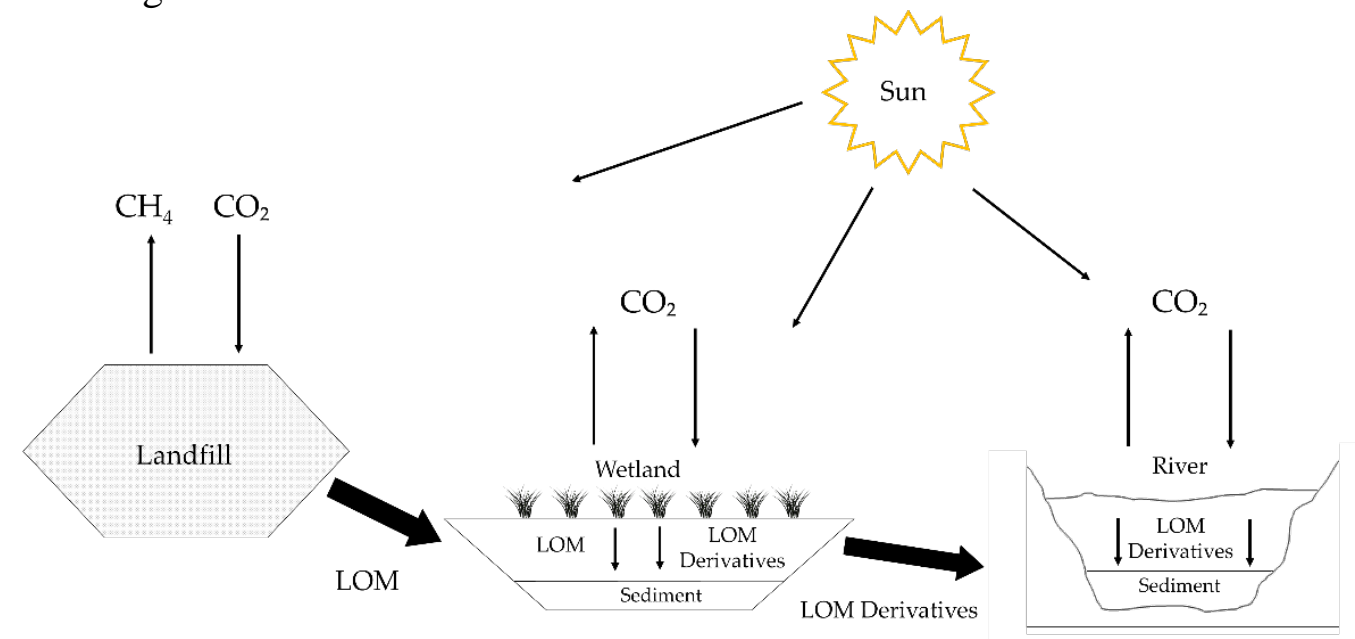

Figure 1-1: Process Schematic of Leachate Organic Matter Treatment through Sunlight Driven Processes

This research investigated the ability to treat LOM through sunlight driven processes in eight batch tests which included eight leachate samples. Each batch was exposed to natural sunlight in central Florida for a period of 90 days. Transformation processes were measured using ultraviolet-visible (UV-Vis) spectroscopy, fluorescence excitation-emission matrix spectroscopy (EEMs), size-exclusion chromatography (SEC), and chemical oxygen demand (COD) from the beginning to the end of the test period. The bioavailability of nitrogen species after exposure to sunlight was evaluated for two of the leachate samples using solid-phase extraction (SPE) to 
fractionate recalcitrant dissolved organic nitrogen $(\mathrm{rDON})$ and bioavailable dissolved organic nitrogen (bDON). 


\section{CHAPTER 2: LITERATURE REVIEW}

Included in this literature review are sections entitled Direct and Indirect Photolysis, Photochemical Reactions with Dissolved Organic Matter, and Photochemical Reactions with Nitrogen. These sections provide a review of the technical literature with a focus on naturally derived dissolved organic matter (DOM) and its fate in aquatic systems as well as photochemically induced reactions. Also included are sections entitled UV-Vis Spectroscopy, Fluorescence Excitation Emission Matrix Spectroscopy, and Size-Exclusion Chromatography. These sections provide a background on the analytical techniques used in this study investigating the transformation mechanisms that occurred.

\section{Direct and Indirect Photolysis}

Photolysis is defined as the absorption of photons resulting in light-induced oxidation or reduction reactions (Crittenden et al., 2012). The mechanisms of photolysis can be described by 'direct' or 'indirect' photolysis. Direct photolysis is the transformation of a compound as a result of that compound absorbing light. Rates of direct photolysis are a function of the compound's rate of light absorption and the quantum yield for reaction of the excited state of the compound (Schwarzenbach et al., 2005). Indirect photolysis occurs when a hydroxyl radical (·OH) is formed as a result of light reacting with sensitizers in water, such as nitrite $\left(\mathrm{NO}_{2}{ }^{-}\right)$, nitrate $\left(\mathrm{NO}_{3}{ }^{-}\right)$, and natural organic matter (NOM) (Hou et al., 2016). The hydroxyl radical is a highly reactive oxidizer with the ability to react with most organic compounds (Crittenden et al., 2012) resulting in oxidative degradation potentially to carbon dioxide $\left(\mathrm{CO}_{2}\right)$ and water $\left(\mathrm{H}_{2} \mathrm{O}\right)$ (Mack et al., 1999). 
Rates of photochemical reactions in water are affected by the solar spectral irradiance at the water surface, the transmission of light into the water, and the radiative transfer from air into the water (Zepp et al., 1977). Light attenuation in water also impacts the extent of photochemical reactions. With increasing depth, a decrease in the photolysis rate is observed as light is absorbed and scattered by constituents in the water (Duntley, 1963). Photolysis from sunlight occurs within the wavelength range from 280 nanometers (American Public Health et al.)(American Public Health et al.)(nm) to $320 \mathrm{~nm}$, which is commonly called UV-B. This spectral intensity of sunlight is constantly changing based on the angle of the sun and absorption by gases and molecules in the atmosphere (Zepp et al., 1977).

\section{$\underline{\text { Photochemical Reactions with Dissolved Organic Matter }}$}

NOM is derived from the degradation of terrestrial plant matter (Stedmon et al., 2003) and is composed of a heterogenous complex and poorly characterized mixture (Salonen et al., 2012; Sanchez et al., 2013) of aliphatic and aromatic compounds which contain oxygen, nitrogen, and sulfur containing functional groups (Chen et al., 2003). The NOM enters surface waters as

allochthonous DOM, which contains humic substances that are refractory to microbial degradation. There is a poor understanding of the fate and transport of allochthonous DOM in aquatic systems (Salonen et al., 2012). Allochthonous NOM is susceptible to photochemical reactions (Sulzberger et al., 2009) and is present in high concentrations in LOM (Zhang et al., 2008).

The fraction of NOM that passes through a filter with a pore size ranging from less than $0.1 \mu \mathrm{m}$ to $0.46 \mu \mathrm{m}$ is DOM (Chin et al., 1998). DOM can be categorized by two fractions, chromophoric DOM (CDOM) and fluorescent DOM (FDOM). CDOM represents the fraction that 
absorbs ultraviolet (UV) and visible light (Helms et al., 2008). It gives aquatic systems its dark color and plays a crucial role in protecting aquatic biota by absorbing harmful UV radiation (Li et al., 2017) including UV-B (280-320 nm) and UV-A (320-400 nm) (Stiig Markager et al., 2000). However, the ability for CDOM to absorb light in the range of photosynthetically available radiation (400-700 $\mathrm{nm}$ ) creates competition amongst photosynthetic organisms by impacting the availability of underwater light (Stiig Markager et al., 2000). FDOM is the smaller fraction, which is characterized by the ability of DOM to emit fluorescence when excited by photons ( $\mathrm{Li}$ et al., 2017). These optical properties make analytical methods such as ultraviolet-visible (UV-Vis) spectroscopy and fluorescence spectroscopy useful in the study of DOM.

Photons in the range of $300 \mathrm{~nm}$ to $800 \mathrm{~nm}$ are absorbed by CDOM in natural waters (Gonsior et al., 2014) creating reactive oxygenated species (Goldstone et al.), such as hydroxyl radicals, superoxide radicals, or singlet oxygen (Cottrell et al., 2013) which have the ability to degrade humic substances, a major fraction in DOM, into volatile organic compounds and biologically labile material (Mopper et al., 1991). In more detail, the photochemical degradation of DOM results in the release of bioavailable low molecular weight compounds such as citric acid, acetic acid, formic acid, pyruvic acid, propanal, acetone, formaldehyde, and acetaldehyde (Miller et al., 1997), dissolved inorganic carbon (DIC) (Gao et al., 1998), and complex aromatic structures (Stubbins et al., 2010). Once labile, humic DOM is, to some extent, utilized by bacteria. (Tranvik et al., 2001). Photochemical degradation of FDOM is $\mathrm{pH}$ dependent and is more effective at a higher $\mathrm{pH}$ (Timko et al., 2015). Photochemical degradation of DOM, as a whole, plays a significant role in carbon limited aquatic systems by stimulating growth and activity of microbial organisms (Moran et al., 1997). 


\section{Photochemical Reactions with Nitrogen}

Research has shown that humic substances irradiated with sunlight were able to support bacterial growth as a result of increased bioavailability of carbon and nitrogen. The nitrogen species present included ammonium $\left(\mathrm{NH}_{4}^{+}\right)$, dissolved primary amines, and other unidentified compounds (Karen et al., 1999). Photochemical reactions with strictly nitrogen species, such as dissolved organic nitrogen (DON) and $\mathrm{NH}_{4}{ }^{+}$, are able to affect bioavailability of nitrogen depending on whether the system is nitrogen limited (Vähätalo et al., 2007). Photochemical reactions have the ability to transform biologically available nitrogen into recalcitrant forms (Kieber et al., 1997) in instances where $\mathrm{NH}_{4}{ }^{+}$concentrations are high (8-33 $\mathrm{mmol} \mathrm{m}{ }^{-3}$ ), but will produce $\mathrm{NH}_{4}{ }^{+}$from recalcitrant DON (rDON) in samples with low $\mathrm{NH}_{4}{ }^{+}$concentrations $(<6 \mathrm{mmol}$ $\mathrm{m}^{-3}$ ) (Tarr et al., 2001). As previously mentioned, photochemical reactions with nitrite $\left(\mathrm{NO}_{2}{ }^{-}\right)$and nitrate $\left(\mathrm{NO}_{3}{ }^{-}\right.$), collectively termed $\mathrm{NO}_{x}$, result in the formation of a hydroxyl radical (Mack et al., 1999).

\section{UV-VIS Spectroscopy}

$\mathrm{UV}$-Vis spectroscopy is a technique which uses portions of the UV and visible spectrum of light to identify constituents in liquid solutions by measuring the amount of light that is absorbed by the sample being studied (Brown, 2012). The absorption at characteristic wavelengths and ratios of various wavelengths can be used to identify substances in the sample. Absorption at a wavelength of $254 \mathrm{~nm}$, commonly termed $\mathrm{UV}_{254}$, is used as an indicator of organic material (Altmann et al., 2016) and aromaticity (Núñez et al., 2007) of a sample. Thus, $U_{254}$ provides an indication of the amount of LOM. 
Ratios of absorbance at different wavelengths can highlight characteristics of the LOM. De Haan and De Boer found that the ratio between absorption at $250 \mathrm{~nm}$ and $365 \mathrm{~nm}$ (termed $\mathrm{E}_{2}: \mathrm{E}_{3}$ ) can be used to characterize the relative molecular weight of DOM (De Haan et al., 1987). They showed that as the molecular weight increases, the $\mathrm{E}_{2}: \mathrm{E}_{3}$ ratio decreases as a result of strong absorption of light at longer wavelengths by high molecular weight CDOM. Another characteristic ratio is that between the absorption at $465 \mathrm{~nm}$ and $665 \mathrm{~nm}$ (termed $\mathrm{E}_{4}: \mathrm{E}_{6}$ ). This ratio was shown to be inversely proportional to the degree of aromaticity or humification of DOM (Piccolo et al., 1992; Roberts et al., 1987). Where absorbance at $665 \mathrm{~nm}$ is below detectable limits, as in the case of many natural waters, the absorption at $254 \mathrm{~nm}$ is used instead as an indicator of aromaticity or humification (Helms et al., 2008).

The slope ratio $\left(S_{R}\right)$ has been used to characterize the relative molecular weight of CDOM. The $S_{R}$ is inversely proportional to the relative molecular weight. The slope ratio is determined from the log-transformed slope of the absorbance from the region of $275-295 \mathrm{~nm}\left(\mathrm{~S}_{275-295}\right)$ over the region of 350-400 nm ( S $\left._{350-400}\right)$ (Helms et al., 2008), as shown in Equation 2.1.

$$
S_{R}=\frac{\ln \left(\frac{\Delta Y_{275-295}}{\Delta X_{275-295}}\right)}{\ln \left(\frac{\Delta Y_{350-400}}{\Delta X_{350-400}}\right)}=\frac{S_{275-295}}{S_{350-400}}
$$

Where, $\Delta Y_{275-295}$ is the change in values along the $\mathrm{y}$-axis from $275-295 \mathrm{~nm}$ $\Delta X_{275-295}$ is the change in values along the $\mathrm{x}$-axis from $275-295 \mathrm{~nm}$ $\Delta Y_{350-400}$ is the change in values along the y-axis from $350-400 \mathrm{~nm}$ $\Delta X_{350-400}$ is the change in values along the $\mathrm{x}$-axis from $350-400 \mathrm{~nm}$ Using a range of absorption measurements, rather than ratios of single wavelengths eliminates errors in analytical measurement near the detection limits of the spectroscopic 
instrument. Studies by Helms et al. (2008) on aquatic DOM showed that the spectral slope region of 275-295 nm increased upon irradiation, while the spectral slope region of 350-400 nm generally decreased.

Humic substances have been shown to have strong UV-Vis absorbance, in the range of 190 to $800 \mathrm{~nm}$, due to the presence of aromatic chromophores and other organic compounds (Gu et al., 1995). Absorbance by these compounds decreases with increasing wavelength (Uyguner et al., 2005). Increased solar irradiation has been shown to decrease the absorbance of samples containing humic substance (mainly humic acid) as a result of photocatalytic oxidation (Kerc et al., 2004). This transformation can be observed by a 'blue shift' across the UV-Vis spectra, or a shift to a shorter wavelength resulting from a reduction of high molecular weight CDOM (Boyd et al., 2004; Jiang et al., 2016).

\section{Fluorescence Excitation Emission Matrix Spectroscopy}

Fluorescence excitation emission matrix (EEMs) spectroscopy is an up and coming method used for the study of DOM (Li et al., 2017). Humic, fulvic, and protein-like compounds contain fluorophores making fluorescence spectroscopy a technique frequently used to characterize the composition of DOM (Sanchez et al., 2013). A molecule undergoes three processes during the emission of light, or fluorescence. The first is excitation of the molecule where the molecule absorbs a photon and energy is increased. Second is vibrational relaxation, or nonradiative decay, where an excited molecule returns to a lower vibrational energy level by losing energy to collisions with nearby molecules. Finally is fluorescence, or radiative decay, where energy is released in the form of light (Lakowicz, 2006). Fluorescence measurements at certain excitation and emission wavelengths are used to characterize materials in solution. 
DOM is characterized by four distinct excitation/emission (Ex/Em) peaks. Peak A is characteristic of humic-like material $(\mathrm{Ex} / \mathrm{Em}=260 / 450 \mathrm{~nm})$, peak C is characteristic of fulvic-like material $(\mathrm{Ex} / \mathrm{Em}=340 / 440 \mathrm{~nm})$, peak $\mathrm{M}$ is characteristic of marine-like material $(\mathrm{Ex} / \mathrm{Em}=$ $300 / 390 \mathrm{~nm})$, and peak $\mathrm{T}$ is characteristic of tryptophan and protein-like material $(\mathrm{Ex} / \mathrm{Em}=$ 275/340 nm) (Coble, 1996). Figure 2-1 shows the image generated from EEMs analysis with emission (in $\mathrm{nm}$ ) on the y-axis and excitation (in $\mathrm{nm}$ ) on the $\mathrm{x}$-axis. The scale on the right side of the image is the fluorescence measured in quinine sulfate equivalents (QSE). Quinine sulfate is used as a standard to quantify DOM fluorescence to correct DOM spectra and make results comparable amongst different instruments and analysts (Lakowicz, 2006).

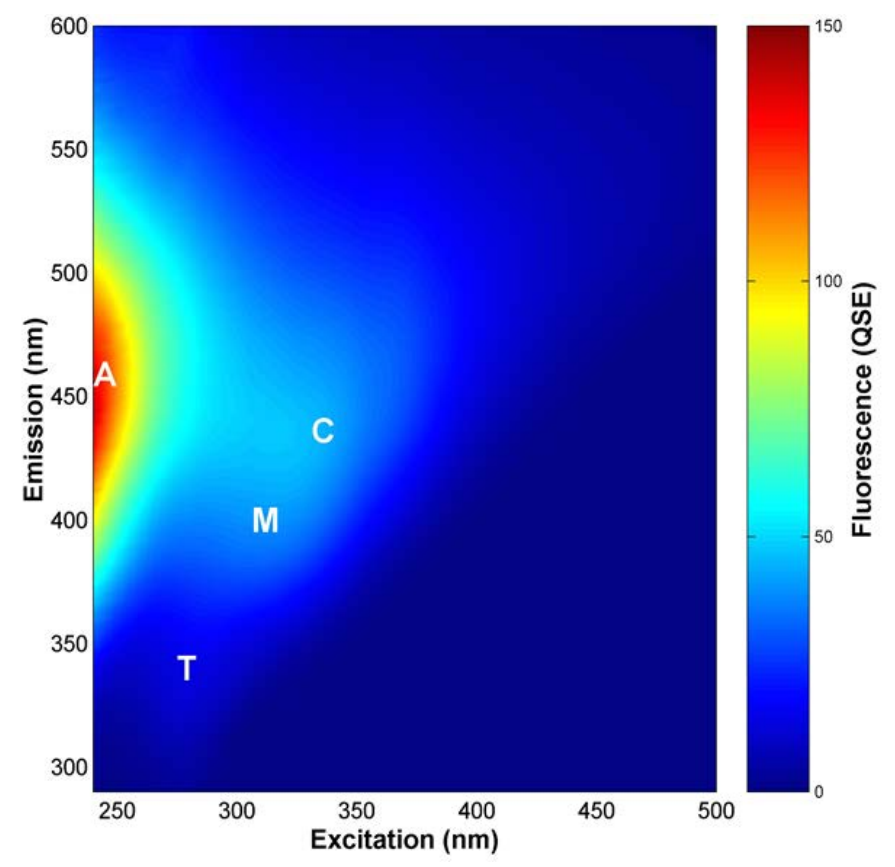

Figure 2-1: Fluorescence Excitation Emission Matrix (EEMs) Output Image

Integrated peak areas provide insight into the chemical makeup of a material. Ratios of peaks A:T and C:T are used to quantify relative amounts of humic-like DOM and fresh-like (or 
labile) DOM. These ratios have been shown to increase when materials undergo biodegradation and decrease as a result of photodegradation (Hansen et al., 2016).

\section{$\underline{\text { Size-Exclusion Chromatography }}$}

Size-exclusion chromatography (SEC) is a technique used to quantify the average apparent molecular weight (Stubbins et al., 2010) and molecular weight distribution (MWD) of a substance (Mori et al., 2013). SEC is useful to characterize leachate, high in humic substances, since it is comprised of heterogeneous compounds of varying molecular sizes (Laborda et al., 2008). Humic substances range in size from hundreds to tens of thousands, Daltons (Da) (Bolea et al., 2006).

SEC separates material by the relative size or hydrodynamic volume of the molecules based on the average pore size of the packing used (Barth et al., 1994). SEC analysis of aqueous solutions typically uses two types of packing material including hydrophilic polymer gels and silica gels bonded with hydrophilic functional groups (Mori et al., 2013). The relative molecular weight of the material is determined from a calibration curve based on the retention time of characteristic substances found in that material, or time it takes to pass through the chromatography system from injection to the detector (Mori et al., 2013). A linear relationship between elution volume and the logarithm of molecular weight suggests a logarithmic relationship between molecular weight and retention time exists (Huber et al., 2011) where high molecular weight material elutes before lower molecular weight material.

\section{$\underline{\text { Summary }}$}

Literature pertaining to the fate of LOM in aquatic systems and photochemical reactions with LOM is limited. However, the compositional similarities between naturally derived DOM and LOM provide a means of studying and analyzing LOM, based on years of scientifically 
accepted research of DOM. While chemical concentrations in leachate can be expected to be greater, as compared to a natural aquatic system, the photochemical reactions with humic material and nitrogen species are still likely to occur. Similarly, the analytical techniques used for characterizing and studying DOM can be applied to LOM, as a result of their similar chemical composition.

The methods for testing and measuring the applicability of LOM treatment using sunlight, as presented in this thesis, were derived based on the aforementioned literature. With the ultimate goal of treatment through photolysis, either direct or indirect, the literature review provided evidence that this is a possible mechanism based on the extensive literature available on photochemical reactions with DOM. 


\section{CHAPTER 3: METHODOLOGY}

Investigating the treatment of leachate organic matter (LOM) through sunlight driven processes was accomplished by four main tasks including: Leachate Collection and Characterization, Photolysis Batch Testing, Evaluation of Dissolved Organic Nitrogen Bioavailability of Leachate, and Data Analysis. These tasks are outlined in the following sections.

\section{Leachate Collection and Characterization}

Leachate samples were collected after landfill in-situ and onsite treatment. Table 3-1 outlines the source from which each sample was collected. Samples were placed in clean highdensity polyethylene bottles and transported on ice to the laboratory where they were stored in a $4^{\circ} \mathrm{C}$ walk-in refrigerator prior to analysis. Leachate D, Leachate $\mathrm{F}$, and Leachate $\mathrm{H}$ were treated onsite using a sequencing batch reactor (SBR) to achieve carbon removal, nitrification, and denitrification. Each of these leachates were the effluent after treatment of Leachate C, Leachate E, and Leachate G, respectively.

Table 3-1: Leachate Sample Collection Source

\begin{tabular}{|c|c|c|}
\hline Sample ID & Batch Test Number & Sample Source \\
\hline Leachate A & 1 & Aeration Tank \\
\hline Leachate B & 2 & Leachate Collection System \\
\hline Leachate C & 3 & Leachate Collection System \\
\hline Leachate D & 4 & Post-onsite Biological Treatment of Leachate C \\
\hline Leachate E & 5 & Leachate Collection System \\
\hline Leachate F & 6 & Post-onsite Biological Treatment of Leachate E \\
\hline Leachate G & 7 & Leachate Collection System \\
\hline Leachate H & 8 & Post-onsite Biological Treatment of Leachate G \\
\hline
\end{tabular}


Leachate samples were characterized for five-day biochemical oxygen demand (BOD5), chemical oxygen demand (COD), $\mathrm{pH}$, total ammonia- $\mathrm{N}\left(\mathrm{NH}_{3}-\mathrm{N}\right)$, total nitrite + nitrate $\left(\mathrm{NO}_{2}{ }^{-}+\right.$ $\mathrm{NO}_{3}{ }^{-}$), total Kjeldahl nitrogen (TKN), total nitrogen (TN), and apparent color, according to Standard Methods for the Examination of Water and Wastewater (American Public Health et al., 2005). Additionally, leachate was filtered using 0.45 -micrometer $(\mu \mathrm{m})$ Whatman ${ }^{\mathrm{TM}}$ nylon membrane filters and analyzed for dissolved TKN and $\mathrm{NH}_{3}-\mathrm{N}$. Dissolved organic nitrogen (DON) concentration was determined by subtracting the dissolved $\mathrm{NH}_{3}-\mathrm{N}$ from the dissolved TKN.

Advanced spectroscopic analytical techniques including ultraviolet-visible (UV-Vis) spectroscopy and fluorescence excitation-emission matrix spectroscopy (EEMs) were performed. UV-Vis was performed by placing leachate samples in a cuvette with a 1-cm path length, and the absorbance was measured at wavelengths of 254 nanometers (nm), $465 \mathrm{~nm}, 665 \mathrm{~nm}, 456 \mathrm{~nm}$, as well as 200-800 nm scans, on a $1 \mathrm{~nm}$ interval, using a HACH DR-5000 UV-Vis spectrophotometer. Samples with an absorbance exceeding 3.5 abs units at $254 \mathrm{~nm}$ were diluted using deionized (DI) water. EEMs analysis was performed using a HORIBA Scientific FluoroMax-4 spectrofluorometer with a 1-cm path-length quartz cuvette.

Size-exclusion chromatography (SEC) was used to fractionate molecules present in the leachate by molecular weight. SEC was performed using a PL Aquagel-OH column with a pore type of 20 and $8 \mu \mathrm{m}$ particle size. The separation was performed using $0.1 \mathrm{M}$ ammonium acetate $\left(\mathrm{C}_{2} \mathrm{H}_{7} \mathrm{NO}_{2}\right)$. The calibration curve was established using polystyrene sulfonic acids (molecular weight: 4300, 17000, 32000) and bovine serum albumin (66400). Samples were filtered through a $0.2 \mu \mathrm{m}$ Whatman ${ }^{\mathrm{TM}}$ nylon membrane filter prior to performing EEMs and SEC. EEMs and SEC were performed by Dr. Barbara Cottrell at the University of California, Irvine. 


\section{Photolysis Batch Testing}

Each of eight batch tests was conducted in 2.0-liter (L) Tedlar sampling bags placed in natural sunlight. For identification purposes, batch tests 1-8 were identified as Leachates A-H. The approximate liquid initial depth in each bag was seven centimeters (cm). After sample extraction over the test period, the depth was approximately three $\mathrm{cm}$. Figure 3-1 shows empty 2.0-L Tedlar bags used for photolysis testing. Literature suggests that longer periods of solar irradiation may be required for adequate efficiencies of LOM destruction (Patel-Sorrentino et al., 2004), therefore, the batch tests were conducted over a 90 day period. Solar irradiation was measured daily at noon using a Megger PVM210 handheld irradiance meter with a measuring range from 0 to 2,000 watts per square meter $\left(\mathrm{W} / \mathrm{m}^{2}\right)$ (APPENDIX $\left.\mathrm{H}\right)$.

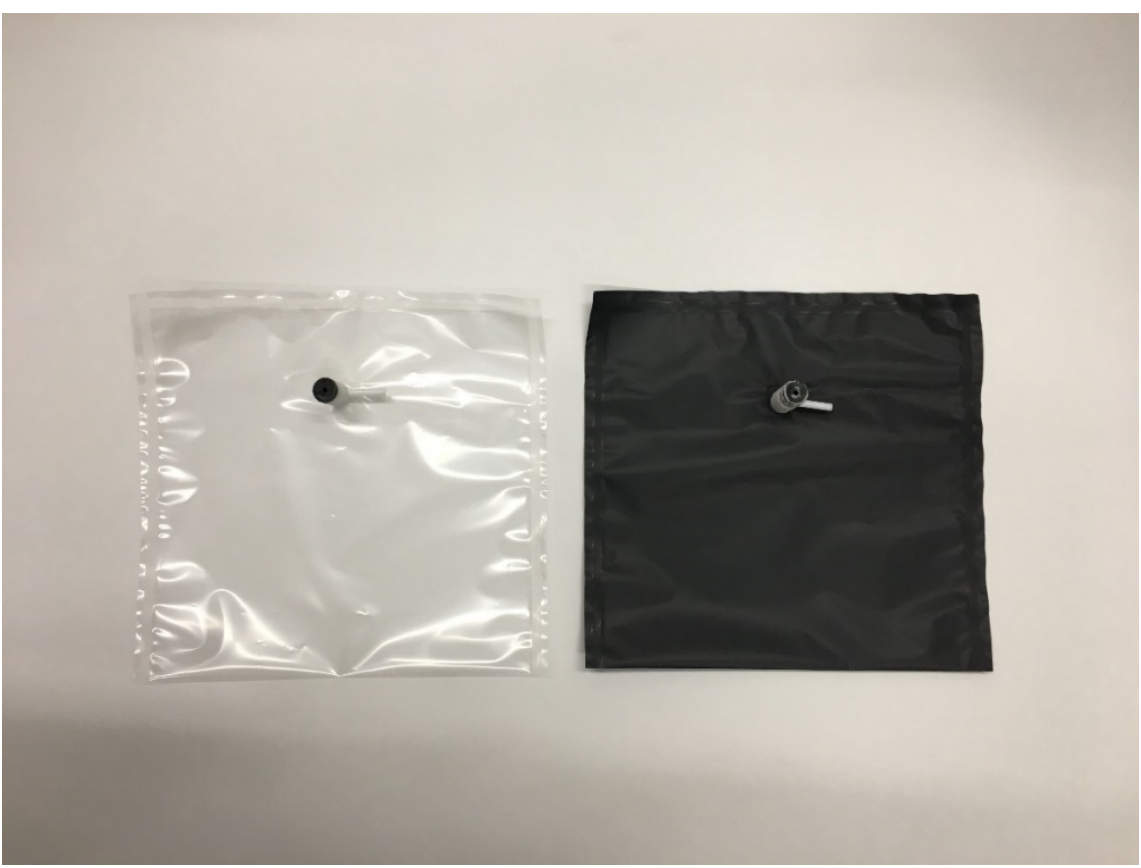

Figure 3-1: Empty 2.0 Liter Tedlar Bags Used for Photolysis Testing

(left: clear test bag, right: black control bag) 
A control was run for each batch test using light-blocking black Tedlar bags treated in the identical manner as the clear bags. Aliquots (approximately 50 milliliters [mL]) were removed weekly and characterized using UV-Vis spectroscopy. At the end of each batch test, leachate characterization using UV-Vis, EEMs, SEC, and COD was completed. These data were compared to the initial values to evaluate the transformation processes.

The test was designed to control liquid volume, exposure to sunlight, and mixing (once per week during sampling) in each of the bags in the batch test. Temparature was not controlled and varied among bags (as black color absorbs more light which is converted into heat energy). Both clear test and black control bags, and non-dilute leachate samples in clear bags which were black in color, had variable temperature during the daylight hours of the test period. Oxygen was able to permeate the Tedlar bags (50 $\mathrm{mL} \mathrm{m}^{-2} \mathrm{~d}^{-1}$ ), where the dissolved oxygen (DO) concentration was dependent on the temperature of the liquid.

To study the impacts that biological and algal growth potentially played in the treatment process, sodium azide $\left(\mathrm{NaN}_{3}\right)$ was added to some of the clear bags of batch tests 7 and 8 . Research has shown that $\mathrm{NaN}_{3}$ at a concentration of $0.01 \%$ is adequate for inhibiting microbial and algal activity (Seligman et al., 1986). A 5\% stock solution of $\mathrm{NaN}_{3}$ was prepared by dissolving 5 grams (g) of $\mathrm{NaN}_{3}$ salts into $100 \mathrm{~mL}$ of deionized (DI) water. From the 5\% stock solution, $40 \mathrm{~mL}$ sodium azide were added to the 2.0 -L Tedlar bags at a final concentration of $0.1 \%$. This concentration was chosen to ensure inhibition of bacteria and algae.

\section{$\underline{\text { Evaluation of Dissolved Organic Nitrogen Bioavailability of Leachate }}$}

To study the bioavailability of the nitrogen, a solid-phase extraction (SPE) technique was performed. Sigma-Aldrich Supelite DAX-8 resin is an acrylic ester resin used as the extraction 
media to separate the recalcitrant dissolved organic nitrogen $(\mathrm{rDON})$ and bioavailable dissolved organic nitrogen (bDON) fractions of the leachate prior to and after batch testing. Studies by Lui et al. (2011) show that the bDON is hydrophilic in nature, while the rDON is hydrophobic in nature (Liu et al., 2011). The SPE fractionated the bDON and rDON based on their hydrophilic and hydrophobic natures, respectively. This method was applied by Bolyard et al. (2017) to fractionate DON in landfill leachate.

Prior to fractionation, the resin was soaked in 0.1 molar $(\mathrm{M})$ sodium hydroxide $(\mathrm{NaOH})$ for three days, replacing the $\mathrm{NaOH}$ after 24 hours, afterwhich it was rinsed with methanol and stored in DI water until use. Twenty grams of resin were packed into a Kimble-Chase glass column with a $1 \mathrm{~cm}$ diameter and $20 \mathrm{~cm}$ in length. Using a Cole-Palmer Masterflex L/S peristaltic pump, the resin was conditioned by flushing with 7.5-L of DI water. Then 2.5-L of $0.1 \mathrm{M}$ hydrochloric acid ( $\mathrm{HCl}$ ) followed by 2.5-L of $0.1 \mathrm{M} \mathrm{NaOH}$ were passed through the column. This step was repeated three times followed by 7.5-L of DI water.

Leachate samples were diluted based on their DON concentration to avoid exhausting the resin bed volume. Prior to passing through the columns, the $\mathrm{pH}$ of the sample was adjusted to less than 2 S.U. using $6 \mathrm{M} \mathrm{HCl}$. The fraction retained on the resin was the hydrophobic DON (or rDON) and the hydrophilic DON (bDON) passed through the column. The rDON fraction was released by eluting, at half the initial volume of the sample, with $0.1 \mathrm{M} \mathrm{NaOH}$ in the reverse direction of flow. After fractionation, each collected sample was adjusted to a pH of $7 \mathrm{~S} . \mathrm{U}$ using either $6 \mathrm{M}$ $\mathrm{HCl}$ or $5 \mathrm{M} \mathrm{NaOH}$. The DON of both fractions was then measured. 


\section{$\underline{\text { Data Analysis }}$}

This section discusses the data analysis used to investigate the treatment of LOM through sunlight driven processes. Sections include UV-Vis Analysis, EEMs Analysis, and SEC Analysis. $\underline{\mathrm{UV}-\mathrm{Vis} \text { Analysis }}$

Data from UV-Vis spectroscopy measurements were used to explore trends of $\mathrm{UV}_{254}$ reduction with time, plotting $200-800 \mathrm{~nm}$ wavelength scans, determining the rate constant for the disappearance of $\mathrm{UV}_{254}$, and determining characteristic ratios (i.e. $\mathrm{E}_{2}: \mathrm{E}_{3}$, and $\mathrm{S}_{\mathrm{R}}$ ). These data were collected from the HACH DR-5000 UV-Vis spectrophotometer.

Weekly $\mathrm{UV}_{254}$ measurements were used in creating a plot of $\mathrm{UV}_{254}$ versus time (in days) over the 90 day test period (APPENDIX B). Graphing the $\mathrm{UV}_{254}$ for the clear test bag and the black control bag highlighted changes over time. Similarly, spectral scans from 200-800 nm were performed on a weekly basis for both the clear and black bags (APPENDIX C). Plotting the day zero and day 90 scans measured spectral shifts. Absorbance measurements at $250 \mathrm{~nm}$ and $365 \mathrm{~nm}$ were used to determine the $\mathrm{E}_{2}$ : $\mathrm{E}_{3}$ ratio (APPENDIX D). Using the scan data, plots of the logtransformed absorbance from the regions of $275 \mathrm{~nm}$ to $295 \mathrm{~nm}$ and $350 \mathrm{~nm}$ to $400 \mathrm{~nm}$ were used to determine spectral slopes and slope ratios $\left(\mathrm{S}_{\mathrm{R}}\right)$ (APPENDIX E).

The weekly $\mathrm{UV}_{254}$ measurements were used in determining the first-order rate constant $(k)$ for the disappearance of $\mathrm{UV}_{254}$ over the test period. The rate constant was determined through a linear regression using the integrated first-order reaction equation as shown Equation 3.1.

$$
\ln (A)=-k t+\ln (A)_{o}
$$

Where, $(A)=$ the final absorbance at $254 \mathrm{~nm}$ 


$$
\begin{aligned}
& (A)_{o}=\text { the initial absorbance at } 254 \mathrm{~nm} \\
& k=\text { first-order rate constant }\left(\text { day }^{-1}\right) \\
& t=\text { time (days) }
\end{aligned}
$$

To explore reduction in apparent color resulting from photobleaching, absorption at 456 nm was used to determine the apparent color of samples. A calibration curve was created to convert absorbance at $456 \mathrm{~nm}$ to platinum cobalt (Pt-Co) color units.

\section{$\underline{\text { EEMs Analysis }}$}

From EEMs analysis, integrated peak areas for characteristic peak A (Ex/Em $=260 / 450$ $\mathrm{nm})$, peak C $(\mathrm{Ex} / \mathrm{Em}=340 / 440 \mathrm{~nm})$, and peak T $(\mathrm{Ex} / \mathrm{Em}=275 / 340 \mathrm{~nm})($ Coble, 1996) were used to determine the A:T and C:T ratios (APPENDIX F), both of which quantify relative amounts of humic-like DOM to fresh-like (or labile) DOM (Hansen et al., 2016). Data output from the HORIBA Scientific FluoroMax-4 spectrofluorometer provided the area surface integration of characteristic peaks or the area converted into quinine sulfate equivalents (QSE). Data are denoted whether they are surface area integration or QSE.

\section{$\underline{\text { SEC Analysis }}$}

From SEC analysis, integrated peak areas were used to show the overall percent reduction by measuring the sum of molecular weights of all characteristic peaks at day 0 and day 90 of the test. To show the changes of each characteristic peak, the normalized area was plotted for each characteristic retention time (in minutes) (APPENDIX G). 


\section{$\underline{\text { Wetland Feasibility }}$}

To show the feasibility of wetlands treatment, the rate constants for the reduction of $U_{254}$ were applied to a first-order complete mix system to determine the volume required for treatment. This approach uses Equation 3.2, derived by Crittenden et al. (2012).

$$
V_{w e t}=\frac{Q\left(\frac{A_{\text {inf }}}{A_{\text {eff }}}-1\right)}{k}
$$

Where, $V_{w e t}$ is the volume of the wetland (liters)

$Q$ is the leachate flowrate (liters per day)

$A_{\text {inf }}$ is the $\mathrm{UV}_{254}$ absorbance of the influent

$A_{e f f}$ is the $\mathrm{UV}_{254}$ absorbance of the effluent

$k$ is the rate constant $\left(\right.$ days $\left.^{-1}\right)$

Assuming that leachate generation is reduced by a factor of four, one year after closure for landfills having a final cover (Barlaz et al., 2002), the influent leachate flow rate was assumed to be 18,900 liters per day. This flow rate is based on the leachate generation of the landfill which generates Leachate A and B. An influent absorbance of 50 abs was assumed, which was the average $\mathrm{UV}_{254}$ of Leachates A, C, D, E, F, G, and H. Leachate B was omitted from the average since its $\mathrm{UV}_{254}$ was determined to be an outlier using Grubb’s test with a 5\% significance level. An effluent absorbance of 0.5 abs was assumed, which would remove most of the high molecular weight LOM. To determine a range of wetland volume, a minimum and maximum rate constant 
of 1.0E-02 and 2.8E-02, respectively, which captures results of the batch tests, was assumed. The depth of the wetland was assumed to be 1 meter. 


\title{
CHAPTER 4: TREATMENT OF LEACHATE ORGANIC MATTER THROUGH SUNLIGHT DRIVEN PROCESSES
}

\begin{abstract}
$\underline{\text { Abstract }}$
Leachate from mature, stabilized landfills is recalcitrant in nature resulting from high concentrations of humic substances, such as humic acids and complex poorly defined organic matter. This research focused on the behavior and fate of leachate organic matter (LOM) in aquatic sun-lit systems to address the extent and mechanisms of LOM photodegradation by exposing leachate to natural sunlight in central Florida for a period of 90 days. Transformation processes were measured using ultraviolet-visible (UV-Vis) spectroscopy, fluorescence excitation-emission matrix spectroscopy (EEMs), size-exclusion chromatography (SEC), and chemical oxygen demand (COD) over the test period. Results of the study suggest that photolytic, and in some cases biological, reactions were responsible for the treatment of LOM shown by transformation of high molecular weight recalcitrant material to lower molecular weight material.
\end{abstract}

\section{$\underline{\text { Introduction }}$}

Leachate is generated as water percolates through a landfill and comes into contact with the waste. Physical (particulate), chemical, and microbial pollutants transfer into the water forming what is termed 'leachate' (Kjeldsen et al., 2002). The quantity of leachate generated is a function of the moisture content of the waste, as well as the amount of precipitation (Zairi et al., 2014). The composition and quality of leachate is a function of the waste composition, age of the waste, and the landfill technology used (Kjeldsen et al., 2002). Leachate from mature, stabilized landfills is highly recalcitrant, characterized by a five-day biochemical oxygen demand to chemical oxygen 
demand $\left(\mathrm{BOD}_{5} / \mathrm{COD}\right.$ ) ratio less than 0.1 (Comstock et al., 2010). A large portion of the recalcitrant organic matter is from humic substances, complex poorly defined organic matter (Stedmon et al., 2003), with other contributions from aliphatic, aromatic, phenolic, and alicyclic compounds (Monje-Ramirez et al., 2004) many of which have high molecular weights (Chian et al., 1977).

Natural organic matter (NOM) is derived from the degradation of terrestrial plant matter (Stedmon et al., 2003) and is composed of a heterogeneous complex and poorly characterized mixture (Sanchez et al., 2013) of aliphatic and aromatic compounds which contain oxygen, nitrogen, and sulfur functional groups (Chen et al., 2003). The fraction that passes through a filter with a pore size ranging from less than 0.1 micrometer $(\mu \mathrm{m})$ to $0.46 \mu \mathrm{m}$ is dissolved organic matter (DOM) (Chin et al., 1998). The recalcitrant organic matter in leachate is comparable to DOM that is found in natural aquatic systems (Comstock et al., 2010). This paper will refer to organic matter that has been derived from leachate, as leachate organic matter (LOM).

DOM has been shown to significantly contribute to the total carbon, total nitrogen (TN), and total phosphorus (TP) found in aquatic systems (Knudsen-Leerbeck et al., 2017). While essential for life in aquatic systems, excess nutrients can lead to eutrophication. LOM is generally recalcitrant and may not lead to eutrophication initially. However, possibilities exist for LOM transform in sun lit systems, releasing carbon, nitrogen, and phosphorus for use by microbial organisms. Additionally, DOM in aquatic environments has been shown to impact metal speciation, alter charges of particles, influence mineral precipitation/dissolution reactions, and drive photochemical and redox reactions (Aiken et al., 2011). In instances where LOM impacted waters are used to produce drinking water, there exist possibilities for disinfection byproduct (DBP) formation from the reactions between chlorine/chloramines with LOM and nitrogen species. DBPs of concern include trihalomethanes (THMs) and haloacetic acids (HAAs). Of more 
concern are emerging nitrogenous disinfection byproducts (N-DBPs) such as Nnitrosodimethylamine (NDMA), as they are believed to be more carcinogenic than other regulated DBPs (Dotson et al., 2009). For these reasons, proper management of LOM is essential for landfill operators to minimize adverse impacts associated with discharging leachate to natural waters.

DOM can be categorized by two fractions, chromophoric DOM (CDOM) and fluorescent DOM (FDOM). CDOM represents the fraction that absorbs ultraviolet (UV) and visible light (Helms et al., 2008). It gives aquatic systems its dark color and plays a crucial role in protecting aquatic biota by absorbing harmful ultraviolet radiation (Li et al., 2017) including UV-B (280-320 nm) and UV-A (320-400 nm) (Stiig Markager et al., 2000). However, the ability for CDOM to absorb light in the range of photosynthetically available radiation $(400-700 \mathrm{~nm})$ creates competition amongst photosynthetic organisms by impacting the availability of underwater light (Stiig Markager et al., 2000). FDOM is the smaller fraction, which is characterized by the ability of DOM to emit fluorescence when excited by photons (Li et al., 2017). These optical properties make analytical methods such as ultraviolet-visible (UV-Vis) spectroscopy and fluorescence spectroscopy useful in the study of DOM.

Mature leachates also have high concentrations of nitrogen-containing compounds which must be managed during post-closure care (PCC) of a landfill particularly where nitrogen emissions are tightly restricted. Dissolved organic nitrogen (DON) in leachate has low molecular weight and is difficult to remove through biological treatment (Bolyard et al., 2017). Research has shown that humic substances irradiated with sunlight were able to support bacterial growth as a result of increased bioavailability of carbon and nitrogen. The nitrogen species present included ammonium $\left(\mathrm{NH}_{4}{ }^{+}\right)$, dissolved primary amines, and other unidentified compounds (Karen et al., 1999). Photochemical reactions with strictly nitrogen species, such as $\mathrm{DON}$ and $\mathrm{NH}_{4}{ }^{+}$, are able to 
increase or decrease bioavailability depending on whether the system is nitrogen limited (Vähätalo et al., 2007). Photochemical reactions have the ability to transform biologically available nitrogen into recalcitrant forms (Kieber et al., 1997) in instances where $\mathrm{NH}_{4}{ }^{+}$concentrations are high (8-33 mmol m${ }^{-3}$ ), but will produce $\mathrm{NH}_{4}{ }^{+}$from recalcitrant DON (rDON) in samples with low $\mathrm{NH}_{4}{ }^{+}$ concentrations ( $\left.<6 \mathrm{mmol} \mathrm{m}^{-3}\right)$ (Tarr et al., 2001).

The main mechanism of treatment investigated in this study was treatability of LOM through sunlight driven photolysis. Photolysis is defined as the absorption of photons resulting in light-induced oxidation or reduction reactions (Crittenden et al., 2012). The mechanisms of photolysis can be described by 'direct' or 'indirect' photolysis. Direct photolysis is the transformation of a compound as a result of that compound absorbing light. Rates of direct photolysis are a function of the compound's rate of light absorption and the quantum yield for reaction of the excited state of the compound (Schwarzenbach et al., 2005). Indirect photolysis occurs when a hydroxyl radical $(\cdot \mathrm{OH})$ is formed as a result of light reacting with sensitizers in water, such as nitrite $\left(\mathrm{NO}_{2}{ }^{-}\right)$, nitrate $\left(\mathrm{NO}_{3}{ }^{-}\right)$, and $\mathrm{NOM}$ (Hou et al., 2016). The hydroxyl radical is a highly reactive oxidizer with the ability to react with most organic compounds (Crittenden et al., 2012) resulting in oxidative degradation potentially to carbon dioxide $\left(\mathrm{CO}_{2}\right)$ and water $\left(\mathrm{H}_{2} \mathrm{O}\right)$ (Mack et al., 1999).

This research focused on the behavior and fate of LOM in aquatic, sun-lit systems to specifically address the extent and mechanisms of LOM degradation by exposing leachate to natural sunlight. The ultimate goals are to understand the fate of LOM exposed to natural sunlight in aquatic systems and to provide insight on the use of manmade wetlands treatment, designed to allow sunlight to penetrate sufficiently to promote photolysis. This research will provide a first 
time investigation of the potential of wetlands treatment as a means for reducing long-term risks and costs associate with LOM treatment during PCC.

The ability to treat LOM through sunlight driven processes was evaluated in eight batch tests which included eight leachate samples. Each batch test was exposed to natural sunlight in central Florida for a period of 90 days. Transformation processes were measured using UV-Vis spectroscopy, fluorescence excitation-emission matrix spectroscopy (EEMs), size- exclusion chromatography (SEC), and COD over the test period. The bioavailability of nitrogen species after exposure to sunlight was evaluated for two of the leachate samples using solid-phase extraction (SPE) to fractionate recalcitrant DON (rDON) and bioavailable DON (bDON).

\section{$\underline{\text { Materials and Methods }}$}

\section{$\underline{\text { Leachate Collection }}$}

Leachate samples were collected after landfill in-situ and onsite treatment. Samples were placed in 1.89-liter (L) clean high-density polyethylene bottles and transported on ice to the laboratory where they were stored in a $4^{\circ} \mathrm{C}$ walk-in refrigerator prior to analysis and batch testing. Table 4-1 outlines the sample ID and batch test number as well as the sample source. Leachate D, Leachate $\mathrm{F}$, and Leachate $\mathrm{H}$ were treated onsite using a sequencing batch reactor (SBR) to achieve carbon removal, nitrification, and denitrification. Each of these leachates were the effluent after treatment of Leachate C, Leachate E, and Leachate G, respectively. 
Table 4-1: Leachate Sample Collection Source

\begin{tabular}{|c|c|c|}
\hline Sample ID & Batch Test Number & Sample Source \\
\hline Leachate A & 1 & Aeration Tank \\
\hline Leachate B & 2 & Leachate Collection System \\
\hline Leachate C & 3 & Leachate Collection System \\
\hline Leachate D & 4 & Post-onsite Biological Treatment of Leachate C \\
\hline Leachate E & 5 & Leachate Collection System \\
\hline Leachate F & 6 & Post-onsite Biological Treatment of Leachate E \\
\hline Leachate G & 7 & Leachate Collection System \\
\hline Leachate H & 8 & Post-onsite Biological Treatment of Leachate G \\
\hline
\end{tabular}

Leachate Characterization

Leachate samples were characterized for $\mathrm{BOD}_{5}, \mathrm{COD}, \mathrm{pH}$, total ammonia- $\mathrm{N}\left(\mathrm{NH}_{3}-\mathrm{N}\right)$, total nitrite + nitrate $\left(\mathrm{NO}_{2}{ }^{-}+\mathrm{NO}_{3}{ }^{-}\right)$, total Kjeldahl nitrogen $(\mathrm{TKN})$, total nitrogen (TN), and apparent color, according to Standard Methods for the Examination of Water and Wastewater (American Public Health et al., 2005). Absorption at $456 \mathrm{~nm}$ was used to determine the apparent color of samples. A calibration curve was created to convert absorbance at $456 \mathrm{~nm}$ to platinum cobalt (PtCo) color units. Leachate was filtered using 0.45 -micrometer $(\mu \mathrm{m})$ Whatman ${ }^{\mathrm{TM}}$ nylon membrane filters and analyzed for TKN and $\mathrm{NH}_{3}-\mathrm{N}$. DON was determined by subtracting the dissolved $\mathrm{NH}_{3}-$ $\mathrm{N}$ from the dissolved TKN.

\section{Batch Testing}

Eight batch tests were performed over a three-year period. Leachate samples were placed in 2.0-liter (L) Tedlar sampling bags and exposed to direct sunlight in central Florida for a period of 90 days. A control was run for each batch test using light-blocking black Tedlar bags treated in the identical manner as the clear bags. Sample aliquots (approximately 50 milliters [mL]) were removed on a weekly basis and characterized using UV-Vis. The approximate liquid initial depth 
in each bag was seven centimeters $(\mathrm{cm})$. After sample extraction over the test period, the depth was approximately three $\mathrm{cm}$. Solar irradiation was measured daily at noon using a Megger PVM210 handheld irradiance meter with a measuring range from 0 to 2,000 watts per square meter $\left(\mathrm{W} / \mathrm{m}^{2}\right)$. At the end of each batch test, leachate characterization based on UV-Vis, EEMs, SEC, and COD was completed. These data were compared to the initial values to evaluate the transformation processes.

The test was designed to control liquid volume, exposure to sunlight, and mixing (once per week during sampling) in each of the bags in the batch test. Temparature was not controlled and varied among bags (as black color absorbs more light which is converted into heat energy). Both clear test and black control bags, and non-dilute leachate samples in clear bags which were black in color, had variable temperature during the daylight hours of the test period. Oxygen was able to permeate the Tedlar bags $\left(50 \mathrm{~mL} \mathrm{~m}^{-2} \mathrm{~d}^{-1}\right)$, where the dissolved oxygen (DO) concentration was dependent on the temperature of the liquid.

\section{Bacteria and Algae Control Using Sodium Azide}

To study the impacts that biological growth played in the treatment process, sodium azide $\left(\mathrm{NaN}_{3}\right)$ was added to some of the clear bags of batch tests 7 and 8 . Research has shown that $\mathrm{NaN}_{3}$ at a concentration of $0.01 \%$ is adequate for inhibiting microbial and algal activity (Seligman et al., 1986). A $5 \%$ stock solution of $\mathrm{NaN}_{3}$ was prepared by dissolving 5 grams (g) of $\mathrm{s} \mathrm{NaN}_{3}$ salts into $100 \mathrm{~mL}$ of deionized (DI) water. From the 5\% stock solution, $40 \mathrm{~mL}$ of sodium azide were added to the 2.0-L Tedlar bags at a final concentration of $0.1 \%$. This concentration was chosen to ensure inhibition of bacteria and algae. 


\section{$\underline{\text { UV-Visible Spectroscopy }}$}

UV-Vis spectroscopy was performed using a HACH DR-5000 UV-Vis spectrophotometer. Absorbance of leachate was measured in a cuvette with a $1 \mathrm{~cm}$ path length at wavelengths of 254 nanometers (nm), $465 \mathrm{~nm}, 665 \mathrm{~nm}, 456 \mathrm{~nm}$, as well as 200-800 nm scans on a $1 \mathrm{~nm}$ interval. Samples with an absorbance exceeding 3.5 abs units at $254 \mathrm{~nm}$ were diluted using DI water. Fluorescence Excitation-Emission Matrix Spectroscopy

EEMs was performed using a HORIBA Scientific FluoroMax-4 spectrofluorometer with a $1 \mathrm{~cm}$ path-length quartz cuvette. Integrated areas of characteristic peaks A, C, M, and T were determined in the following excitation/emission (Ex/Em) peak regions: peak A (Ex/Em = 260/450 $\mathrm{nm})$ characteristic of humic-like material, peak C $(\mathrm{Ex} / \mathrm{Em}=340 / 440 \mathrm{~nm})$ characteristic of fulviclike material, peak M (Ex/Em = 300/390 nm) characteristic of marine-like material, and peak T $(\mathrm{Ex} / \mathrm{Em}=275 / 340 \mathrm{~nm})$ characteristic of tryptophan and protein-like material (Coble, 1996).

\section{Size-Exclusion Chromatography}

SEC was performed using a PL Aquagel-OH column with a pore type of 20 and $8 \mu \mathrm{m}$ particle size. The separation was performed using $0.1 \mathrm{M}$ ammonium acetate $\left(\mathrm{C}_{2} \mathrm{H}_{7} \mathrm{NO}_{2}\right)$. The calibration curve was established using polystyrene sulfonic acids (molecular weight: 4300, 17000,

32000) and bovine serum albumin (66400). Samples were filtered through a $0.2 \mu \mathrm{m}$ Whatman ${ }^{\mathrm{TM}}$ nylon membrane filter prior to performing SEC.

Bioavailability of Dissolved Organic Nitrogen

To study the bioavailability of the organic matter, a SPE technique was performed. SigmaAldrich Supelite DAX-8 resin is an acrylic ester resin was used as the extraction media to separate 
the rDON and bDON fractions of the leachate prior to and after batch testing. Studies by (Liu et al., 2011) showed that the bDON is hydrophilic in nature, while the rDON is hydrophobic in nature. The SPE fractionated the bDON and rDON based on their hydrophilic and hydrophobic natures, respectively.

Prior to fractionation, the resin was soaked in 0.1-molar (M) sodium hydroxide $(\mathrm{NaOH})$ for three days, replacing the $\mathrm{NaOH}$ after 24 hours, after which it was rinsed with methanol $\left(\mathrm{CH}_{3} \mathrm{OH}\right)$ and stored in DI water until use. Twenty grams of resin were packed into a KimbleChase glass column with a $1 \mathrm{~cm}$ diameter and $20 \mathrm{~cm}$ in length. Using a Cole-Palmer Masterflex L/S peristaltic pump, the resin was conditioned by flushing with 7.5-L of DI water. Then 2.5-L of 0.1 M hydrochloric acid (HCl) followed by 2.5-L of $0.1 \mathrm{M} \mathrm{NaOH}$ were passed through the column. This step was repeated three times followed by 7.5-L of DI water.

Leachate samples were diluted based on their DON concentration to avoid exhausting the resin bed volume. Prior to passing through the columns, the $\mathrm{pH}$ of the sample was adjusted to less than $2 \mathrm{~S} . \mathrm{U}$. using $6 \mathrm{M} \mathrm{HCl}$. The fraction retained on the resin was the hydrophobic DON (or rDON) and the hydrophilic DON (or bDON) passed through the column. The rDON fraction was released by eluting, at half the initial volume of the sample, with $0.1 \mathrm{M} \mathrm{NaOH}$ in the reverse direction of flow. After fractionation, each collected sample was adjusted to a pH of 7 S.U. using either $6 \mathrm{M}$ $\mathrm{HCl}$ or $5 \mathrm{M} \mathrm{NaOH}$. The DON of both fractions was then measured. 


\section{$\underline{\text { Results and Discussion }}$}

\section{Leachate Chemical Characterization}

Complete chemical characterization of Leachates A through $\mathrm{H}$, prior to batch testing, can be seen in Table 4-2. The significant variation of leachate characteristics can be attributed to the impact of factors which affect leachate quality and quantity, including waste composition, age of the waste, and the landfill technology used (Kjeldsen et al., 2002). 
Table 4-2: Raw Leachate Sample Characteristics

\begin{tabular}{|c|c|c|c|c|c|c|c|c|}
\hline Parameter & Leachate A & Leachate B & Leachate C & Leachate D & Leachate E & Leachate F & Leachate G & Leachate $\mathrm{H}$ \\
\hline $\begin{array}{l}\text { Total BOD } 5 \\
(\mathrm{mg} / \mathrm{L})\end{array}$ & 121 & 3730 & N/A & N/A & N/A & N/A & 188 & 60 \\
\hline $\begin{array}{c}\text { Total COD } \\
(\mathrm{mg} / \mathrm{L})\end{array}$ & 5050 & 12300 & 3850 & 1800 & 3600 & 2250 & 7300 & 3050 \\
\hline $\mathrm{pH}$ (S.U.) & 8.5 & 7.6 & N/A & N/A & 7.9 & 7.6 & 7.9 & 7.9 \\
\hline $\begin{array}{c}\text { Total } \mathrm{NH}_{3}-\mathrm{N} \\
(\mathrm{mg} / \mathrm{L})\end{array}$ & 1710 & 2300 & 545 & 12 & 679 & 5 & 1010 & 83 \\
\hline $\begin{array}{c}\text { Total } \mathrm{NO}_{\mathrm{x}} \\
(\mathrm{mg} / \mathrm{L})\end{array}$ & 60 & 61 & 31 & 113 & 42 & 110 & 80 & 45 \\
\hline $\begin{array}{c}\text { Total TKN } \\
(\mathrm{mg} / \mathrm{L})\end{array}$ & 1790 & 2360 & 610 & 78 & 793 & 255 & 1150 & 162 \\
\hline $\begin{array}{c}\text { Total } \\
\text { Nitrogen } \\
(\mathrm{mg} / \mathrm{L})\end{array}$ & 1850 & 2440 & 641 & 191 & 835 & 364 & 1230 & 207 \\
\hline $\begin{array}{c}\mathrm{DON} \\
(\mathrm{mg} / \mathrm{L})\end{array}$ & 97 & 60 & 56 & 55 & 104 & 236 & 108 & 73 \\
\hline $\begin{array}{l}\text { Apparent } \\
\text { Color } \\
\text { (Pt-Co) }\end{array}$ & 28800 & 17400 & 3520 & 3100 & 14600 & 13700 & 39900 & 21100 \\
\hline $\begin{array}{l}\text { Total } U V_{254} \\
\text { (abs) }\end{array}$ & 70 & 191 & 45 & 23 & 42 & 31 & 96 & 46 \\
\hline $\begin{array}{l}\text { Sample } \\
\text { Source }\end{array}$ & $\begin{array}{l}\text { Aeration } \\
\text { Tank }\end{array}$ & $\begin{array}{l}\text { Leachate } \\
\text { Collection } \\
\text { System }\end{array}$ & $\begin{array}{l}\text { Leachate } \\
\text { Collection } \\
\text { System }\end{array}$ & $\begin{array}{c}\text { Post-onsite } \\
\text { Biological } \\
\text { Treatment }\end{array}$ & $\begin{array}{l}\text { Leachate } \\
\text { Collection } \\
\text { System }\end{array}$ & $\begin{array}{c}\text { Post-onsite } \\
\text { Biological } \\
\text { Treatment }\end{array}$ & $\begin{array}{l}\text { Leachate } \\
\text { Collection } \\
\text { System }\end{array}$ & $\begin{array}{c}\text { Post-onsite } \\
\text { Biological } \\
\text { Treatment }\end{array}$ \\
\hline
\end{tabular}




\section{$\underline{\text { UV-Visible Spectroscopy }}$}

Absorption at a wavelength of $254 \mathrm{~nm}$, commonly termed ' $\mathrm{UV}_{254}$ ', is used as an indicator of sample organic material (Altmann et al., 2016) and aromaticity (Núñez et al., 2007). The average percent reduction of $\mathrm{UV}_{254}$ in clear test bags was $62 \%$ for all the dilutions tested. The standard deviation was 25\%. Grouping by dilution showed that at higher dilution, larger reduction was possible (1:10 dilution $[\mathrm{n}=5]$, avg. $=55 \%$, std. dev. $=24 \% ; 1: 16$ to 1:50 dilution $[\mathrm{n}=6]$, avg. $=$ 75\%, std. dev. = 7.0\%; 1:100 dilution $[\mathrm{n}=2]$, avg. $=84 \%$, std. dev. $=4.0 \%$ ). To further support this observation, the percent reduction of $U_{254}$ was plotted as a function of the initial absorbance, shown in Figure 4-1.There is an exponential relationship between the percent reduction of $\mathrm{UV}_{254}$ and the initial absorbance indicating the dependency of the reduction of $U^{254}$ on the initial UV absorption (or first-order kinetics).

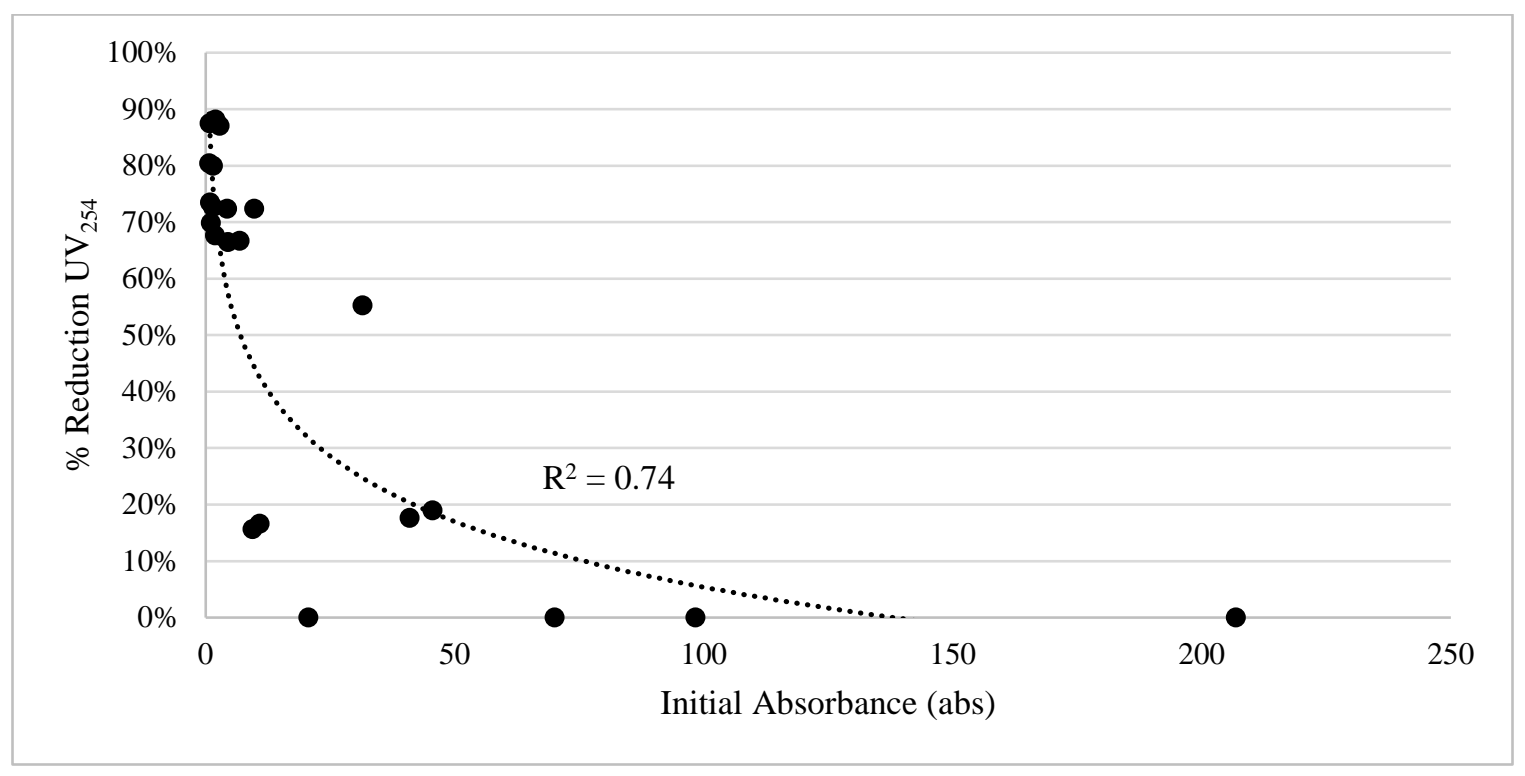

Figure 4-1: Percent Reduction of UV254 versus Initial Absorbance

$\mathrm{UV}_{254}$ measurements taken on a weekly basis were used to determine the first-order rate constant $(k)$ for the reduction of $\mathrm{UV}_{254}$ in the clear test bags. The rate constants are summarized in 
Table 4-3. Excluding the samples which saw no reduction in $\mathrm{UV}_{254}$, the average rate constant for all dilutions tested was $1.33 \mathrm{E}-02$ days $^{-1}$, with a standard deviation of $8.00 \mathrm{E}-03$. The coefficient of determination $\left(\mathrm{R}^{2}\right)$ provides evidence that the data fit well to a first-order reaction for most of the dilutions tested.

The data show a general trend that as dilution increased, the rate constant also increased. During the photolytic oxidation of humic substances, lower molecular weight compounds are formed which have higher degradation rates (Kerc et al., 2004). As dilution is increased, sunlight is able to penetrate the liquid more easily resulting in photolytic oxidation to lower molecular weight material and an increased degradation rate. 
Table 4-3: First-Order Rate Constant ( $k$ ) for the Reduction of UV254 over 90 Day Test Period

\begin{tabular}{|c|c|c|c|c|}
\hline Sample ID & Dilution & $\begin{array}{c}\text { Initial Absorbance } \\
\text { @ } 254 \text { nm (abs) }\end{array}$ & $\begin{array}{c}\text { Rate Constant (k) } \\
\left.\text { (days }^{-1}\right)\end{array}$ & $\begin{array}{c}\text { Coefficient of } \\
\text { Determination }\left(\mathbf{R}^{2}\right)\end{array}$ \\
\hline \multirow{3}{*}{ Leachate A } & None & 70 & NR & N/A \\
\hline & $1: 10$ & 6.8 & $1.04 \mathrm{E}-02$ & 0.80 \\
\hline & $1: 100$ & 0.67 & $1.87 \mathrm{E}-02$ & 0.95 \\
\hline \multirow{3}{*}{ Leachate B } & None & 207 & NR & N/A \\
\hline & $1: 10$ & 21 & NR & N/A \\
\hline & $1: 100$ & 2.0 & $2.82 \mathrm{E}-02$ & 0.92 \\
\hline \multirow{2}{*}{ Leachate C } & $1: 4.1$ & 11 & 2.03E-03 & 0.63 \\
\hline & $1: 31$ & 1.4 & $1.67 \mathrm{E}-02$ & 0.97 \\
\hline \multirow{2}{*}{ Leachate D } & $1: 2.4$ & 9.7 & $1.75 \mathrm{E}-02$ & 0.95 \\
\hline & $1: 16$ & 1.4 & $1.96 \mathrm{E}-02$ & 0.94 \\
\hline \multirow{3}{*}{ Leachate E } & None & 41 & $2.27 \mathrm{E}-03$ & 0.92 \\
\hline & $1: 10$ & 4.3 & $1.41 \mathrm{E}-02$ & 0.98 \\
\hline & $1: 40$ & 1.0 & $1.35 \mathrm{E}-02$ & 0.91 \\
\hline \multirow{3}{*}{ Leachate F } & None & 31 & $9.69 \mathrm{E}-03$ & 0.83 \\
\hline & $1: 10$ & 2.8 & $2.53 E-02$ & 0.96 \\
\hline & $1: 40$ & 0.74 & $2.24 \mathrm{E}-02$ & 0.88 \\
\hline \multirow{3}{*}{ Leachate G } & None & 98 & NR & N/A \\
\hline & $1: 10$ & 9.4 & $1.15 \mathrm{E}-03$ & 0.26 \\
\hline & $1: 50$ & 1.9 & $1.24 \mathrm{E}-02$ & 0.82 \\
\hline \multirow{3}{*}{ Leachate H } & None & 46 & $2.28 \mathrm{E}-03$ & 0.81 \\
\hline & $1: 10$ & 4.5 & $1.13 \mathrm{E}-02$ & 0.82 \\
\hline & $1: 50$ & 0.86 & $1.24 \mathrm{E}-02$ & 0.77 \\
\hline
\end{tabular}

$\mathrm{NR}=$ no reduction; $\mathrm{N} / \mathrm{A}=$ not available

To show the reduction of $\mathrm{UV}_{254}$ over the test period, the absorbance was plotted as a function of time (over 90 days). Figures for the eight batch tests can be found in Appendix B. As an example, the results from the batch test for Leachate A are shown in Figure 4-2. The test and control bags with no dilution displayed similar behavior. No reduction of $\mathrm{UV}_{254}$ in the clear test bag was observed due to the high initial absorbance $\left(\mathrm{UV}_{254}=70 \mathrm{abs}\right)$ and dark color, preventing sunlight from penetrating the liquid. The 1:10 and 1:100 dilutions showed that reduction of $\mathrm{UV}_{254}$ occurred in the clear test bag, while the black control bags remained relatively constant. The data 
suggest that photolytic reactions are responsible for the treatment resulting from sunlight penetrating the liquid depth.

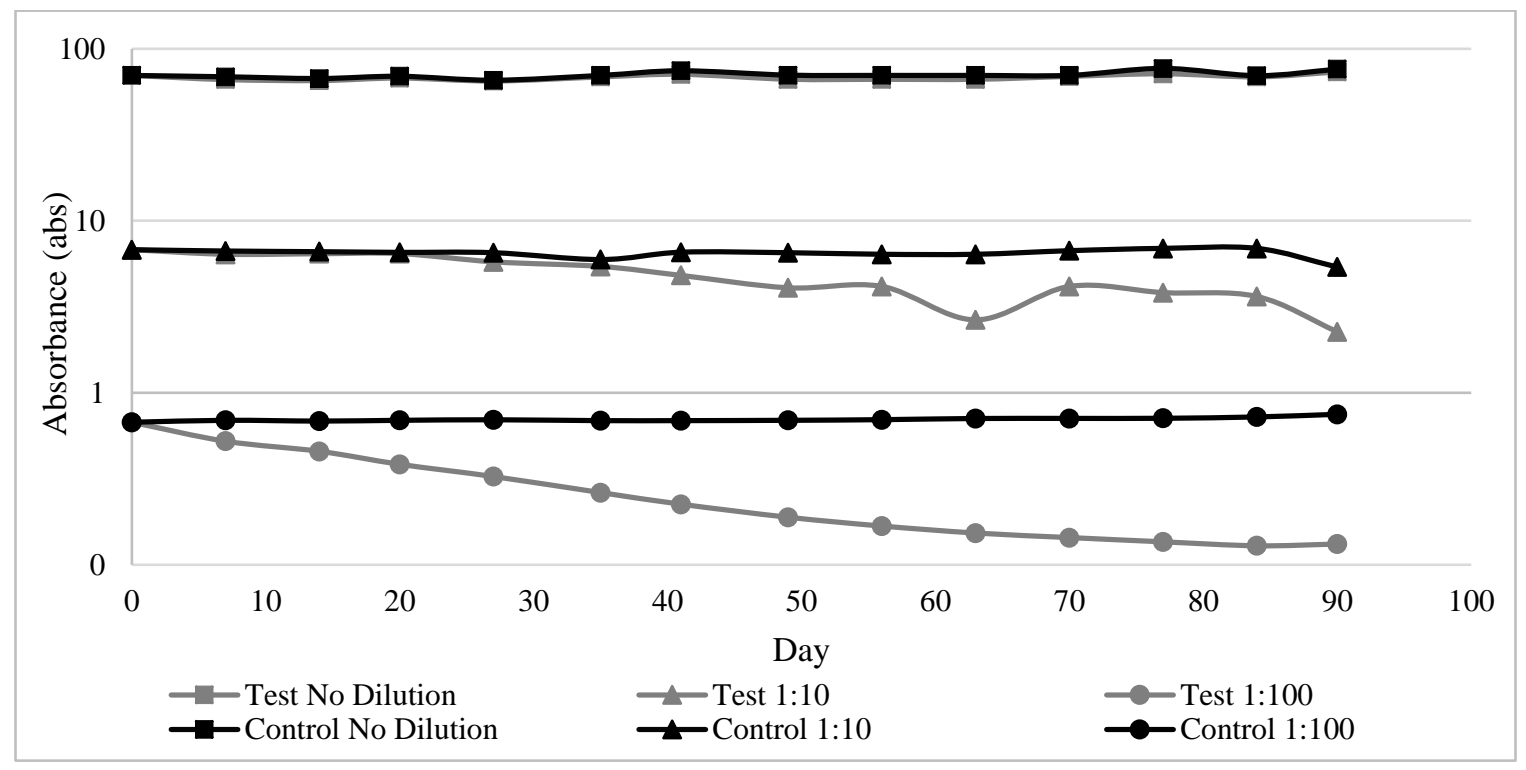

\section{Figure 4-2: Leachate A UV254 90 Day Trend}

Figure 4-3 and Figure 4-4 show spectral scans from 200-800 nm of the non-dilute and 1:10 dilution for Leachate A, respectively. Figures for the remaining leachates can be found in Appendix C. Increased solar irradiation has been shown to decrease absorbance of samples containing humic substance (mainly humic acid) as a result of photolytic oxidation (Kerc et al., 2004). This transformation can be observed by a 'blue shift' across the UV-Visible spectra, or a shift to a shorter wavelength resulting from a reduction of high molecular weight CDOM (Boyd et al., 2004; Jiang et al., 2016). The 1:10 dilution showed a blue shift of the sample after being irradiated by sunlight for 90 days. The shift indicates a reduction in high molecular weight CDOM. 


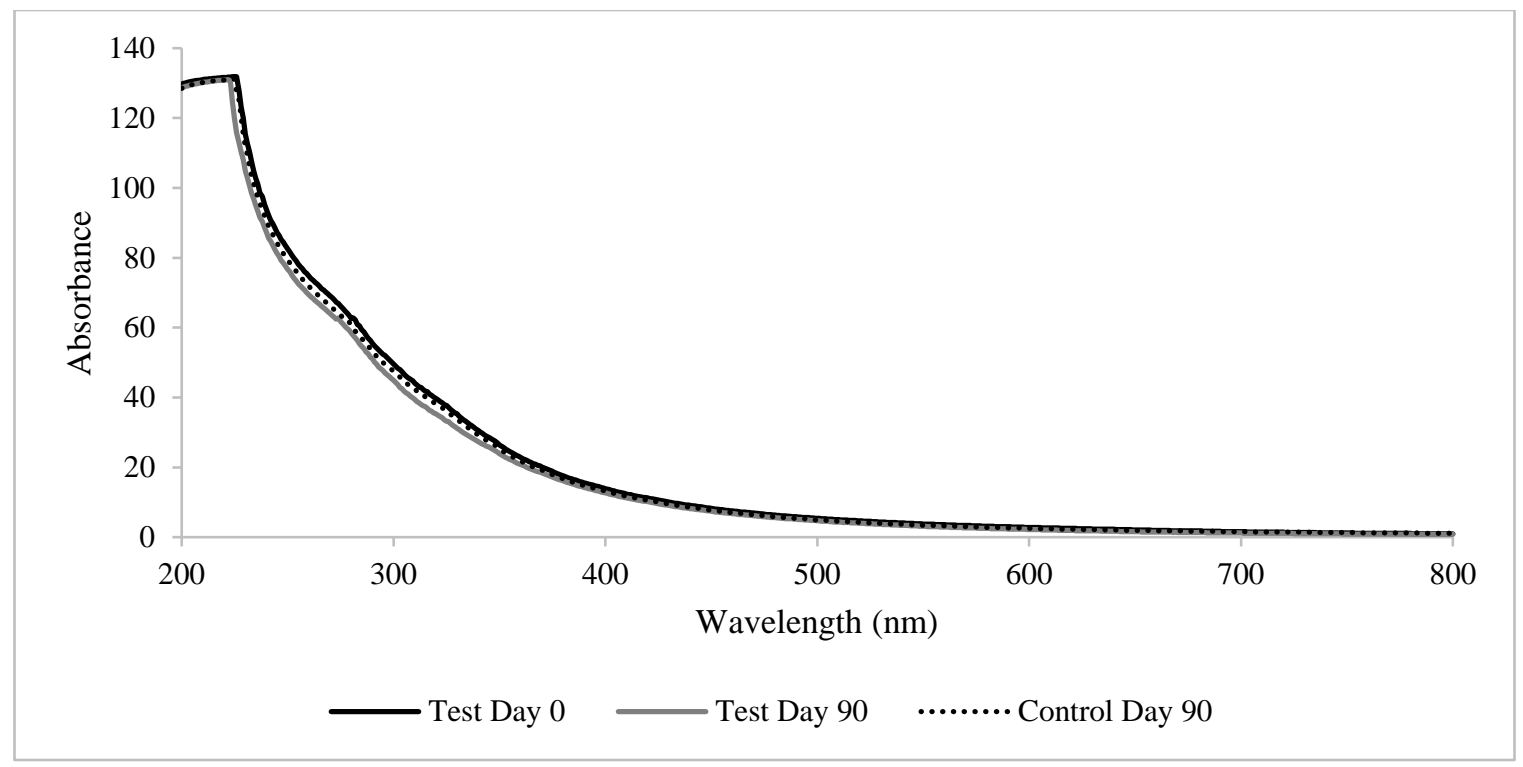

Figure 4-3: Leachate A No Dilution Day 0 and Day 90 UV-Vis Scans

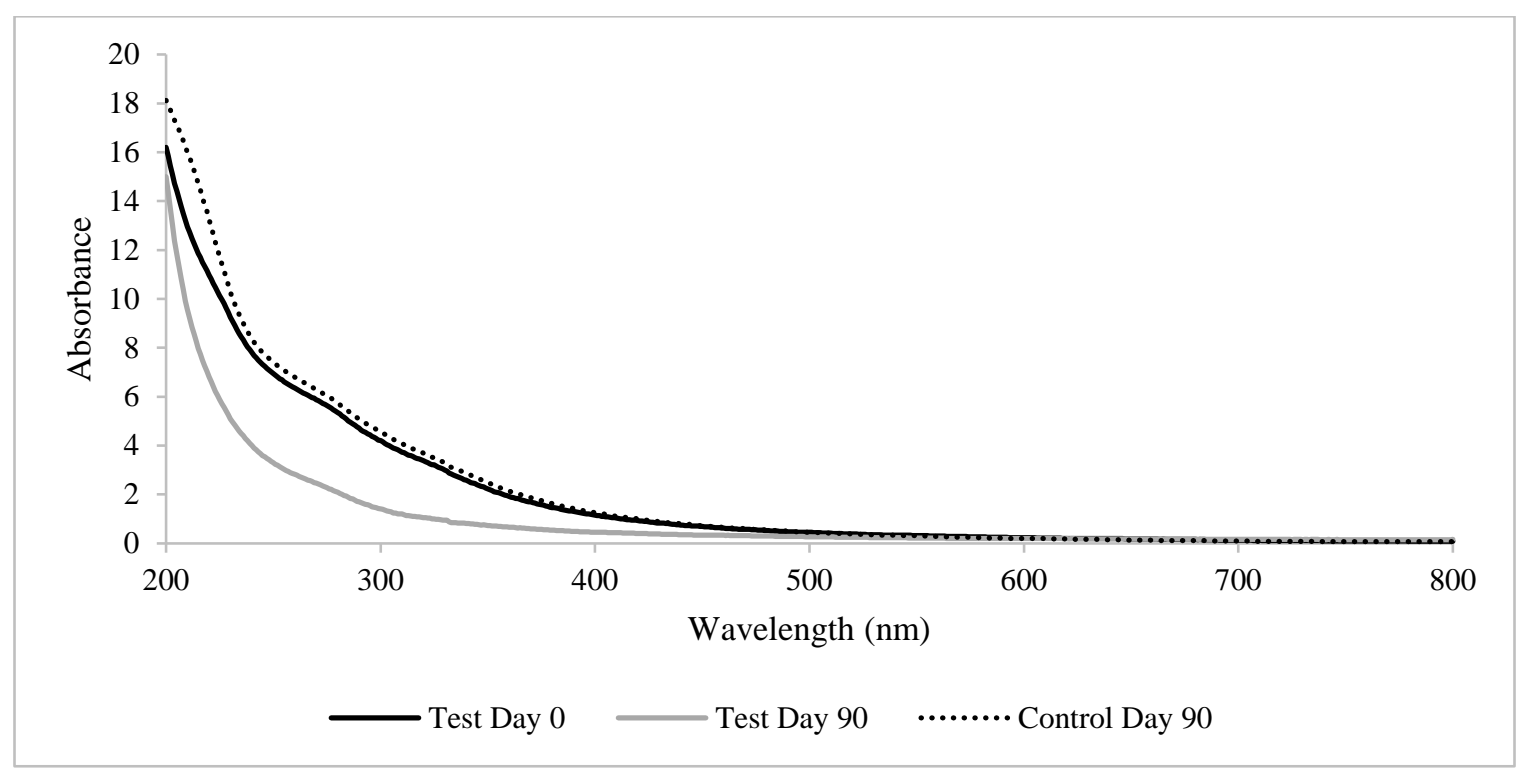

Figure 4-4: Leachate A 1:10 Dilution Day 0 and Day 90 UV-Vis Scans

De Haan and De Boer (1987) found that the ratio between absorption at $250 \mathrm{~nm}$ and 365 nm (termed $E_{2}: E_{3}$ ) can be used to characterize the relative molecular weight of DOM. They showed that the relative molecular weight and $E_{2}: E_{3}$ ratio are inversely proportional, where the $E_{2}: E_{3}$ ratio decreases with increasing molecular weight as a result of strong absorption of light at longer 
wavelengths by high molecular weight CDOM (De Haan et al., 1987). The $\mathrm{E}_{2}$ : $\mathrm{E}_{3}$ ratios for the eight leachates can be found in Appendix D. Figure 4-5 shows the $\mathrm{E}_{2}: \mathrm{E}_{3}$ ratios for the non-dilute, 1:10, and 1:100 dilutions of Leachate $\mathrm{A}$. An increase in the $\mathrm{E}_{2}: \mathrm{E}_{3}$ is observed as dilution increases. The remaining seven leachates, except Leachate B, presented a similar trend, where diluted samples displayed an increase in the $\mathrm{E}_{2}: \mathrm{E}_{3}$ ratio. The increase indicates the generation of a relatively larger amount of low molecular weight material resulting from degradation of high molecular weight material through photolytic reactions.

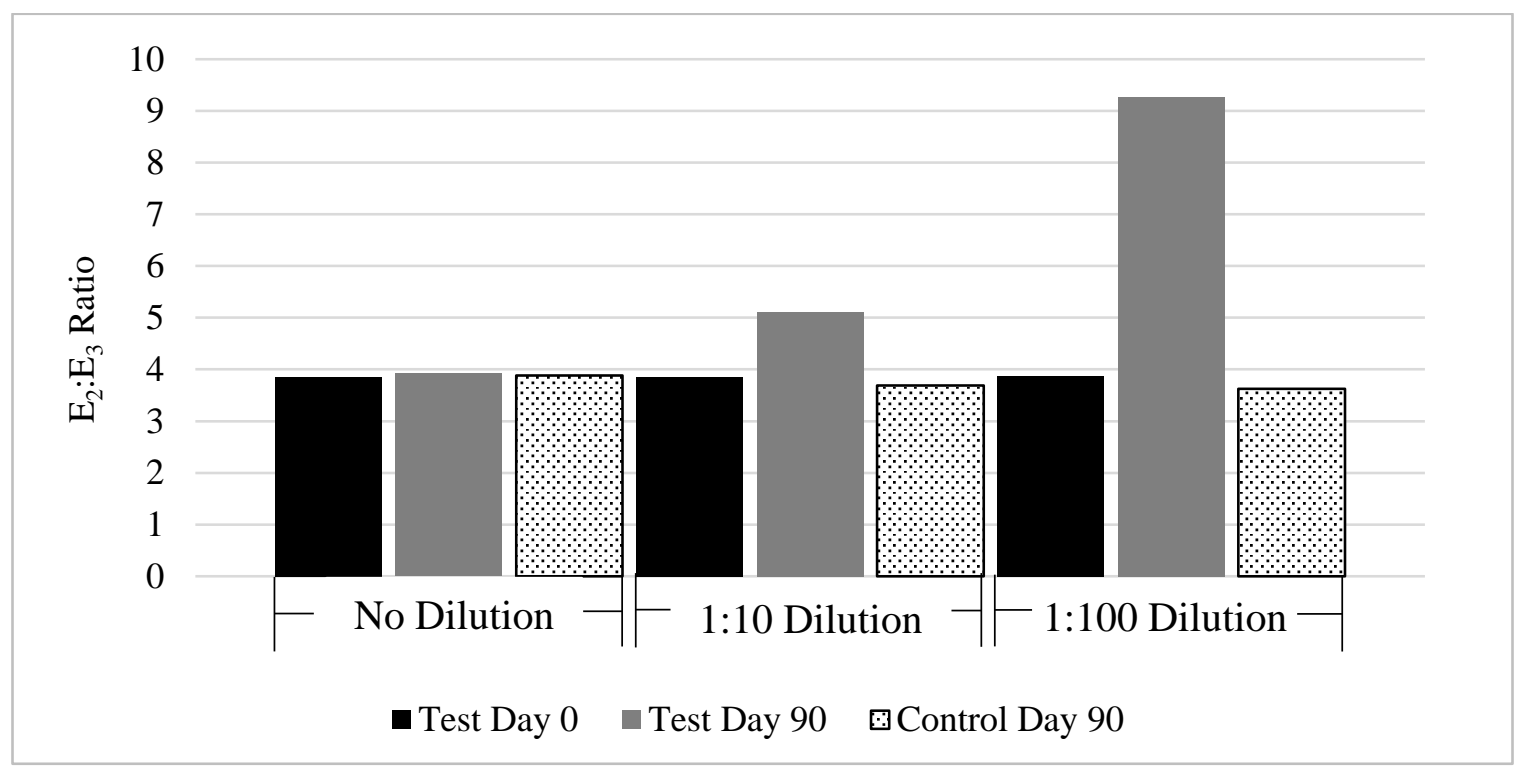

Figure 4-5: Leachate A E2:E3 Ratios

Another measure of relative molecular weight using spectroscopy is the slope ratio $\left(S_{R}\right)$. The $S_{R}$ has been used to characterize the relative molecular weight of CDOM. The $S_{R}$ is inversely proportional to the relative molecular weight, where an increase indicates lower molecular weight material. The $S_{R}$ is determined from the log-transformed slope of the absorbance from the region of 275-295 nm ( $\left.\mathrm{S}_{275-295}\right)$ over the region of 350-400 nm ( $\left.\mathrm{S}_{350-400}\right)$ (Helms et al., 2008), as shown in Equation 4.1. 


$$
S_{R}=\frac{\ln \left(\frac{\Delta Y_{275-295}}{\Delta X_{275-295}}\right)}{\ln \left(\frac{\Delta Y_{350-400}}{\Delta X_{350-400}}\right)}=\frac{S_{275-295}}{S_{350-400}}
$$

Where, $\Delta Y_{275-295}$ is the change in values along the y-axis from $275-295 \mathrm{~nm}$

$\Delta X_{275-295}$ is the change in values along the $\mathrm{x}$-axis from $275-295 \mathrm{~nm}$

$\Delta Y_{350-400}$ is the change in values along the y-axis from $350-400 \mathrm{~nm}$

$\Delta X_{350-400}$ is the change in values along the $\mathrm{x}$-axis from $350-400 \mathrm{~nm}$

Using a range of absorption measurements, rather than ratios of single wavelengths eliminates errors in analytical measurement near the detection limits of the spectroscopic instrument (Helms et al., 2008).

Figure 4-6 and Figure 4-7 present slope ratios of the non-dilute and 1:10 dilution for Leachate A, respectively. Appendix E presents the figures for the remaining leachates. As samples are diluted, the slope ratio of leachate in clear test bags increases while the slope ratio of the leachate in black control bag remains constant over the test period. These data show an increase in low molecular weight material as a result of photodegradation of high molecular weight material.

Studies by Helms et al. (2008) on aquatic DOM show that spectral slope region of 275-295 $\mathrm{nm}$ also increased upon irradiation, while the slope region of 350-400 nm generally decreased (Helms et al., 2008). In the eight batch tests, the $\mathrm{S}_{275-295}$ increases for $64 \%$ of the samples and the $\mathrm{S}_{350-400}$ decreases for $82 \%$, suggesting that transformation of organic material resulted from solar irradiation. 


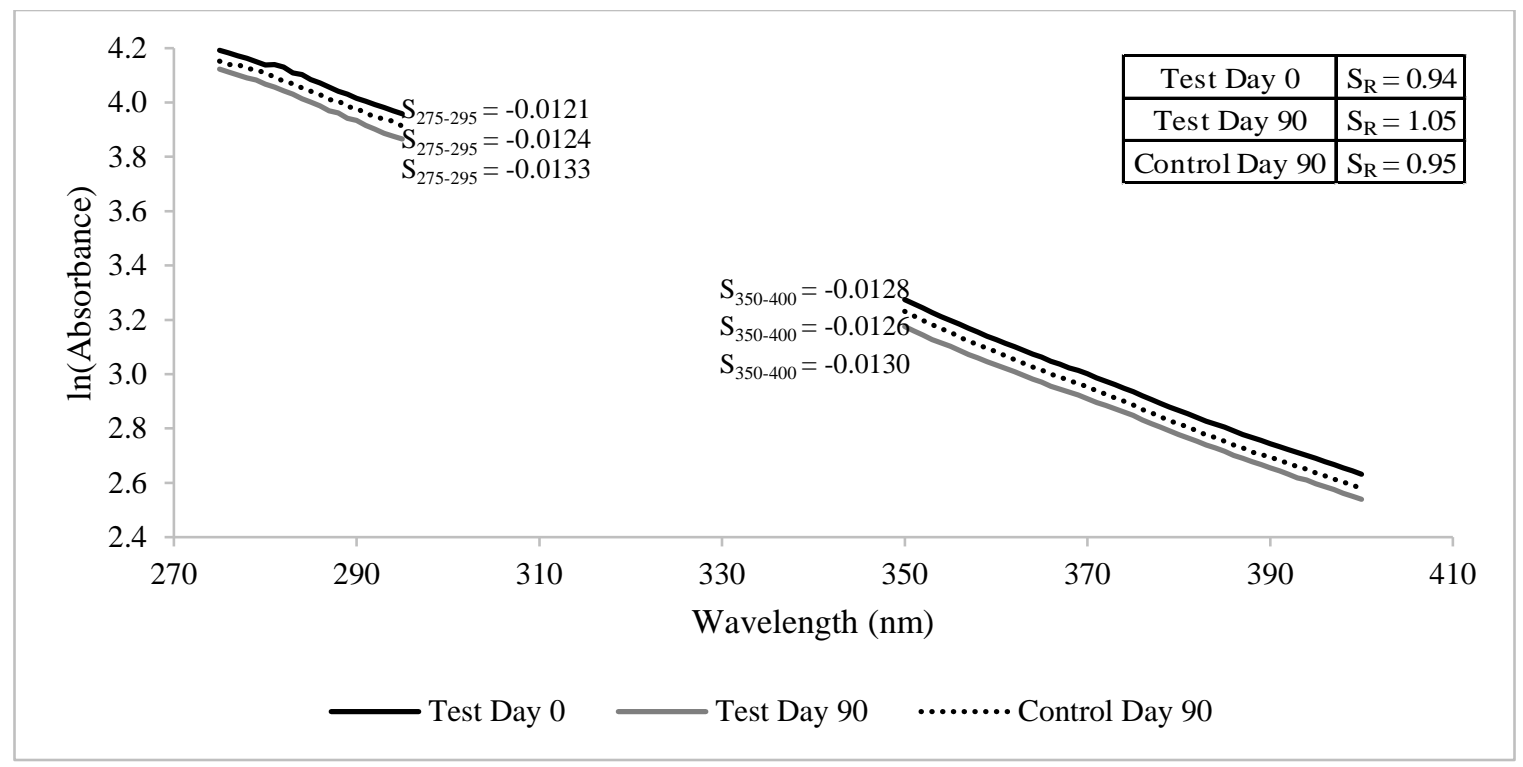

Figure 4-6: Leachate A No Dilution Day 0 and Day 90 Slope Ratios

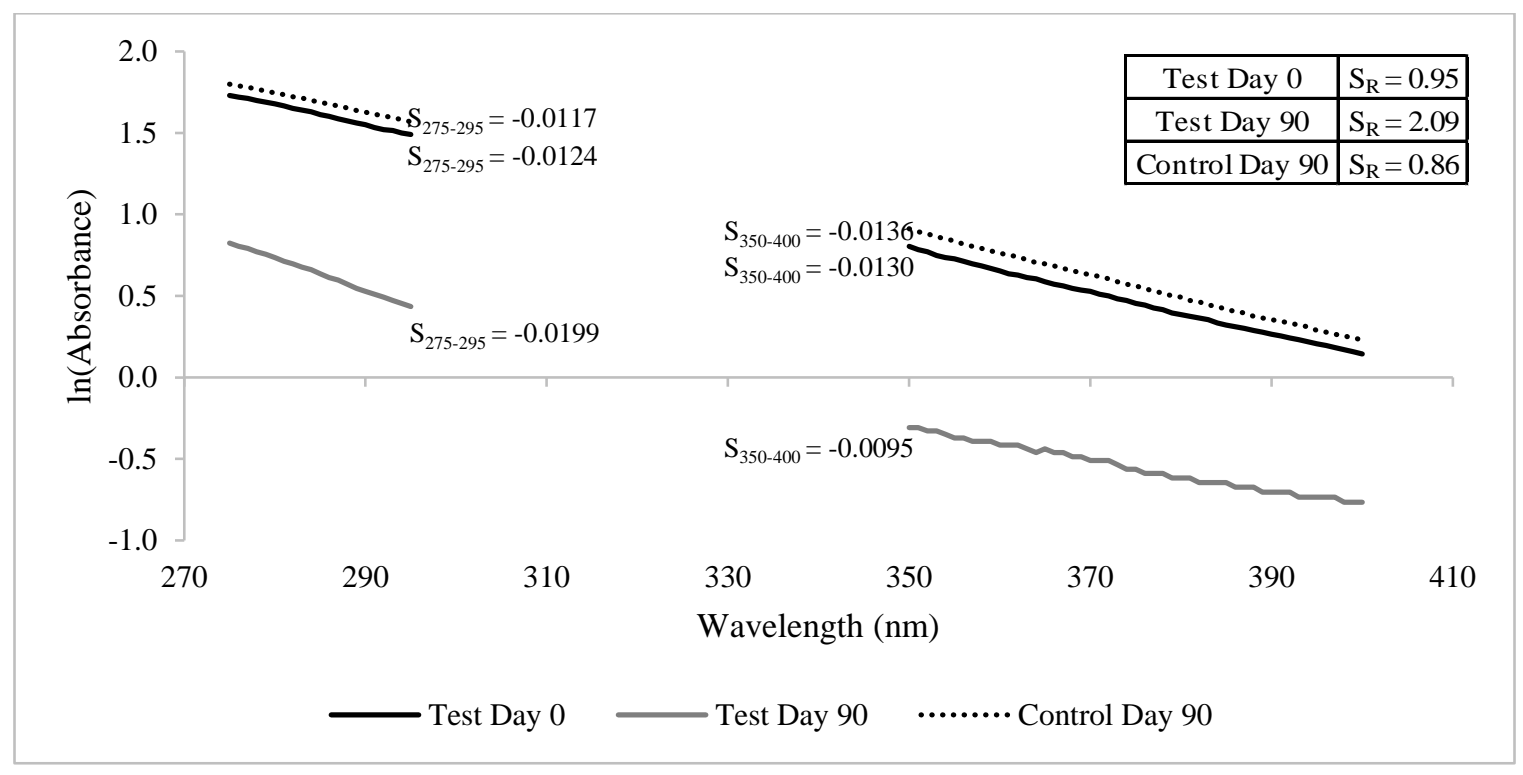

Figure 4-7: Leachate A 1:10 Dilution Day 0 and Day 90 Slope Ratios 


\section{Apparent Color}

Unfiltered leachate samples were analyzed before and after photoexposure to explore reduction in apparent color resulting from photobleaching. These results, summarized in Table 4-4, show that reduction in color is possible and tends to increase with dilution. The reduction in color implies that when CDOM is irradiated, high molecular weight CDOM is converted to lower molecular weight CDOM with lower color, as shown by Helms et al. (2008).

Table 4-4: Percent Reduction of Apparent Color over 90 Day Test Period

\begin{tabular}{|c|c|c|}
\hline Sample ID & Dilution & \% Reduction Apparent Color \\
\hline \multirow{3}{*}{ Leachate A } & None & 11 \\
\hline & $1: 10$ & 49 \\
\hline & $1: 100$ & 92 \\
\hline \multirow{3}{*}{ Leachate B } & None & NR \\
\hline & $1: 10$ & NR \\
\hline & $1: 100$ & 73 \\
\hline \multirow{2}{*}{ Leachate C } & $1: 4.1$ & NR \\
\hline & $1: 31$ & 58 \\
\hline \multirow{2}{*}{ Leachate D } & $1: 2.4$ & 69 \\
\hline & $1: 16$ & 57 \\
\hline \multirow{3}{*}{ Leachate E } & None & NR \\
\hline & $1: 10$ & 98 \\
\hline & $1: 40$ & 78 \\
\hline \multirow{3}{*}{ Leachate F } & None & 94 \\
\hline & $1: 10$ & 97 \\
\hline & $1: 40$ & 84 \\
\hline \multirow{3}{*}{ Leachate G } & None & 17 \\
\hline & $1: 10$ & 35 \\
\hline & $1: 50$ & 80 \\
\hline \multirow{3}{*}{ Leachate H } & None & 22 \\
\hline & $1: 10$ & 34 \\
\hline & $1: 50$ & 84 \\
\hline
\end{tabular}

$\mathrm{NR}=$ no reduction 


\section{Chemical Oxygen Demand}

Over the test period, average percent reduction of COD in the clear bags tended to increase with increasing dilution (1:10 dilution $[\mathrm{n}=4]$, avg. $=28 \%$, std. dev. $=21.5$; $1: 16$ to $1: 50$ dilution [n=4], avg. = 38\%, std. dev. = 12.7; 1:100 dilution $[\mathrm{n}=2]$, avg. = 51\%, std. dev. = 13.5). However, these results were variable amongst the eight leachates as indicated by the large standard deviations (std. dev.). COD in black control bags also declined slightly indicating that the reduction was not due to photolytic reactions alone. Table 4-5 shows the percent reduction in COD over the 90 day test period of Leachates A through $\mathrm{H}$. COD reduction was less than that of UV absorption, which suggests that LOM is transformed but not destroyed. 
Table 4-5: Percent Reduction of COD over 90 Day Test Period

\begin{tabular}{|c|c|c|}
\hline Sample ID & Dilution & \% Reduction COD \\
\hline \multirow{3}{*}{ Leachate A } & None & NR \\
\hline & $1: 10$ & 2 \\
\hline & $1: 100$ & 37 \\
\hline \multirow{3}{*}{ Leachate B } & None & NR \\
\hline & $1: 10$ & NR \\
\hline & $1: 100$ & 64 \\
\hline \multirow{2}{*}{ Leachate C } & $1: 4.1$ & NR \\
\hline & $1: 31$ & 33 \\
\hline \multirow{2}{*}{ Leachate D } & $1: 2.4$ & 7 \\
\hline & $1: 16$ & 38 \\
\hline \multirow{3}{*}{ Leachate E } & None & 31 \\
\hline & $1: 10$ & 47 \\
\hline & $1: 40$ & 22 \\
\hline \multirow{3}{*}{ Leachate F } & None & 20 \\
\hline & $1: 10$ & 51 \\
\hline & $1: 40$ & 57 \\
\hline \multirow{3}{*}{ Leachate G } & None & 14 \\
\hline & $1: 10$ & 11 \\
\hline & $1: 50$ & NR \\
\hline \multirow{3}{*}{ Leachate $\mathrm{H}$} & None & 31 \\
\hline & $1: 10$ & NR \\
\hline & $1: 50$ & NR \\
\hline
\end{tabular}

$\mathrm{NR}=$ no reduction

\section{Fluorescence Excitation Emission Matrix Spectroscopy (EEMs)}

Ratios of peaks A:T and C:T are used to quantify relative amounts of humic-like DOM and fresh-like (or labile) DOM. These ratios have been shown to increase when materials undergo biodegradation and decrease as a result of photodegradation (Hansen et al., 2016). Figure 4-8 and Figure 4-9 present the A:T and C:T ratios, respectively, for Leachate A. Figures for the remaining leachates can be found in Appendix F. Dilution of samples showed greater reduction in A:T and $\mathrm{C}: \mathrm{T}$ ratios resulting from increased light penetration in the clear bags. The decrease in ratios 
suggest fluorescent material has transformed from humic-like to fresh-like as a result of photodegradation.

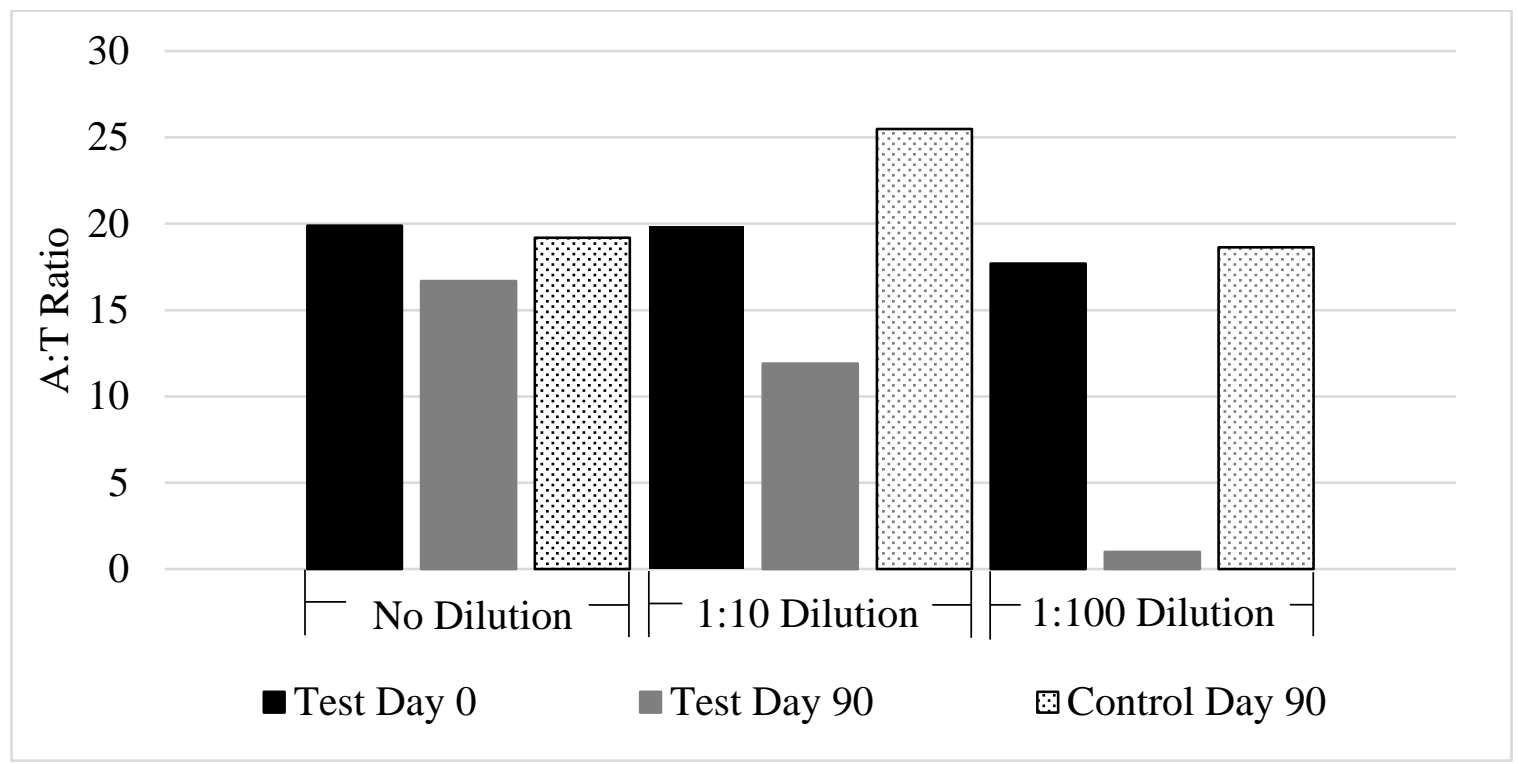

Figure 4-8: Leachate A EEMs A:T Ratio

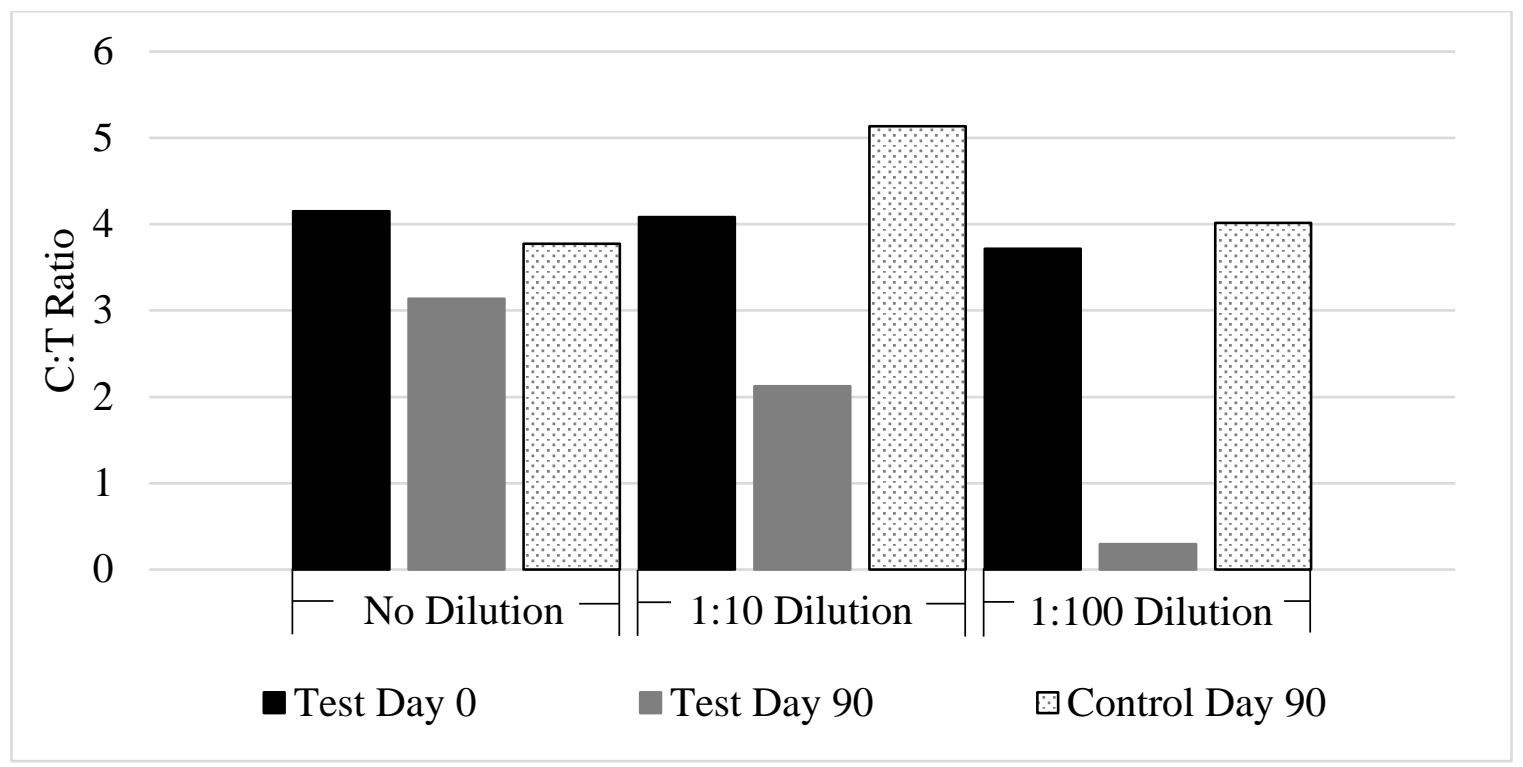

Figure 4-9: Leachate A EEMs C:T Ratio 


\section{$\underline{\text { Size-Exclusion Chromatography }}$}

SEC was used to quantify changes in molecular weight of LOM after photoexposure. Table 4-6 shows the overall percent reduction of total area, determined from integrating peaks of characteristic retention times. The total area reduction provides an indication of the reduction of total molecular weight of a sample. The results show that as dilution of the leachate is increased, the ability for reduction in total molecular weight of the sample increases. The average and standard deviation for the percent reduction of area is as follows: 1:10 dilution [ $\mathrm{n}=4$ ], avg. $=38 \%$, std. dev. = 26; $1: 16$ to $1: 50$ dilution $[\mathrm{n}=4]$, avg. $=90 \%$, std. dev. $=9.9 ; 1: 100$ dilution $[\mathrm{n}=2]$, avg. $=83 \%$, std. dev. $=2.2$. Large standard deviations seen in this measurement are a result of high variability in characteristics amongst leachate samples. SEC was not performed on Leachates G and $\mathrm{H}$. 
Table 4-6: SEC Percent Reduction of Area

\begin{tabular}{|c|c|c|}
\hline Sample ID & Dilution & \% Reduction Area \\
\hline \multirow{3}{*}{ Leachate A } & None & 6.4 \\
\cline { 2 - 3 } & $1: 10$ & 68 \\
\cline { 2 - 3 } & $1: 100$ & 81 \\
\hline \multirow{3}{*}{ Leachate B } & None & N/A \\
\cline { 2 - 3 } & $1: 10$ & 3.8 \\
\cline { 2 - 3 } Leachate C & $1: 100$ & 85 \\
\cline { 2 - 3 } & $1: 4.1$ & 41 \\
\hline \multirow{2}{*}{ Leachate D } & $1: 31$ & 80 \\
\cline { 2 - 3 } & $1: 2.4$ & 61 \\
\hline \multirow{3}{*}{ Leachate E } & $1: 16$ & 100 \\
\cline { 2 - 3 } & None & 15 \\
\cline { 2 - 3 } & $1: 10$ & 41 \\
\hline \multirow{3}{*}{ Leachate F } & $1: 40$ & $31^{*}$ \\
\cline { 2 - 3 } & None & 44 \\
\cline { 2 - 3 } & $1: 10$ & $50^{*}$ \\
\hline \multirow{2}{*}{ N/A } & $1: 40$ & $72^{*}$ \\
\hline
\end{tabular}

N/A = not available

*\% reduction is from day 0 to day 41 of test, concentrations at day 90 were below detectable limits

To quantify changes in molecular weight further, the normalized area of each characteristic peaks was plotted at day 0 and day 90 . Normalized area was determined by dividing the integrated area at characteristic retention times by the total area of all retention times, providing an indication of the molecular sizes found in the sample. These figures can be found in Appendix G for Leachates A, C, D, E, and F. The normalized peak areas for Leachate A are shown in Figure 4-10. Transformation of high molecular weight material to low molecular weight material is shown by a shift from a large normalized area percentage at short retention times to longer retention times. This trend was more pronounced in samples with higher dilution. 


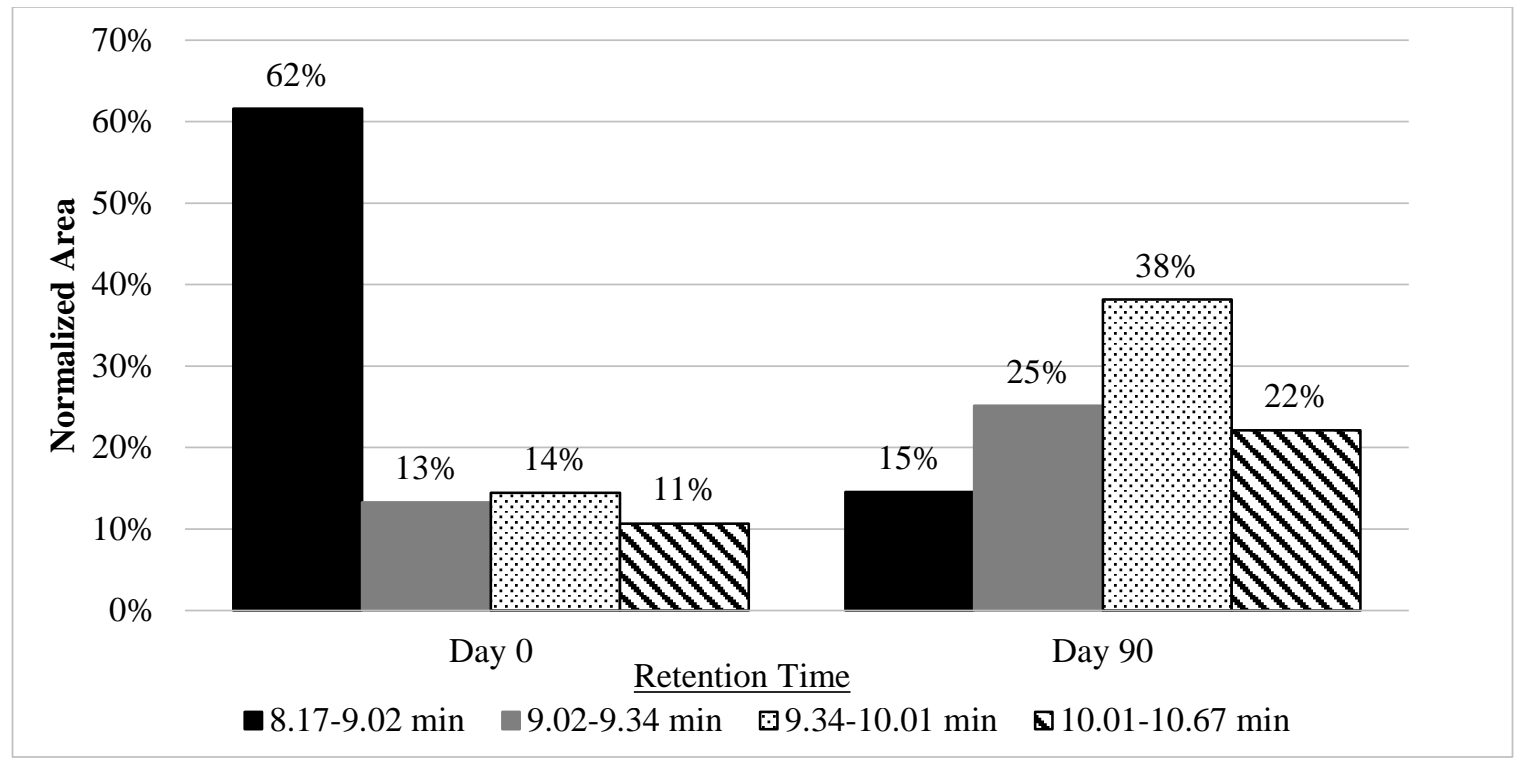

Figure 4-10: Leachate A 1:100 Dilution SEC Normalized Peak Areas

Bacteria and Algae Control Using Sodium Azide

The sodium azide experiment was used to determine whether bacteria and algal growth played a role in treatment. A green material was observed the clear bags of all batch tests, to some degree. It is suspected that this growth impacted the treatment efficiency, either through metabolic action or by blocking sunlight from penetrating into the bag. The impact of biological processes was examined in batch tests seven and eight, which included Leachates $\mathrm{G}$ and $\mathrm{H}$, by dosing some of the clear test bags with $0.1 \%$ sodium azide to kill bacteria or algae present. Leachates $\mathrm{G}$ and $\mathrm{H}$ were from the same landfill as Leachates $\mathrm{E}$ and F, but were sampled at different times of the year. The figures presented in this section are for the 1:10 and 1:50 dilutions of Leachate $\mathrm{H}$. The additional figures for these batch tests can be found in the Appendix.

The results of samples with sodium azide showed that the growth observed in the bags likely had an impact, as hypothesized. Figure 4-11 and Figure 4-12 show, for Leachate H 1:10 and 1:50 dilutions, the $\mathrm{UV}_{254}$ trend over 90 days, respectively. The reduction of $\mathrm{UV}_{254}$ was less in the 
presence of sodium azide as compared to the un-inhibited tests. However, given the fact that some treatment occurred in the absence of biological activity, results suggest that both photo and biodegradation of UV absorbing compounds occurred. The higher initial absorbance occurred as a result of sodium azide having a UV absorbance. Because, this treatment does not occur in dark bags, it appears to be a sunlight-driven biological process. Leachate G diluted samples behaved similarly.

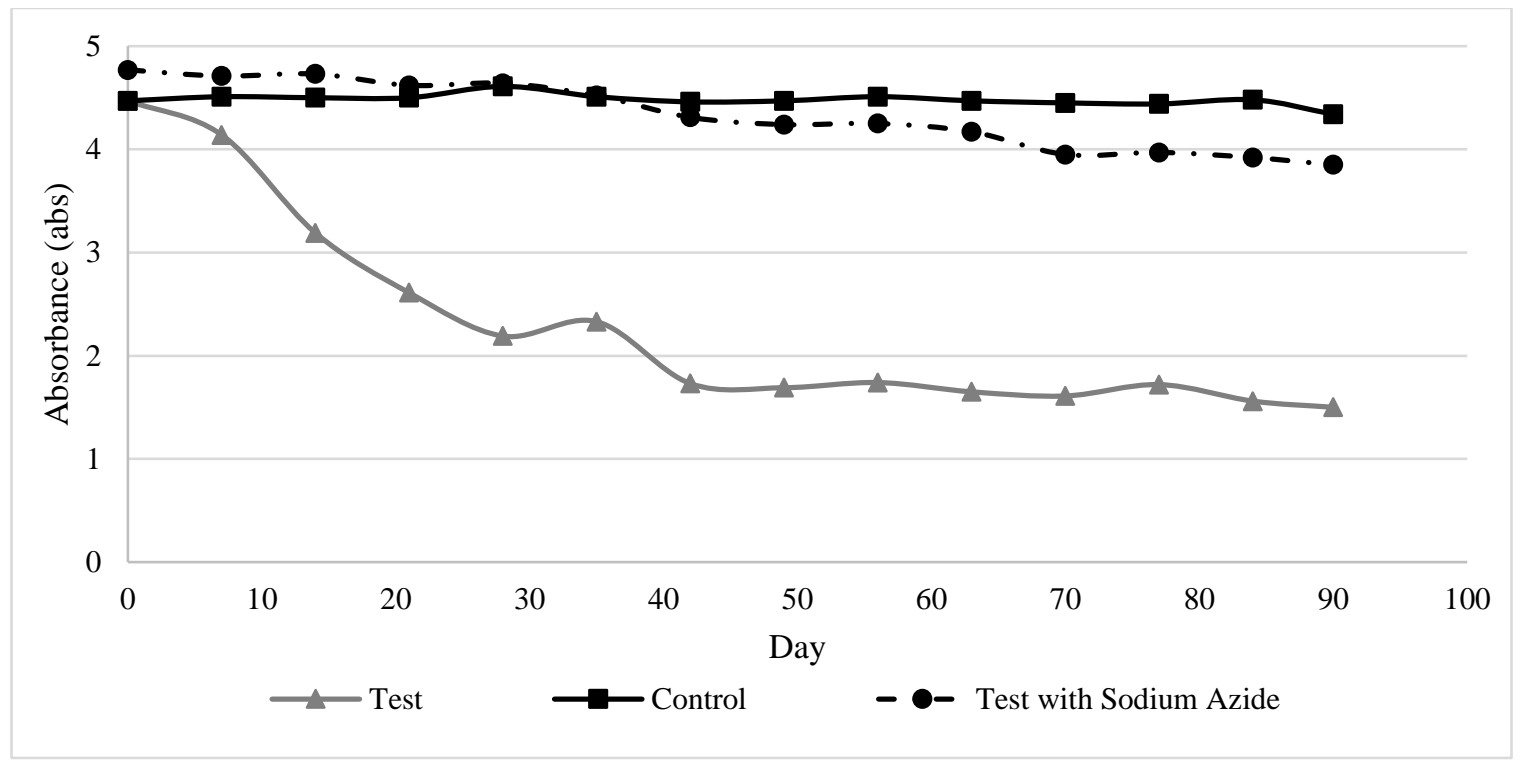

Figure 4-11: Leachate H 1:10 Dilution UV254 Trend Over 90 Days 


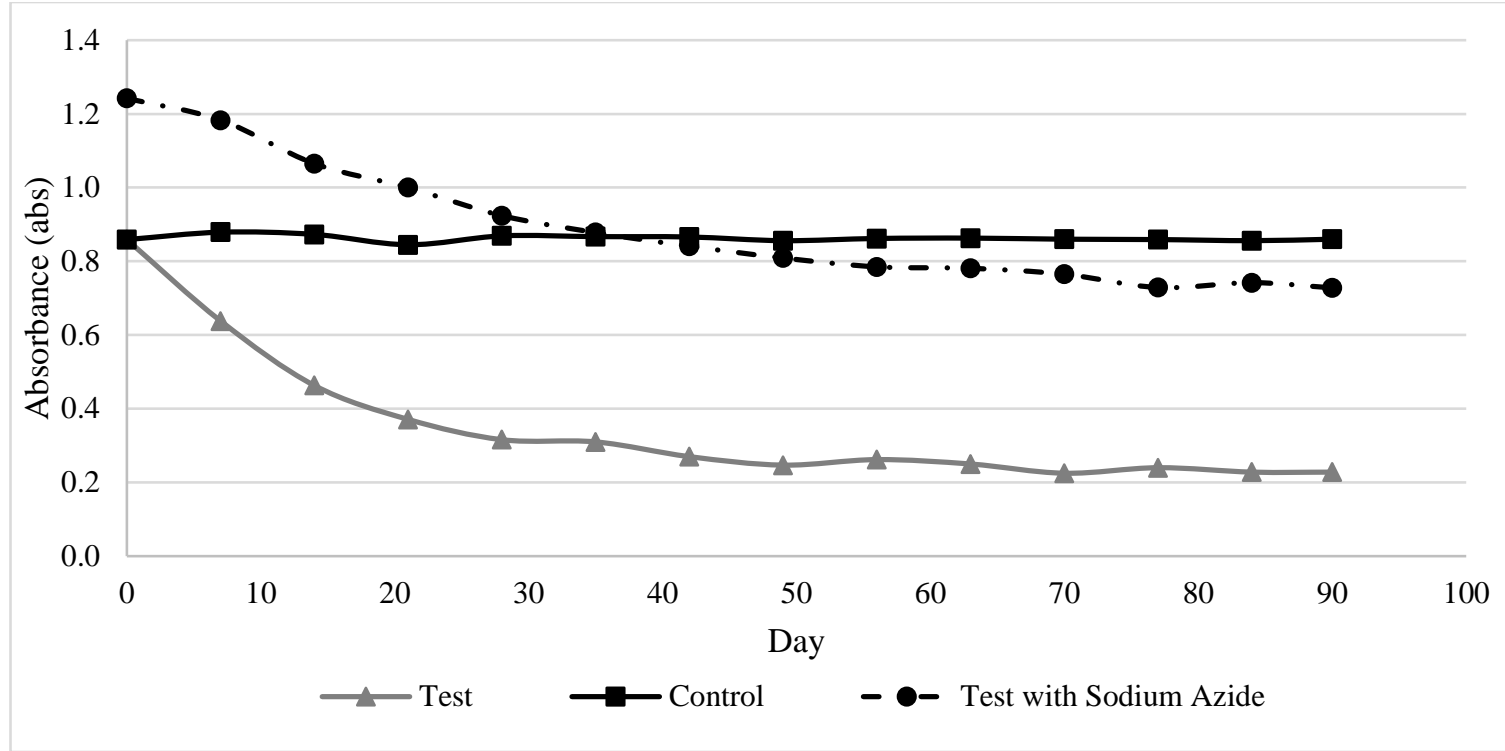

Figure 4-12: Leachate H 1:50 Dilution UV254 Trend Over 90 Days

Both samples with and without sodium azide showed a blue shift across the UV-Vis spectra. These results are shown in Figure 4-13 and Figure 4-14 for the 1:10 and 1:50 dilutions of Leachate $\mathrm{H}$, respectively. While not as significant as the samples without sodium azide, a shift was still apparent in inhibited samples, indicating a reduction of high molecular weight CDOM.

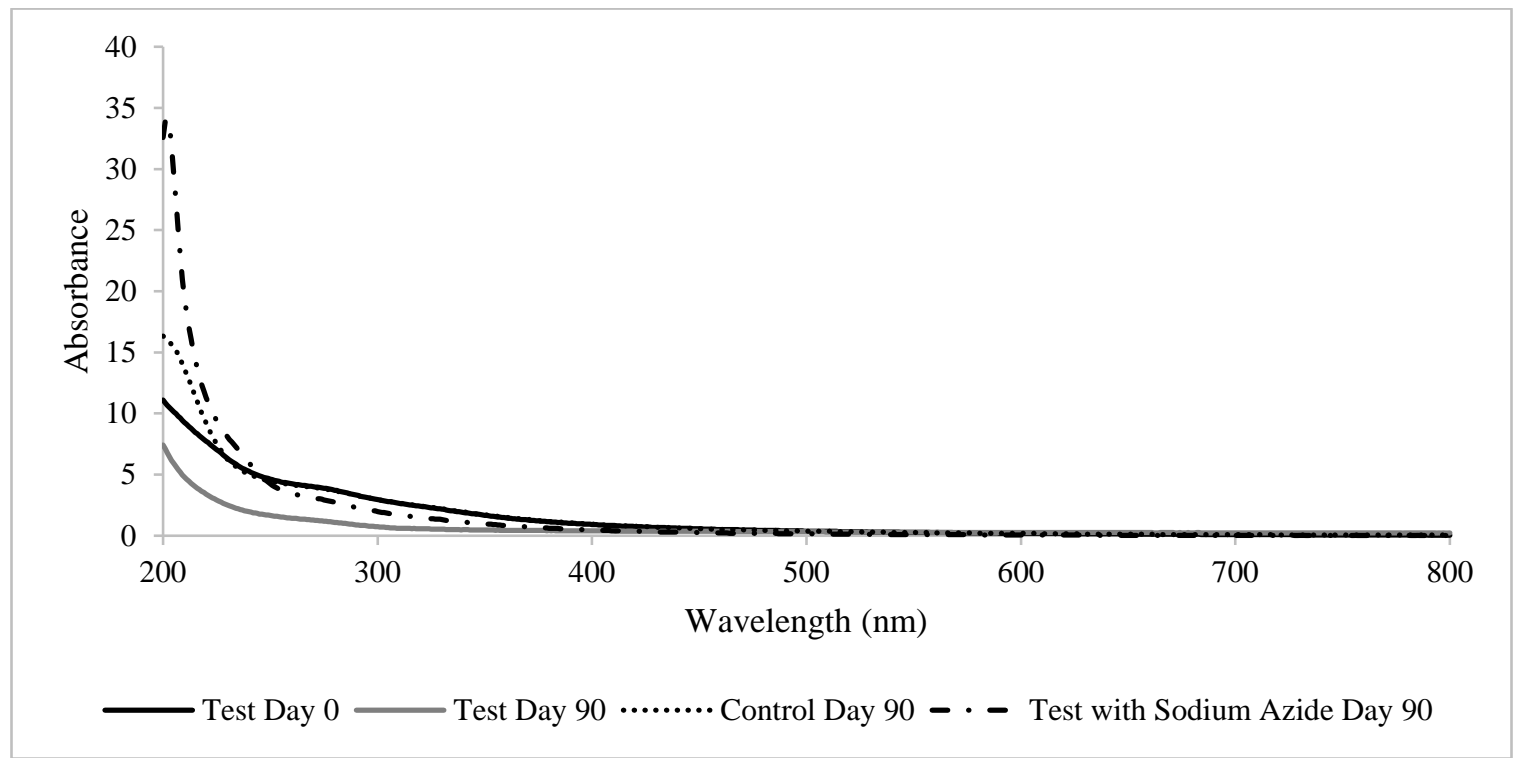

Figure 4-13: Leachate H 1:10 No Dilution Day 0 and Day 90 UV-Vis Scans 


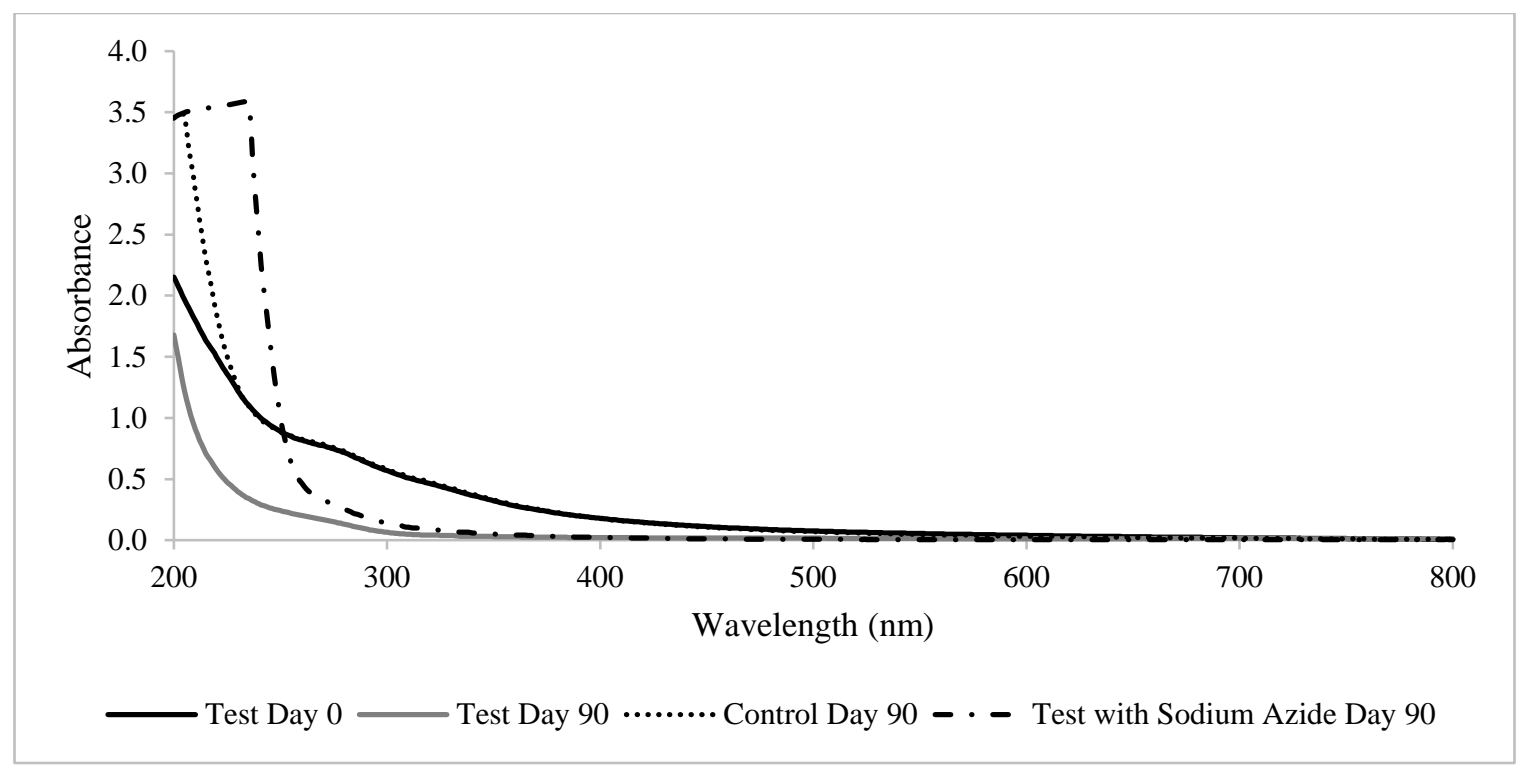

Figure 4-14: Leachate H 1:50 Dilution Day 0 and Day 90 UV-Vis Scans

The $\mathrm{E}_{2}: \mathrm{E}_{3}$ ratios for Leachate $\mathrm{H}$ with sodium azide show increased treatment efficiency, as seen in Figure 4-15. The increased $E_{2}: E_{3}$ ratios of the bags with sodium azide suggest a larger portion of low molecular weight material. These results are supported by studies by Fox et al. (2017) which showed that byproducts of terrestrial fluorescent organic matter bacterial degradation resulted in an increase in high molecular weight allochthonous material. The fluorescent organic matter in leachate exhibits similar properties to that of terrestrially derived fluorescent organic matter of allochthonous derivation and is susceptible to photochemical reactions (Sulzberger et al., 2009). 


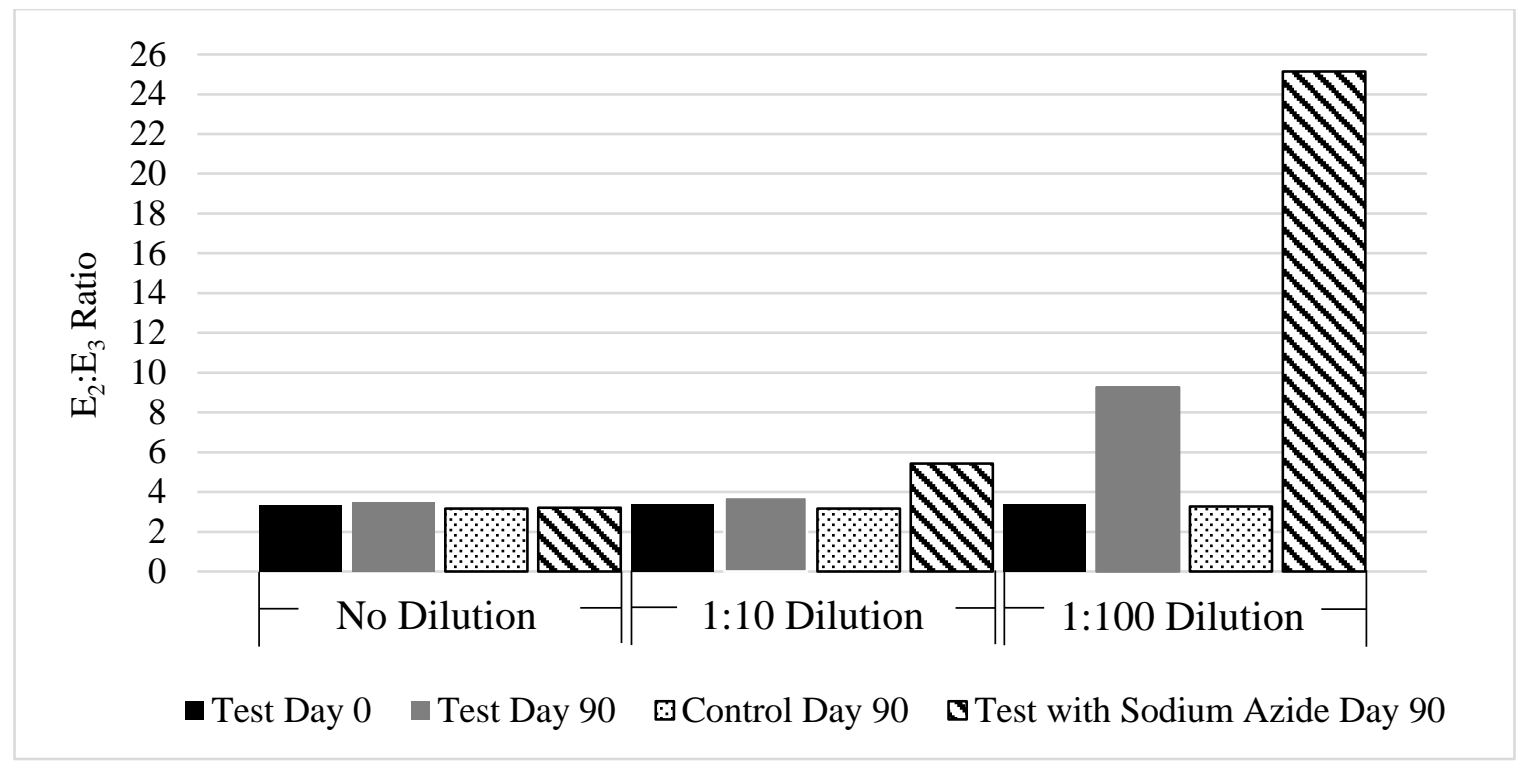

Figure 4-15: Leachate $\mathrm{H} \mathrm{E}_{2}: \mathrm{E}_{3}$ Ratios

The slope ratios for Leachate $\mathrm{H} \mathrm{1:10}$ and 1:50 dilutions, presented in Figure 4-16 and Figure 4-17, respectively, showed that treatment still occurred, as indicated by an increase in the spectral ratio. However, the increase was not as significant in the bags containing sodium azide as compared to those that didn't. This observation supports the hypothesis that biological degradation was impacting the overall treatment of LOM and treatment was not a result of photolytic reactions alone. The fact that treatment does not occur in black bags suggests that sunlight plays a role in both biological and photolytic reactions. 


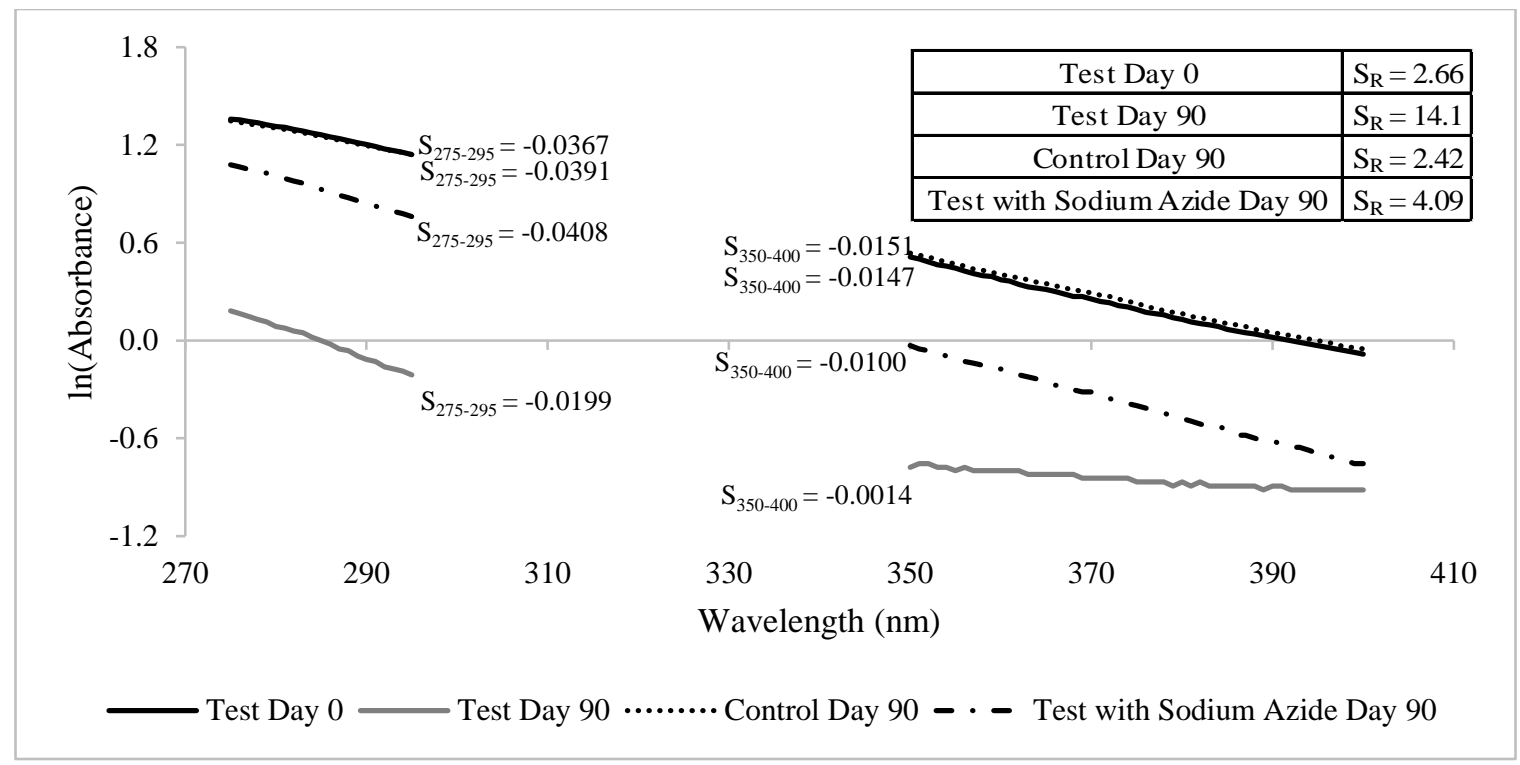

Figure 4-16: Leachate H 1:10 Dilution Day 0 and Day 90 Slope Ratios

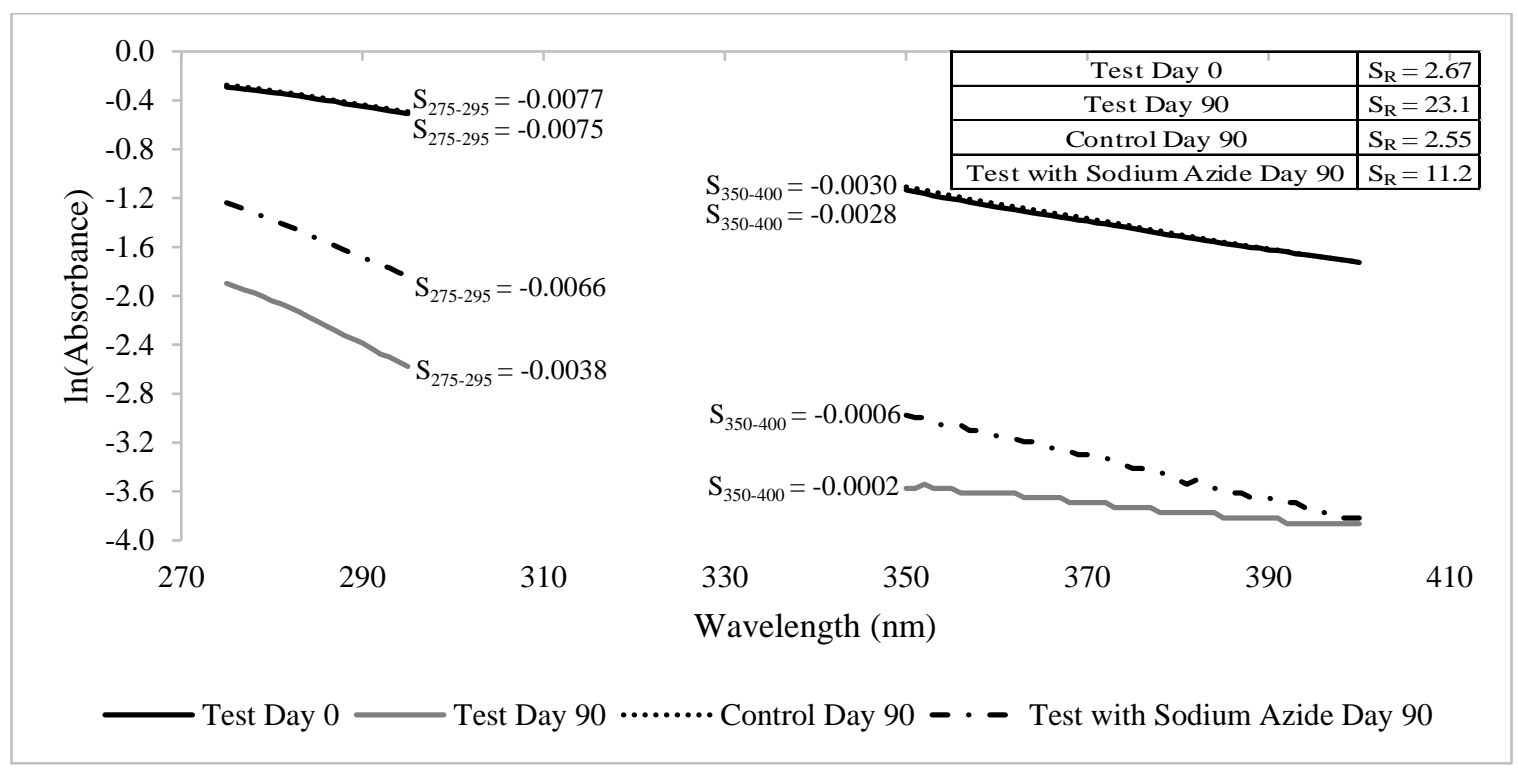

Figure 4-17: Leachate H 1:50 Dilution Day 0 and Day 90 Slope Ratios

The EEMs for Leachate $\mathrm{H}$ showed that the ratio of humic-like to fresh-like material (A:T and C:T ratios) in the bags with sodium azide were similar to those that did not have sodium azide, however, minor differences were observed. This is seen in Figure 4-18 and Figure 4-19 showing the A:T and C:T ratios, respectively. Studies by Fox et al. (2017) showed that bacterial organisms 
have the ability to produce fluorescent material as a metabolic byproduct, which was mainly protein-like in nature, characteristic of peak T. An increase in fluorescent protein-like material would result in lower A:T and C:T ratios. The results support this, particularly for the 1:50 dilutions, as the test sample without sodium azide resulted in lower ratios than the samples with sodium azide due to the probable presence of organisms. For the 1:10 dilution, the A:T ratio of the sample without sodium azide was lower than the sample with sodium azide and the C:T ratio of the sample without sodium azide was higher than the inhibited sample after 90 days. Transformations other than biological metabolic activity, such as photo degradation, are assumed to have occurred. A reduction in the A:T and C:T ratio for the 1:50 dilution control day 90 sample was observed, it is suspected that this resulted from error in the measurement, as the A:T and C:T ratios of other control day 90 samples did not decrease as significantly.

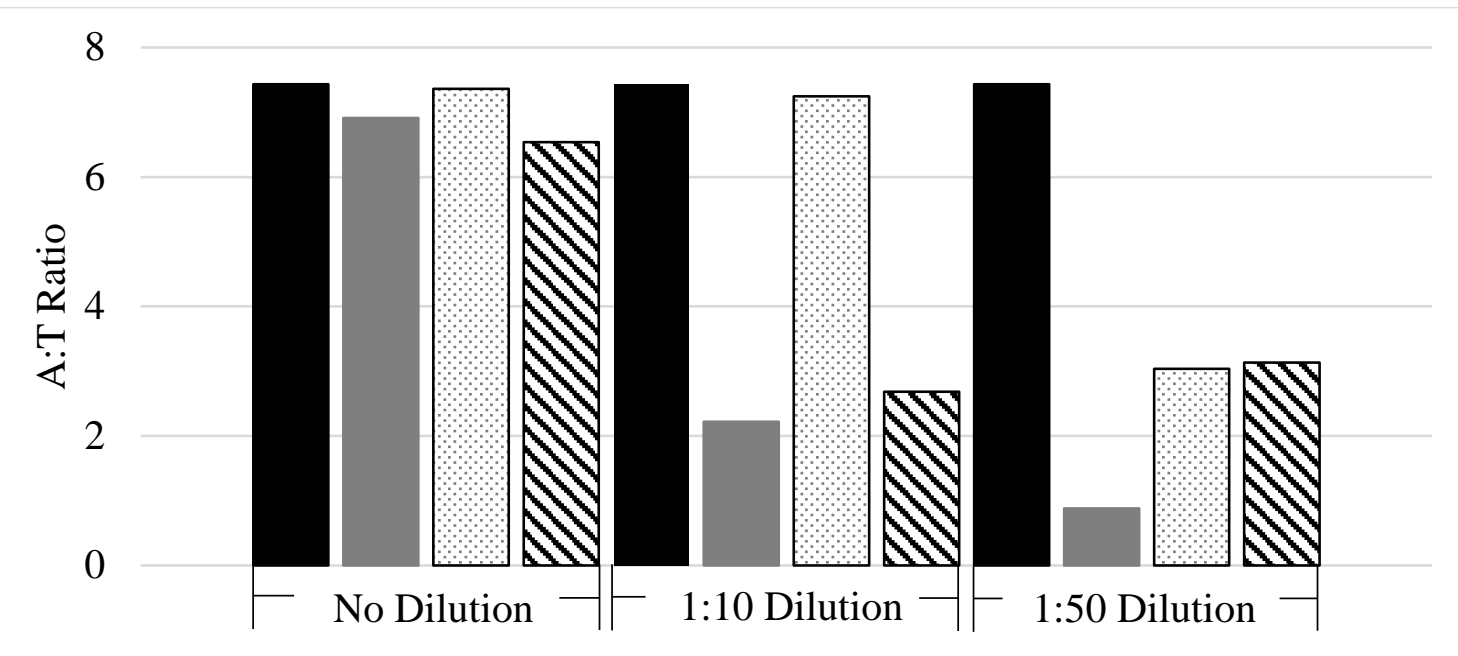

- Test Day 0 - Test Day 90 Control Day 90 వ Test with Sodium Azide Day 90

Figure 4-18: Leachate H EEMs A:T Ratio 


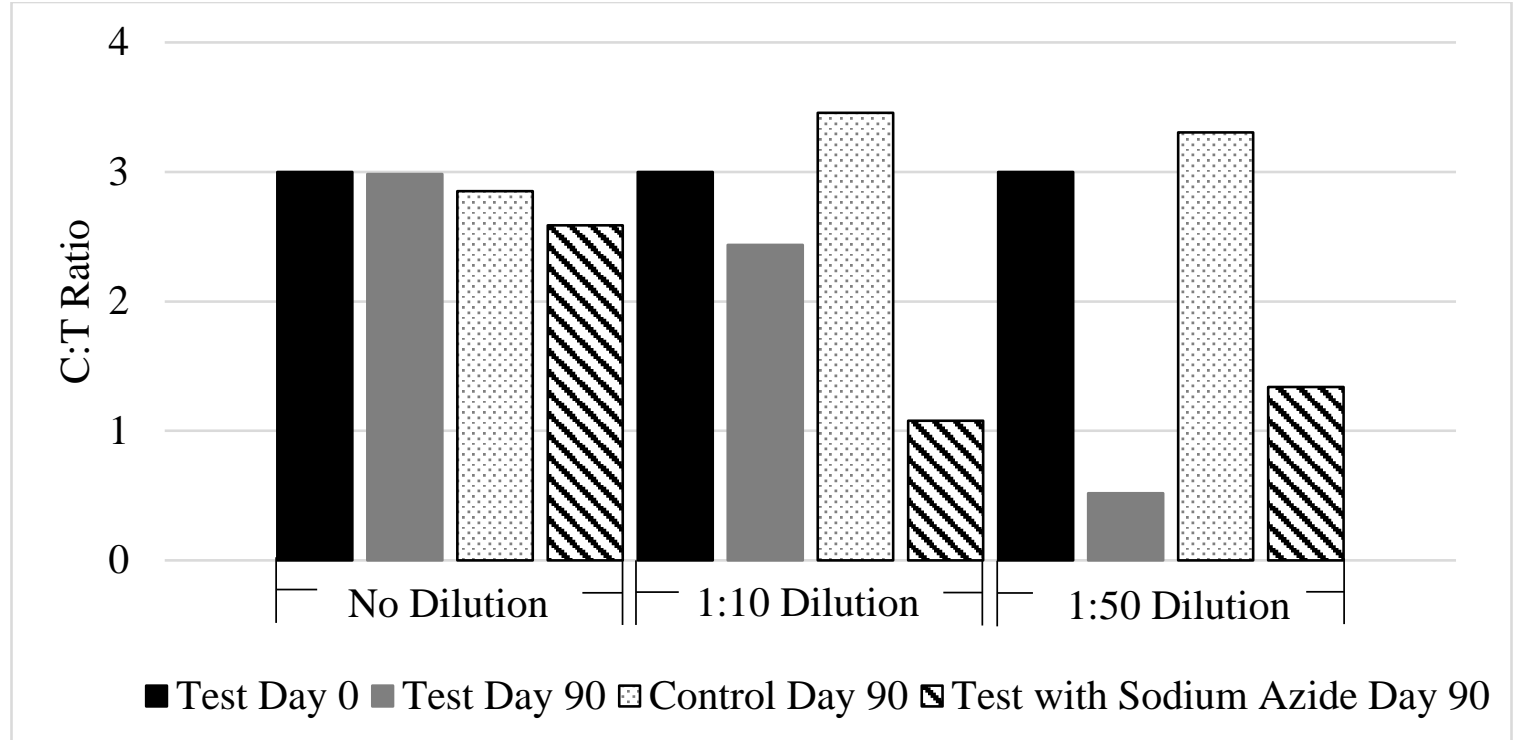

Figure 4-19: Leachate H EEMs C:T Ratio

\section{Bioavailability of Dissolved Organic Nitrogen}

Literature has shown that irradiation of humic substances can result in an increase in bDON (Karen et al., 1999) and irradiation of $\mathrm{NH}_{4}{ }^{+}$and DON results in either an increase or decrease in bDON depending on whether the system is nitrogen limited (Vähätalo et al., 2007). Studies by Kieber et al. (1997) on the incorporation of nitrogen into marine humic substances showed that samples with higher ammonia concentration increased in humic substance concentrations after photolysis.

The bioavailability of dissolved organic nitrogen was evaluated for the 1:10 dilutions of Leachates $\mathrm{E}$ and $\mathrm{F} . \mathrm{NH}_{3}-\mathrm{N}$ concentrations prior to batch testing for Leachates $\mathrm{E}$ and $\mathrm{F}$ were as follows: Leachate $\mathrm{E}, \mathrm{NH}_{3}-\mathrm{N}=679 \mathrm{mg} / \mathrm{L}$; Leachate $\mathrm{F}, \mathrm{NH}_{3}-\mathrm{N}=5 \mathrm{mg} / \mathrm{L}$. Figure 4-20 presents the results of DON fractionation using SPE. An increase in the percentage of rDON was observed for both samples after 90 days presumably driven by the high ammonia concentration of the leachate and incorporation into humic substances upon photoexposure. The percent recovery of DON 
during the solid-phase extraction of Leachate $\mathrm{E}$ and Leachate $\mathrm{F}$ at day 0 was $84 \%$ and $44 \%$, respectively. The percent recovery of DON of Leachate E and Leachate F 1:10 dilutions at day 90 was $89 \%$ and $98 \%$, respectively. Therefore, the reduction in DON for Leachate $\mathrm{F}$ may be overestimated. The overall reduction of DON over the test period was $24 \%$ for Leachate E and $70 \%$ for Leachate F indicating that while some of the DON was transformed to a recalcitrant form, there was still reduction in total DON.

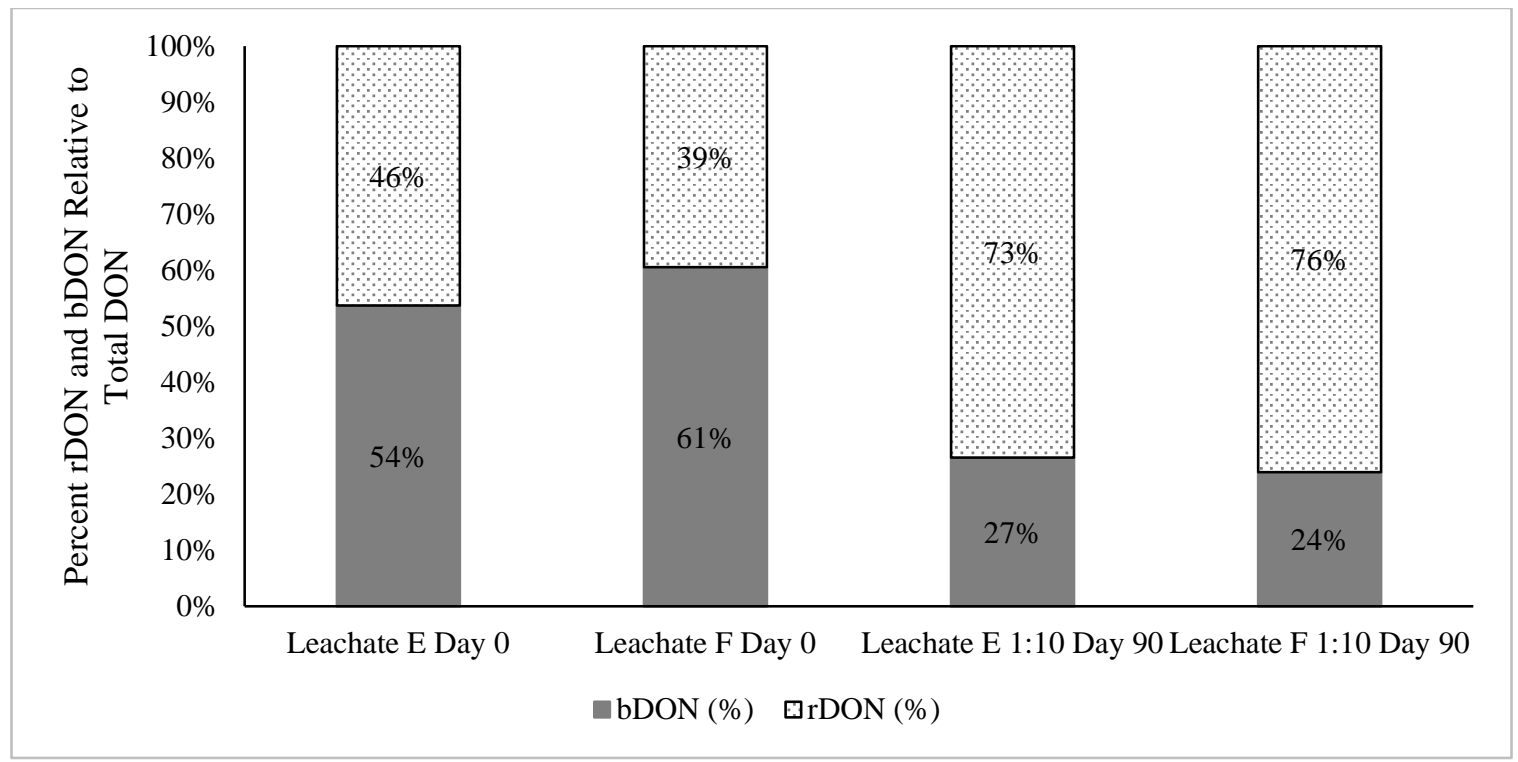

Figure 4-20: Leachates E and F Bioavailability of Dissolved Organic Nitrogen

\section{Wetland Feasibility}

To show the feasibility of wetlands treatment, the rate constants for the reduction of $\mathrm{UV}_{254}$ were applied to a first-order complete mix system to determine the volume required for treatment. This approach uses Equation 4.2, derived by Crittenden et al. (2012).

$$
V_{\text {wet }}=\frac{Q\left(\frac{A_{\text {inf }}}{A_{\text {eff }}}-1\right)}{k}
$$


Where, $V_{\text {wet }}$ is the volume of the wetland (liters)

$Q$ is the leachate flowrate (liters per day)

$A_{\text {inf }}$ is the $\mathrm{UV}_{254}$ absorbance of the influent

$A_{\text {eff }}$ is the $\mathrm{UV}_{254}$ absorbance of the effluent

$k$ is the rate constant $\left(\right.$ days $\left.^{-1}\right)$

Assuming that leachate generation is reduced by a factor of four, one year after closure for landfills having a final cover (Barlaz et al., 2002), the influent leachate flow rate was assumed to be 18,900 liters per day. This flow rate is based on the leachate generation of the landfill which generates Leachate $\mathrm{A}$ and $\mathrm{B}$. An influent absorbance of 50 abs was assumed, which was the average $\mathrm{UV}_{254}$ of Leachates A, C, D, E, F, G, and H. Leachate B was omitted from the average since its $\mathrm{UV}_{254}$ was determined to be an outlier using Grubb’s test with a 5\% significance level. An effluent absorbance of 0.5 abs was assumed, which would remove most of the high molecular weight LOM. To determine a range of wetland volume, a minimum and maximum rate constant of 1.0E-02 and 2.8E-02, respectively, which captures results of the batch tests, was assumed. The depth of the wetland was assumed to be 1 meter.

The resulting minimum pond area is 6.7 hectare (ha) and the maximum pond area is 19 ha. Completely mixed conditions would be required to dilute leachate entering the wetland and allow sunlight to penetrate the liquid. Complete mixing within the wetland can be accomplished using mixers or surface aerators. 


\section{$\underline{\text { Conclusions }}$}

The results suggest that treatment of LOM through sunlight driven processes is possible. UV-Vis, EEMs, and SEC show that high molecular weight recalcitrant material is undergoing transformation into lower molecular weight material because of reactions driven by sunlight. The results show that reduction in color through photobleaching is possible and tends to increase with dilution. To explore the role of biological activity, sodium azide was added to samples run in parallel with untreated leachate. Although treatment efficiency was reduced in samples with sodium azide compared to untreated bags, the results provided evidence that photolytic reactions were responsible for some of the treatment of LOM. Because untreated bags achieved greater changes in absorbance and black control bags were unchanged in treated and untreated tests, it was concluded that biological activity was also stimulated by sunlight. The relative amount of recalcitrant nitrogen species increased after undergoing photoexposure, perhaps driven by the high concentration of ammonia in leachate samples which is supported by the studies from Kieber et al. (1997) and Vähätalo et al. (2007) on recalcitrant nitrogen formation in samples with high concentrations of ammonia.

The above results were dependent upon dilution of leachate, which must ensure that UV absorption is sufficiently reduced to allow sunlight to penetrate the depth of the liquid. Such dilution will occur in aquatic systems receiving leachate or in wastewater effluent where leachate is co-treated with domestic wastewater, and ultimately discharged to natural waters. Photolysis of LOM in aquatic systems could result in the release of biodegradable low molecular weight organic matter and nitrogen species. 
Alternatively, this research explored use of constructed completely mixed wetlands, which could directly receive leachate on landfill sites. The wetland feasibility calculation shows that treatment is possible, however, would require areas of 6.7 to 19 ha, assuming irradiation similar to those of the photolysis tests. The use of wetland treatment could eliminate large capital costs associated with advanced treatment technologies and operational cost would potentially be low with only the operation of mixers and surface aerators to achieve complete mixing. Before applying at field scale, pilot scale testing is recommended to determine optimal flow rates of leachate into the wetland to achieve treatment. Pilot testing would more closely simulate field conditions by eliminating increased temperature that was observed in the Tedlar bags and provide better understanding of the sunlight driven processes occurring, both photolytic and biological. 


\section{CHAPTER 5: CONCLUSIONS}

The ability to manage leachate during post-closure care of a landfill becomes increasingly difficult as leachate organic matter becomes more recalcitrant as a landfill ages, requiring advanced and costly treatment technologies. This thesis provided evidence of the treatment of leachate organic matter through sunlight driven processes. The fate of LOM in aquatic systems and reactions driven by sunlight was studied in detail using eight batch tests where leachate was exposed to natural sunlight in central Florida for a period of 90 days. Transformation processes were measured to indicate the ability for LOM treatment in manmade wetlands systems and receiving waters where sunlight would be the main driver of treatment.

The results suggest that treatment of LOM through sunlight driven processes is possible. UV-Vis, EEMs, and SEC show that high molecular weight recalcitrant material is undergoing transformation into lower molecular weight material because of reactions driven by sunlight. The results show that reduction in color through photobleaching is possible and tends to increase with dilution. To explore the role of biological activity, sodium azide was added to samples run in parallel with untreated leachate. Although treatment efficiency was reduced in samples with sodium azide compared to untreated bags, the results provided evidence that photolytic reactions were responsible for some of the treatment of LOM. Because untreated bags achieved greater changes in absorbance and black control bags were unchanged in treated and untreated tests, it was concluded that biological activity was also stimulated by sunlight. The relative amount of recalcitrant nitrogen species increased after undergoing photoexposure, perhaps driven by the high concentration of ammonia in leachate samples which is supported by the studies from Kieber et 
al. (1997) and Vähätalo et al. (2007) on recalcitrant nitrogen formation in samples with high concentrations of ammonia.

The above results were dependent upon dilution of leachate, which must ensure that UV absorption is sufficiently reduced to allow sunlight to penetrate the depth of the liquid. Such dilution will occur in aquatic systems receiving leachate or in wastewater effluent where leachate is co-treated with domestic wastewater, and ultimately discharged to natural waters. Photolysis of LOM in aquatic systems could result in the release of biodegradable low molecular weight organic matter and nitrogen species.

Alternatively, this research explored use of constructed mixed wetlands, which could directly receive leachate on landfill sites. The wetland feasibility calculation shows that treatment is possible, however, would require areas of 6.7 to 19 ha, assuming irradiation similar to those of the photolysis tests. The use of wetland treatment could eliminate large capital costs associated with advanced treatment technologies and operational cost would potentially be low with only the operation of mixers and surface aerators to achieve complete mixing. Before applying at field scale, pilot scale testing is recommended to determine optimal flow rates of leachate into the wetland to achieve treatment. Pilot testing would more closely simulate field conditions by eliminating increased temperature that was observed in the Tedlar bags and provide better understanding of the sunlight driven processes occurring, both photolytic and biological. 


\section{CHAPTER 6: RECOMMENDATIONS}

This research addresses the fate of leachate organic matter (LOM) in aquatic systems, photolytic reactions with LOM, and the applicability of treatment in a manmade wetland system. In this study, it appears photolysis was the major mechanism of treatment, but this study was a first look at the potential for sunlight driven treatment and factors such as temperature and bacterial/algal growth need to be better defined to support the feasibility of full scale wetland treatment. The following recommendations have been developed which would further quantify the level of treatment in future batch testing and possible application at full scale.

- Temperature control using a water bath, where Tedlar bags can be suspended near the water surface, will promote more regulated temperature of the bags. It is not suspected that temperature played a significant role, but to eliminate the possibility of treatment capability through increased temperatures, the water bath methodology is recommended for future batch tests.

- Implementation of LOM treatment using a wetland at full scale will require pilot scale testing to determine the feasibility. In a full scale system, treatment through photolytic reactions and natural treatment through biology are likely to occur. A pilot scale complete mix reactor will show the feasibility of treatment at a scale that is more representative of field-scale. It is recommended that an algaecide be used in the reactor to prevent algal growth. This would allow the study to show results from photolytic reactions alone. With an exposed system, evaporation becomes an issue. The complete mix reactor would have to be designed large enough, such that evaporation can be 
negated and volume remains relatively constant. In addition, microbial testing to identify organisms present is recommended.

- This study shows that treatment efficiency is increased with dilution of leachate, allowing sunlight to penetrate the liquid. Dilution resulting in an initial $\mathrm{UV}_{254}$ of 10 or less provides optimum conditions. However, this is leachate specific and all leachates have different characteristics. At field scale, dilution would occur through complete mixing in the wetland using surface aerators. 
APPENDIX A: RAW LEACHATE SAMPLE CHARACTERISTICS 
Table A-1: Raw Leachate Sample Characteristics

\begin{tabular}{|c|c|c|c|c|c|c|c|c|}
\hline Parameter & Leachate A & Leachate B & Leachate C & Leachate D & Leachate E & Leachate F & Leachate G & Leachate $\mathbf{H}$ \\
\hline $\begin{array}{c}\text { Total BOD } 5 \\
(\mathrm{mg} / \mathrm{L})\end{array}$ & 121 & 3730 & N/A & N/A & N/A & N/A & 188 & 60 \\
\hline $\begin{array}{c}\text { Total COD } \\
(\mathrm{mg} / \mathrm{L})\end{array}$ & 5050 & 12300 & 3850 & 1800 & 3600 & 2250 & 7300 & 3050 \\
\hline pH (S.U.) & 8.5 & 7.6 & N/A & N/A & 7.9 & 7.6 & 7.9 & 7.9 \\
\hline $\begin{array}{c}\text { Total } \mathrm{NH}_{3}-\mathrm{N} \\
(\mathrm{mg} / \mathrm{L})\end{array}$ & 1710 & 2300 & 545 & 12 & 679 & 5 & 1010 & 83 \\
\hline $\begin{array}{c}\text { Total } \mathrm{NO}_{\mathrm{x}} \\
(\mathrm{mg} / \mathrm{L})\end{array}$ & 60 & 61 & 31 & 113 & 42 & 110 & 80 & 45 \\
\hline $\begin{array}{c}\text { Total TKN } \\
(\mathrm{mg} / \mathrm{L})\end{array}$ & 1790 & 2360 & 610 & 78 & 793 & 255 & 1150 & 162 \\
\hline $\begin{array}{l}\text { Total } \\
\text { Nitrogen } \\
(\mathrm{mg} / \mathrm{L})\end{array}$ & 1850 & 2440 & 641 & 191 & 835 & 364 & 1230 & 207 \\
\hline $\begin{array}{c}\mathrm{DON} \\
(\mathrm{mg} / \mathrm{L})\end{array}$ & 97 & 60 & 56 & 55 & 104 & 236 & 108 & 73 \\
\hline $\begin{array}{l}\text { Apparent } \\
\text { Color } \\
\text { (pt-Co) }\end{array}$ & 28800 & 17400 & 3520 & 3100 & 14600 & 13700 & 39900 & 21100 \\
\hline $\begin{array}{l}\text { Total UV } 254 \\
\text { (abs) }\end{array}$ & 70 & 191 & 45 & 23 & 42 & 31 & 96 & 46 \\
\hline $\begin{array}{l}\text { Sample } \\
\text { Source }\end{array}$ & $\begin{array}{c}\text { Aeration } \\
\text { Tank }\end{array}$ & $\begin{array}{l}\text { Leachate } \\
\text { Collection } \\
\text { System }\end{array}$ & $\begin{array}{l}\text { Leachate } \\
\text { Collection } \\
\text { System }\end{array}$ & $\begin{array}{c}\text { Post-onsite } \\
\text { Biological } \\
\text { Treatment }\end{array}$ & $\begin{array}{l}\text { Leachate } \\
\text { Collection } \\
\text { System }\end{array}$ & $\begin{array}{c}\text { Post-onsite } \\
\text { Biological } \\
\text { Treatment }\end{array}$ & $\begin{array}{l}\text { Leachate } \\
\text { Collection } \\
\text { System }\end{array}$ & $\begin{array}{c}\text { Post-onsite } \\
\text { Biological } \\
\text { Treatment }\end{array}$ \\
\hline
\end{tabular}


APPENDIX B: UV 25490 DAY TREND DATA 


\section{Leachate A}

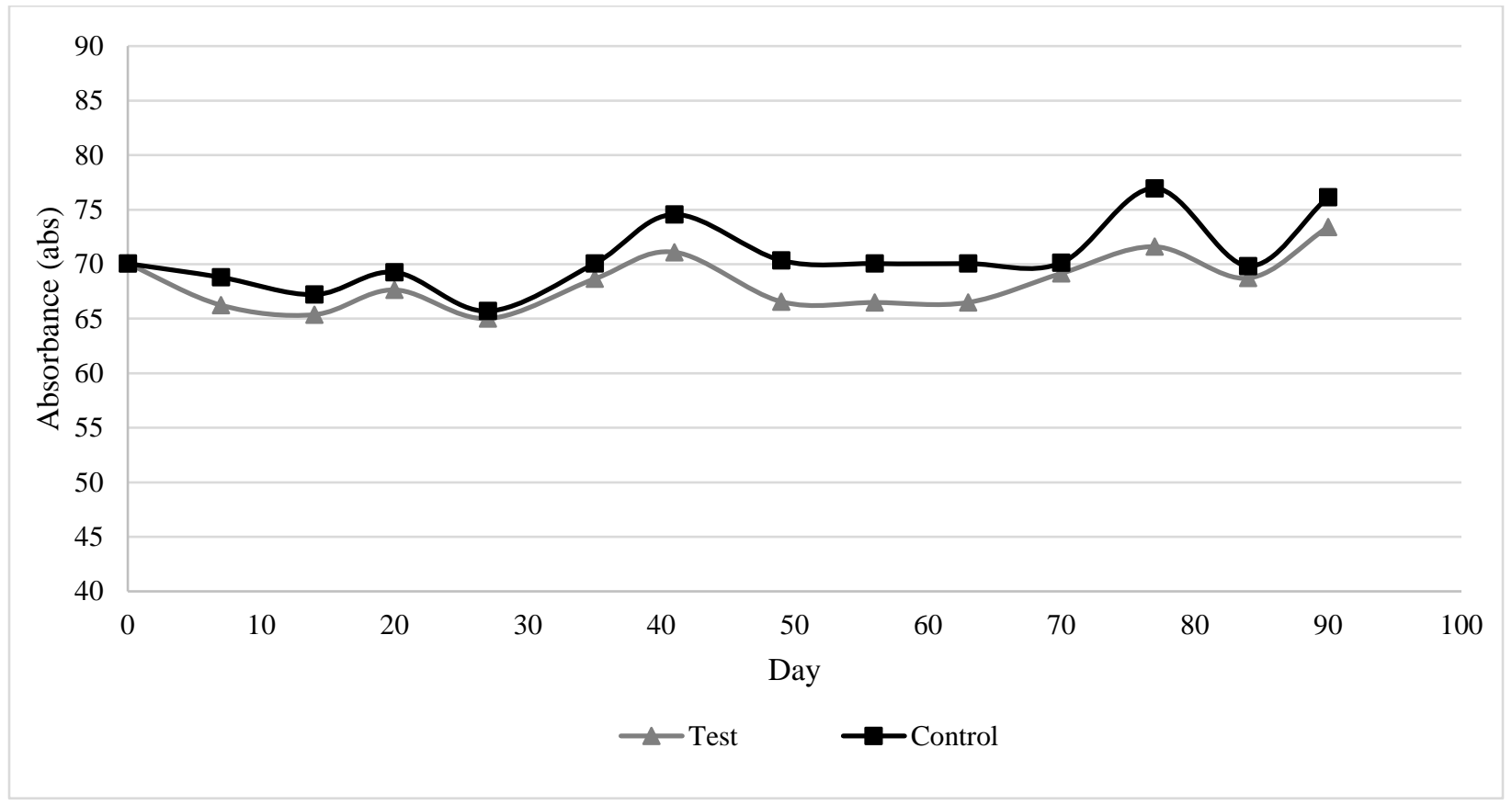

Figure B-1: Leachate A No Dilution UV254 Trend Over 90 Days

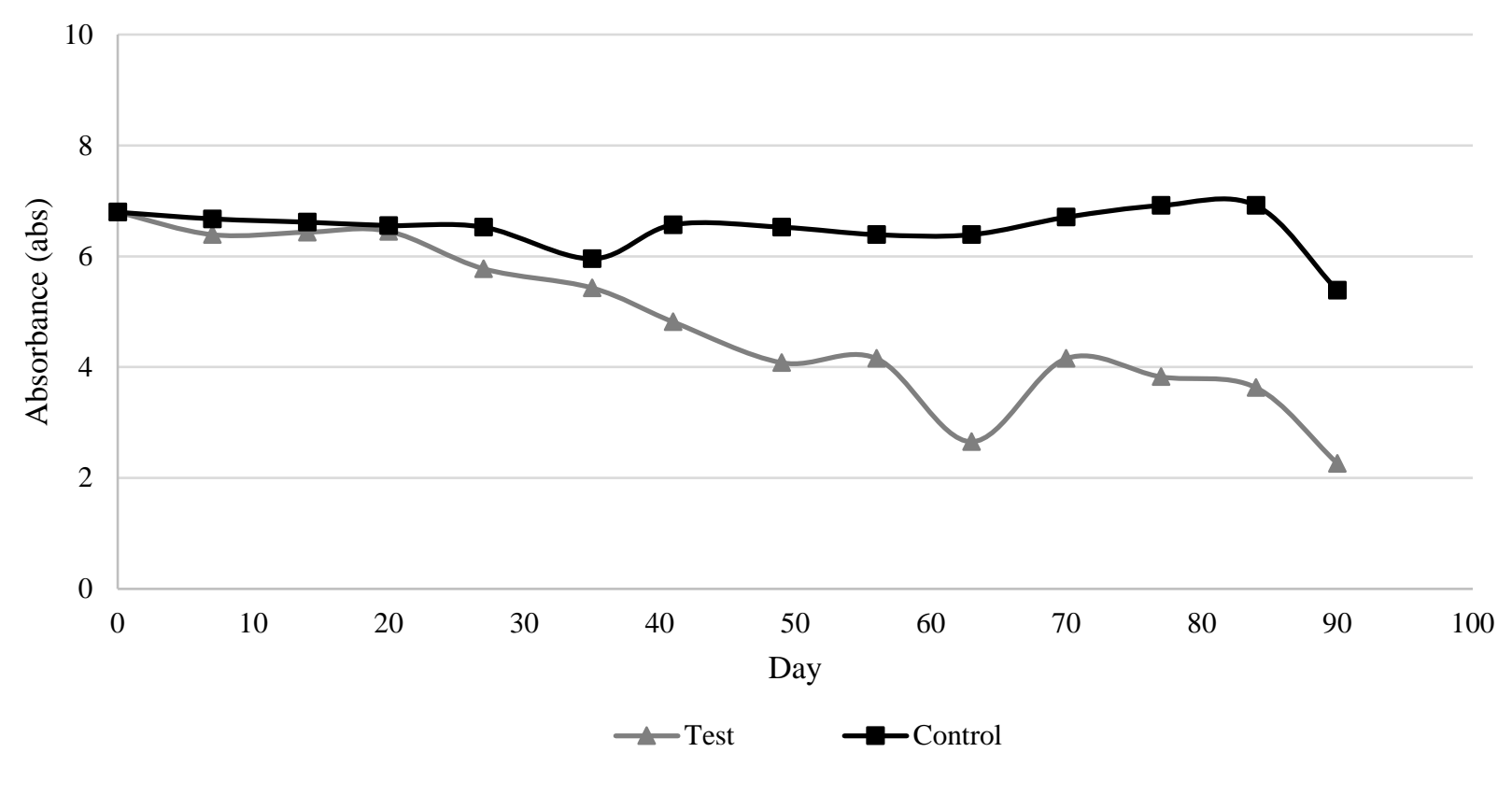

Figure B-2: Leachate A 1:10 Dilution UV254 Trend Over 90 Days 


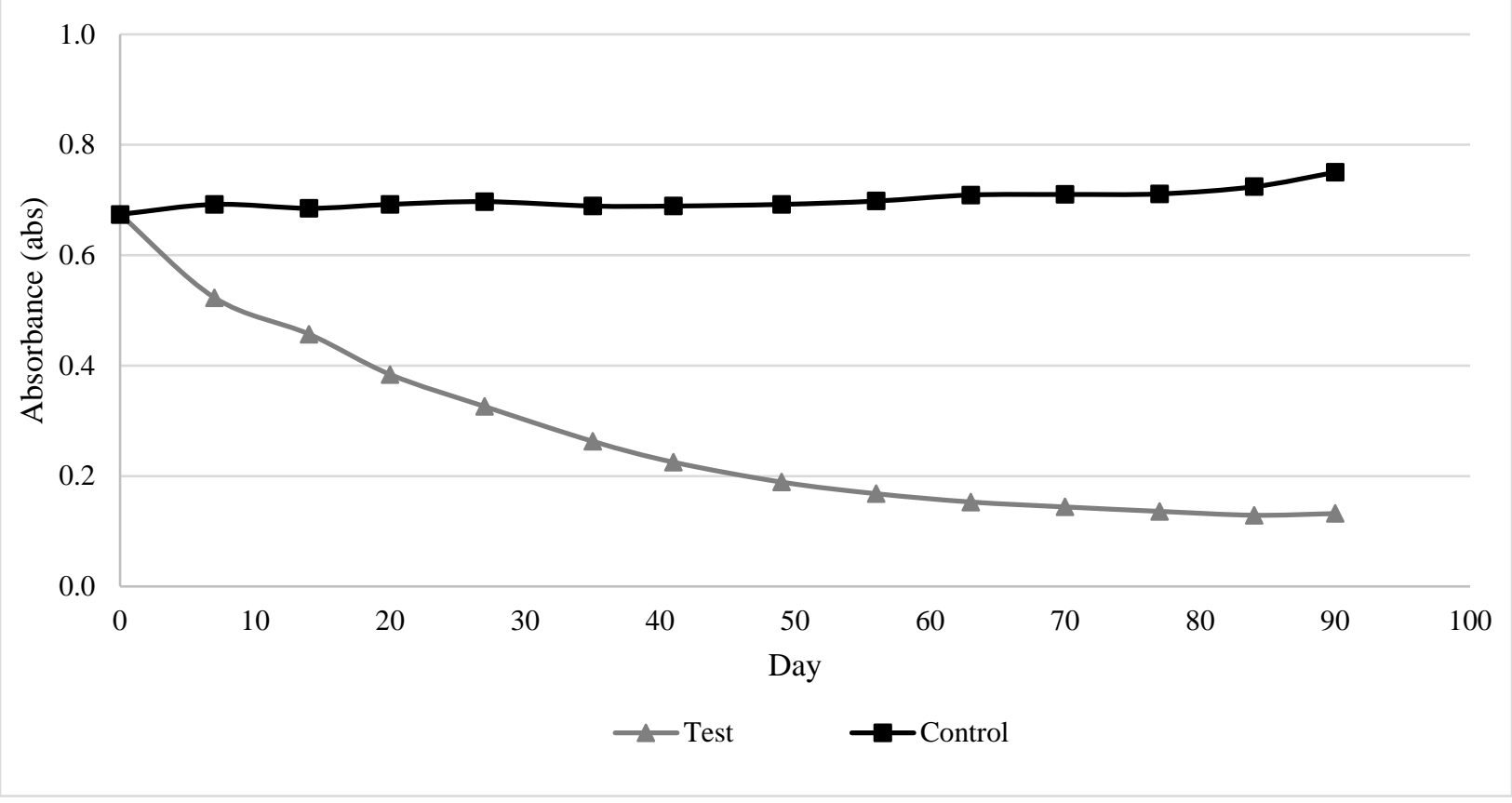

Figure B-3: Leachate A 1:100 Dilution UV254 Trend Over 90 Days

Leachate B

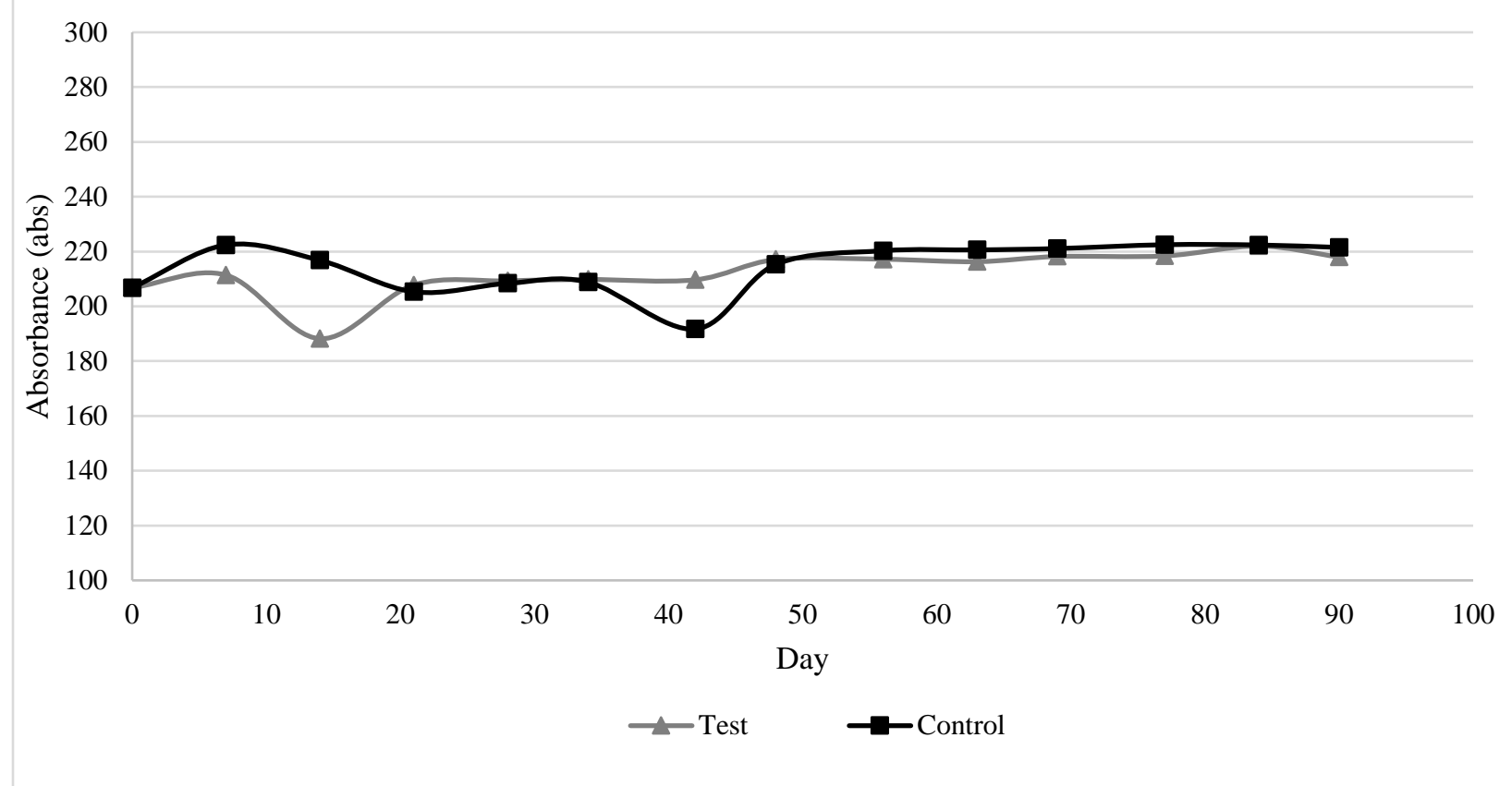

Figure B-4: Leachate B No Dilution UV 254 Trend Over 90 Days 


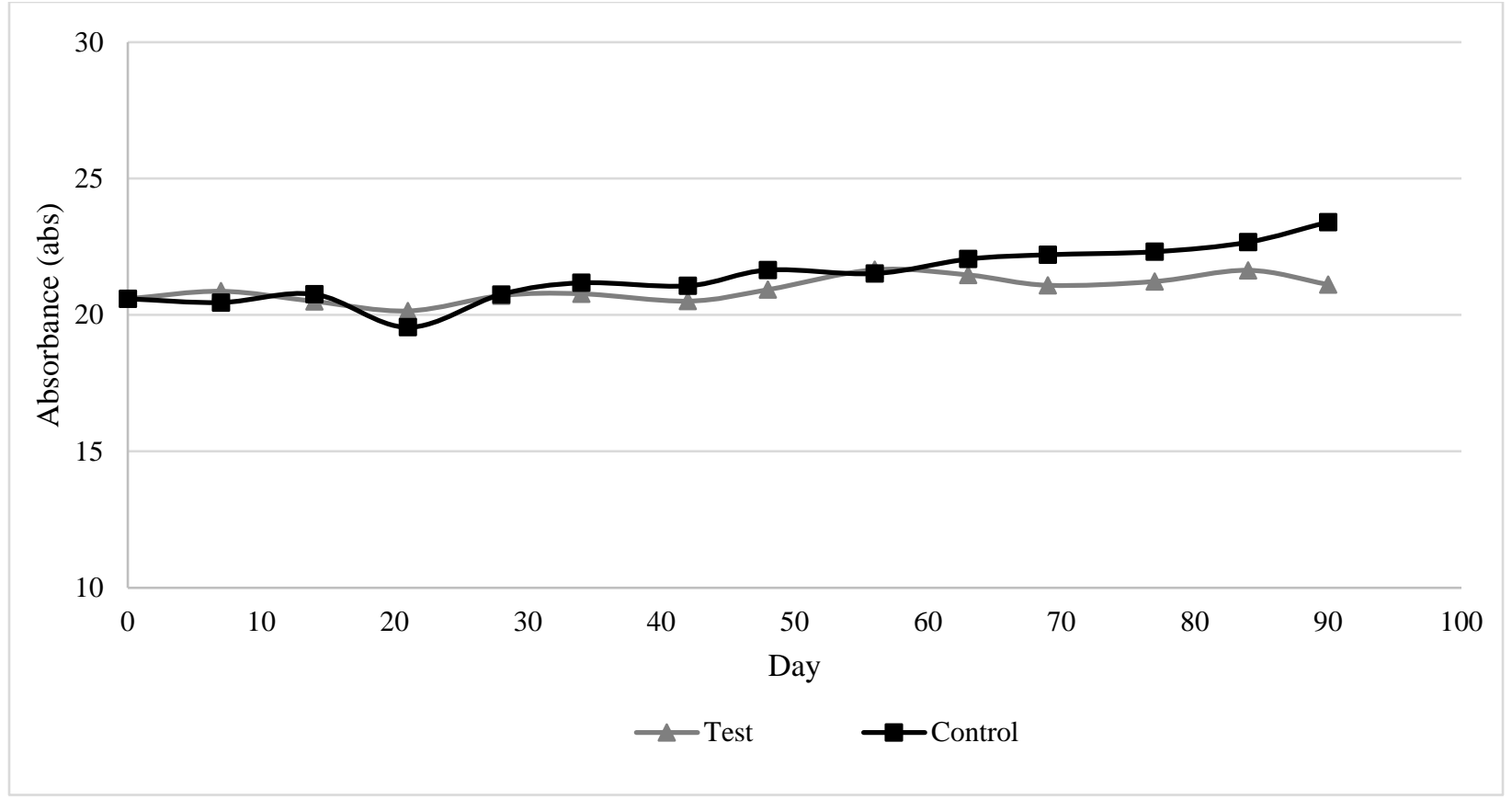

Figure B-5: Leachate B 1:10 Dilution UV254 Trend Over 90 Days

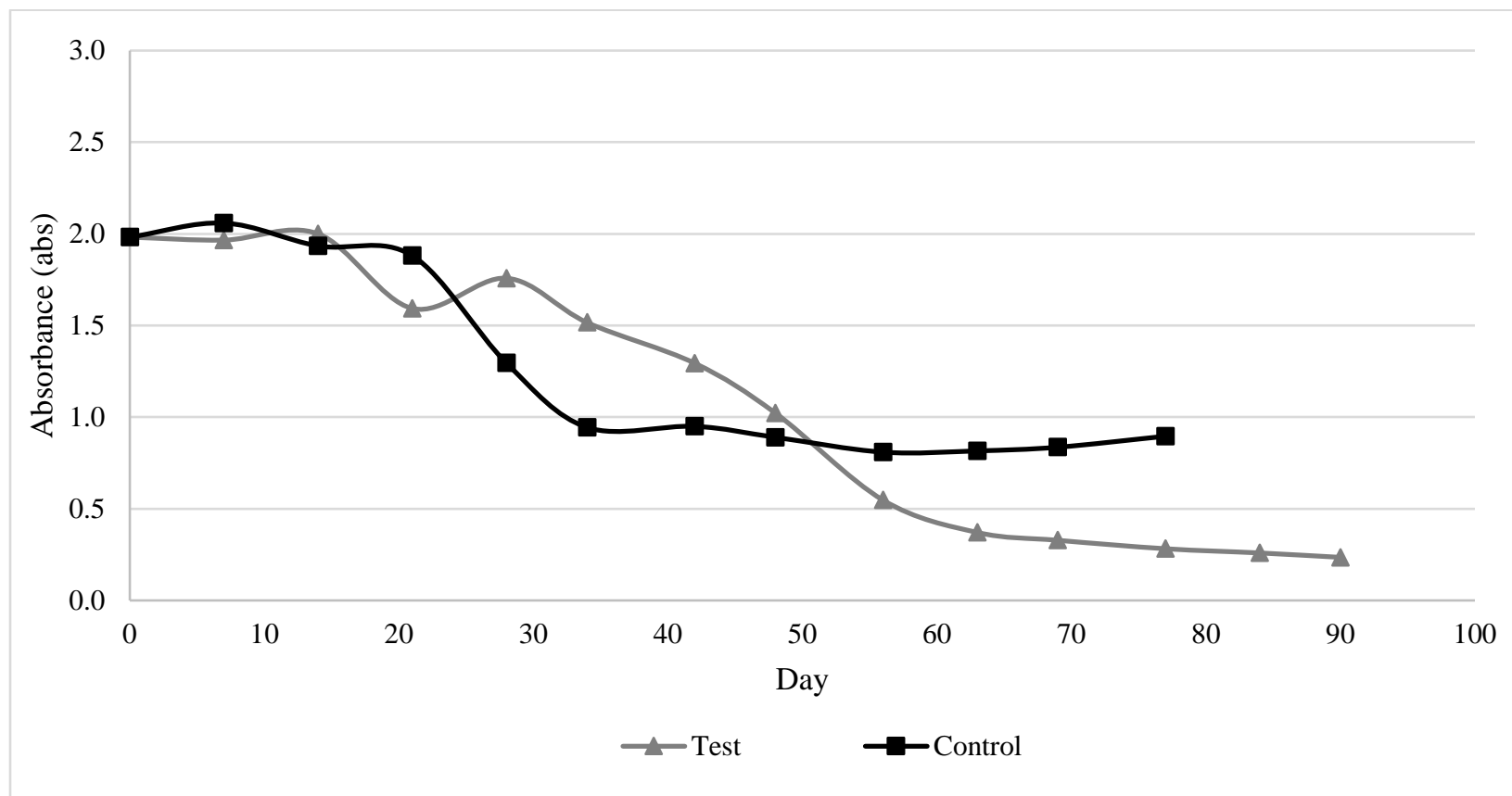

Figure B-6: Leachate B 1:100 Dilution UV254 Trend Over 90 Days

( ${ }^{*} 1: 100$ dilution control bag broke on day 77 of experimental test) 
$\underline{\text { Leachate C }}$

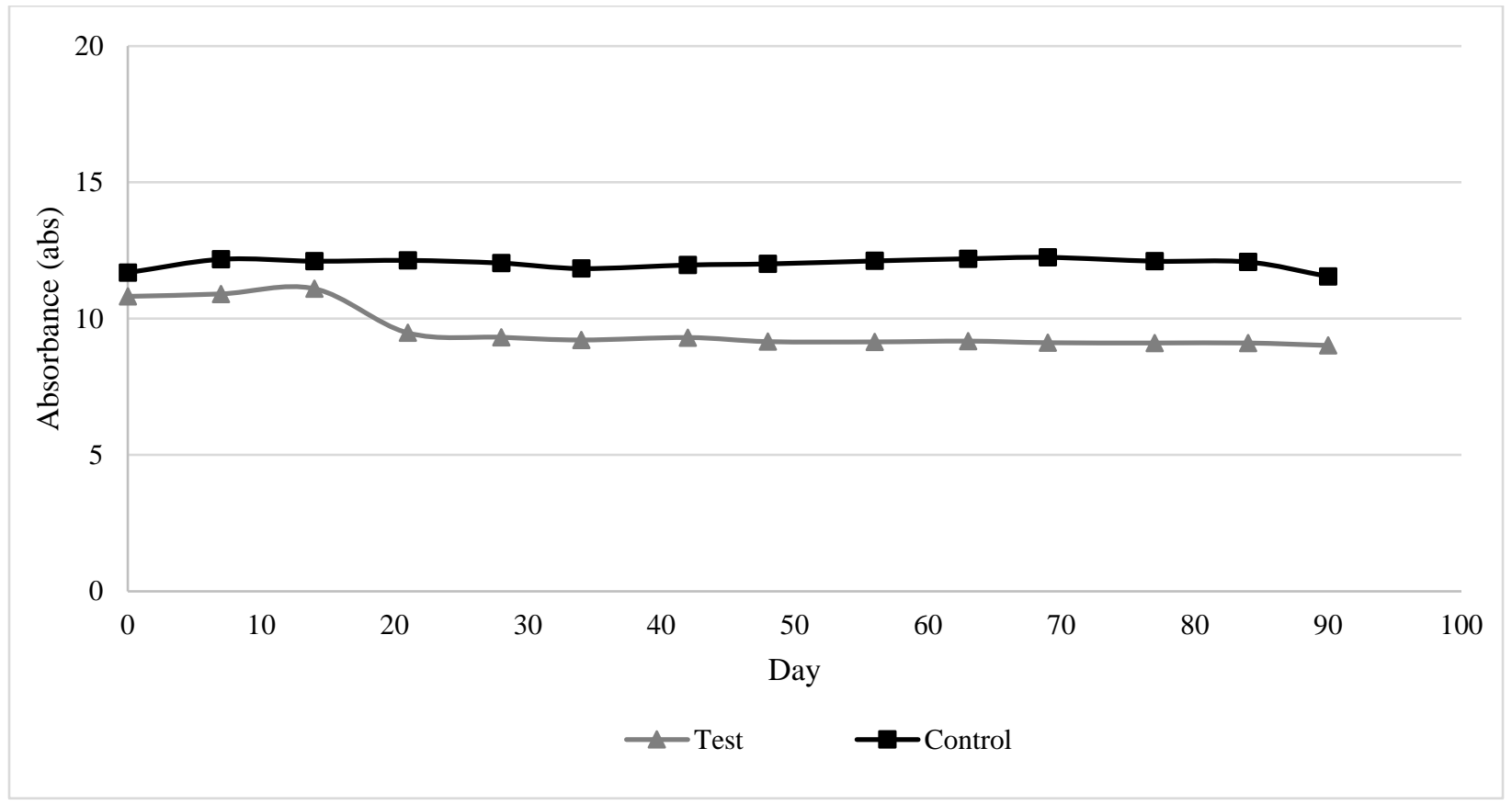

Figure B-7: Leachate C 1:4.1 Dilution UV254 Trend Over 90 Days

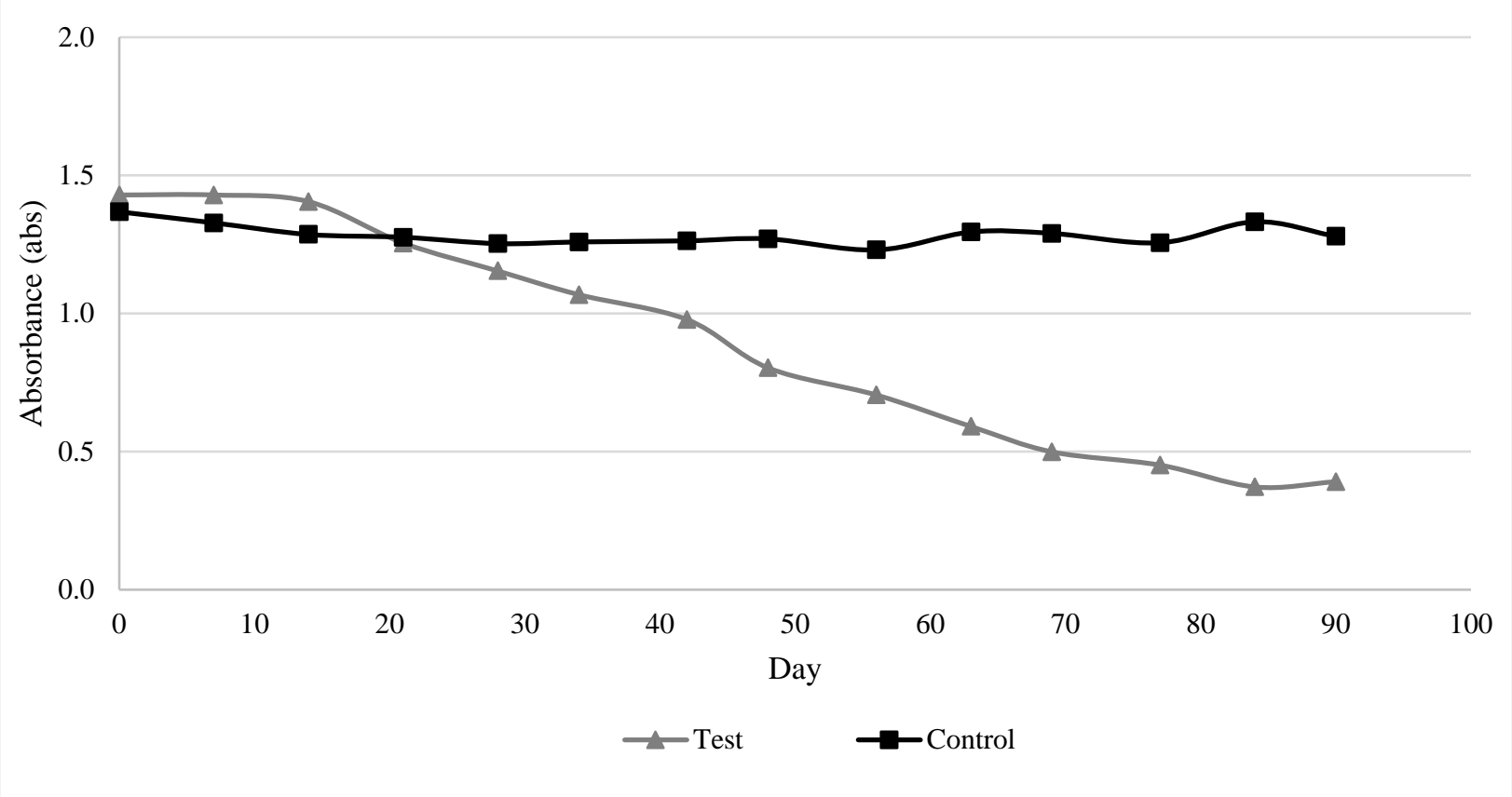

Figure B-8: Leachate C 1:31 Dilution UV254 Trend Over 90 Days 
$\underline{\text { Leachate D }}$

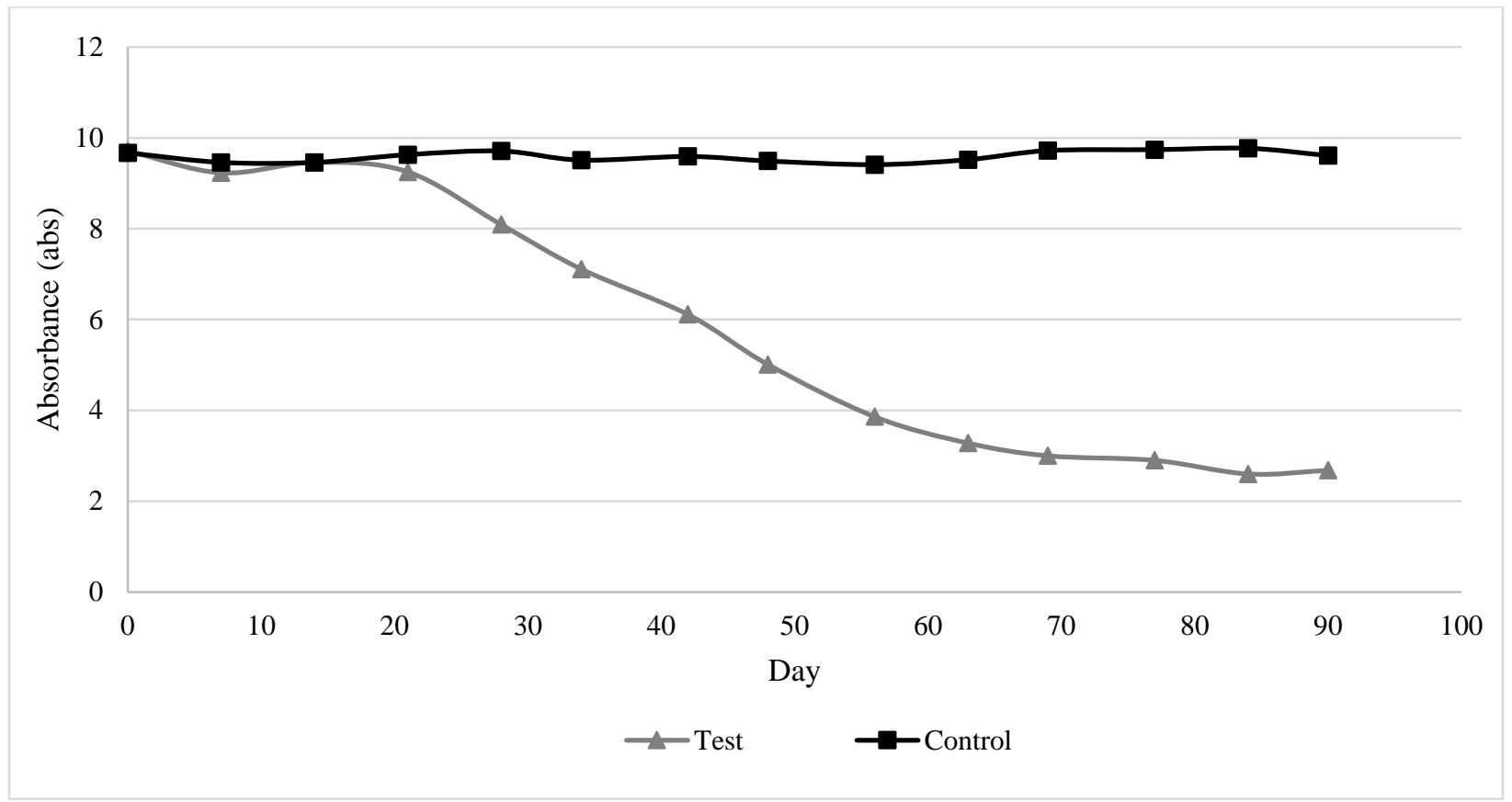

Figure B-9: Leachate D 1:2.4 Dilution UV254 Trend Over 90 Days

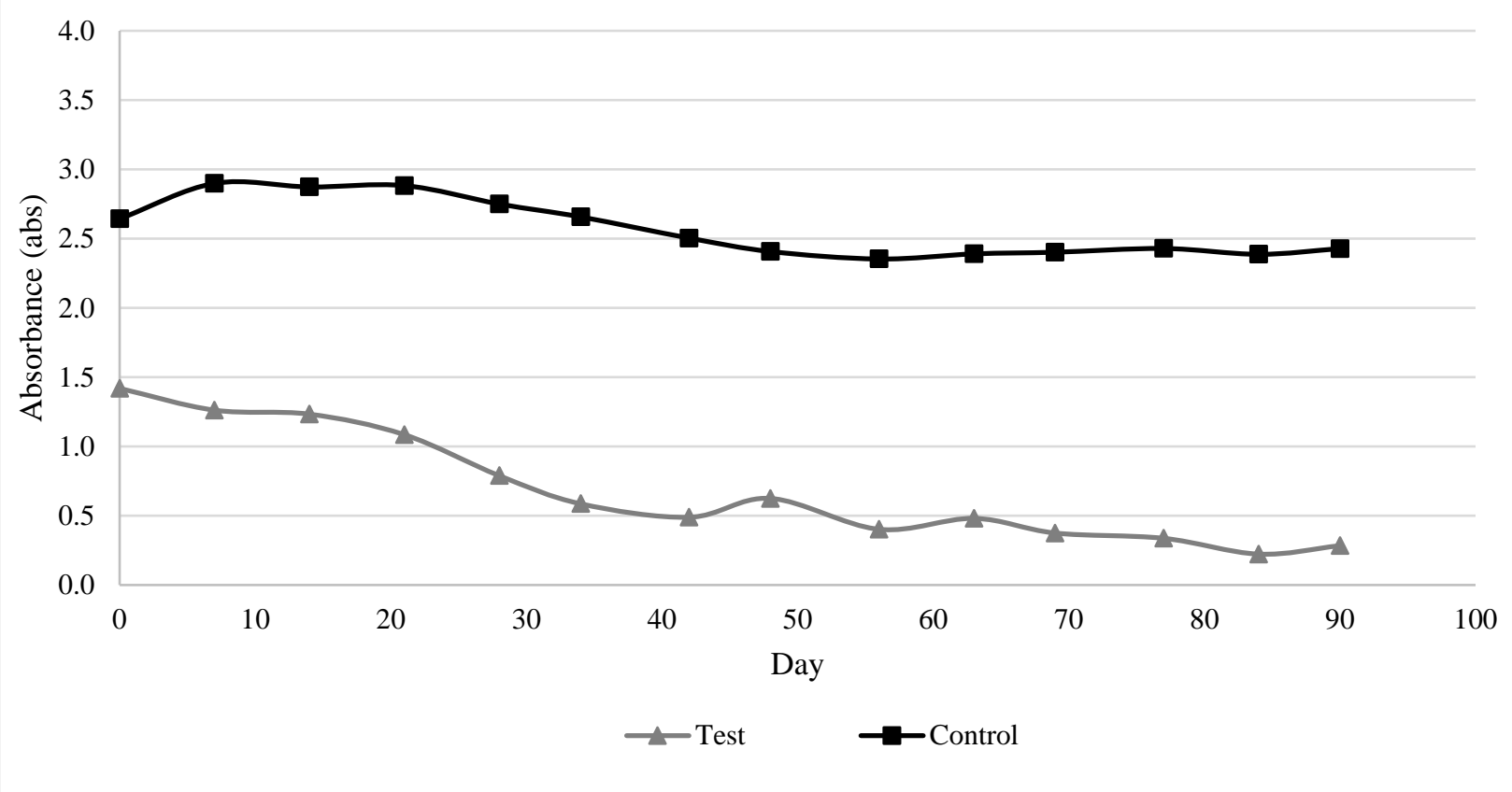

Figure B-10: Leachate D 1:16 Dilution UV254 Trend Over 90 Days 


\section{Leachate E}

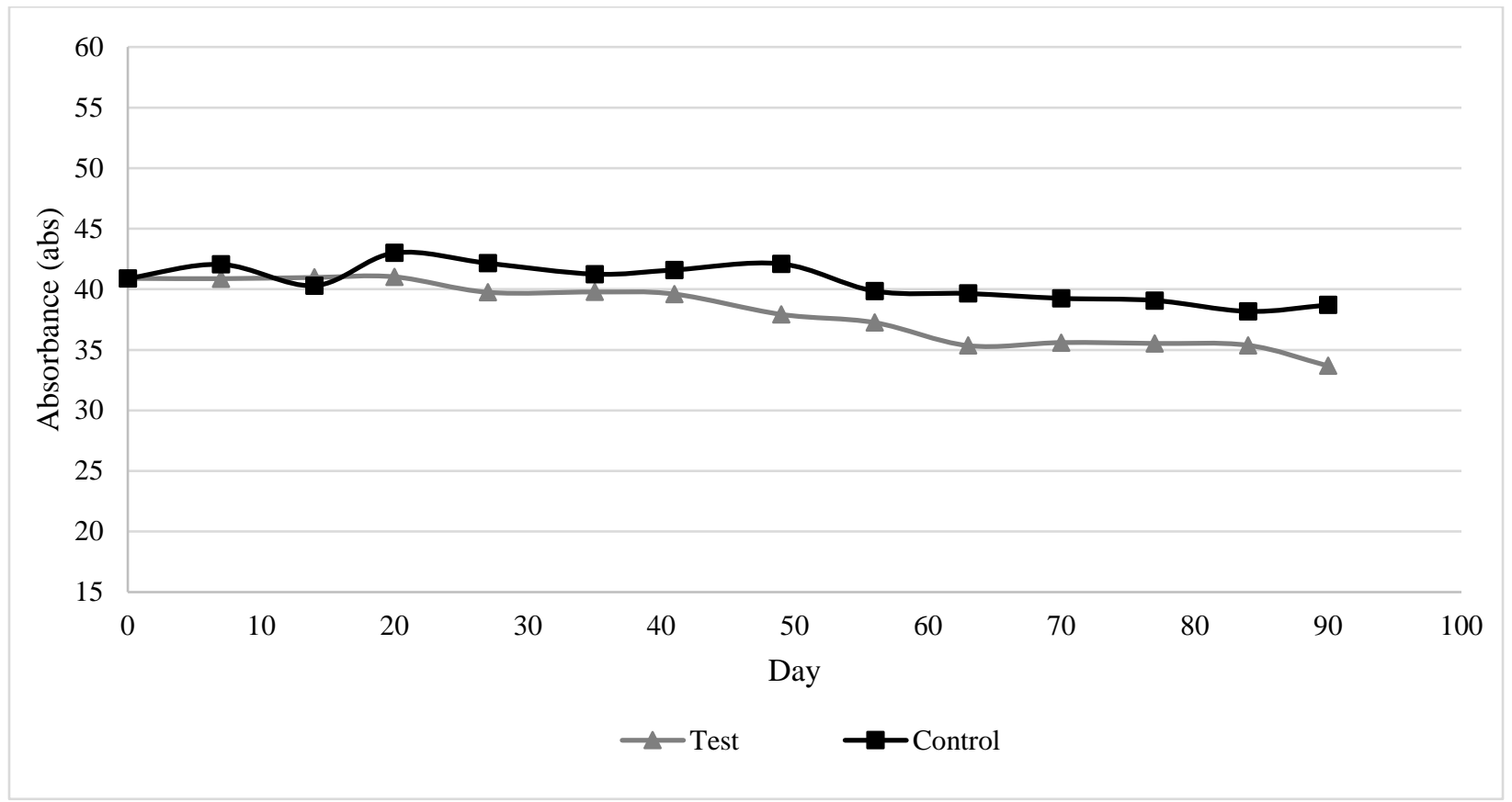

Figure B-11: Leachate E No Dilution UV254 Trend Over 90 Days

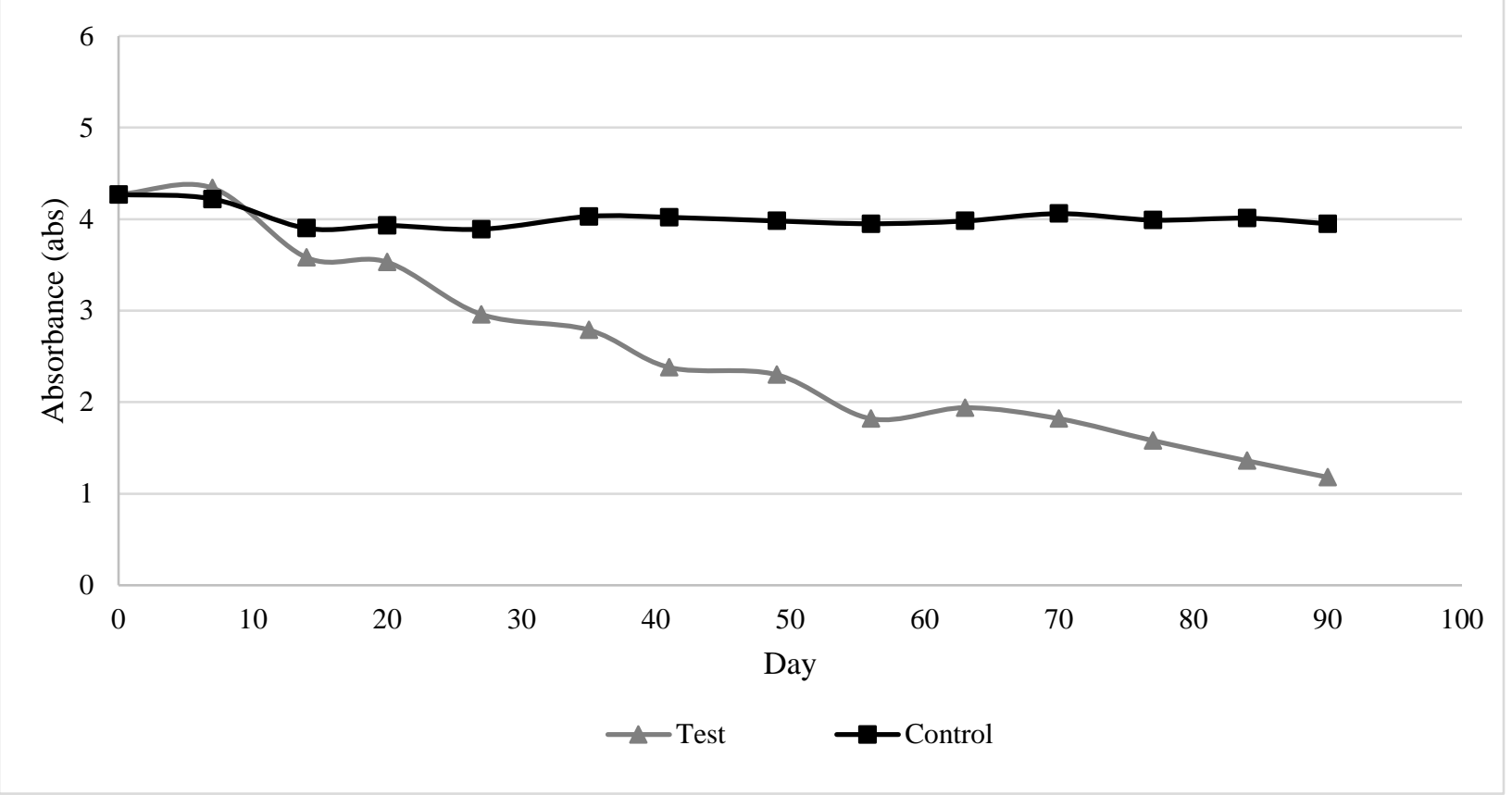

Figure B-12: Leachate E 1:10 Dilution UV254 Trend Over 90 Days 


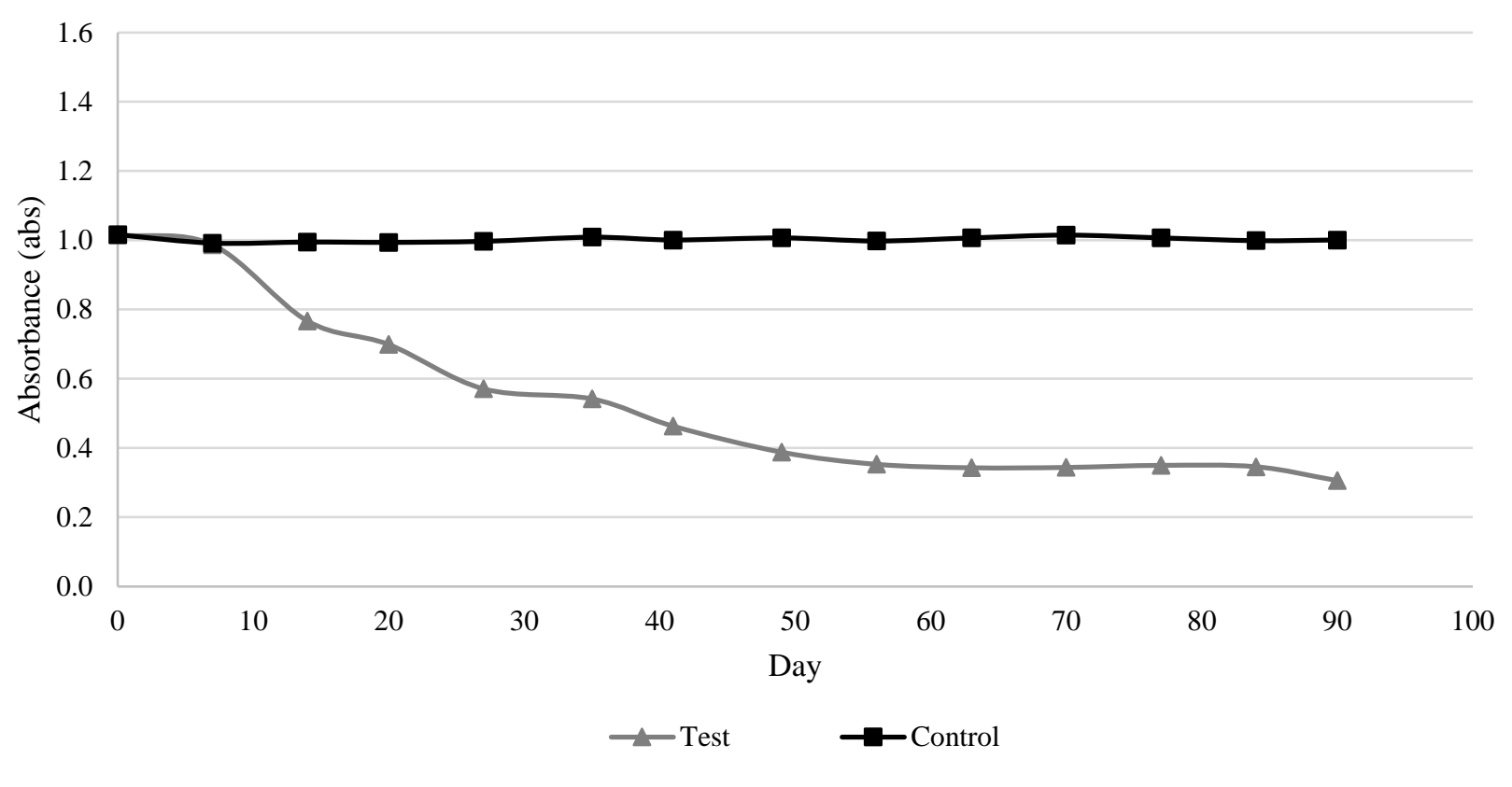

Figure B-13: Leachate E 1:50 Dilution UV254 Trend Over 90 Days

$\underline{\text { Leachate F }}$

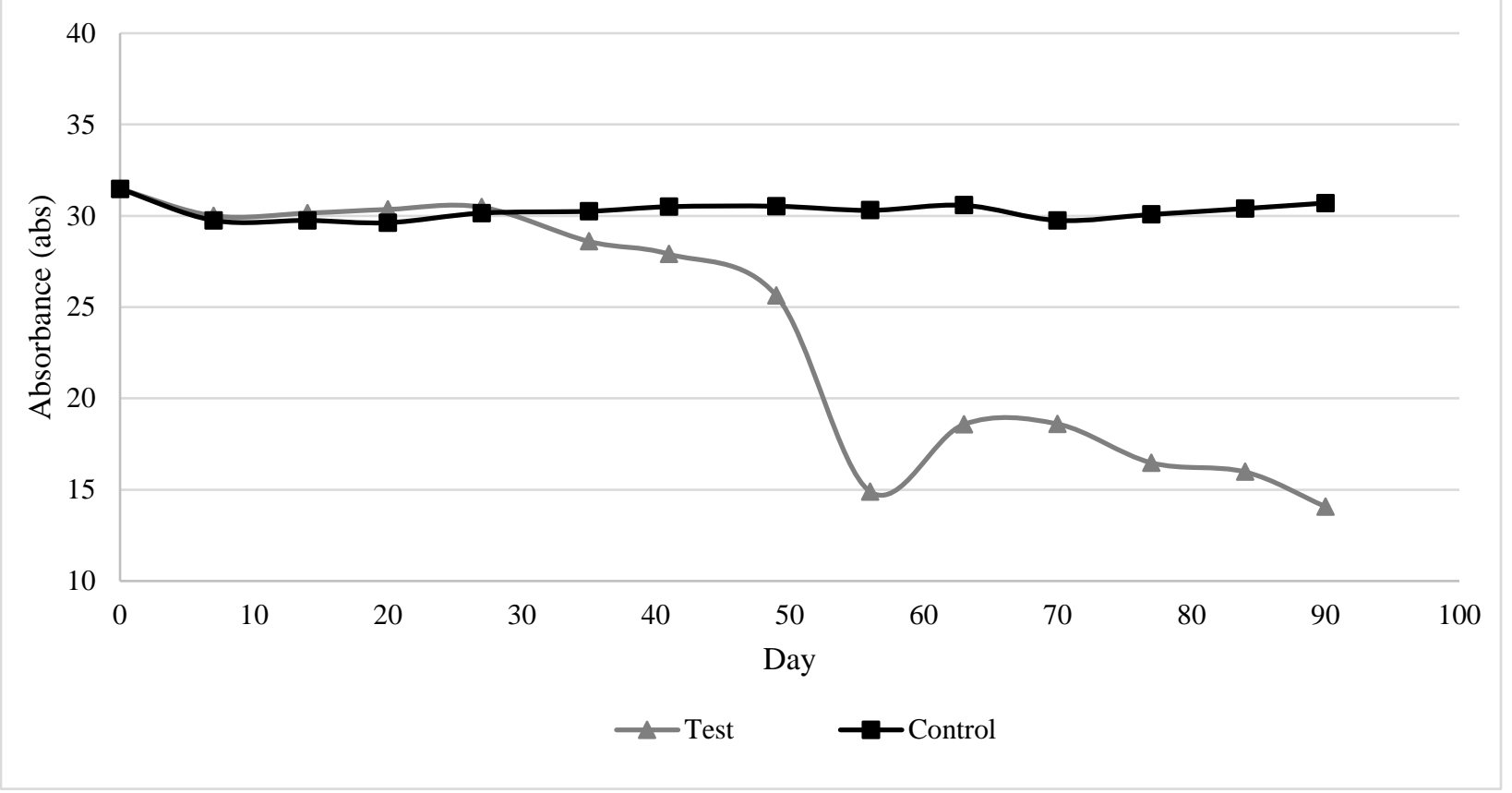

Figure B-14: Leachate F No Dilution UV 254 Trend Over 90 Days 


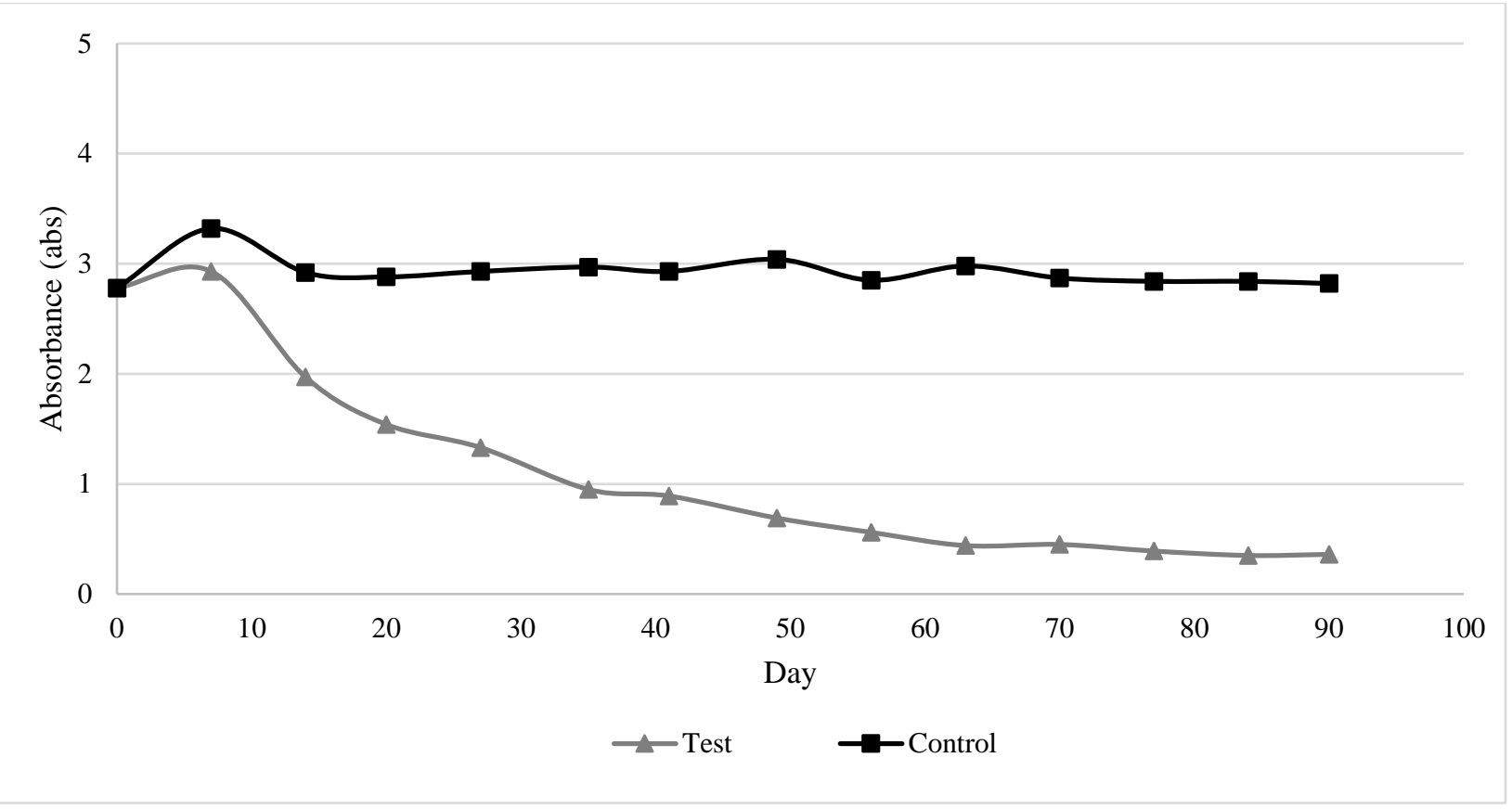

Figure B-15: Leachate F 1:10 Dilution UV254 Trend Over 90 Days

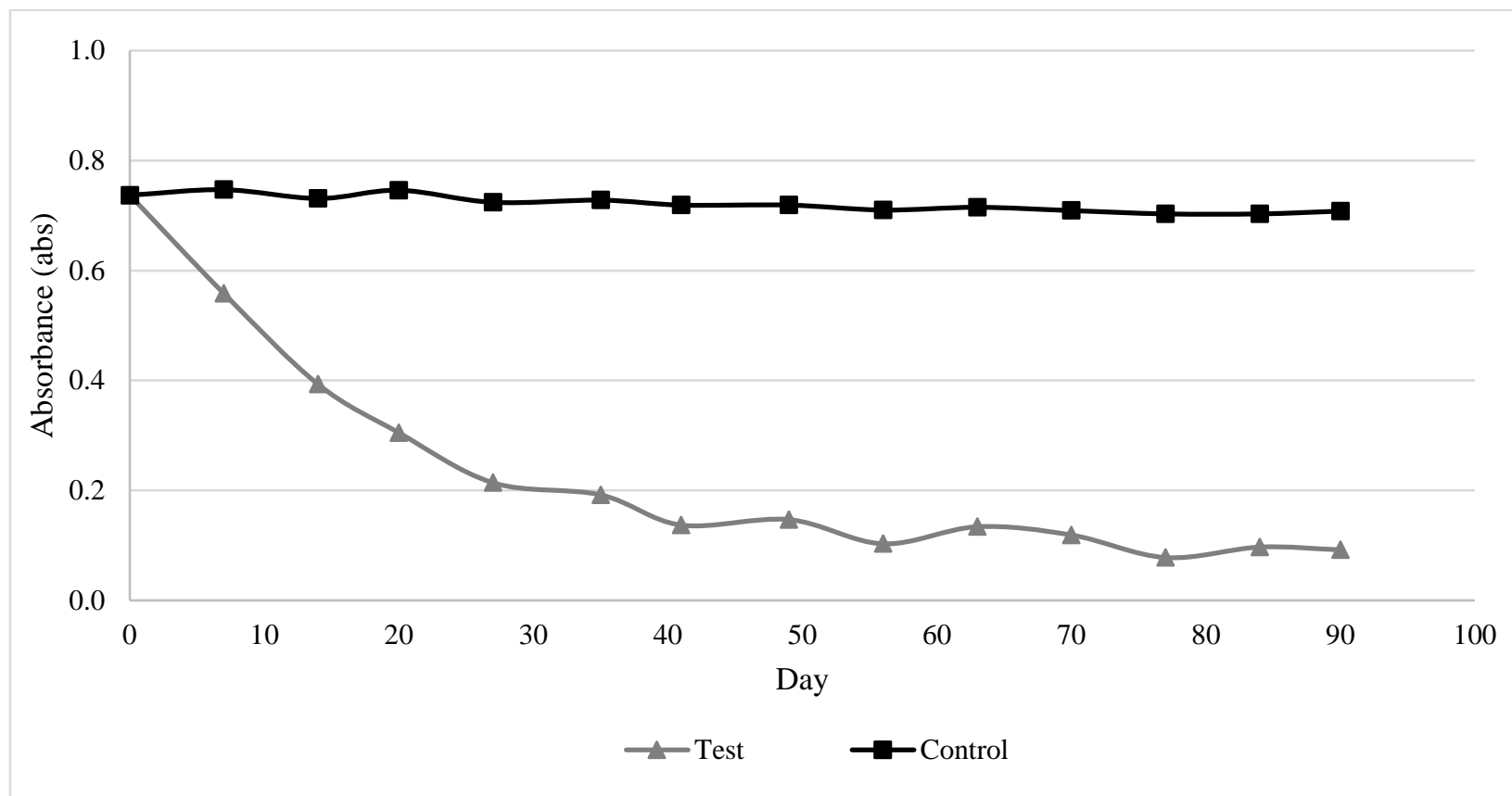

Figure B-16: Leachate F 1:50 Dilution UV254 Trend Over 90 Days 


\section{Leachate G}

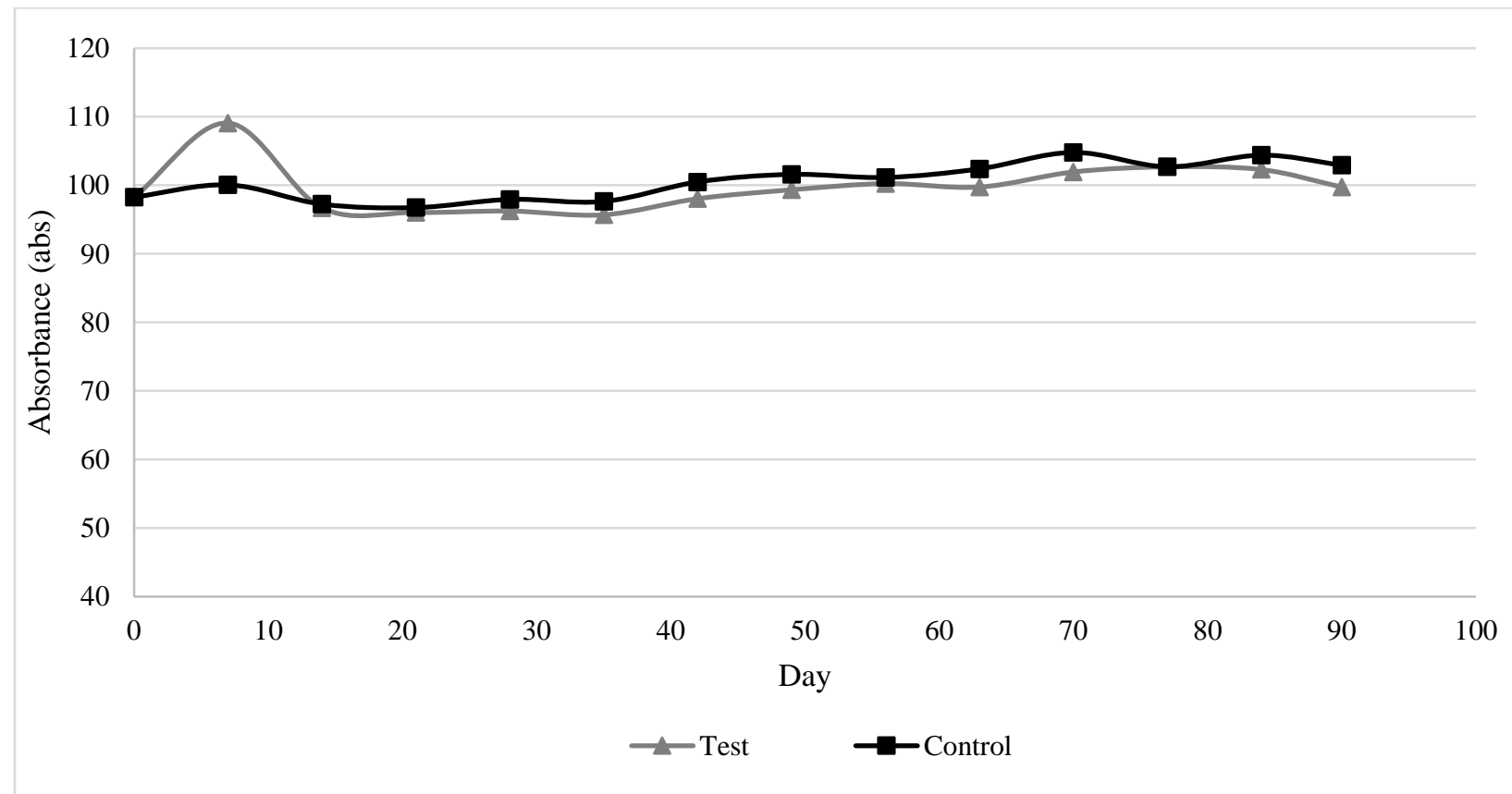

Figure B-17: Leachate G No Dilution UV254 Trend Over 90 Days

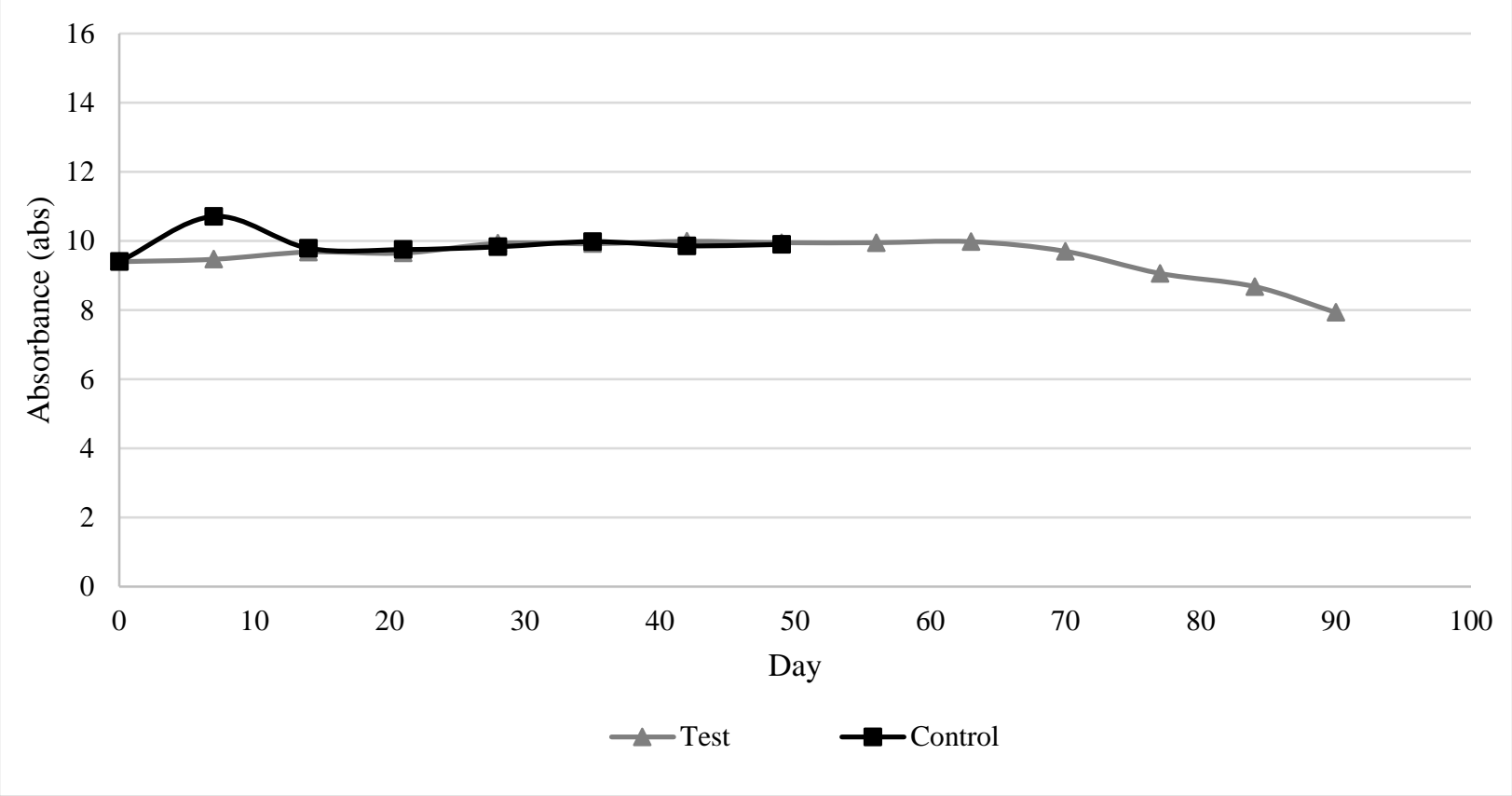

Figure B-18: Leachate G 1:10 Dilution UV 254 Trend Over 90 Days

(*1:10 dilution control bag broke on day 49 of experimental test) 


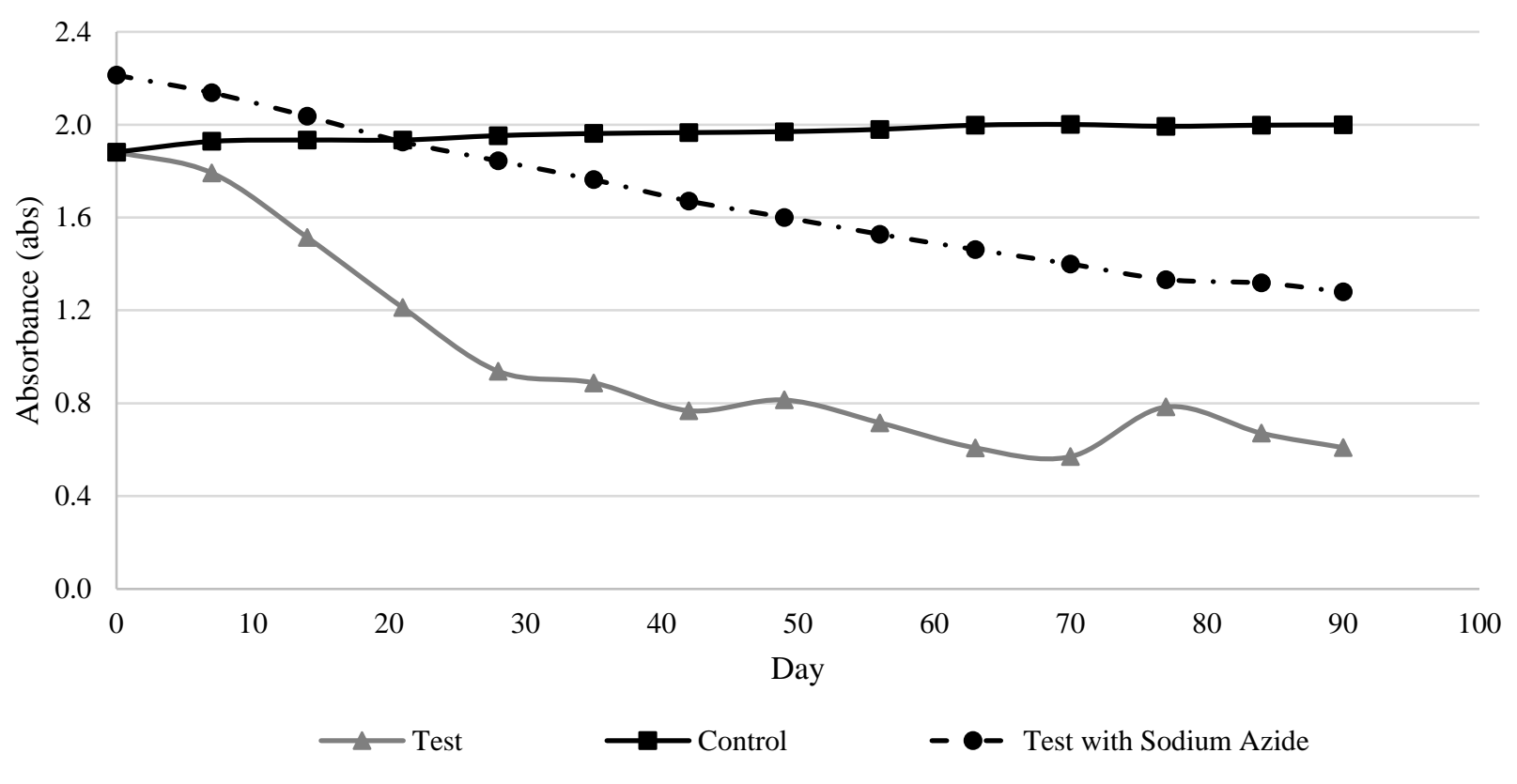

Figure B-19: Leachate G 1:50 Dilution UV254 Trend Over 90 Days

Leachate $\mathrm{H}$

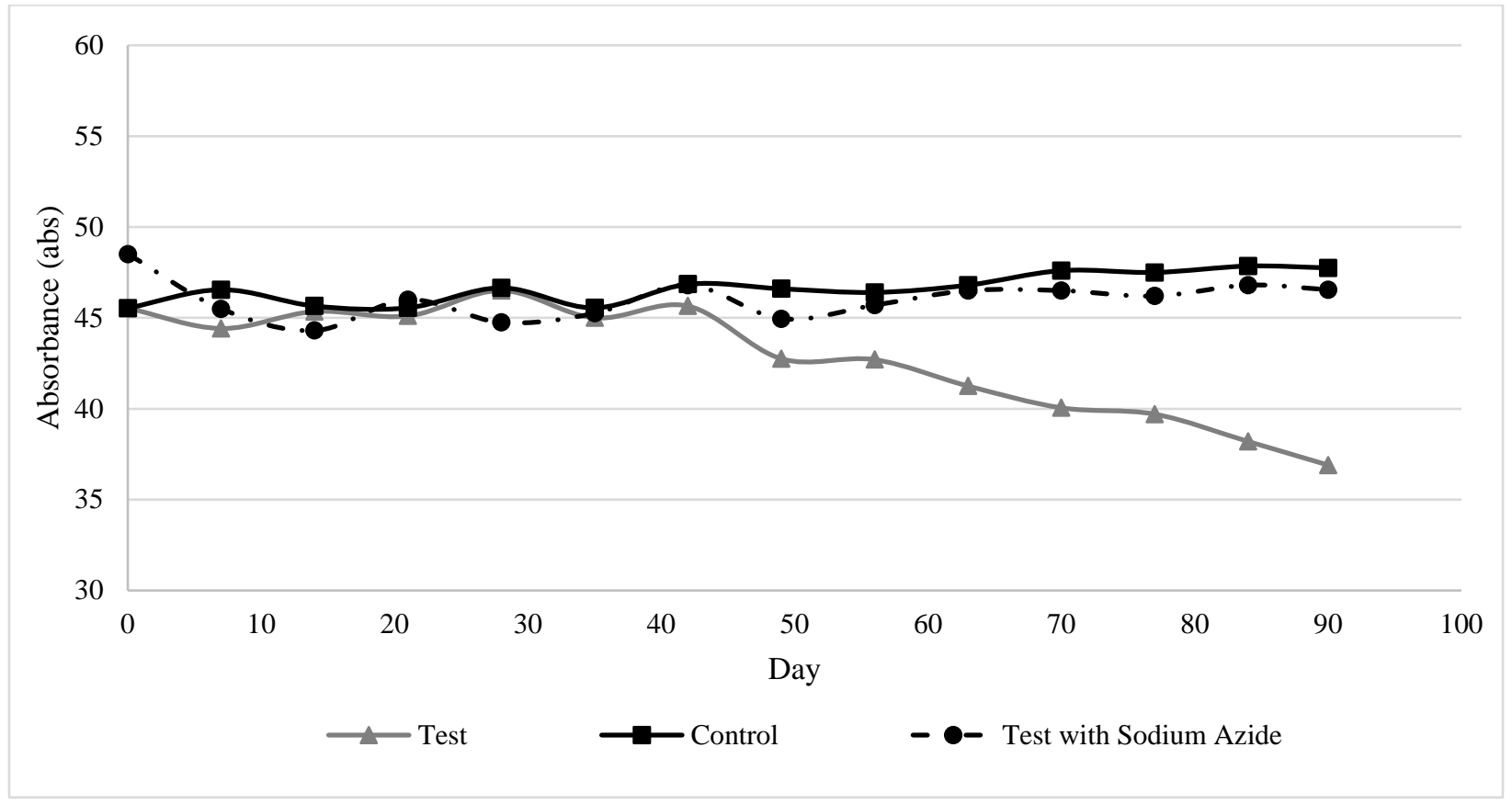

Figure B-20: Leachate H No Dilution UV254 Trend Over 90 Days 


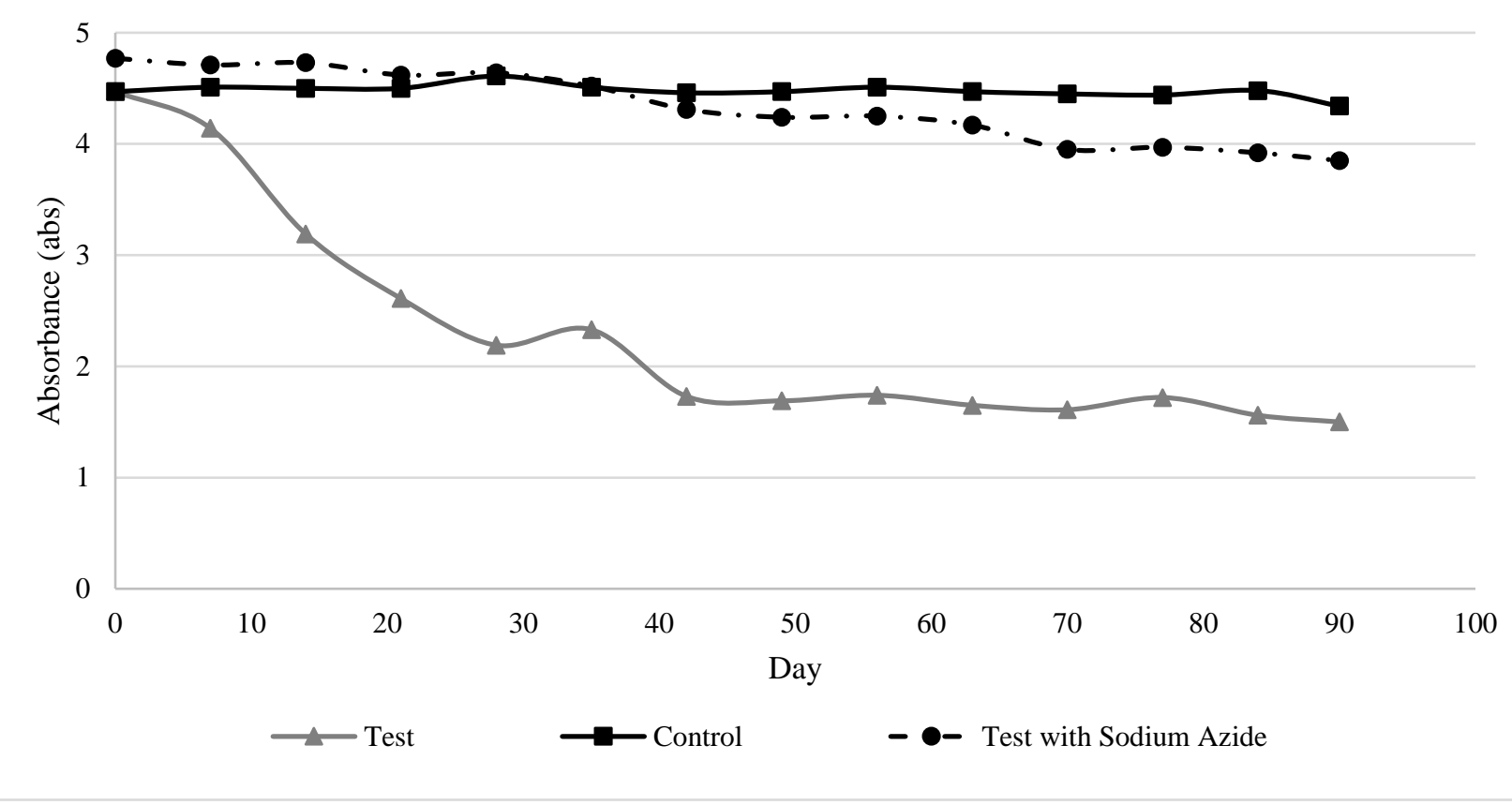

Figure B-21: Leachate H 1:10 Dilution UV254 Trend Over 90 Days

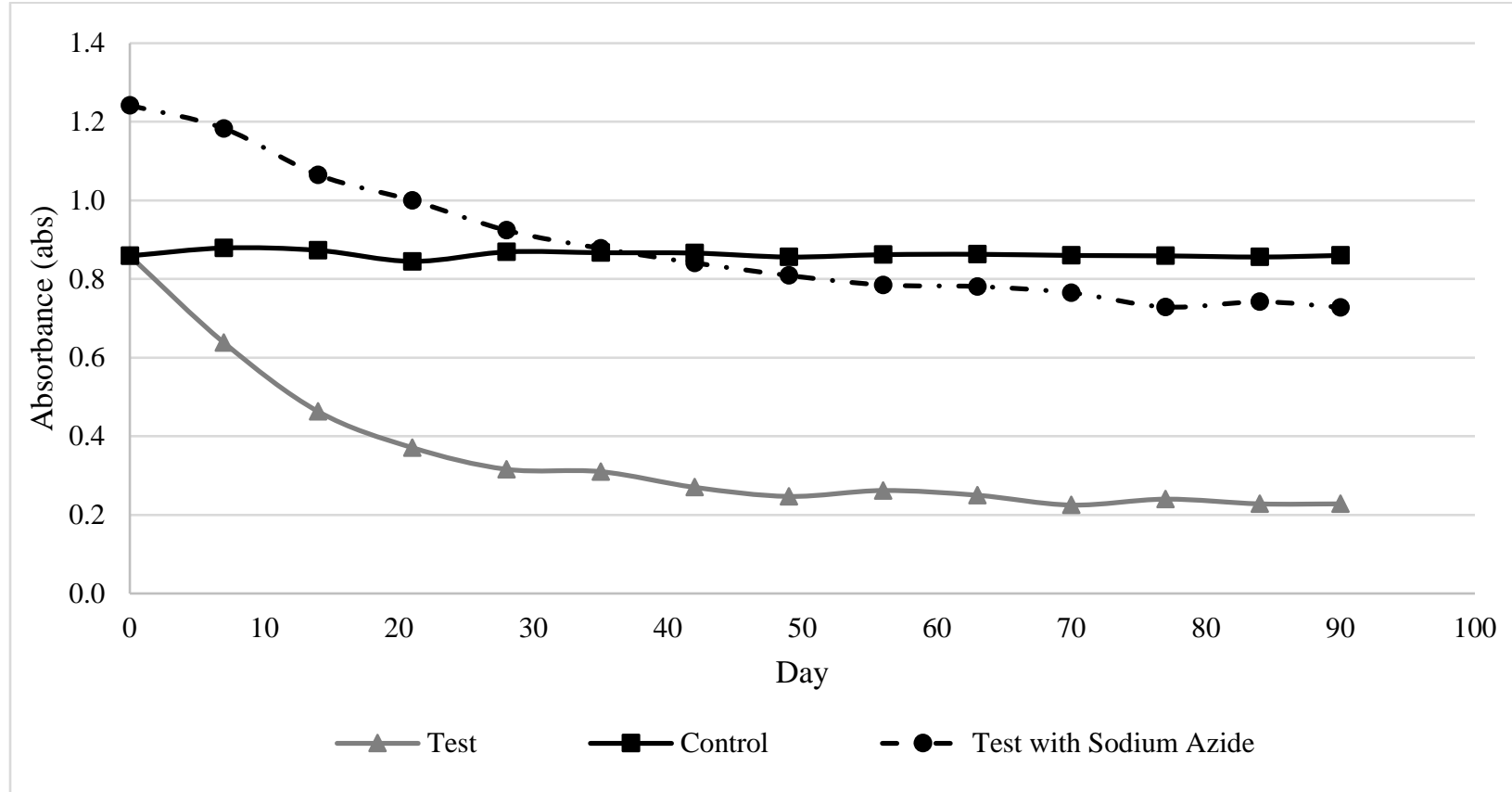

Figure B-22: Leachate H 1:50 Dilution UV 254 Trend Over 90 Days 
APPENDIX C: DAY 0 AND DAY 90 UV-VIS SCANS 


\section{Leachate A}

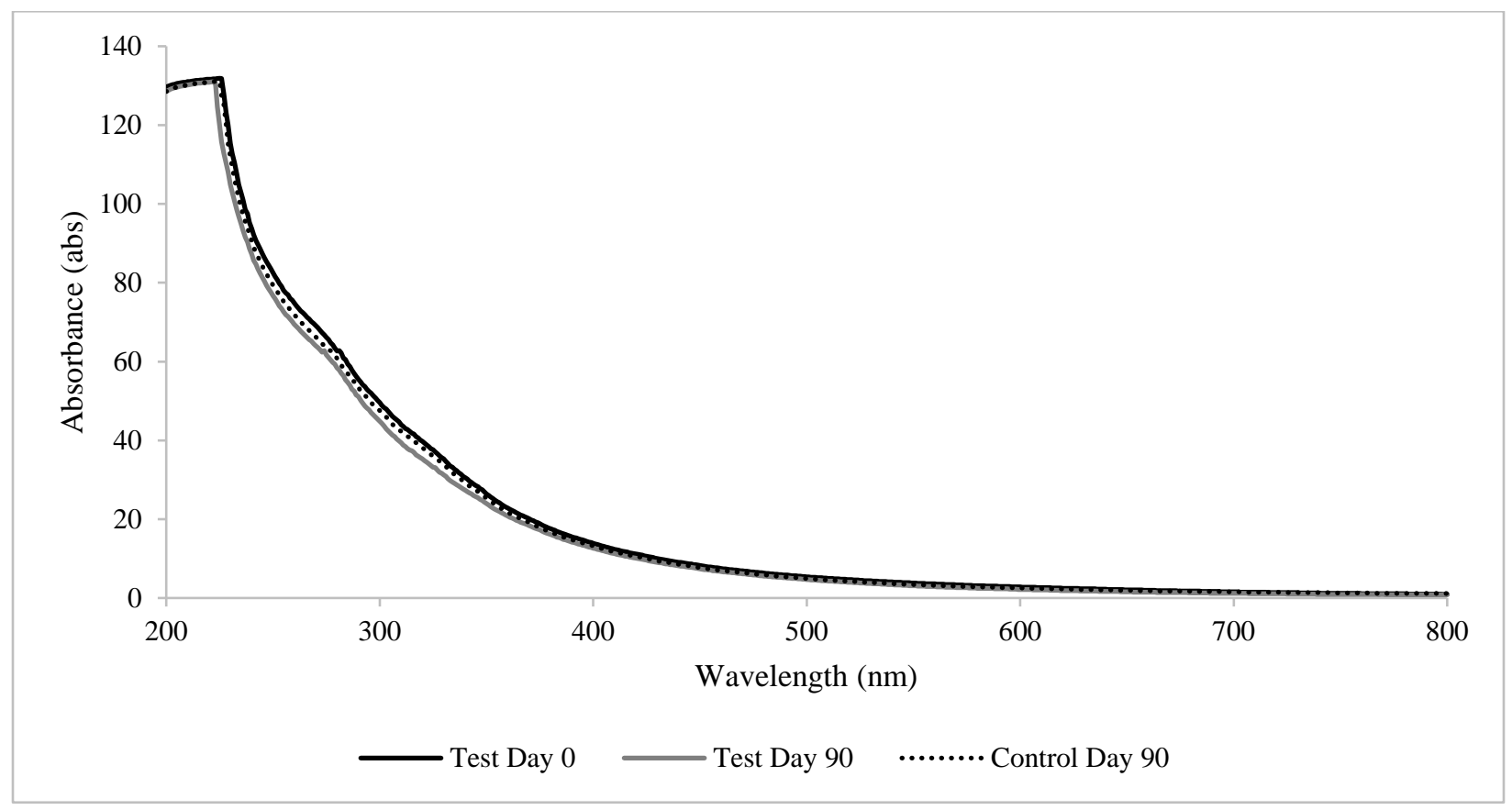

Figure C-1: Leachate A No Dilution Day 0 and Day 90 UV-Vis Scans

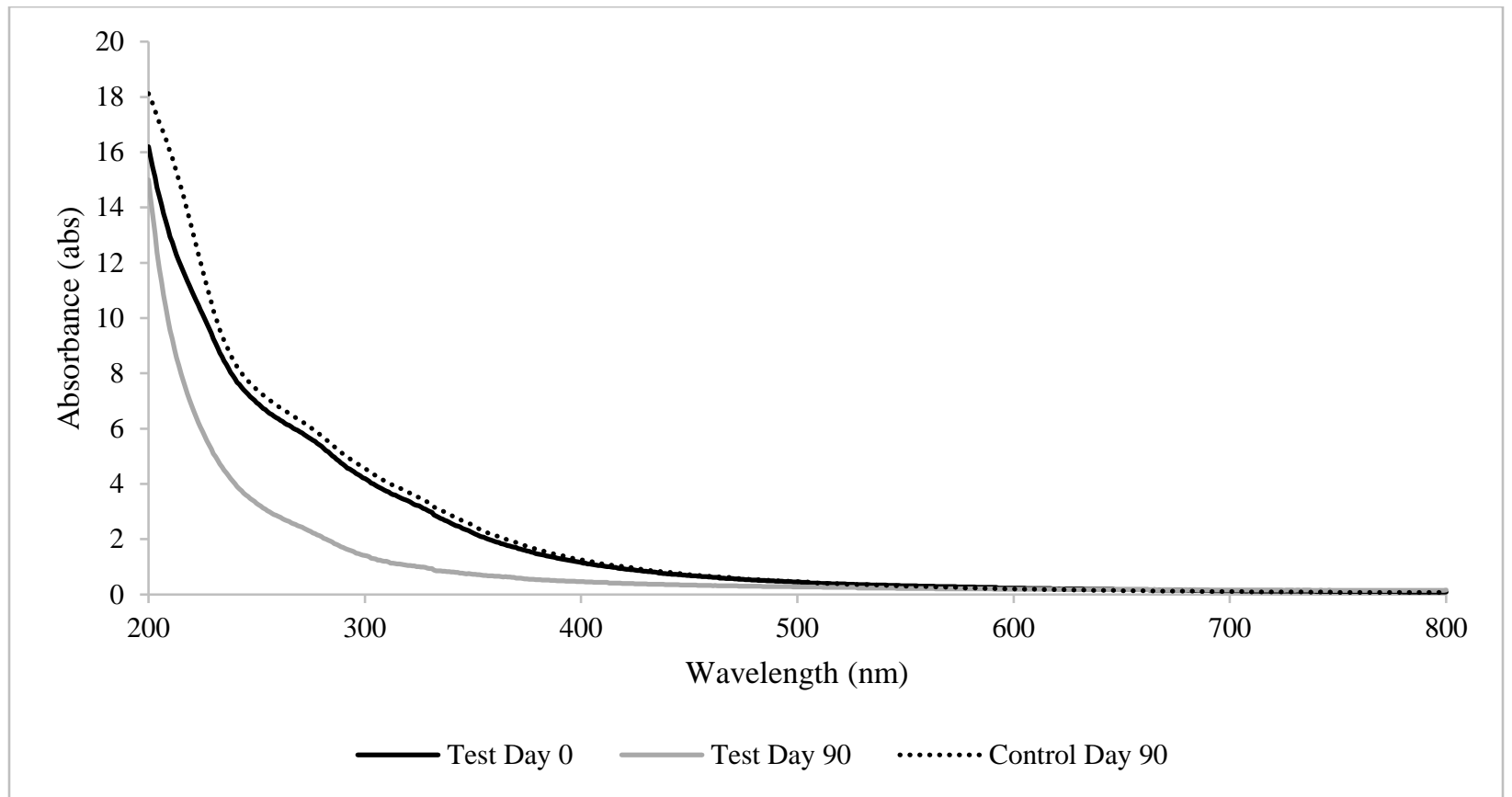

Figure C-2: Leachate A 1:10 Dilution Day 0 and Day 90 UV-Vis Scans 


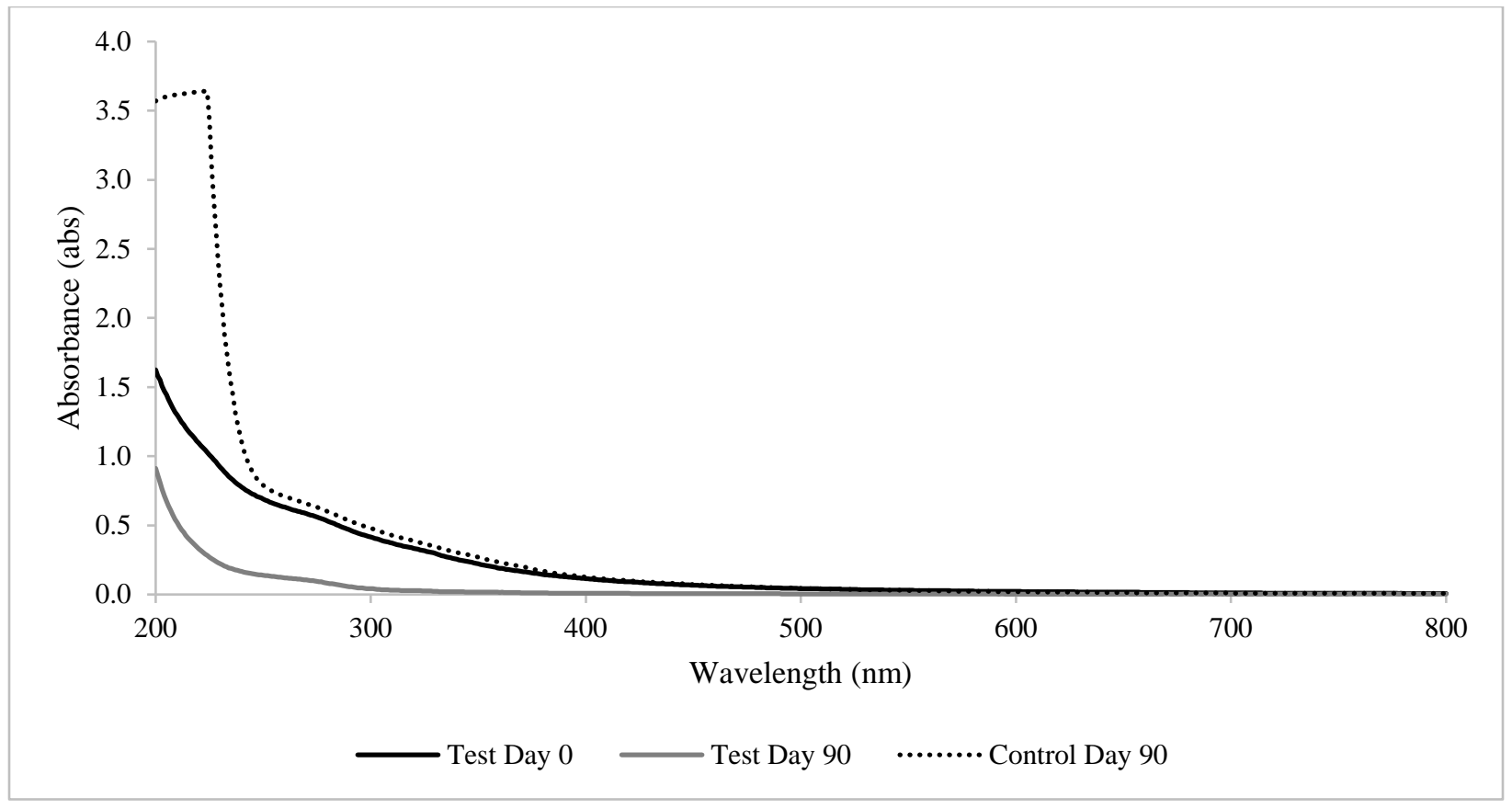

Figure C-3: Leachate A 1:100 Dilution Day 0 and Day 90 UV-Vis Scans

Leachate B

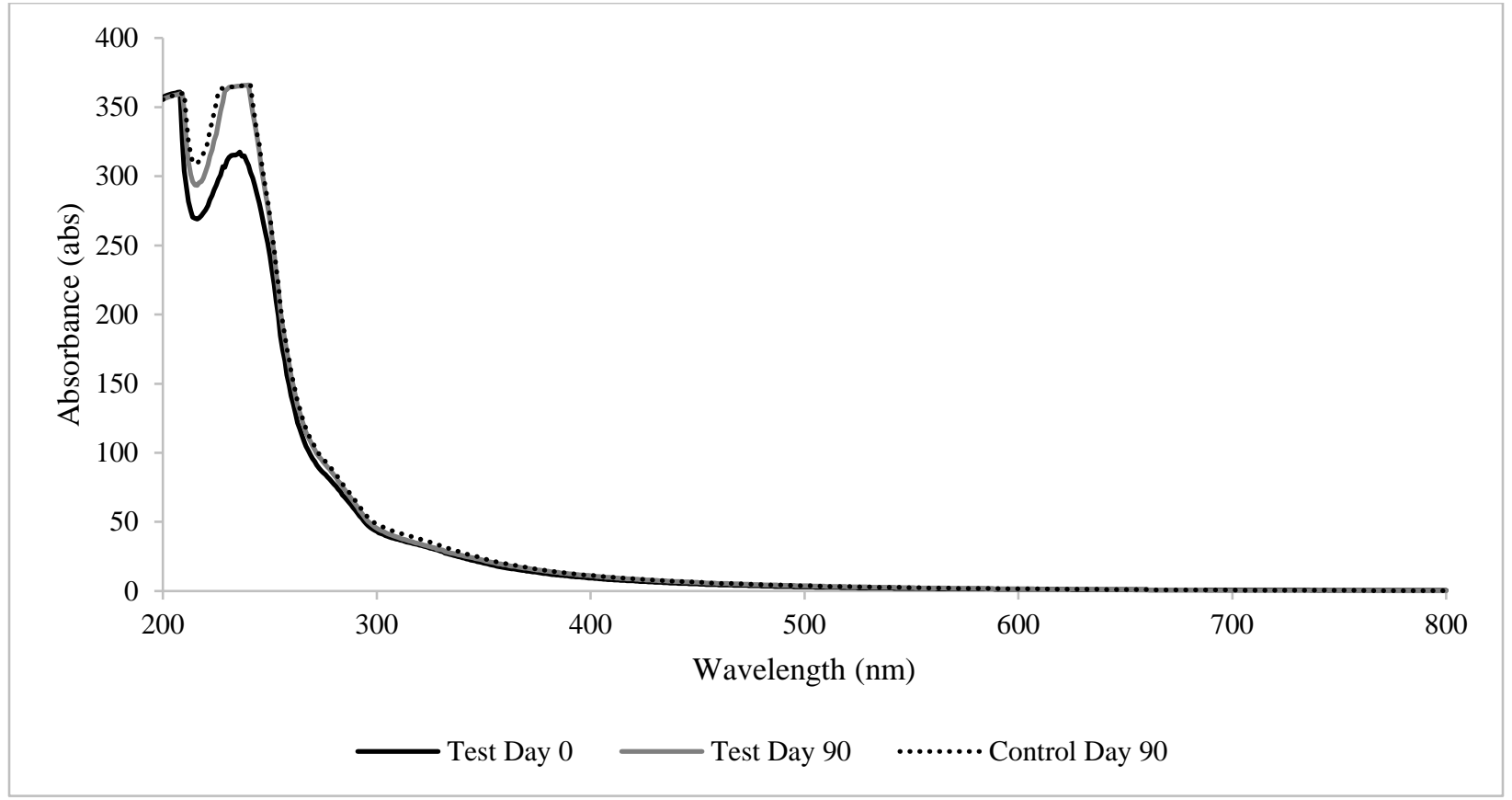

Figure C-4: Leachate B No Dilution Day 0 and Day 90 UV-Vis Scans 


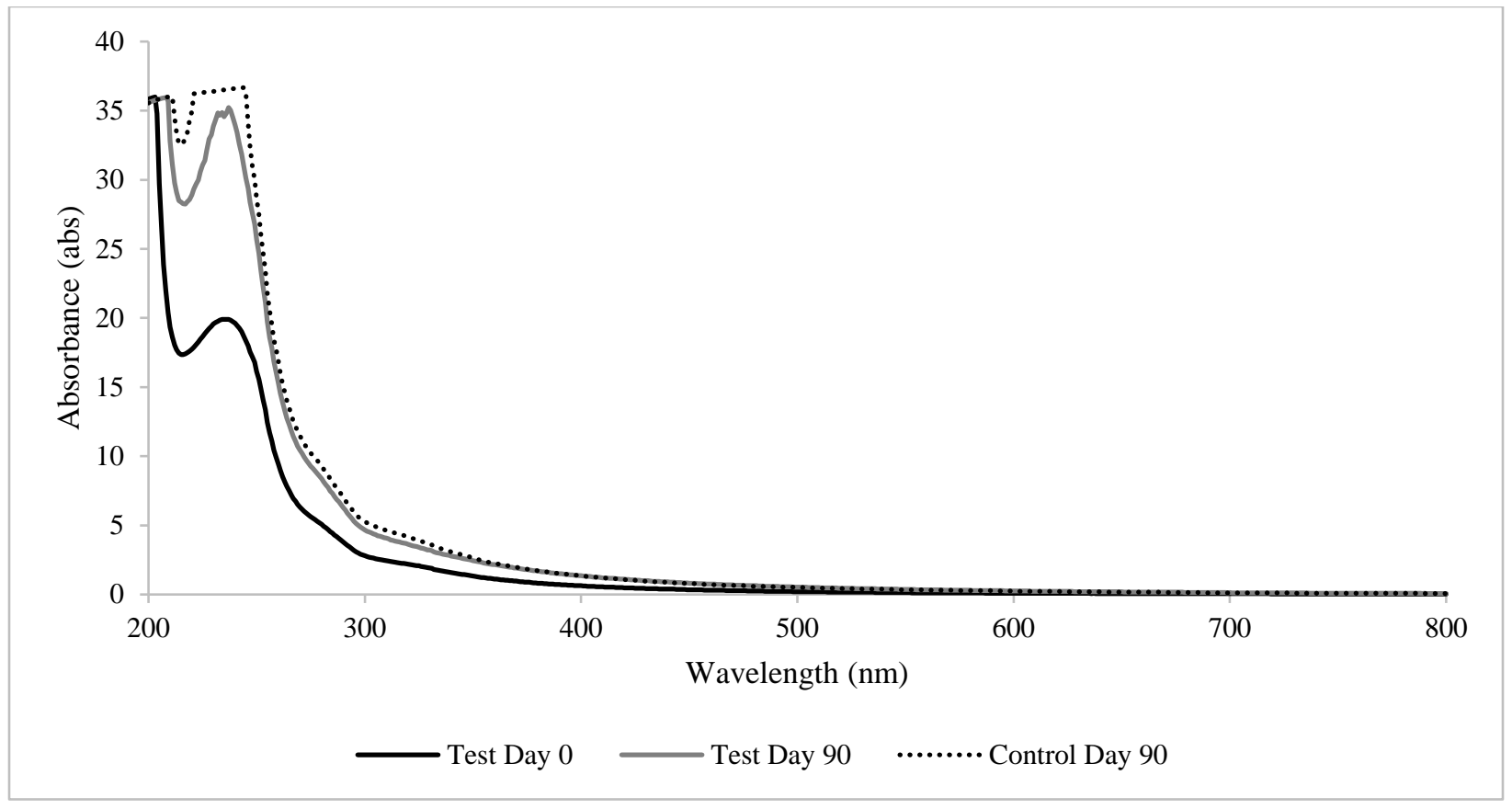

Figure C-5: Leachate B 1:10 Dilution Day 0 and Day 90 UV-Vis Scans

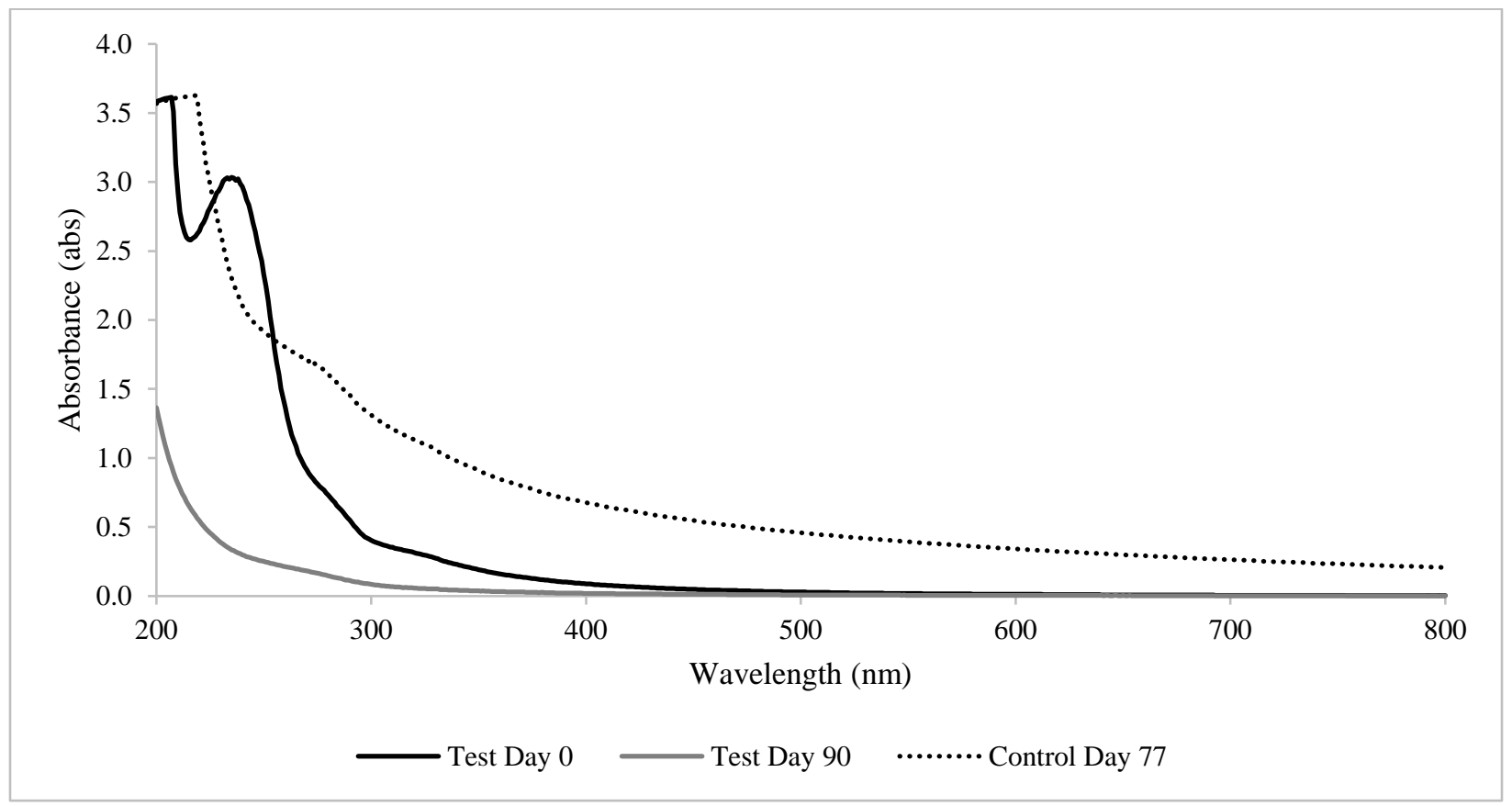

Figure C-6: Leachate B 1:100 Dilution Day 0 and Day 90 UV-Vis Scans

(*1:100 dilution control bag broke on day 77 of experimental test) 


\section{Leachate C}

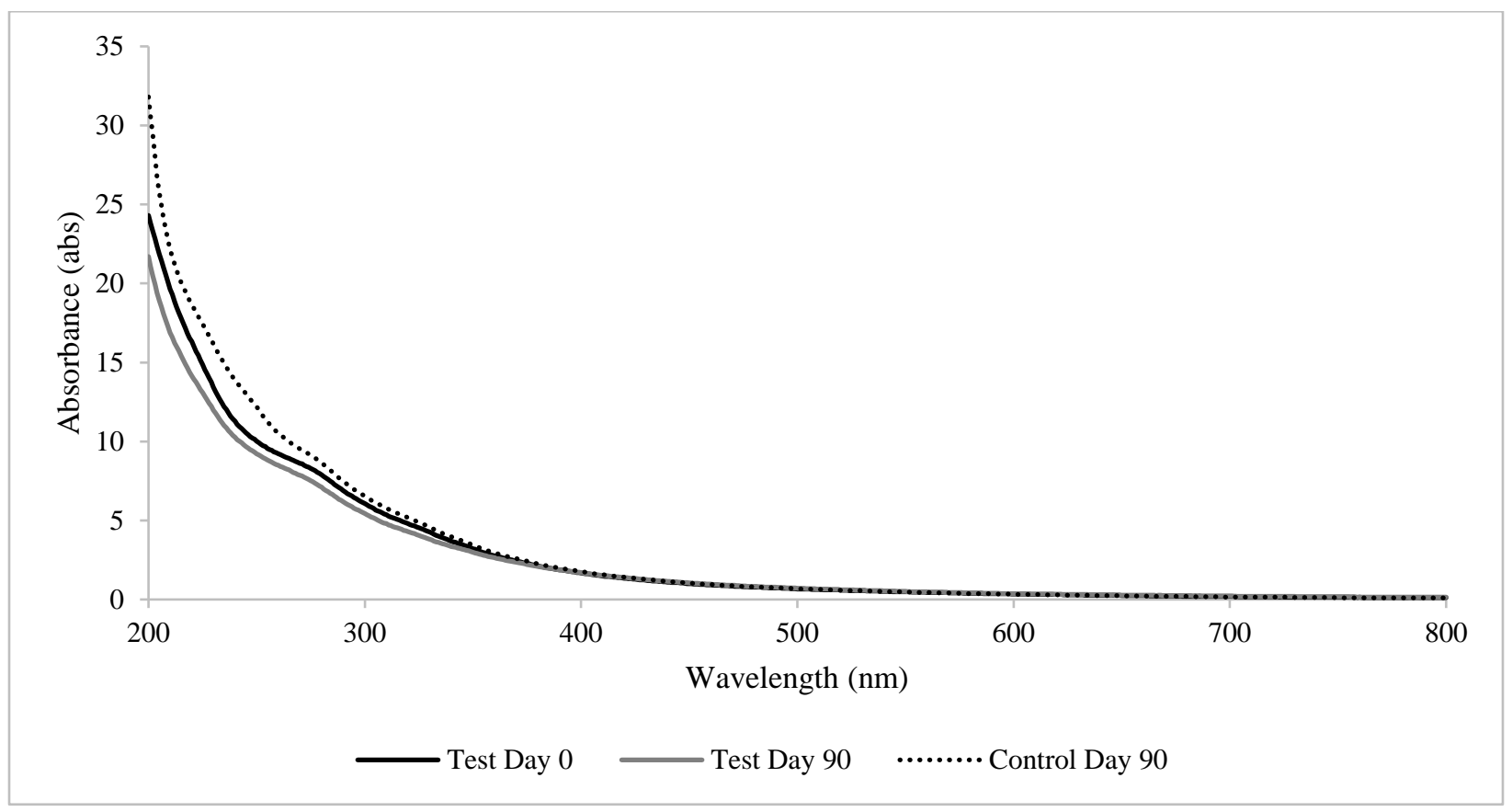

Figure C-7: Leachate C 1:4.1 Dilution Day 0 and Day 90 UV-Vis Scans

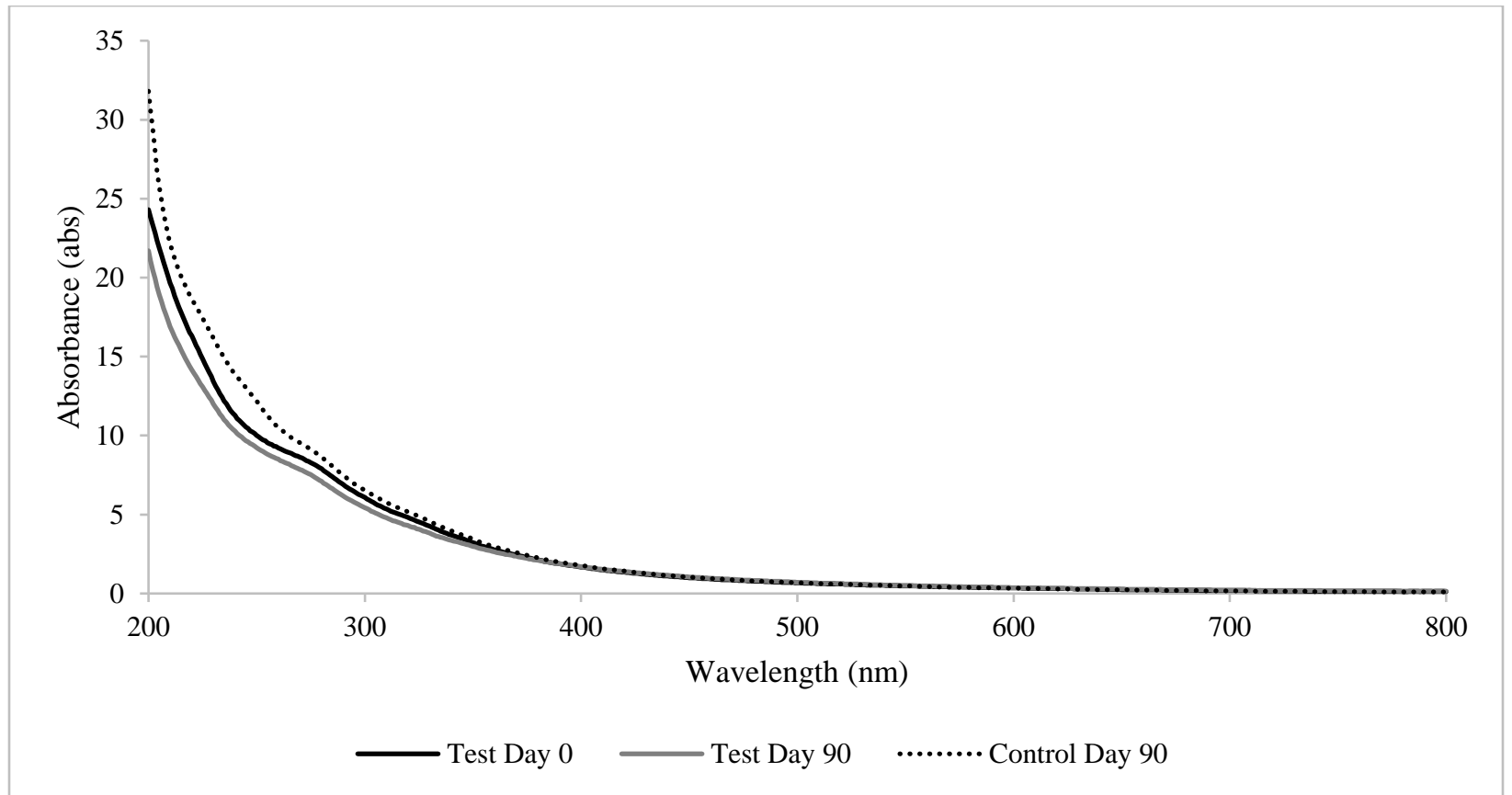

Figure C-8: Leachate C 1:31 Dilution Day 0 and Day 90 UV-Vis Scans 


\section{Leachate D}

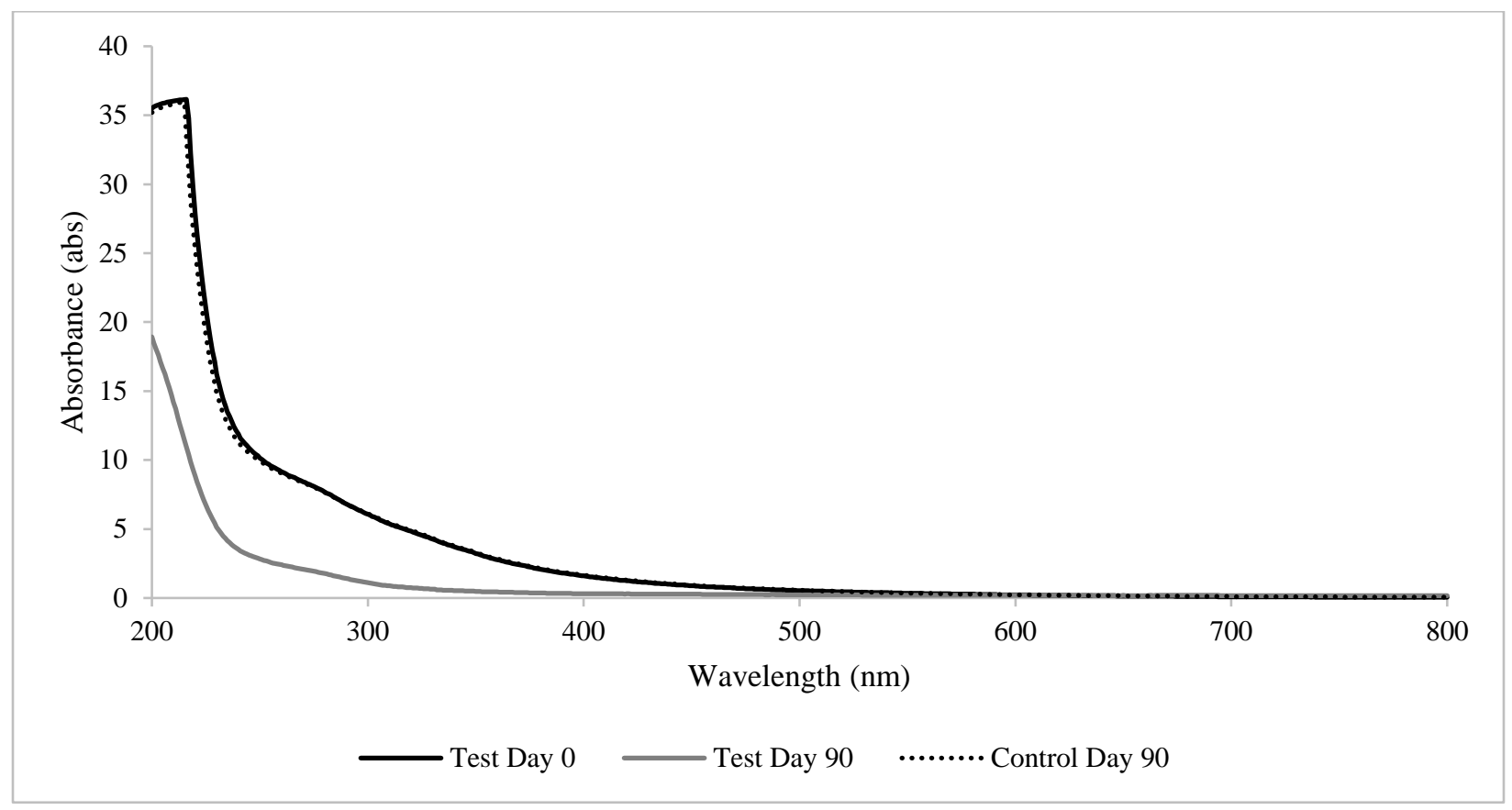

Figure C-9: Leachate D 1:2.4 Dilution Day 0 and Day 90 UV-Vis Scans

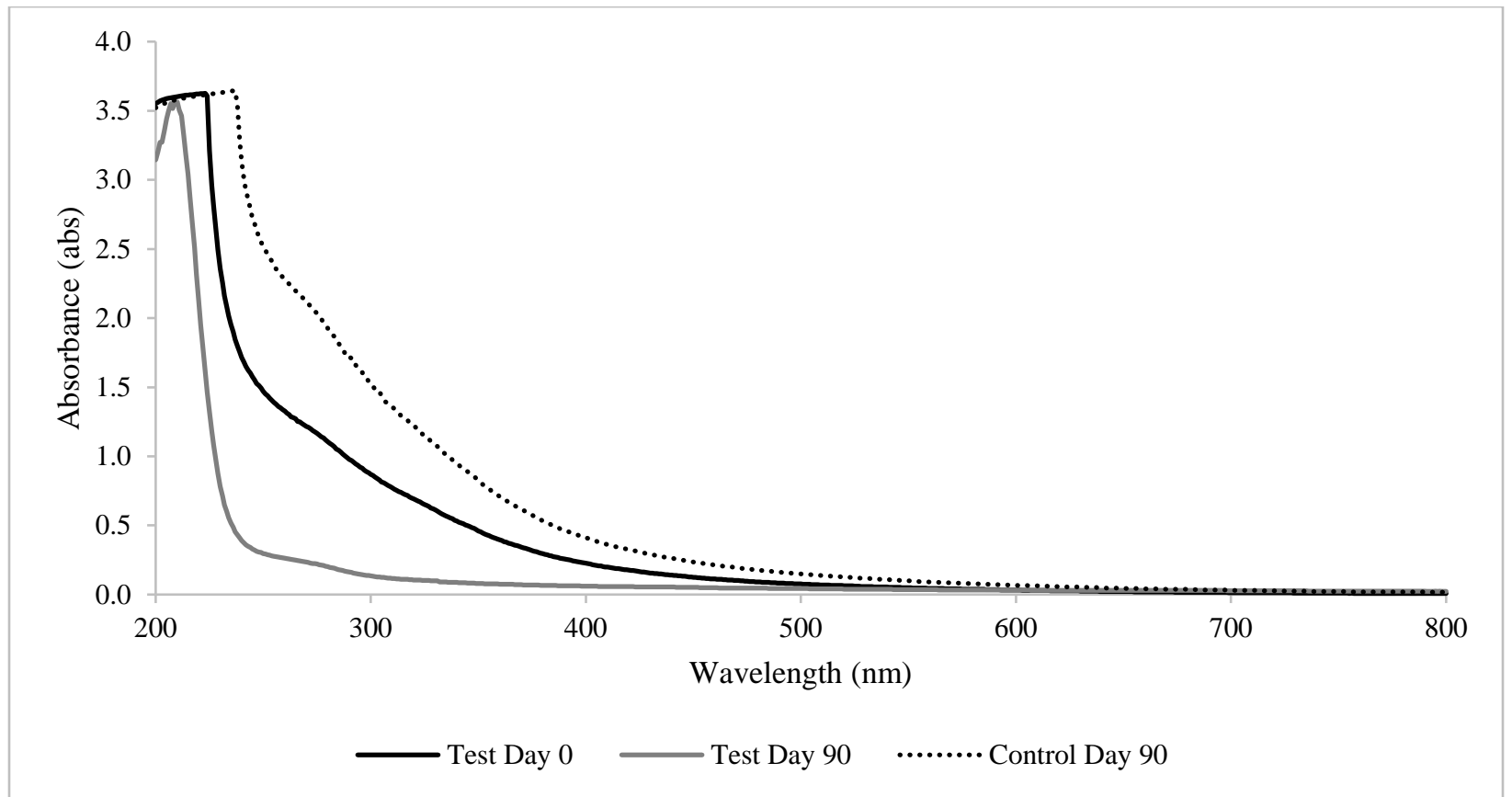

Figure C-10: Leachate D 1:16 Dilution Day 0 and Day 90 UV-Vis Scans 


\section{Leachate E}

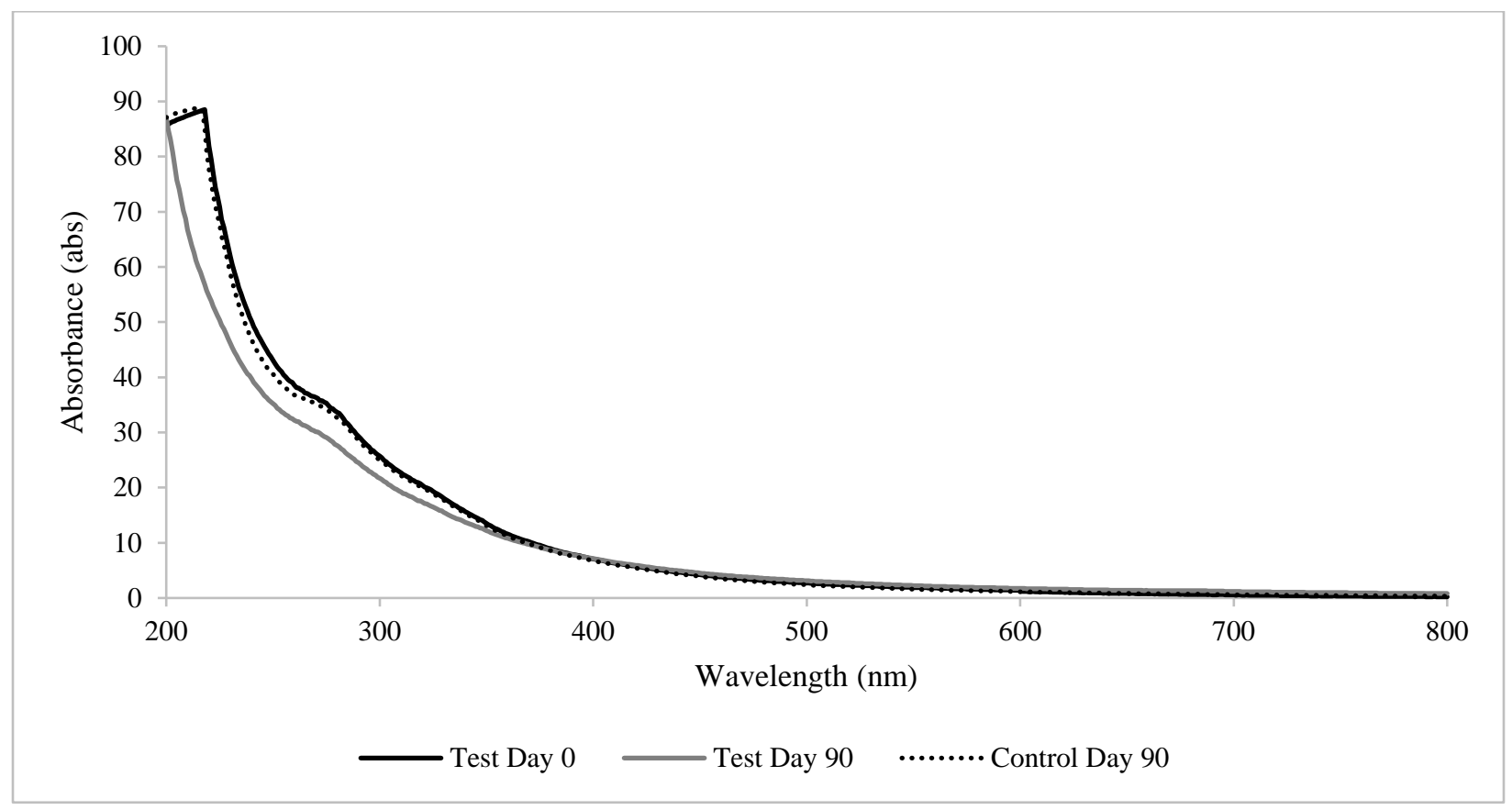

Figure C-11: Leachate E No Dilution Day 0 and Day 90 UV-Vis Scans

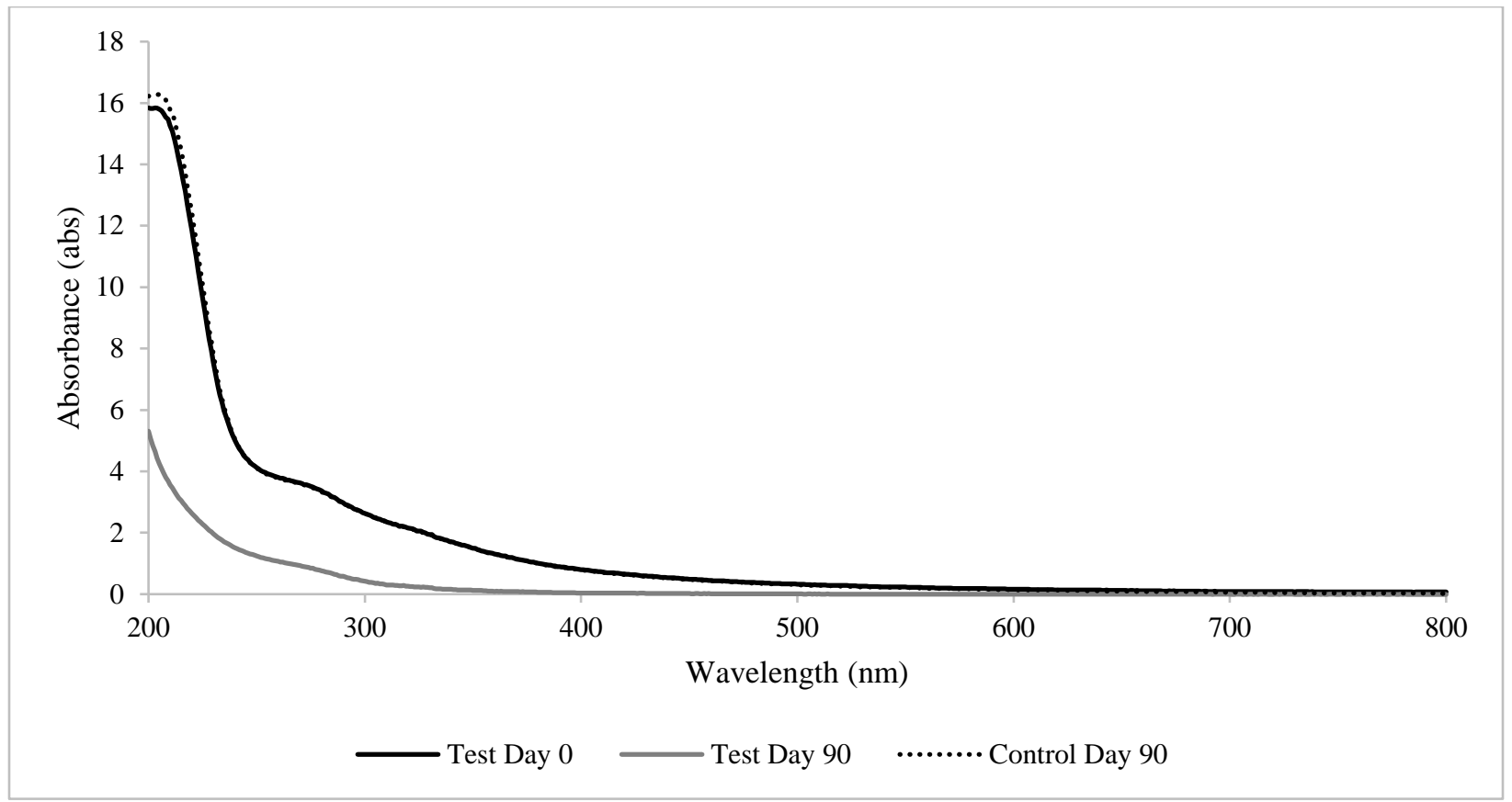

Figure C-12: Leachate E 1:10 Dilution Day 0 and Day 90 UV-Vis Scans 


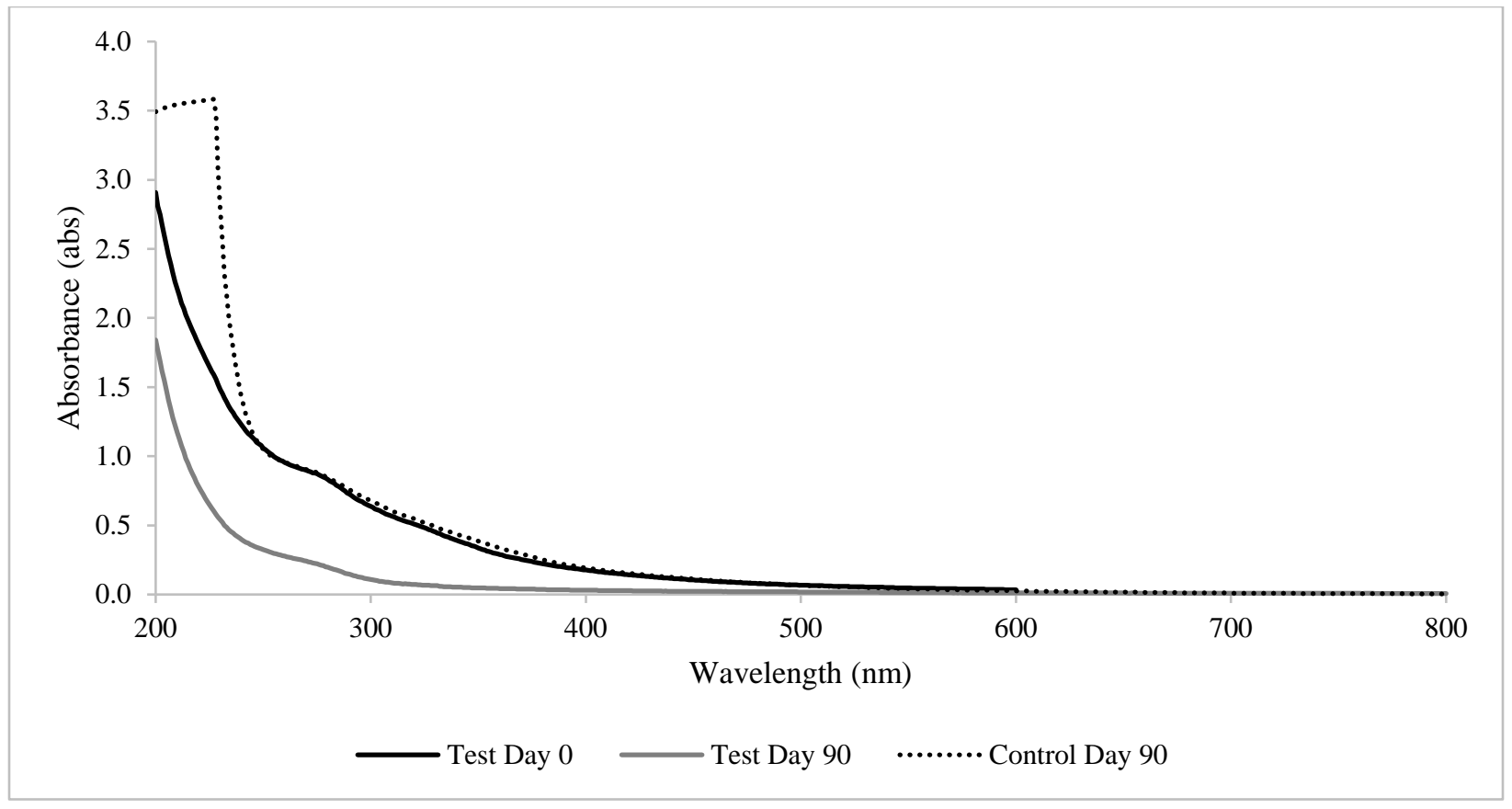

Figure C-13: Leachate E 1:40 Dilution Day 0 and Day 90 UV-Vis Scans

Leachate F

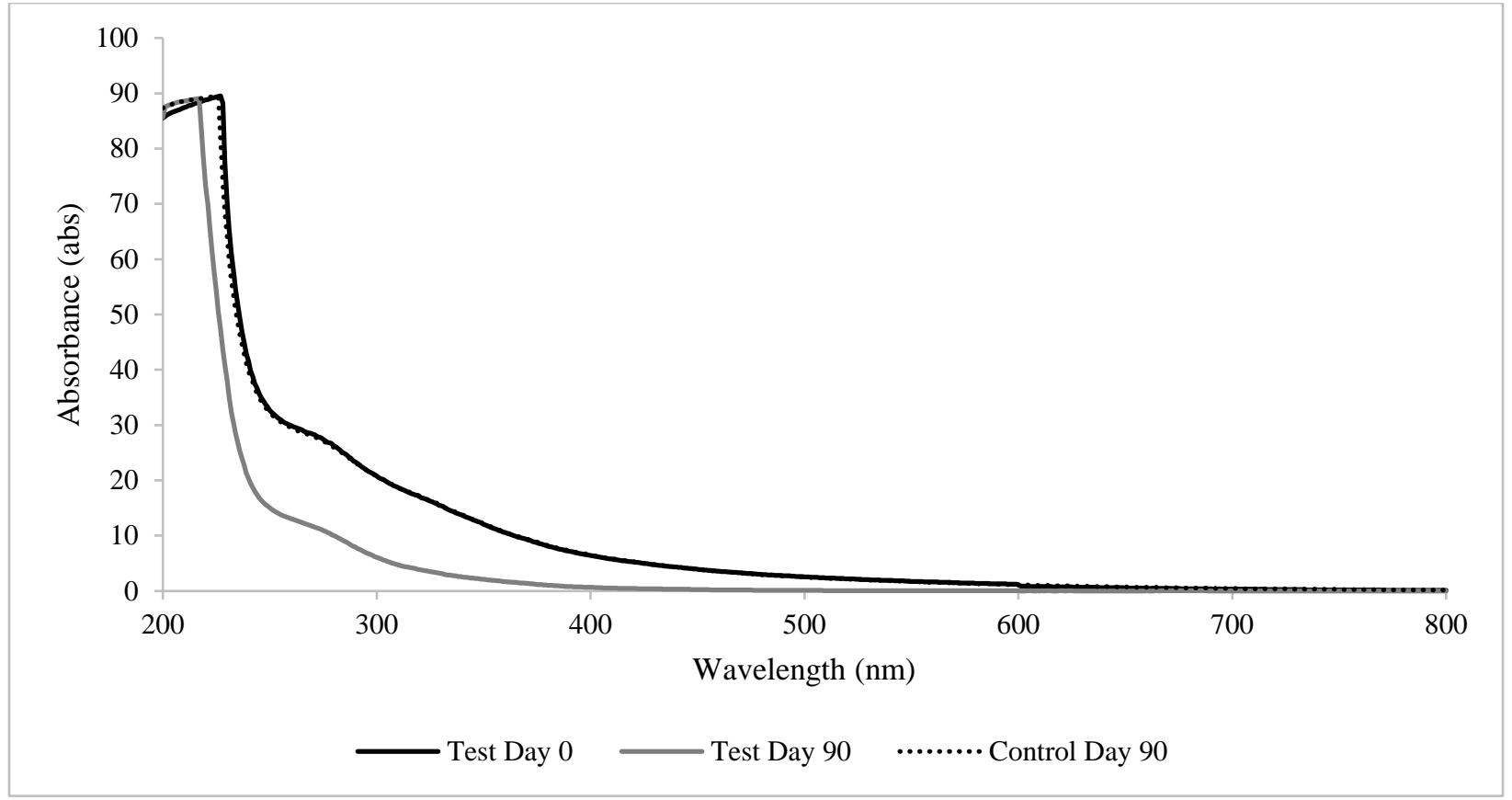

Figure C-14: Leachate F No Dilution Day 0 and Day 90 UV-Vis Scans 


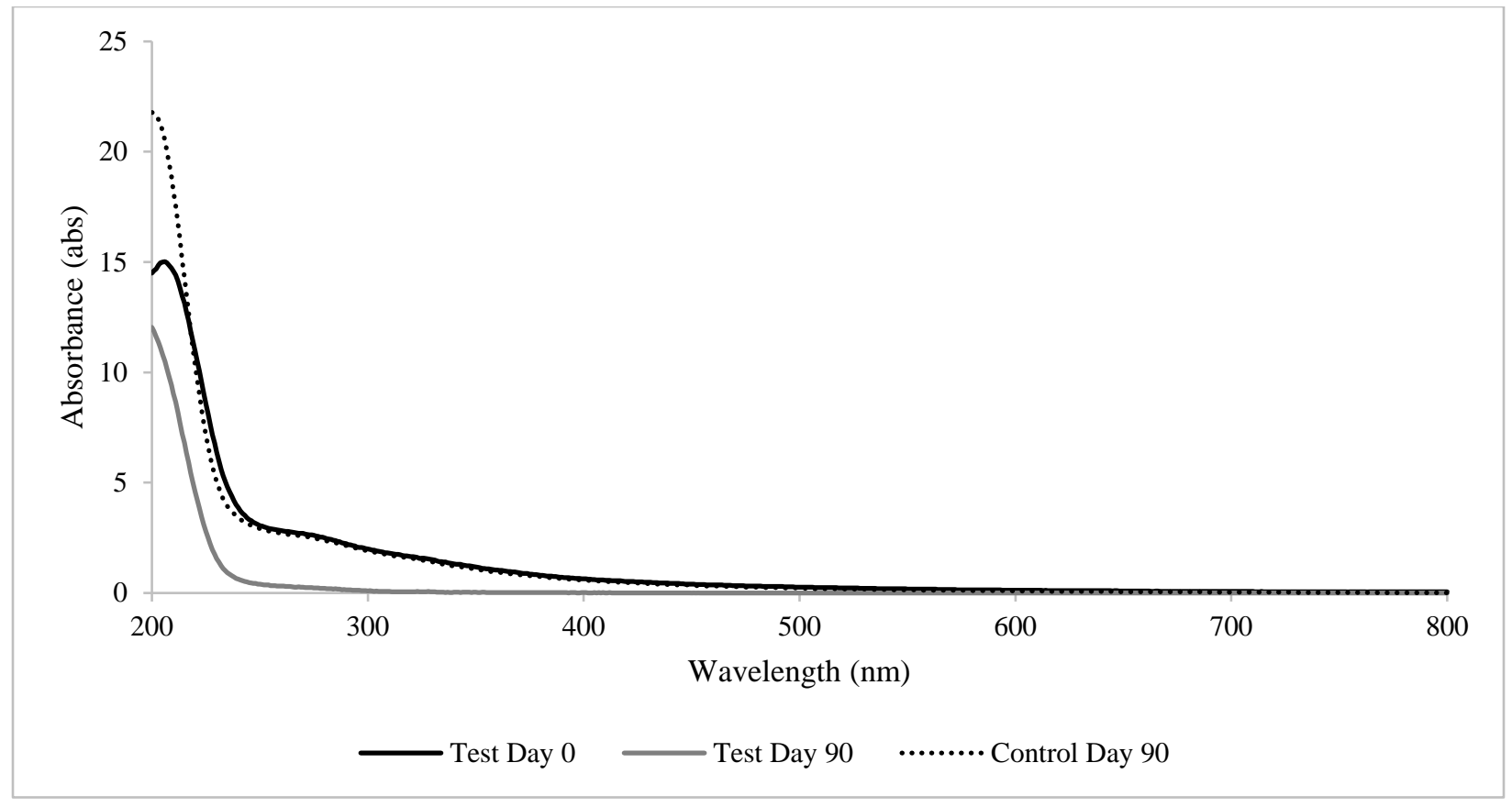

Figure C-15: Leachate F 1:10 Dilution Day 0 and Day 90 UV-Vis Scans

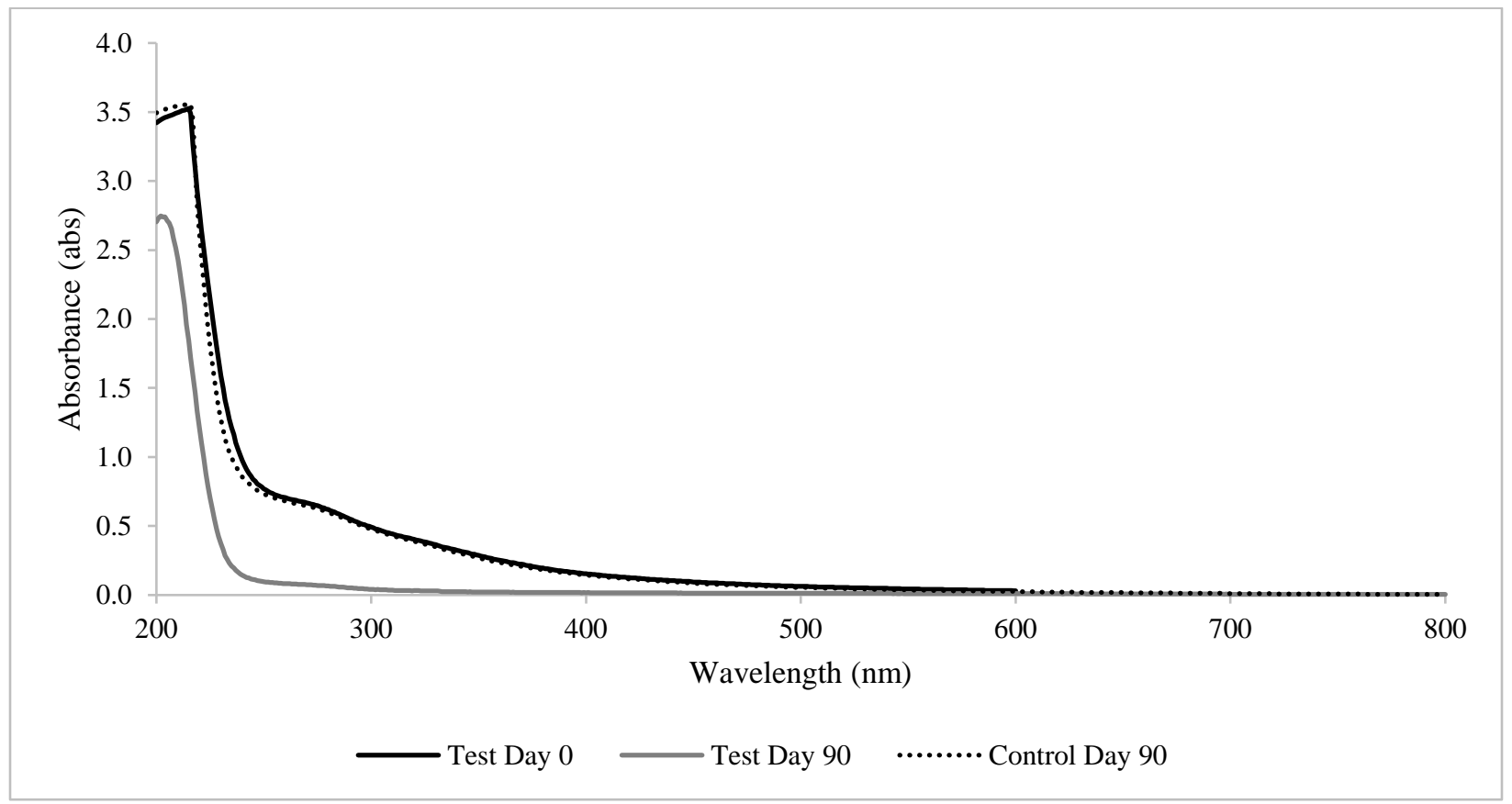

Figure C-16: Leachate F 1:40 Dilution Day 0 and Day 90 UV-Vis Scans 


\section{Leachate G}

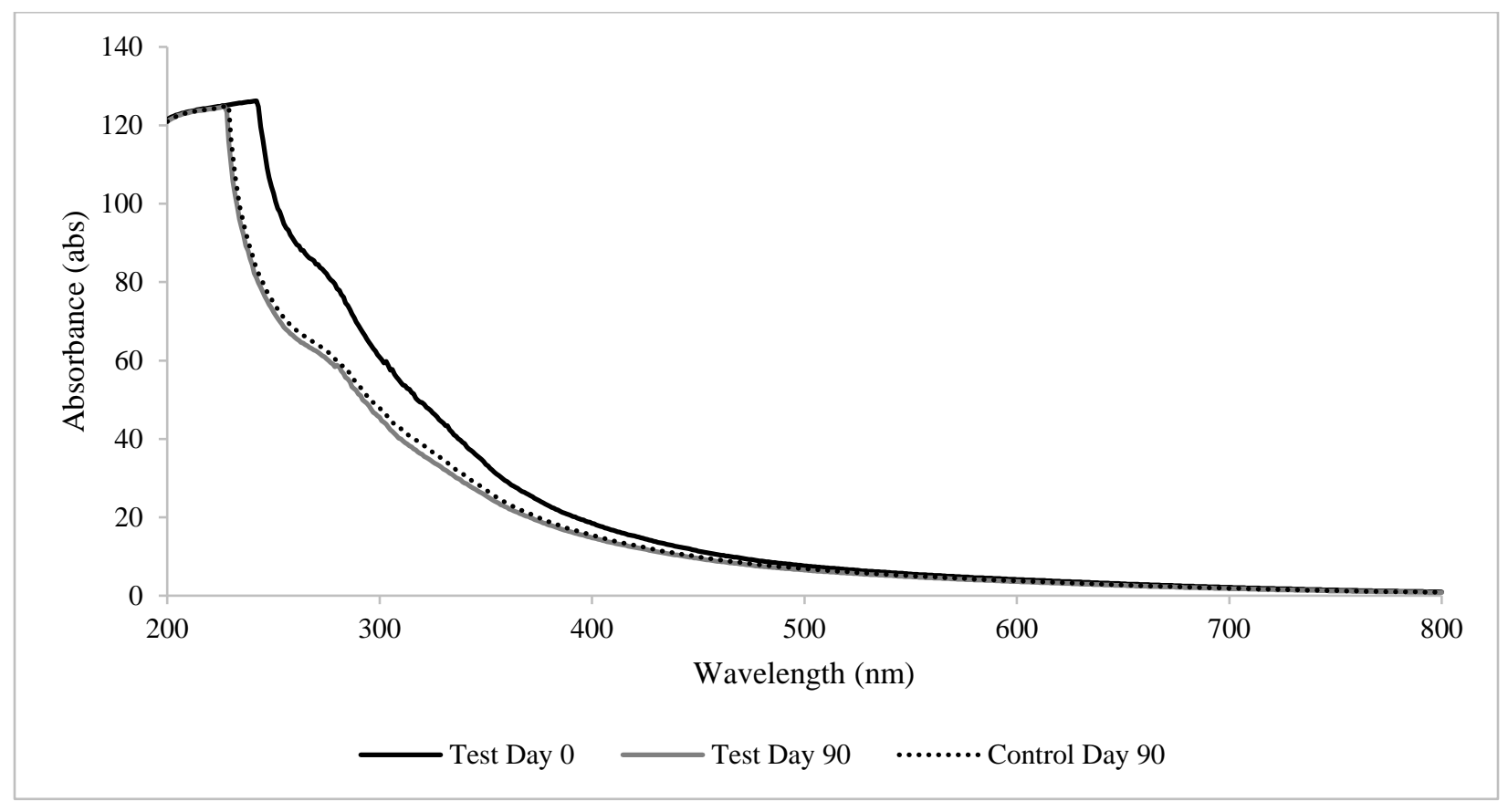

Figure C-17: Leachate G No Dilution Day 0 and Day 90 UV-Vis Scans

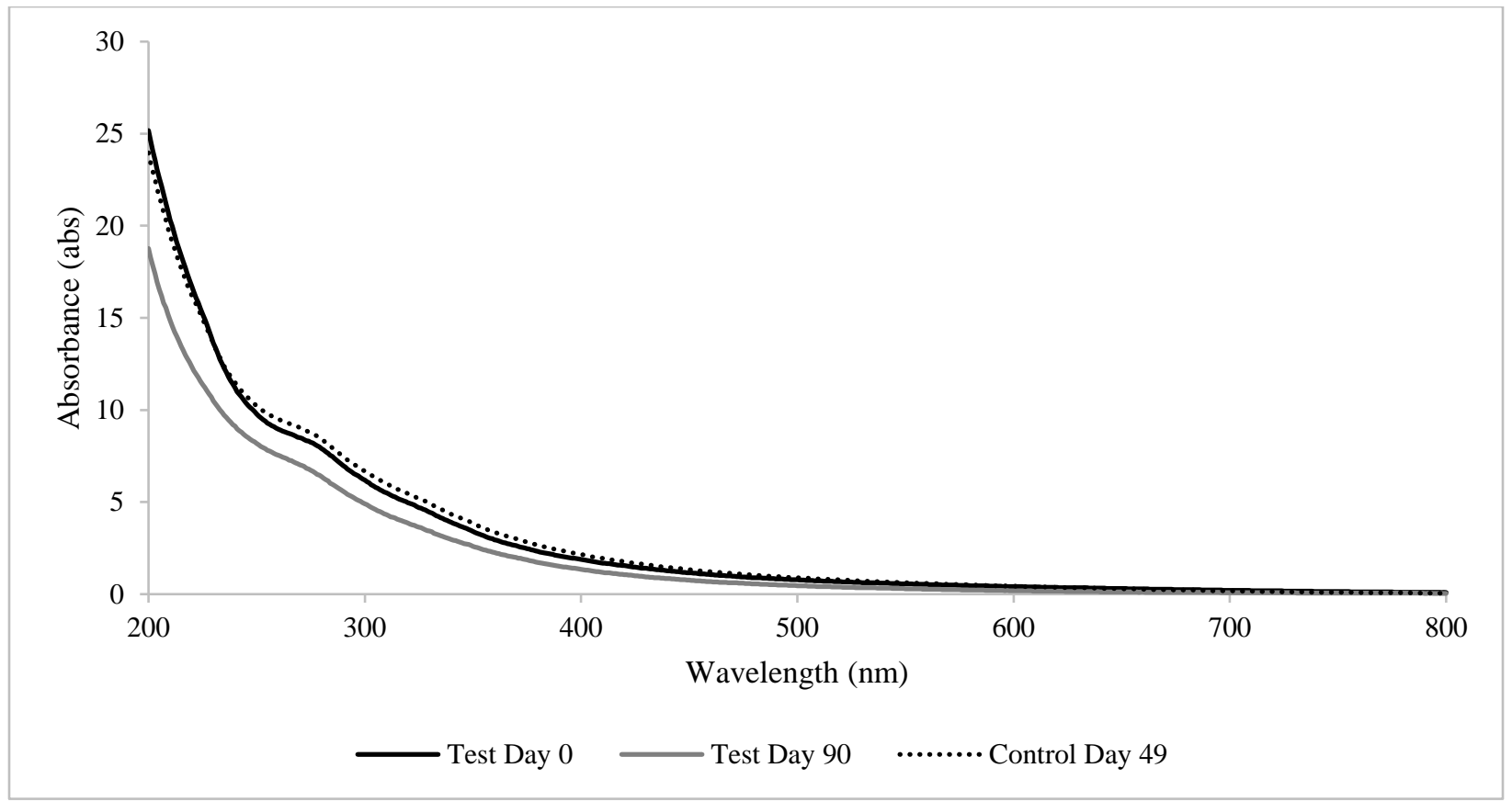

Figure C-18: Leachate G 1:10 Dilution Day 0 and Day 90 UV-Vis Scans

(*1:10 dilution control bag broke on day 49 of experimental test) 


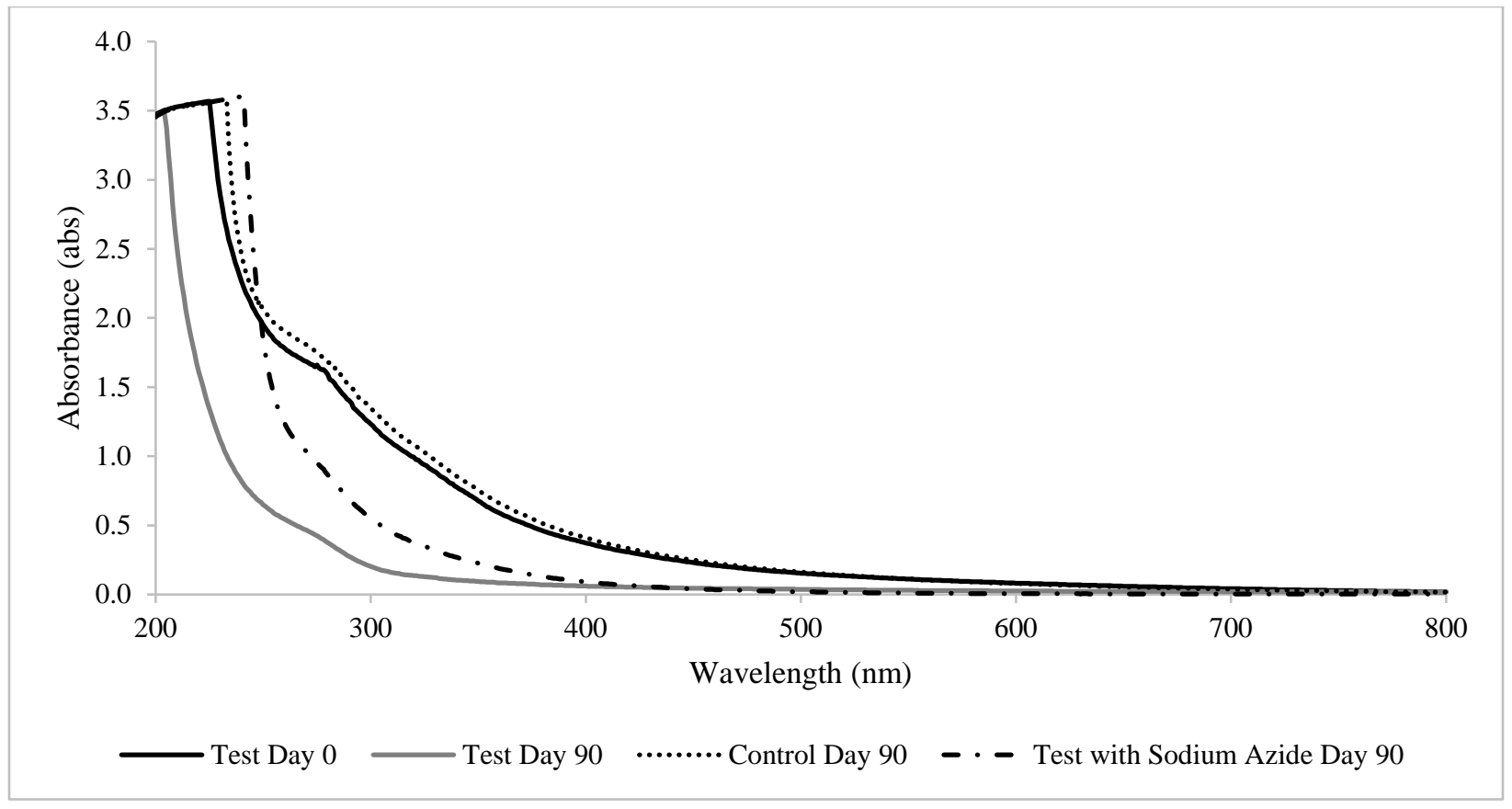

Figure C-19: Leachate G 1:50 Dilution Day 0 and Day 90 UV-Vis Scans

Leachate $\mathrm{H}$

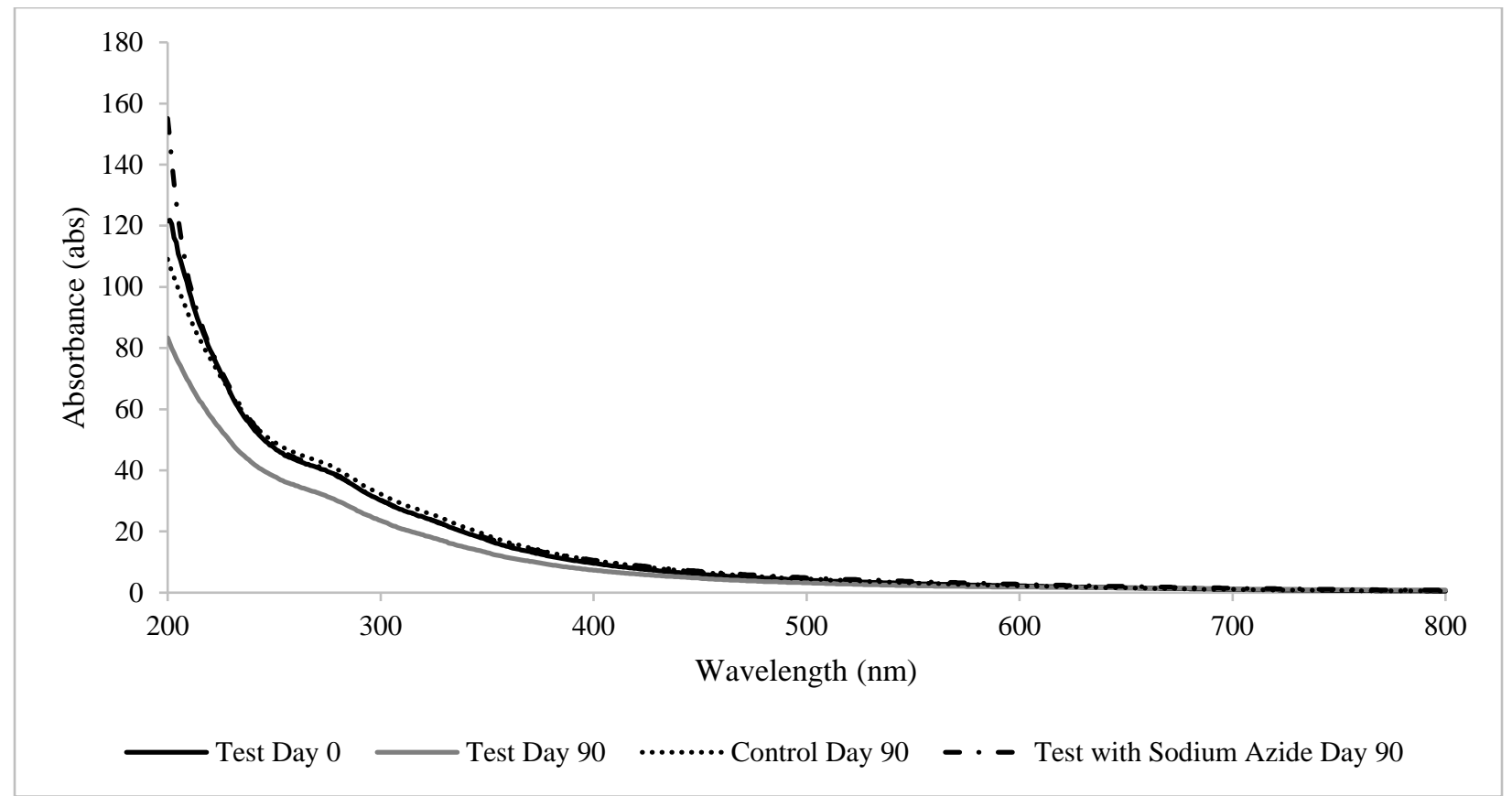

Figure C-20: Leachate H No Dilution Day 0 and Day 90 UV-Vis Scans 


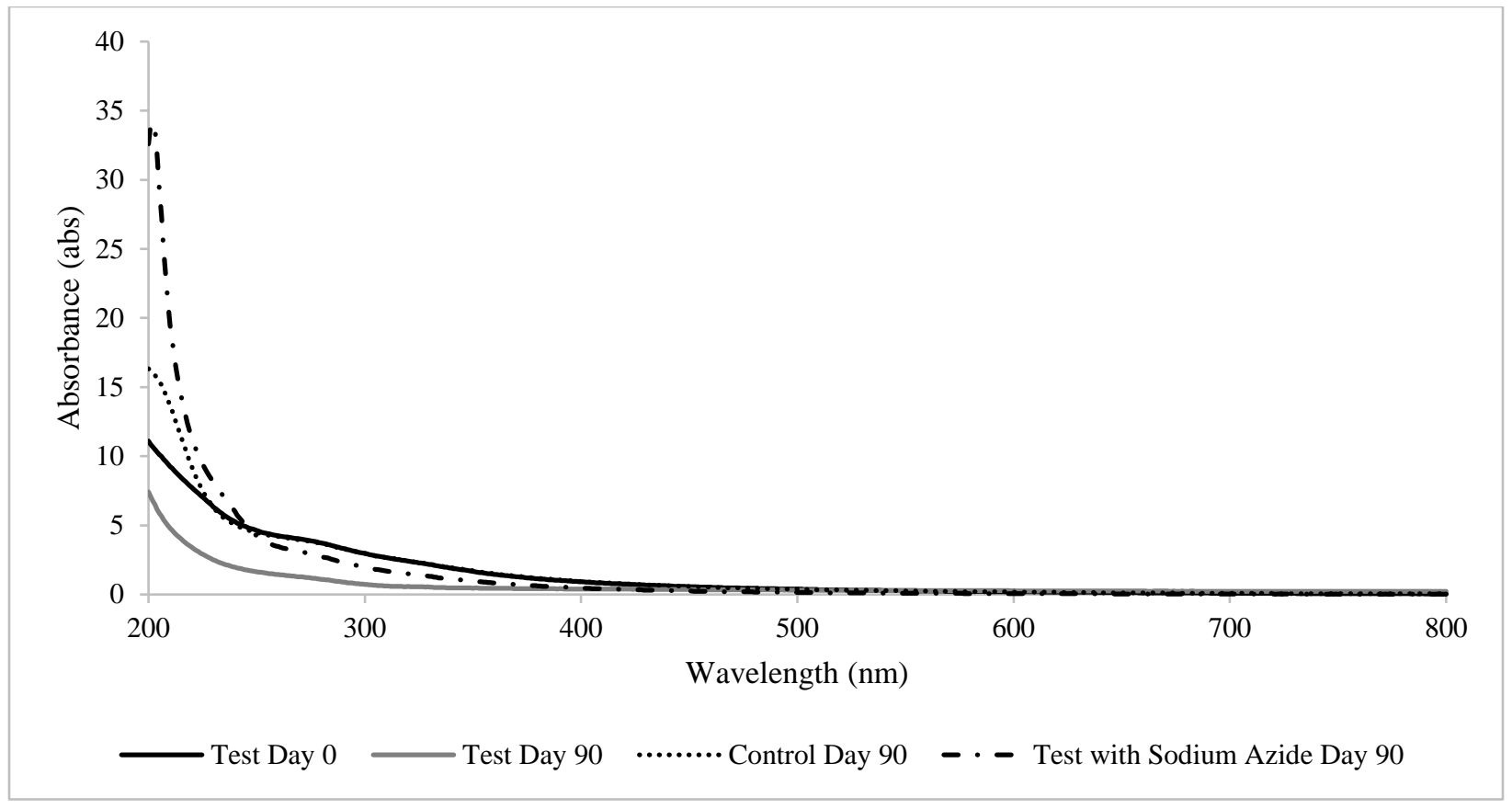

Figure C-21: Leachate H 1:10 No Dilution Day 0 and Day 90 UV-Vis Scans

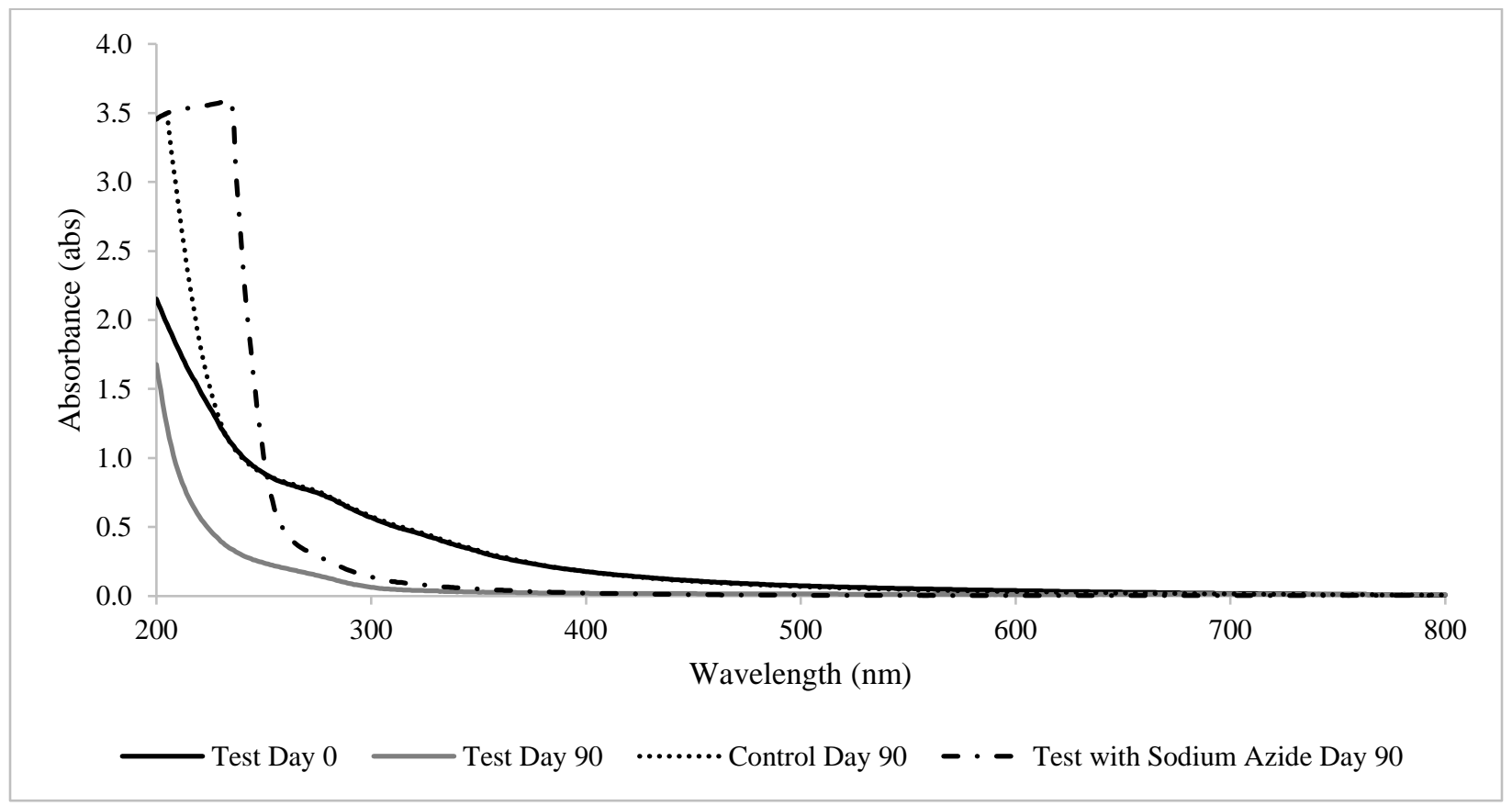

Figure C-22: Leachate H 1:50 Dilution Day 0 and Day 90 UV-Vis Scans 
APPENDIX D: $E_{2}: E_{3}$ RATIOS 


\section{$\underline{\text { Leachate A }}$}

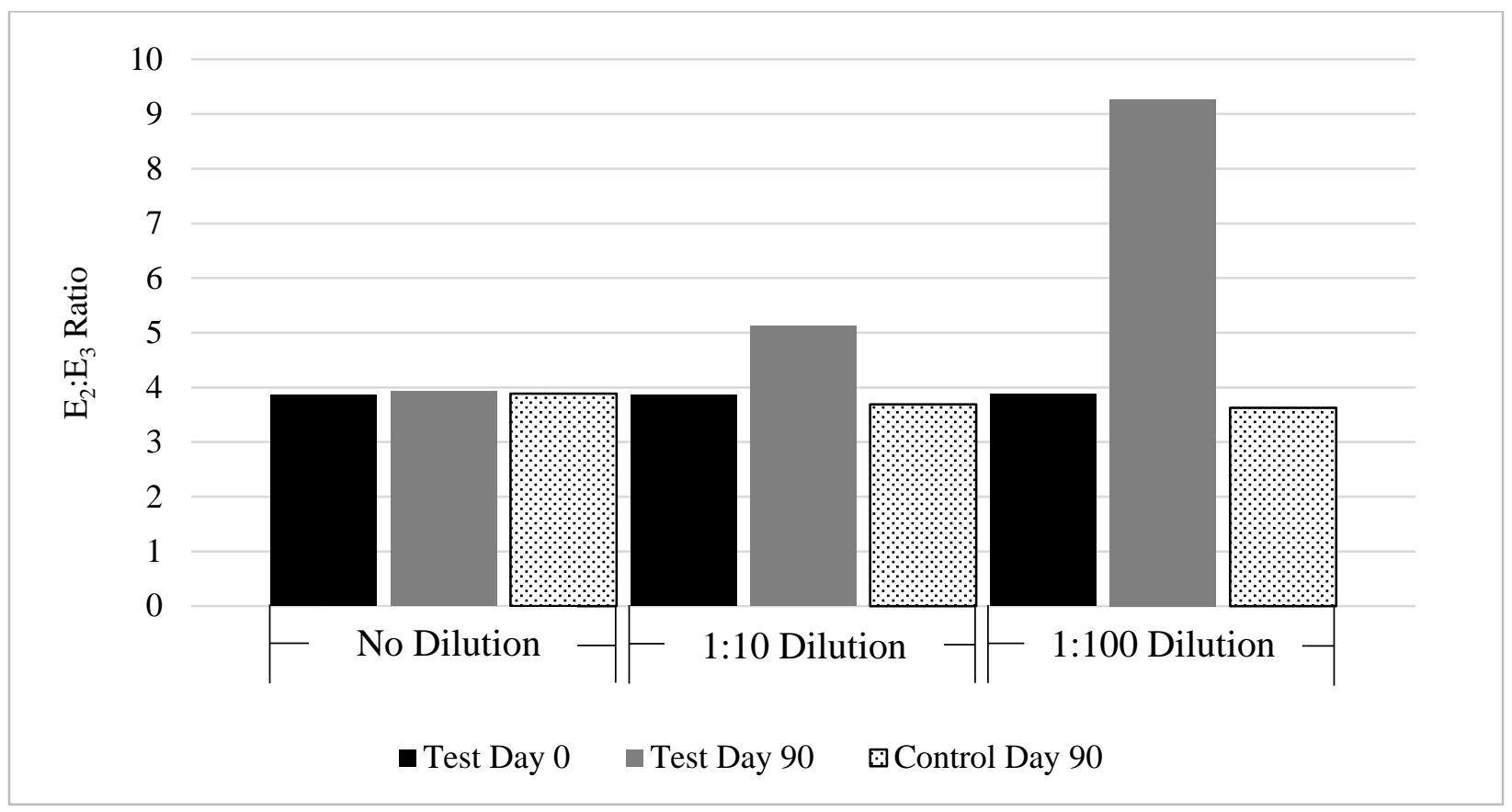

Figure D-1: Leachate A E2:E3 Ratios 


\section{Leachate B}

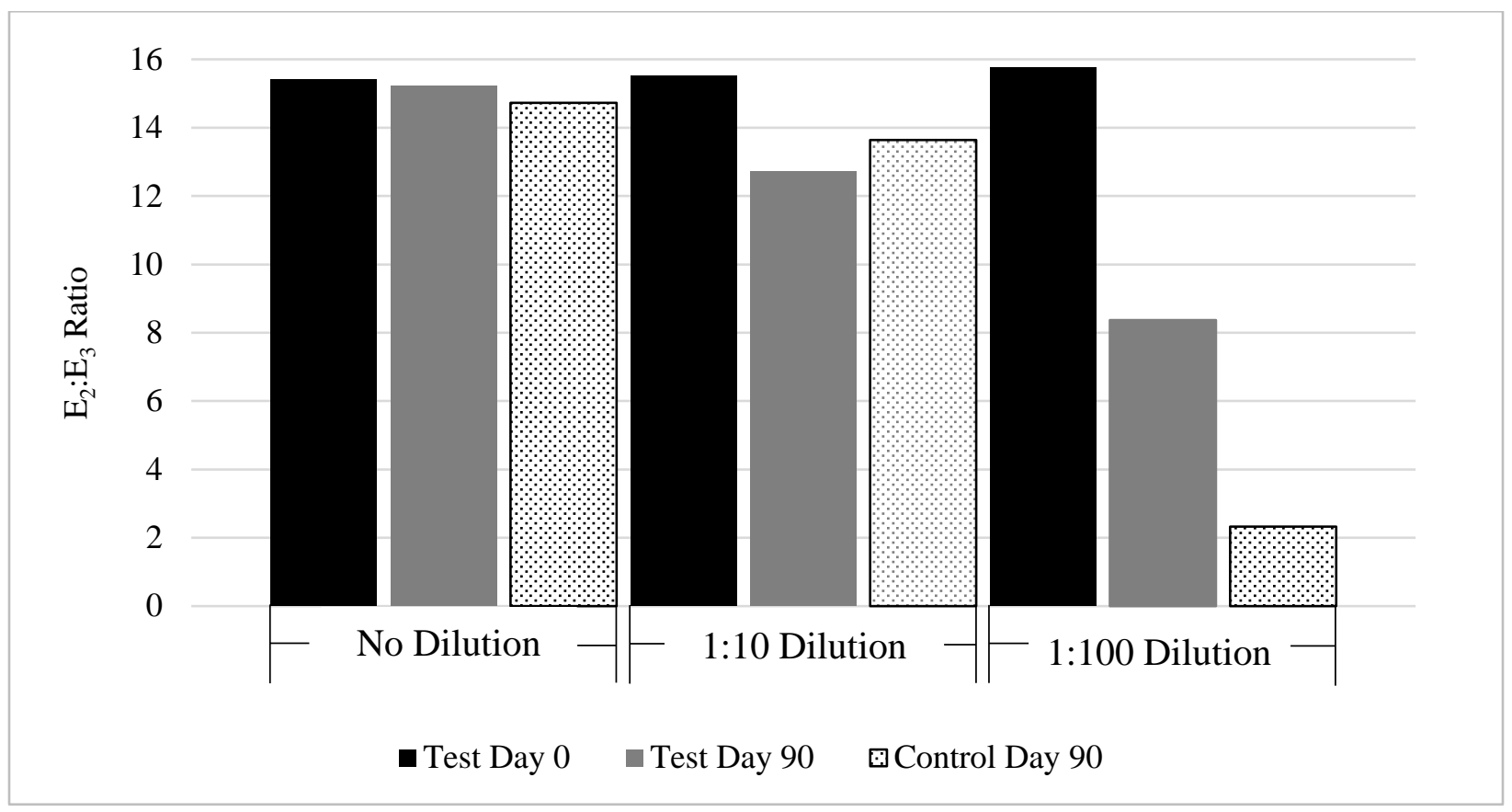

Figure D-2: Leachate B E2:E3 Ratios

(*1:100 dilution control bag broke on day 77 of experimental test, shown is day 77) 


\section{Leachate C}

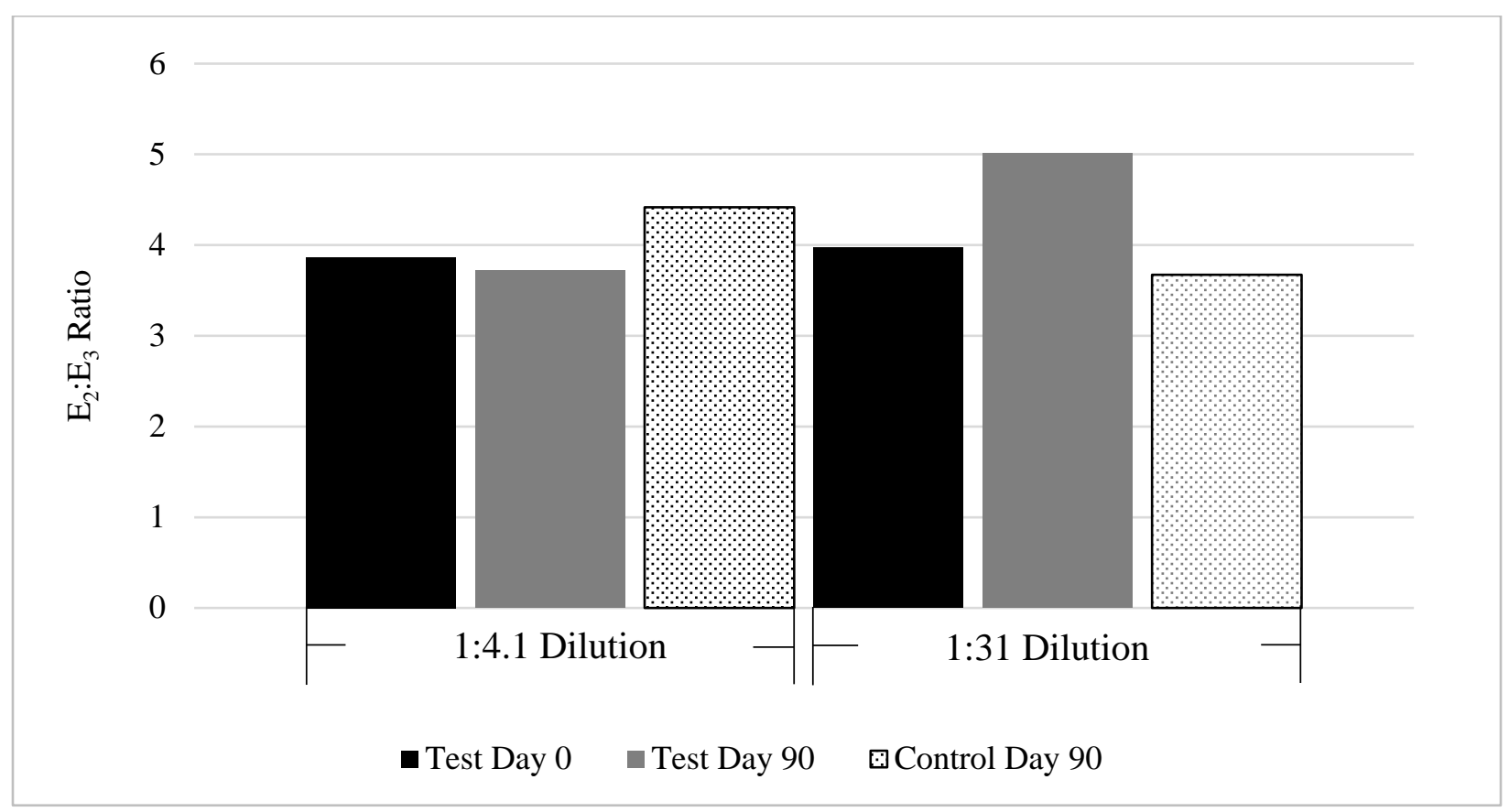

Figure D-3: Leachate C E2:Eз Ratios 


\section{Leachate D}

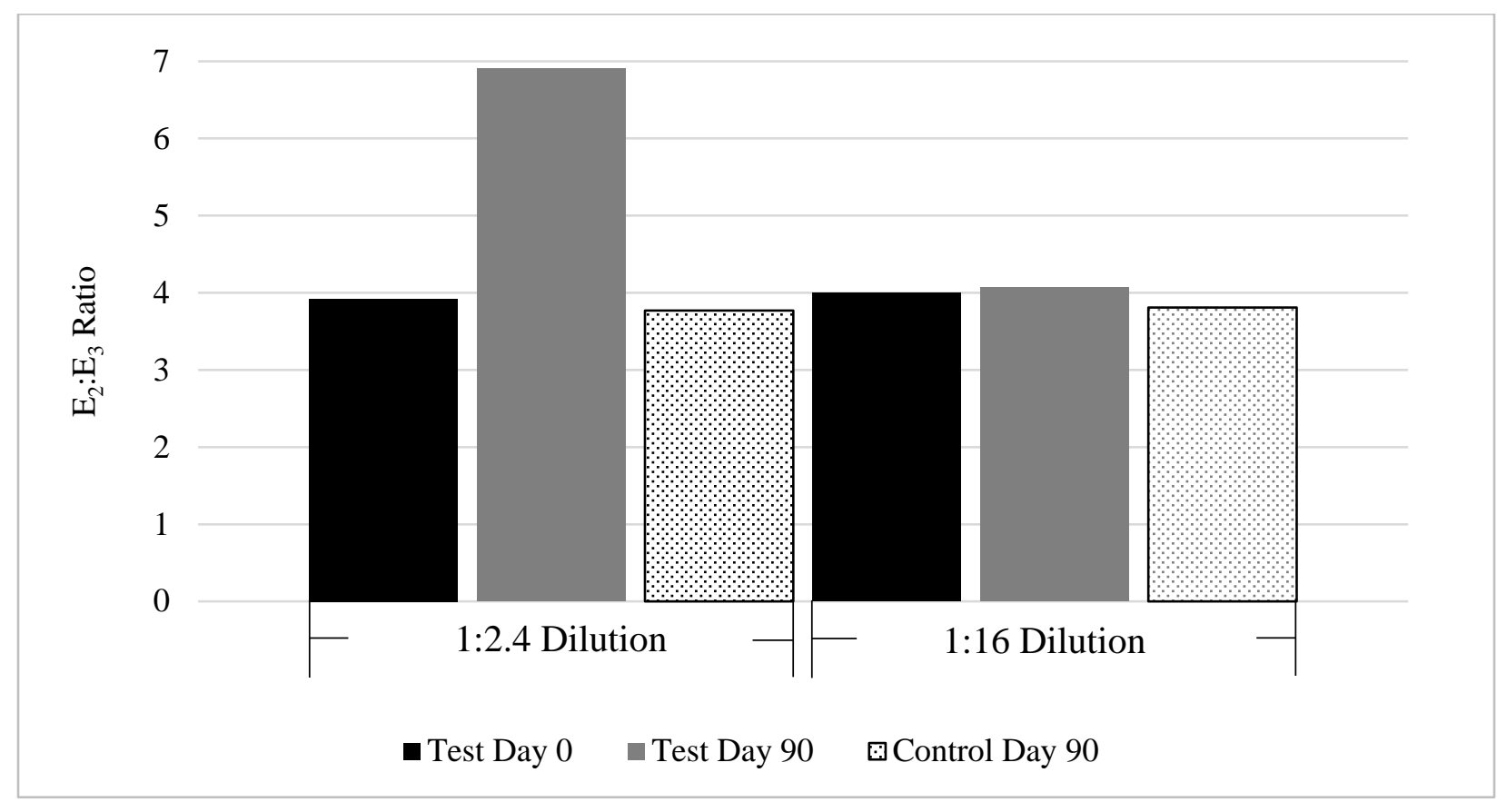

Figure D-4: Leachate D E2:E3 Ratios 


\section{Leachate E}

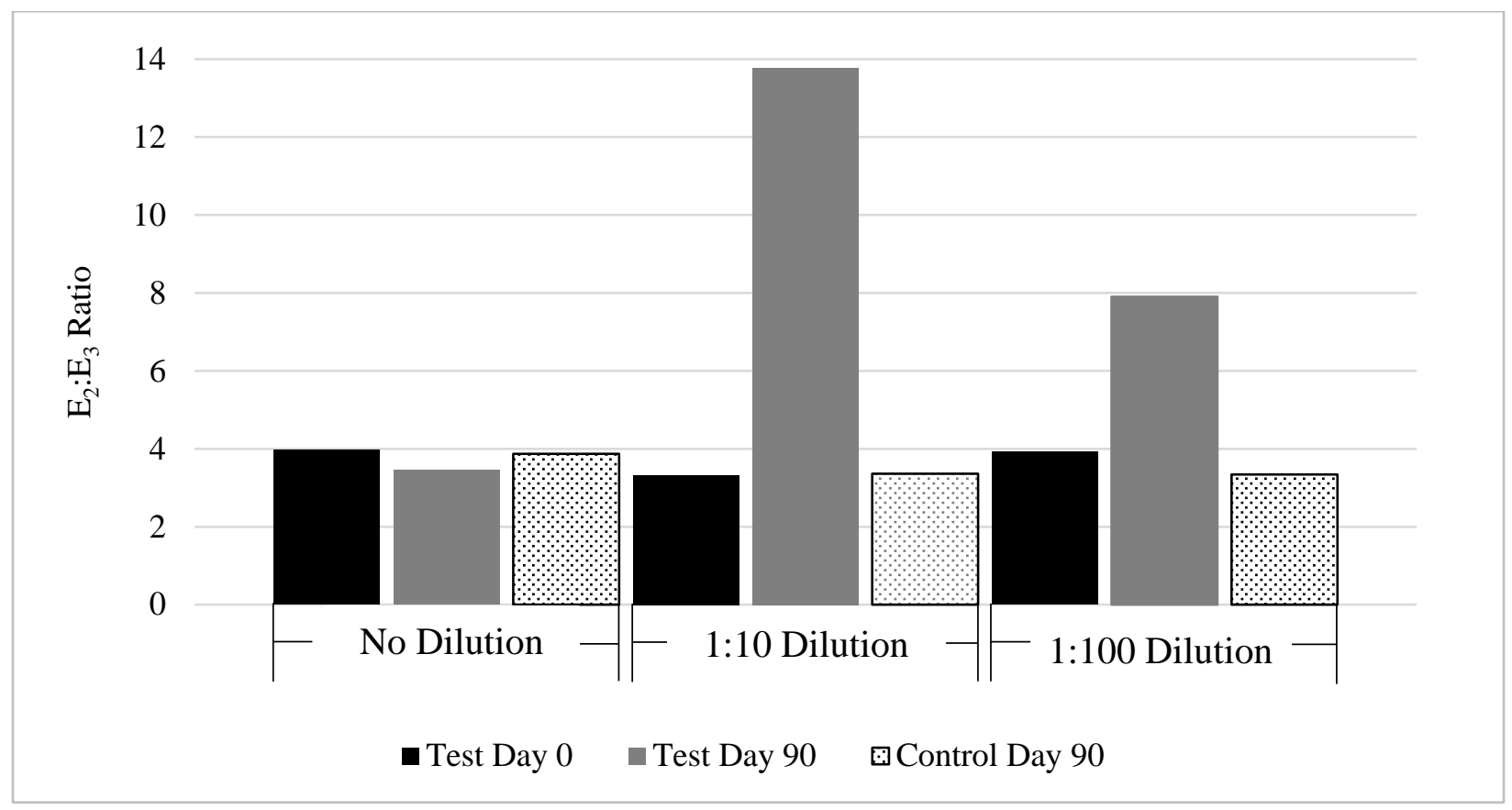

Figure D-5: Leachate E E2:E3 Ratios 


\section{Leachate F}

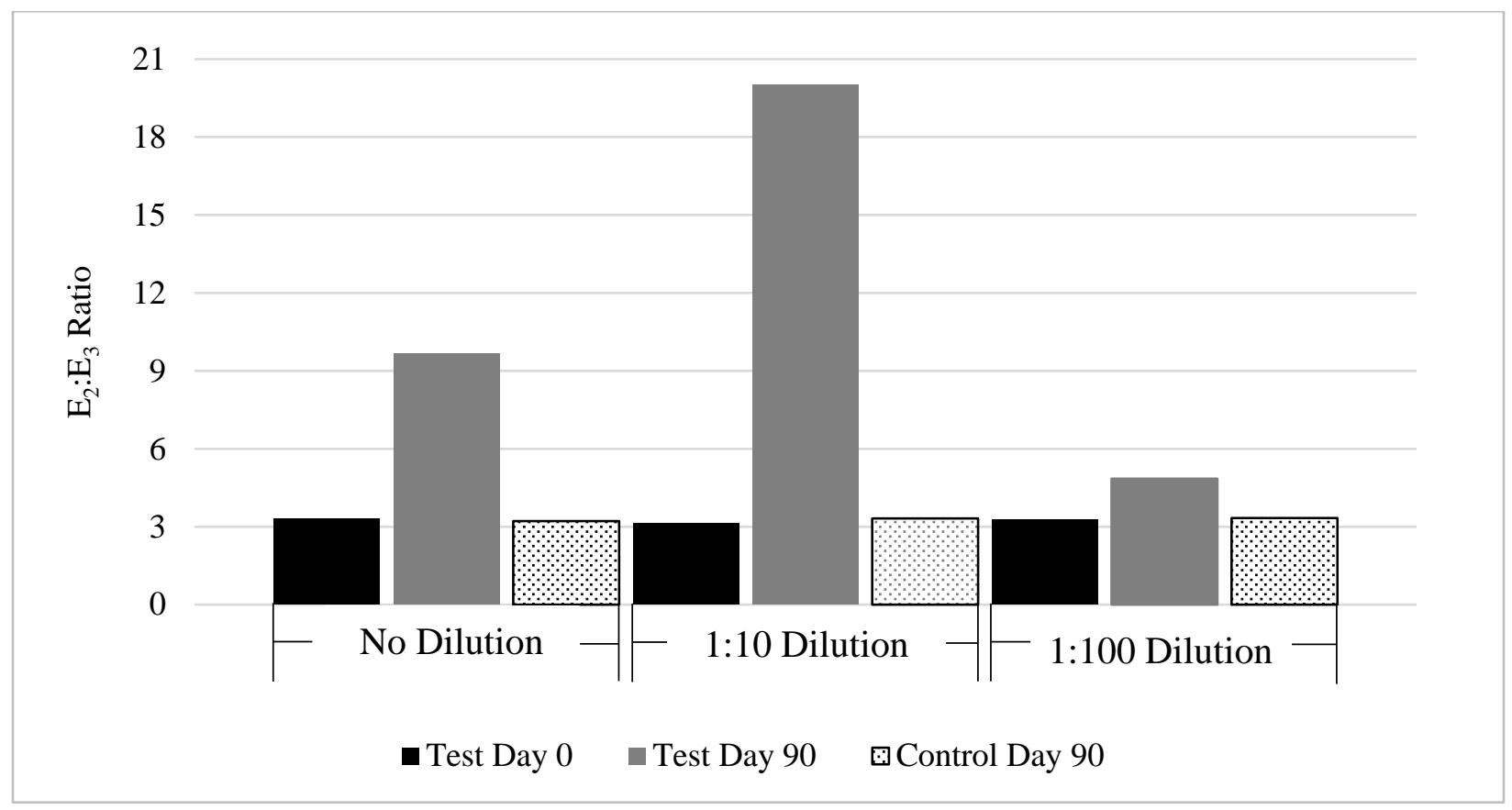

Figure D-6: Leachate F E2:E3 Ratios 


\section{Leachate G}

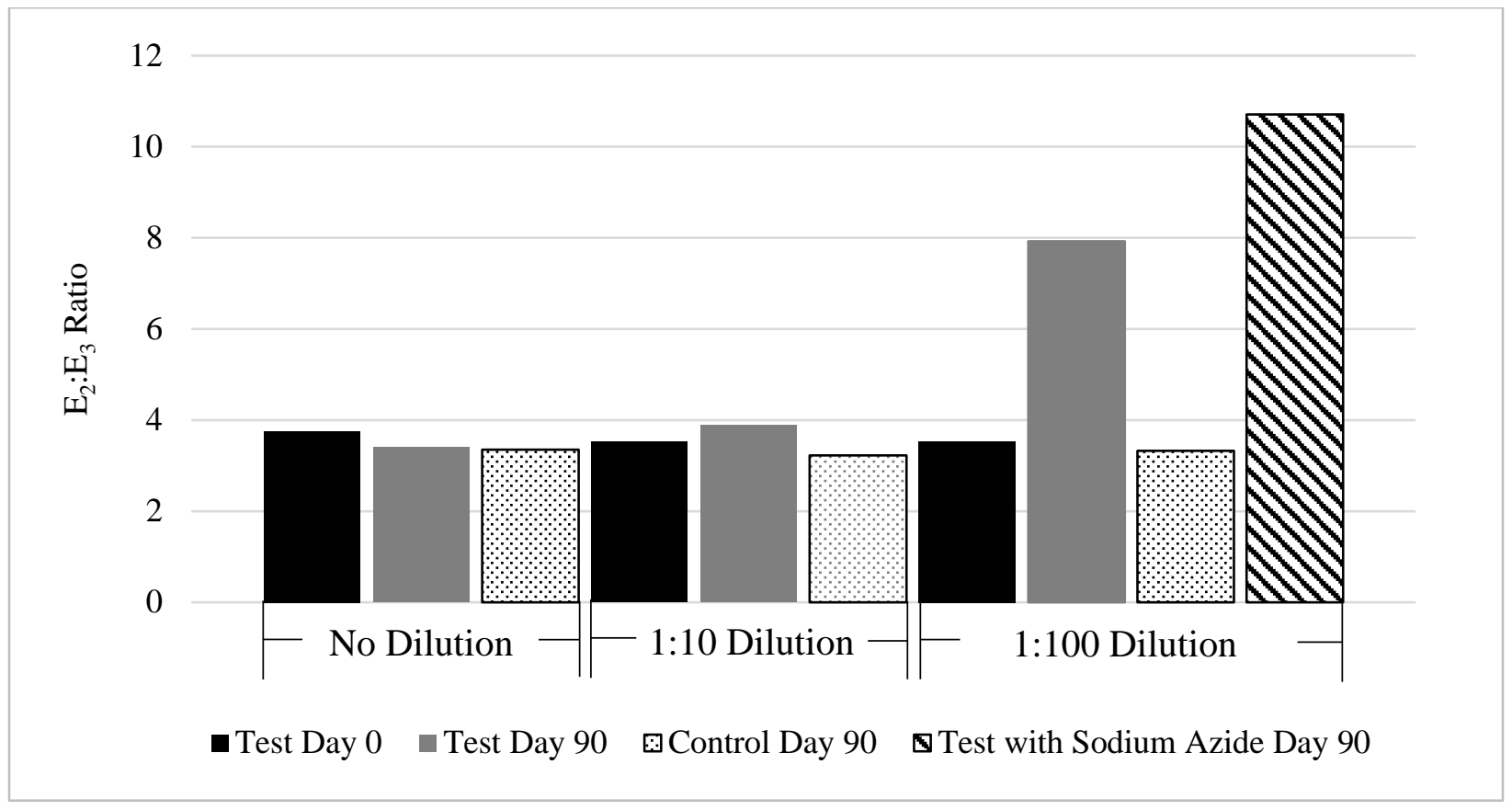

Figure D-7: Leachate G E2:E3 Ratios

(*1:10 control bag broke on day 49 of experimental test) 


\section{Leachate $\mathrm{H}$}

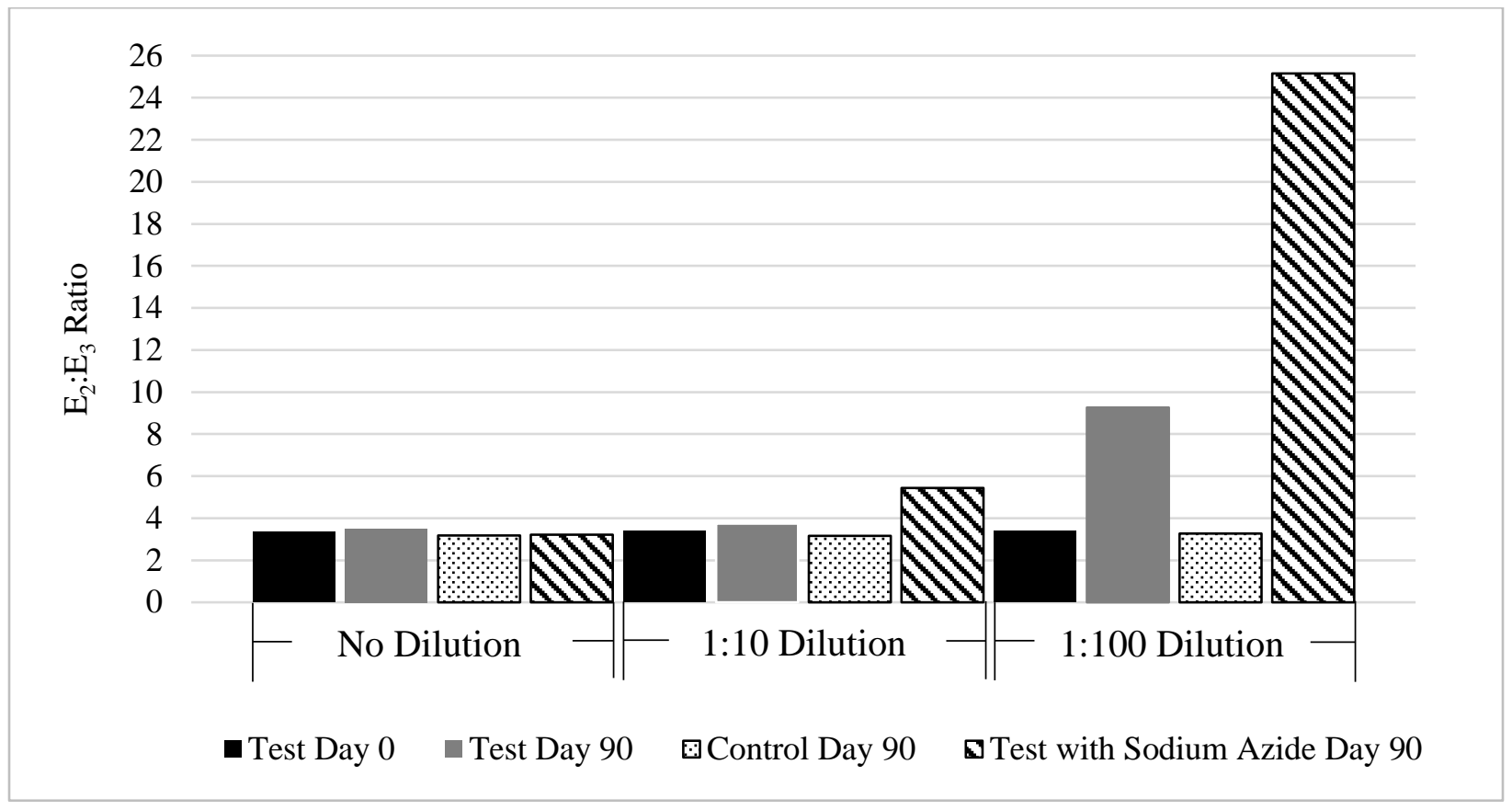

Figure D-8: Leachate H E2:E3 Ratios 
APPENDIX E: SLOPE RATIOS 


\section{Leachate A}

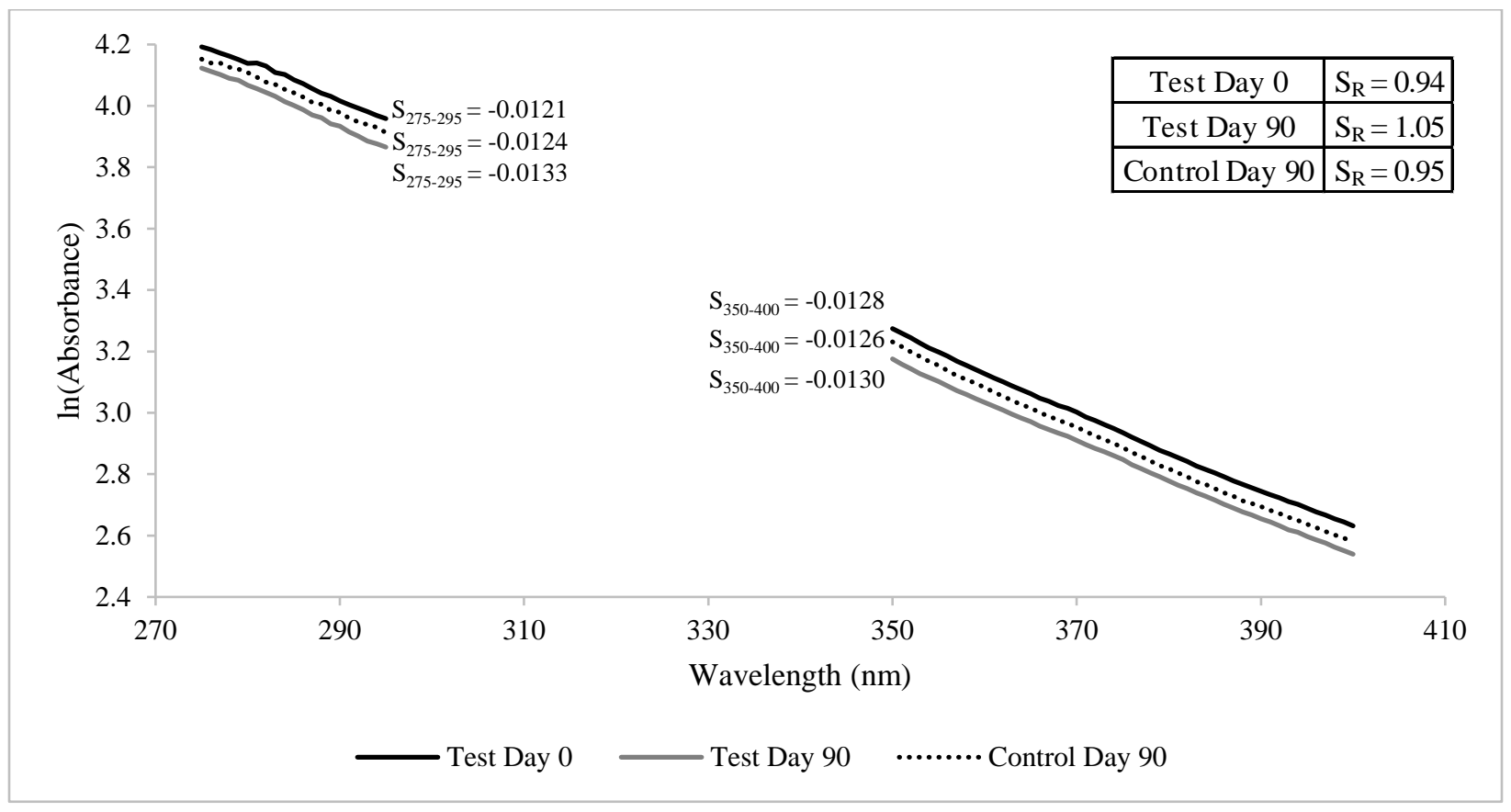

Figure E-1: Leachate A No Dilution Day 0 and Day 90 Slope Ratios

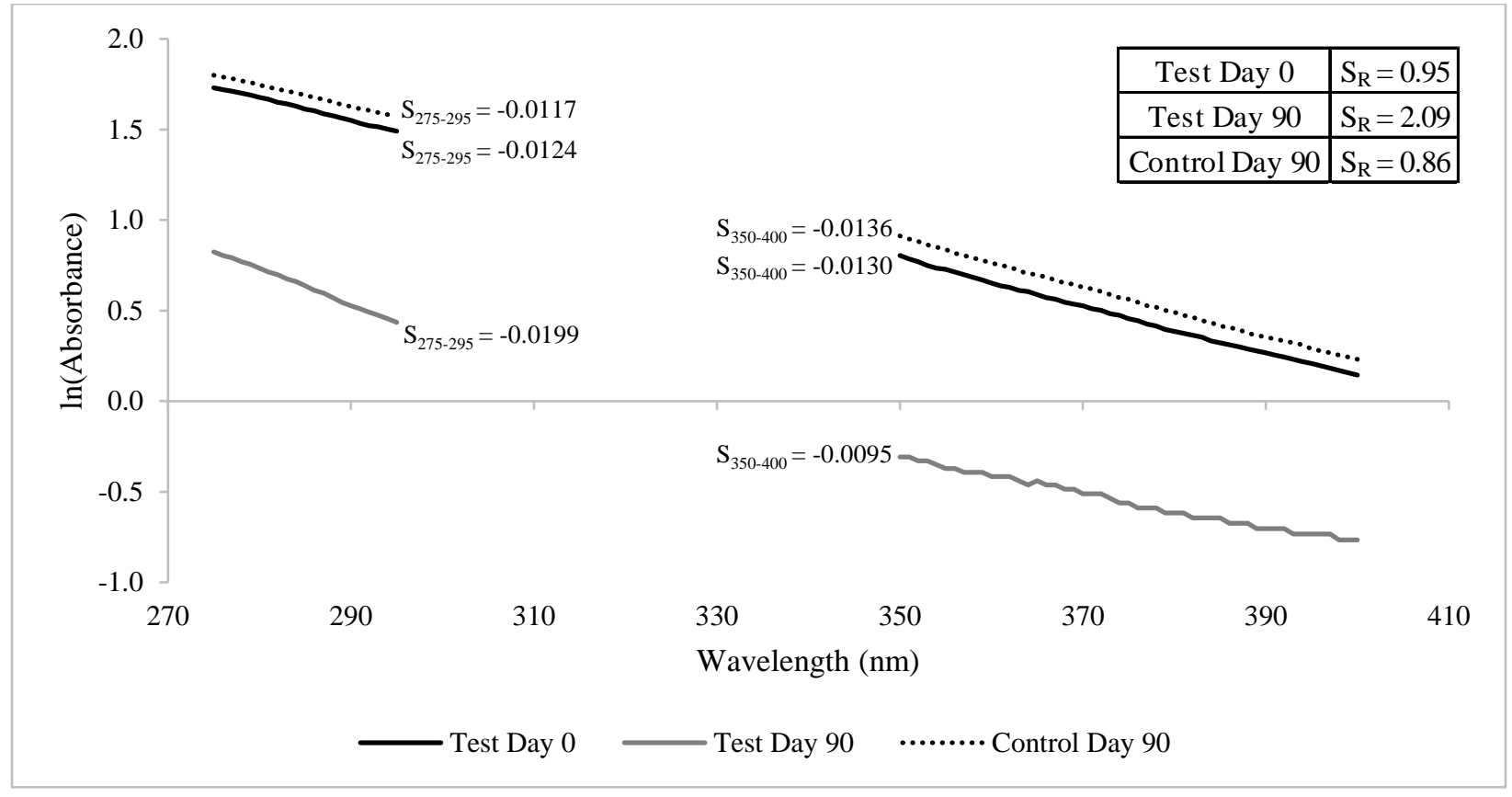

Figure E-2: Leachate A 1:10 Dilution Day 0 and Day 90 Slope Ratios 


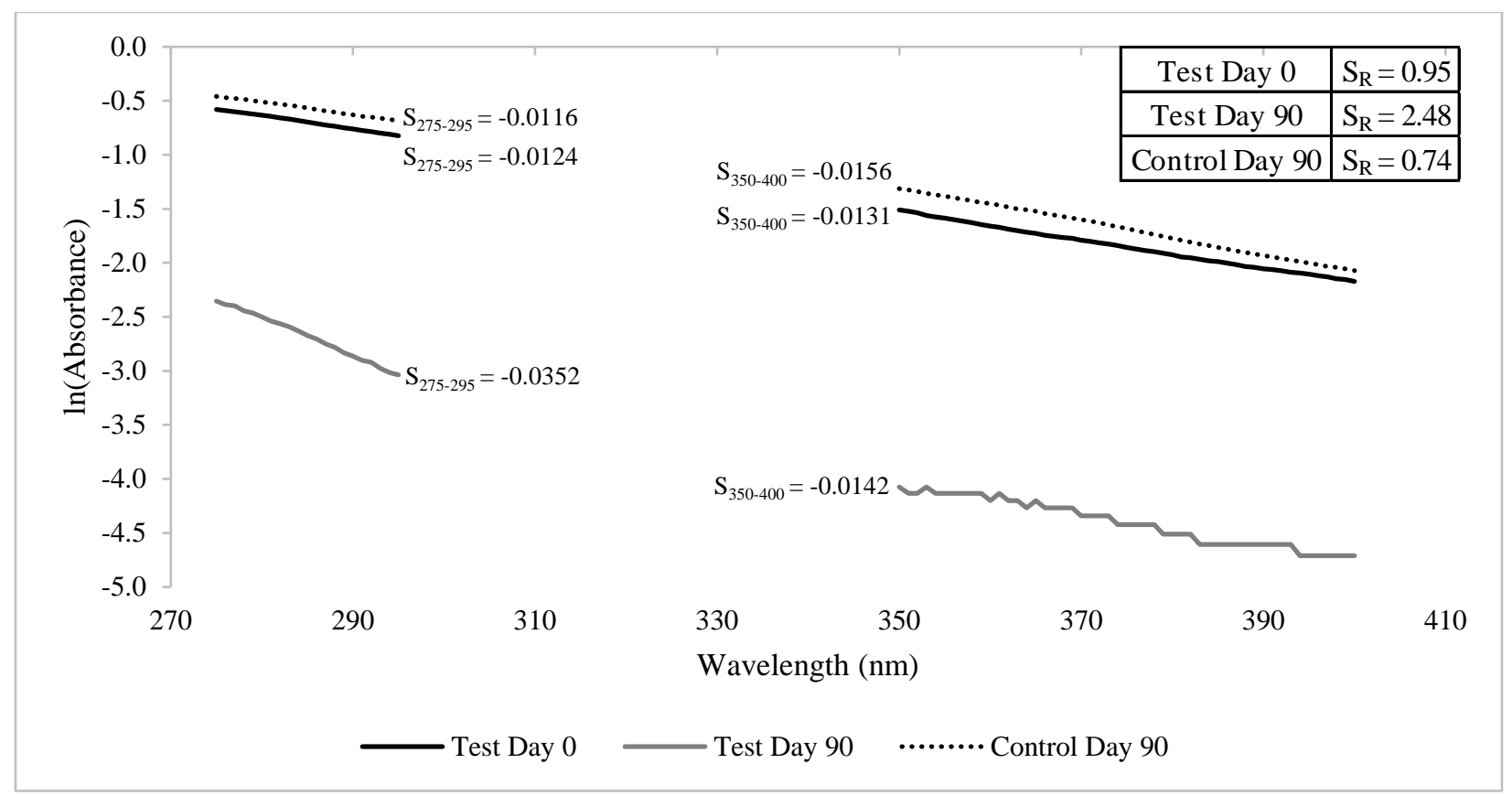

Figure E-3: Leachate A 1:100 Dilution Day 0 and Day 90 Slope Ratios

\section{Leachate B}

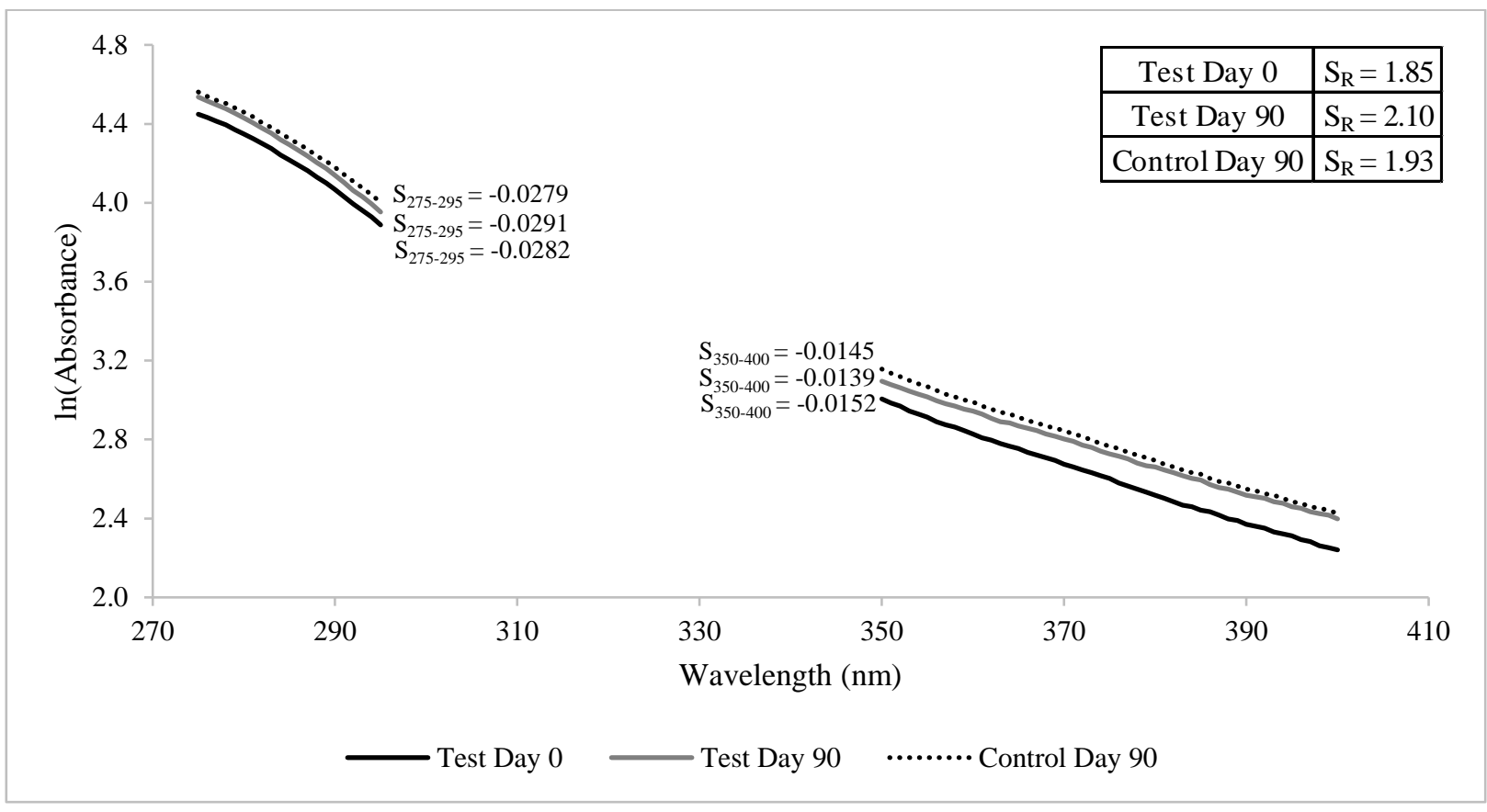

Figure E-4: Leachate B No Dilution Day 0 and Day 90 Slope Ratios 


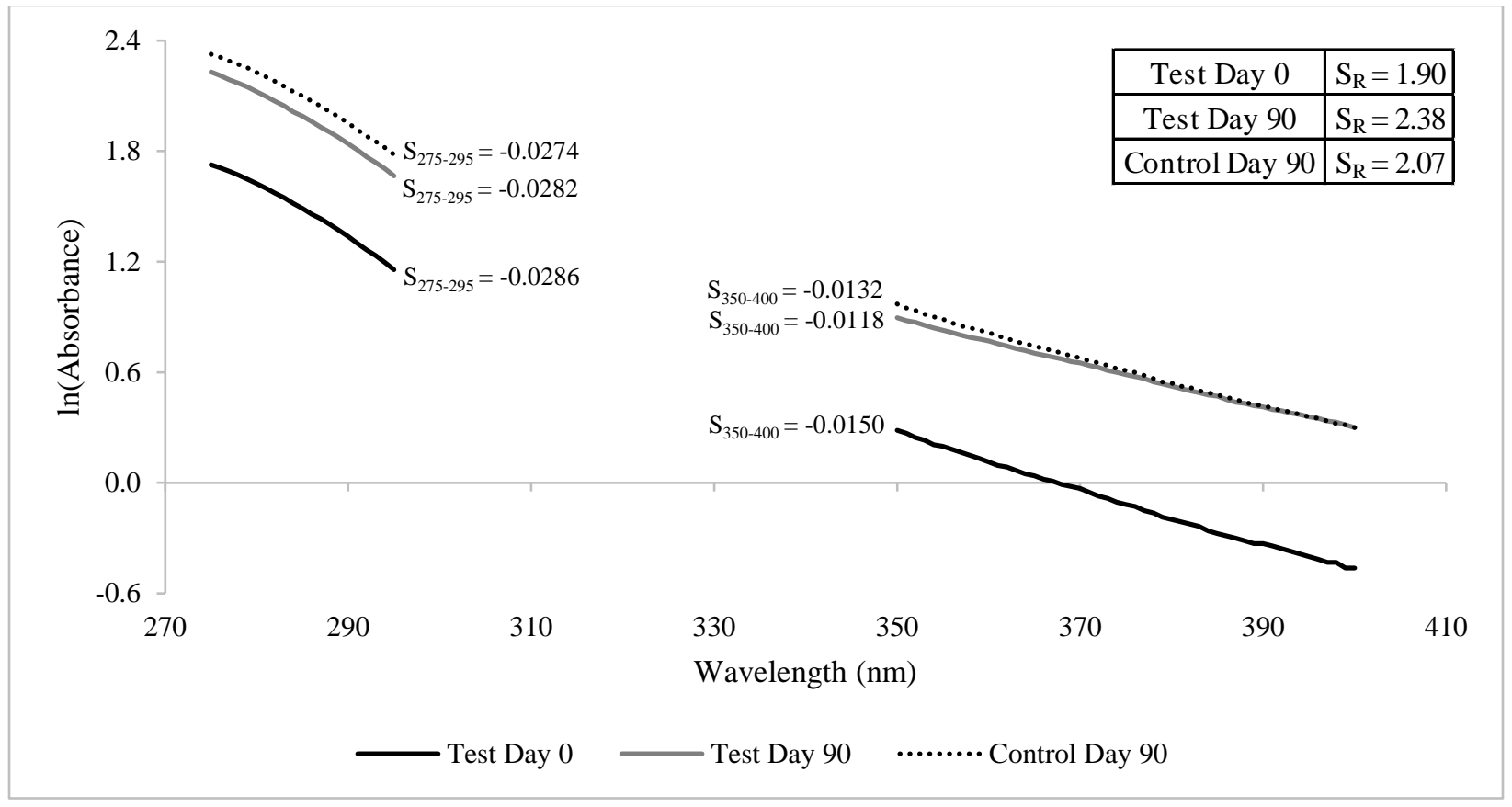

Figure E-5: Leachate B 1:10 Dilution Day 0 and Day 90 Slope Ratios

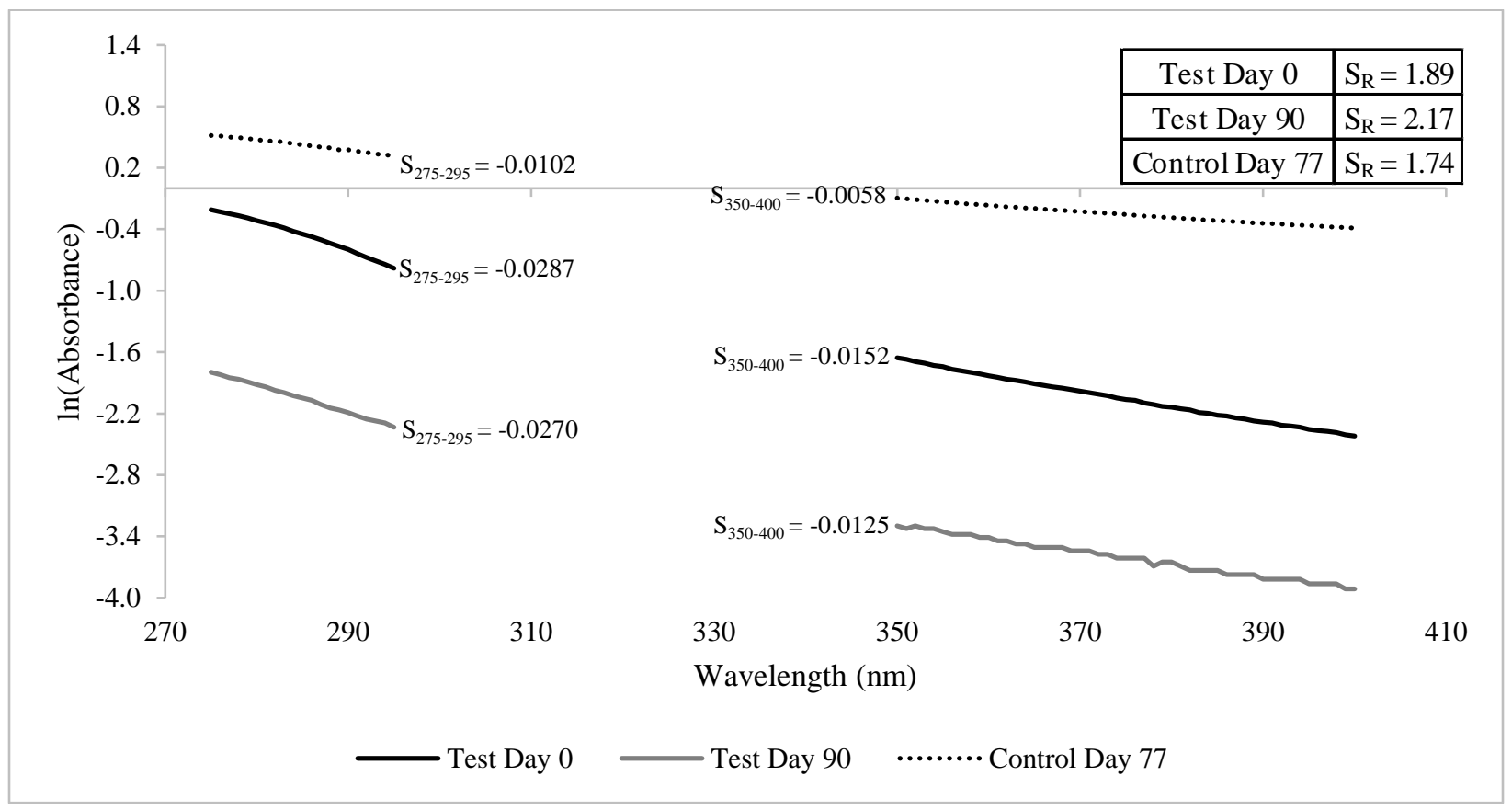

Figure E-6: Leachate B 1:100 Dilution Day 0 and Day 90 Slope Ratios

(*1:100 dilution control bag broke on day 77 of experimental test) 


\section{Leachate C}

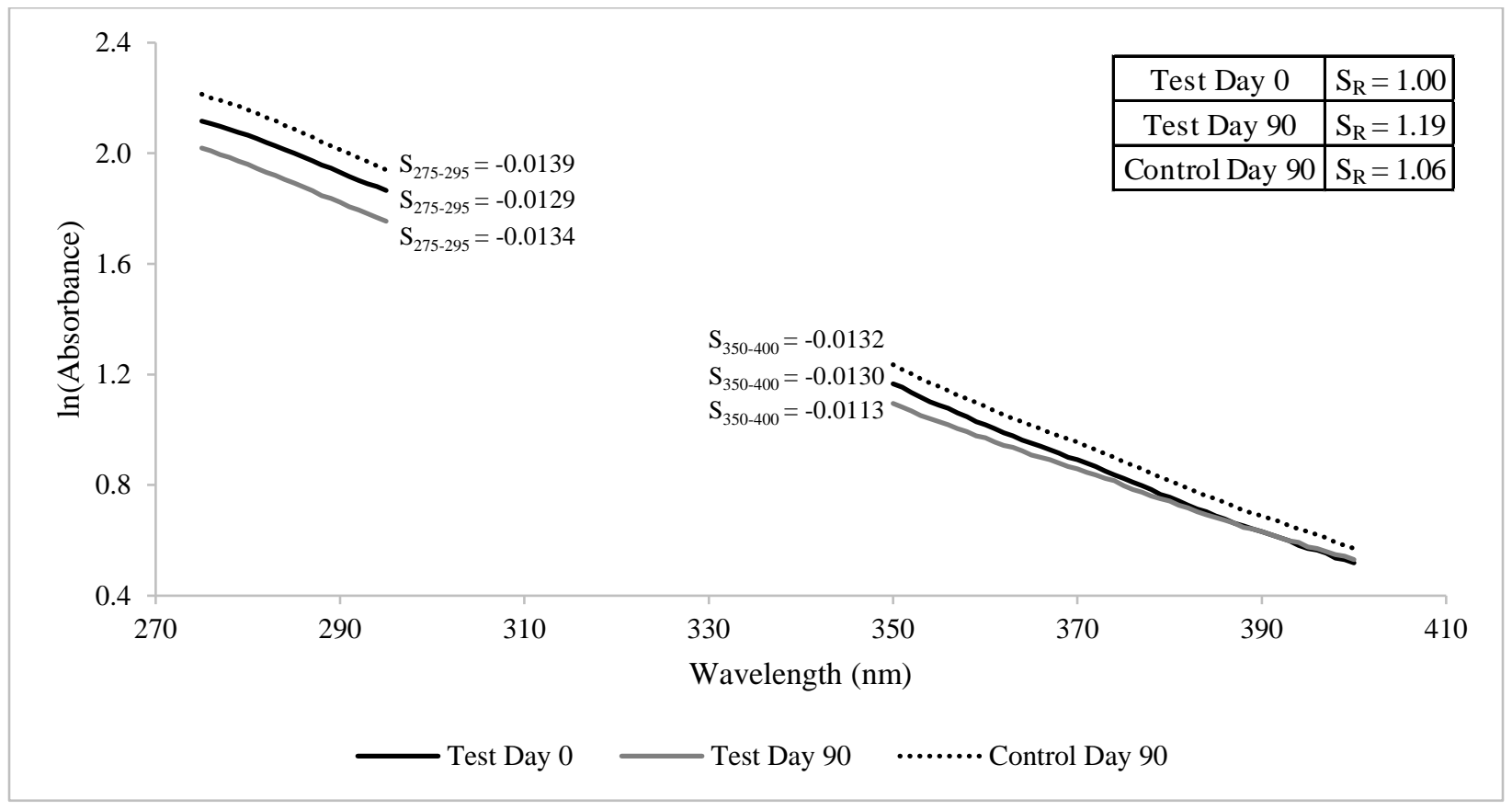

Figure E-7: Leachate C 1:4.1 Dilution Day 0 and Day 90 Slope Ratios

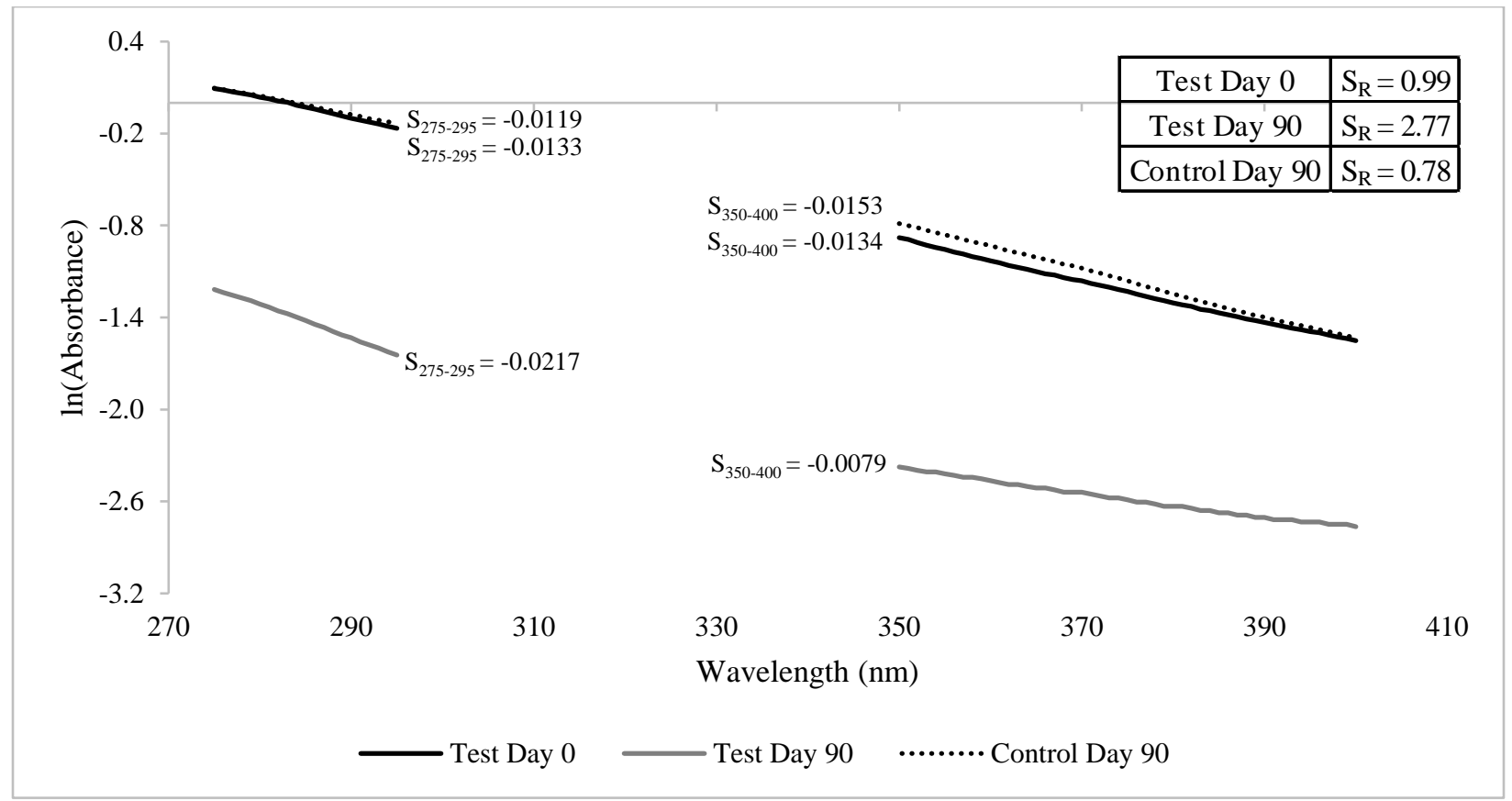

Figure E-8: Leachate C 1:31 Dilution Day 0 and Day 90 Slope Ratios 


\section{Leachate D}

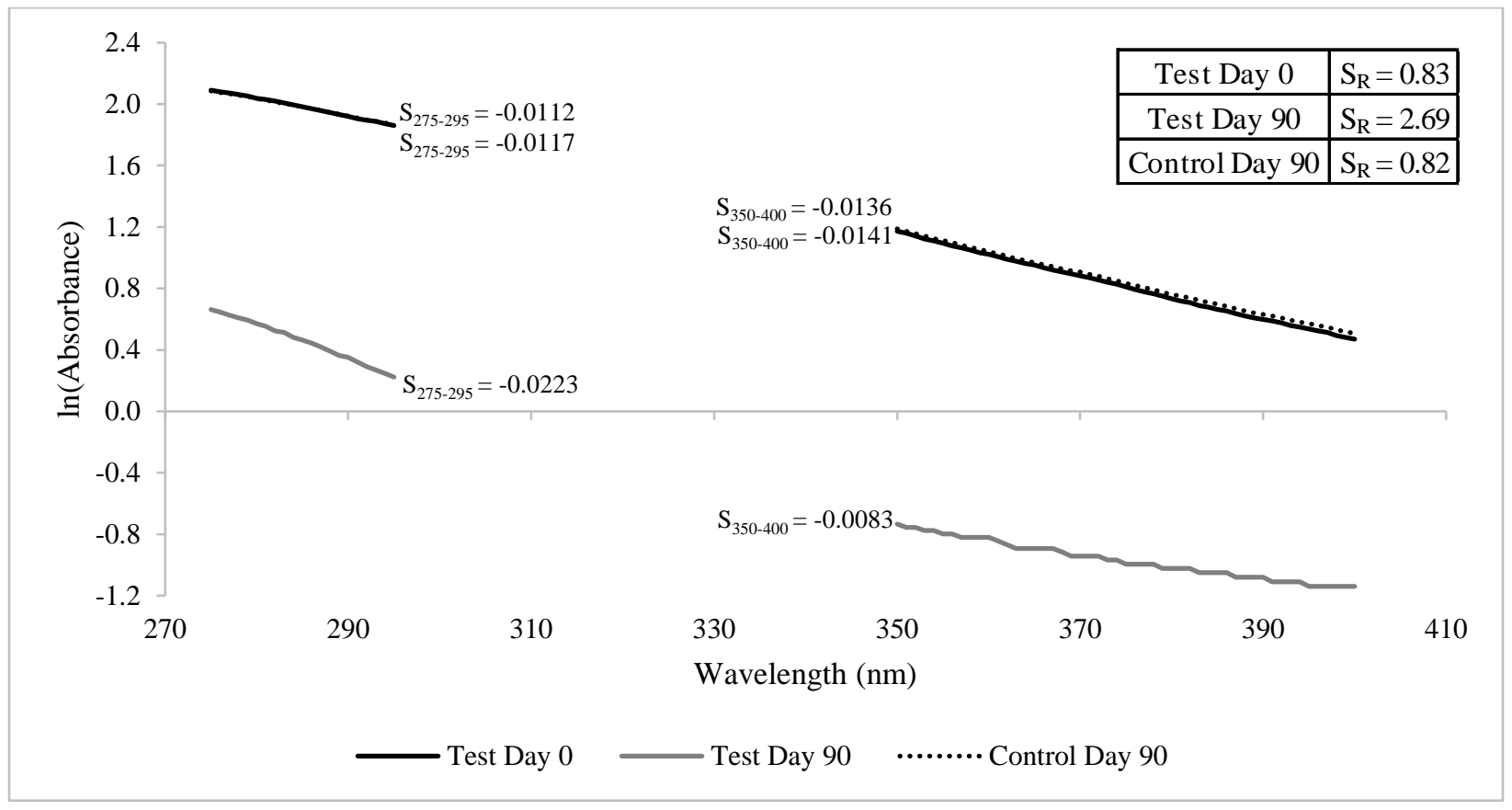

Figure E-9: Leachate D 1:2.4 Dilution Day 0 and Day 90 Slope Ratios

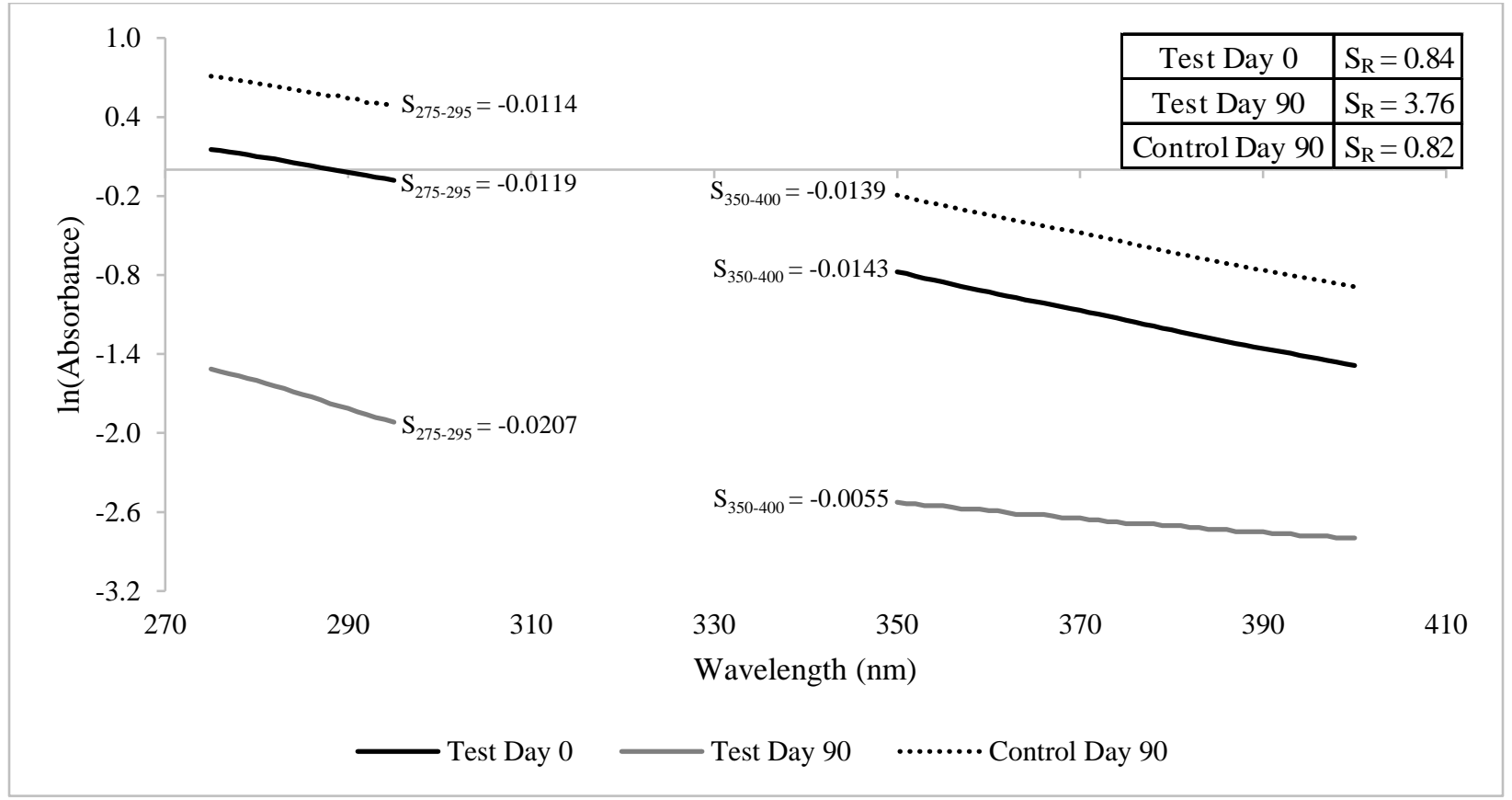

Figure E-10: Leachate D 1:16 Dilution Day 0 and Day 90 Slope Ratios 


\section{Leachate E}

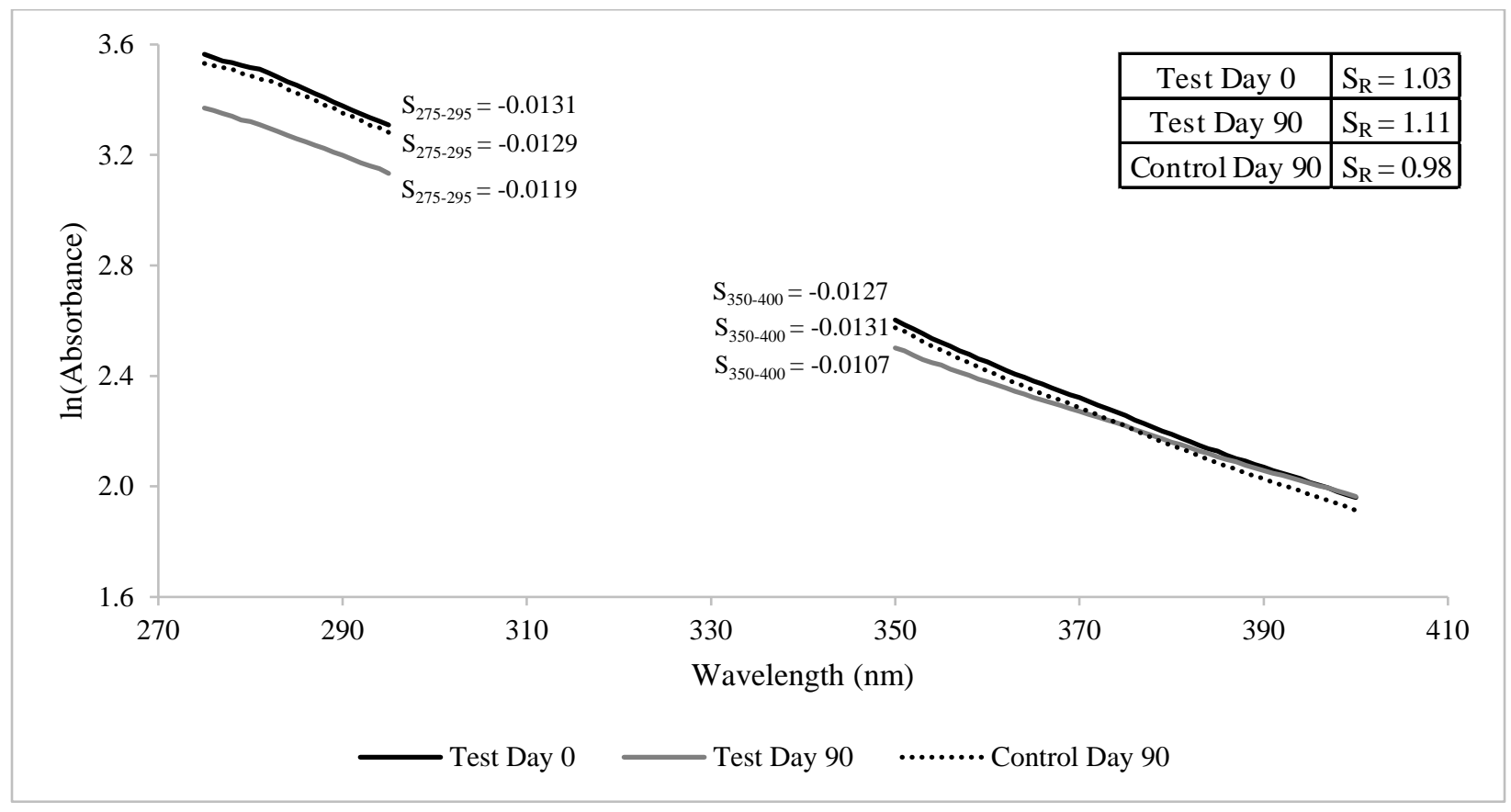

Figure E-11: Leachate E No Dilution Day 0 and Day 90 Slope Ratios

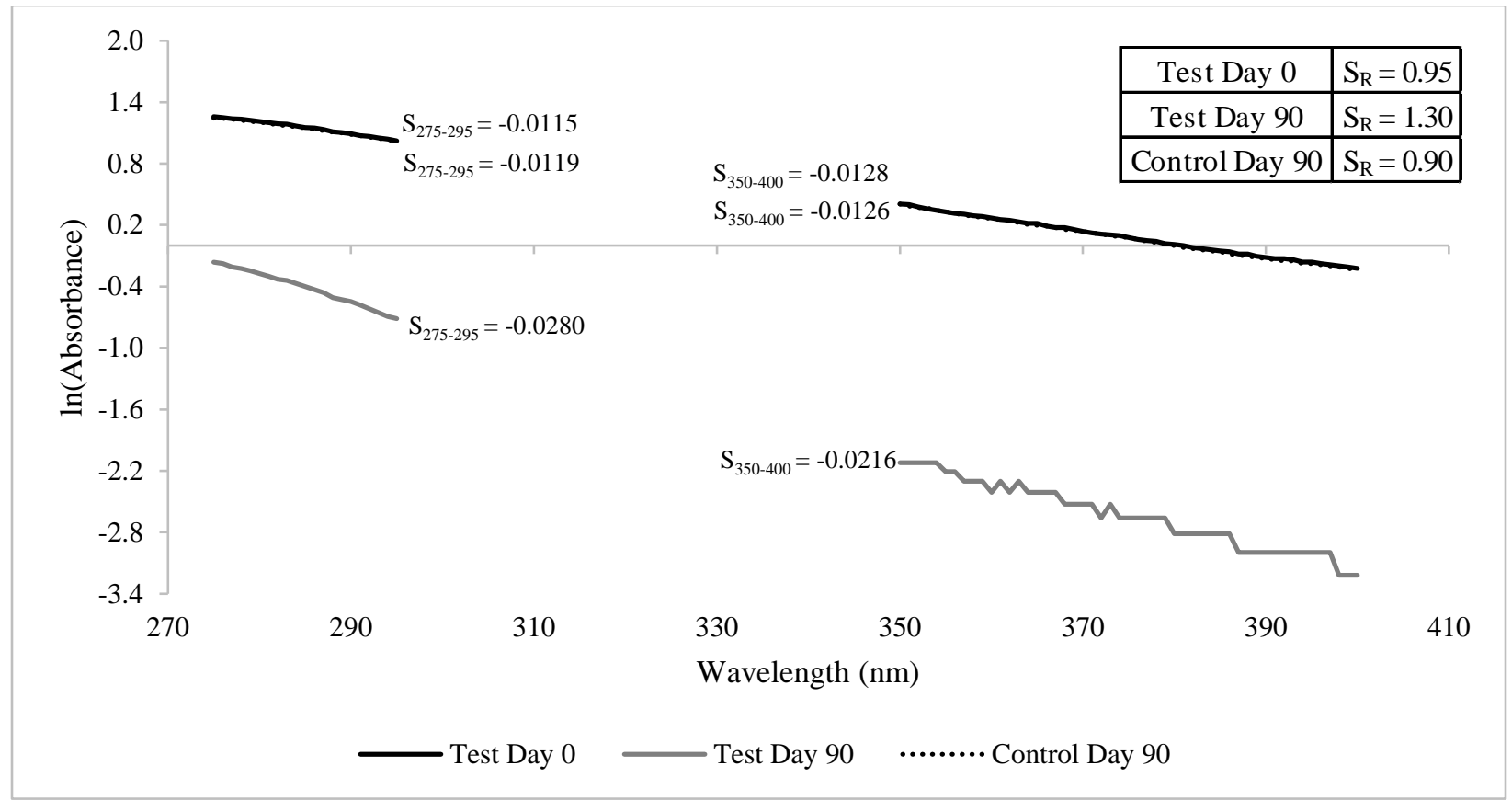

Figure E-12: Leachate E 1:10 Dilution Day 0 and Day 90 Slope Ratios 


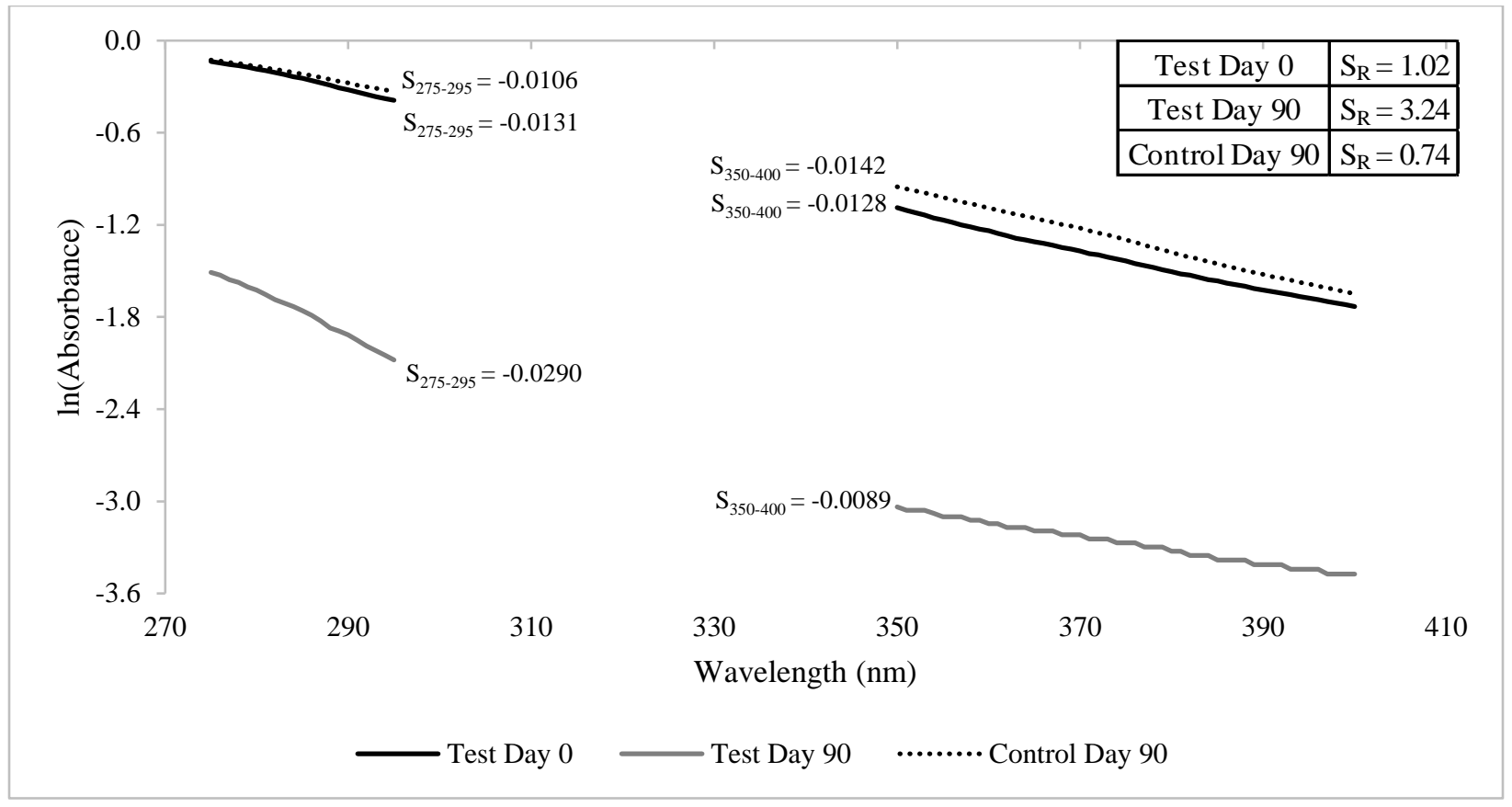

Figure E-13: Leachate E 1:40 Dilution Day 0 and Day 90 Slope Ratios

Leachate F

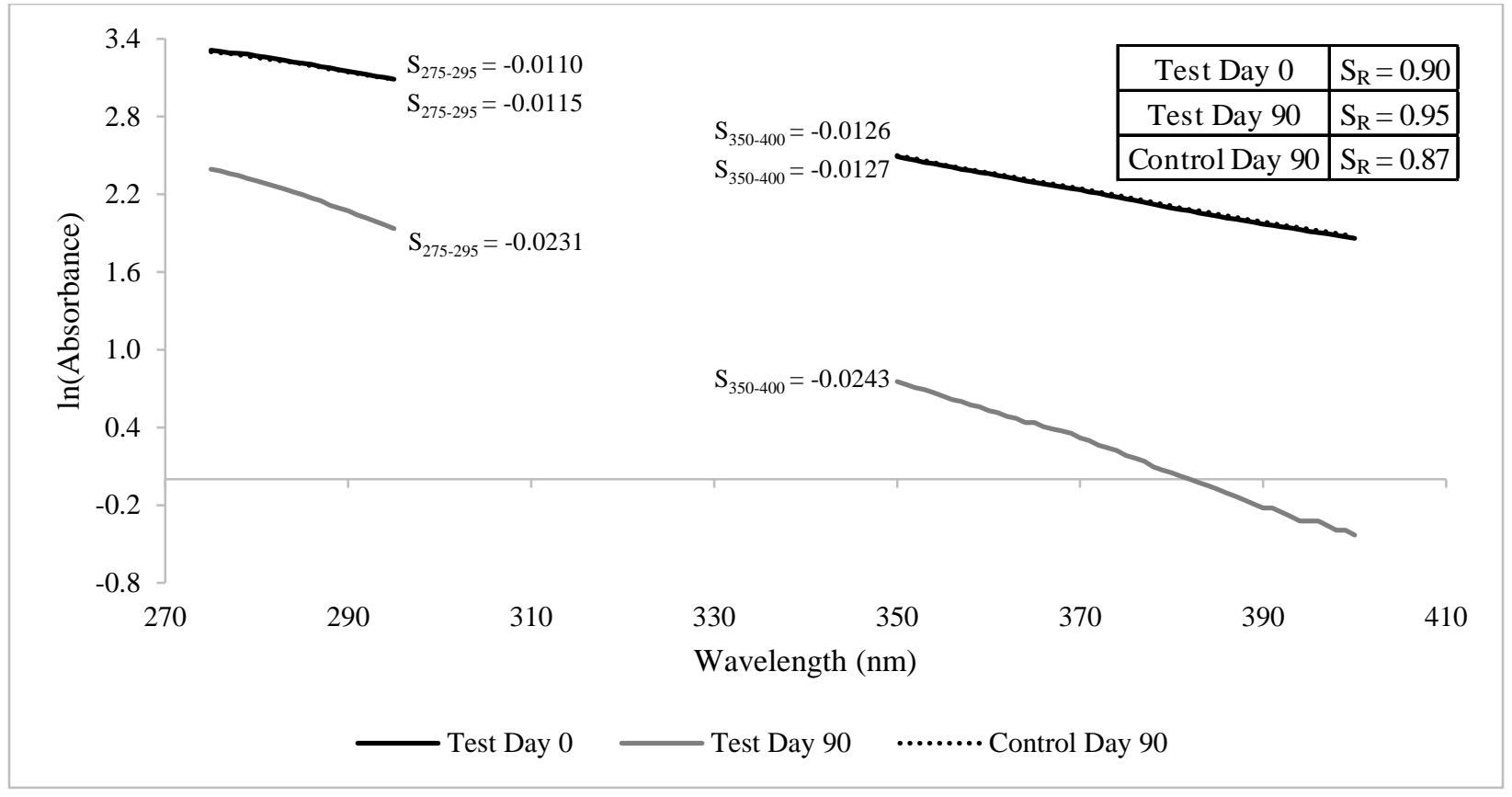

Figure E-14: Leachate F No Dilution Day 0 and Day 90 Slope Ratios 


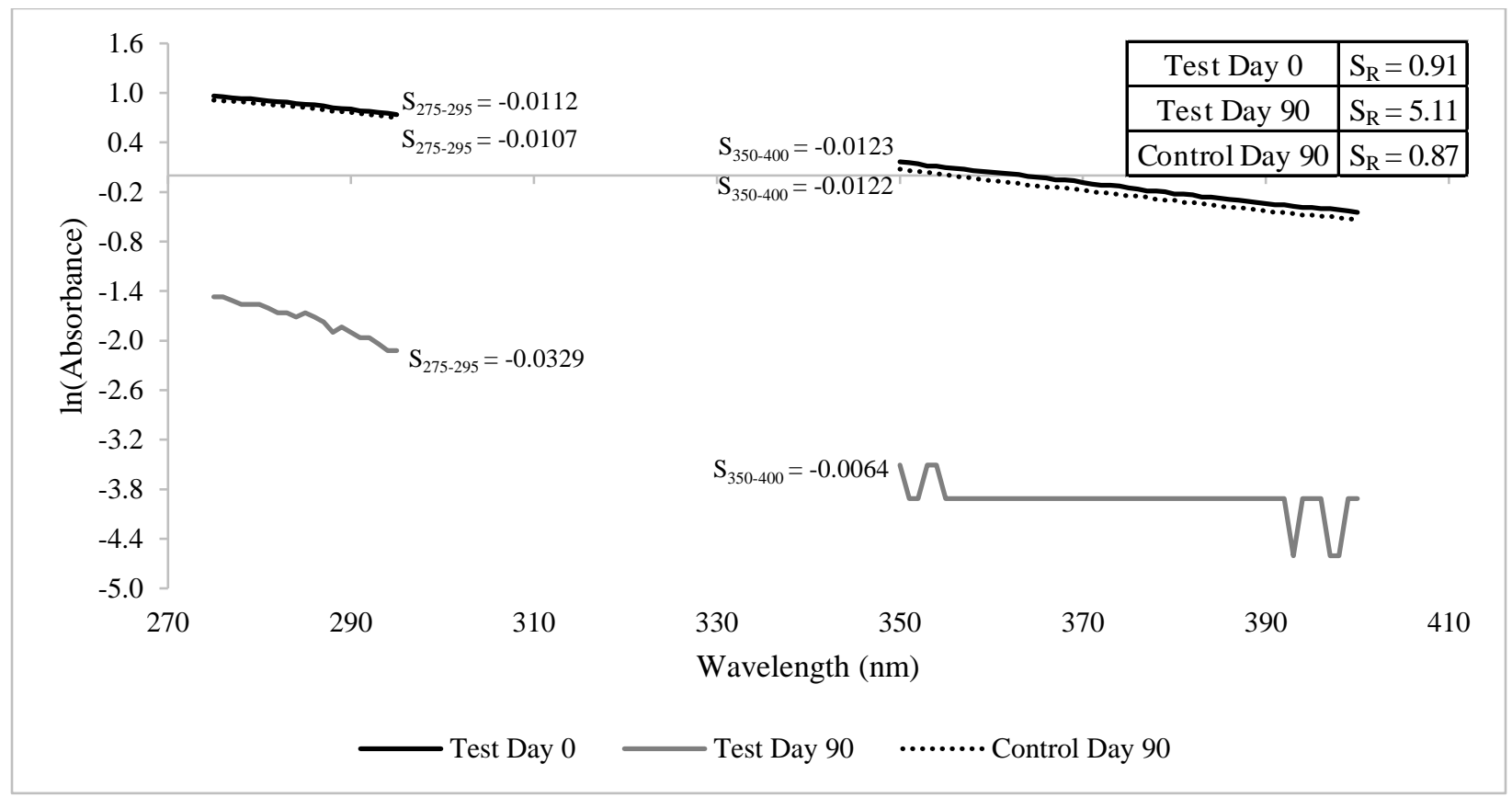

Figure E-15: Leachate F 1:10 Dilution Day 0 and Day 90 Slope Ratios

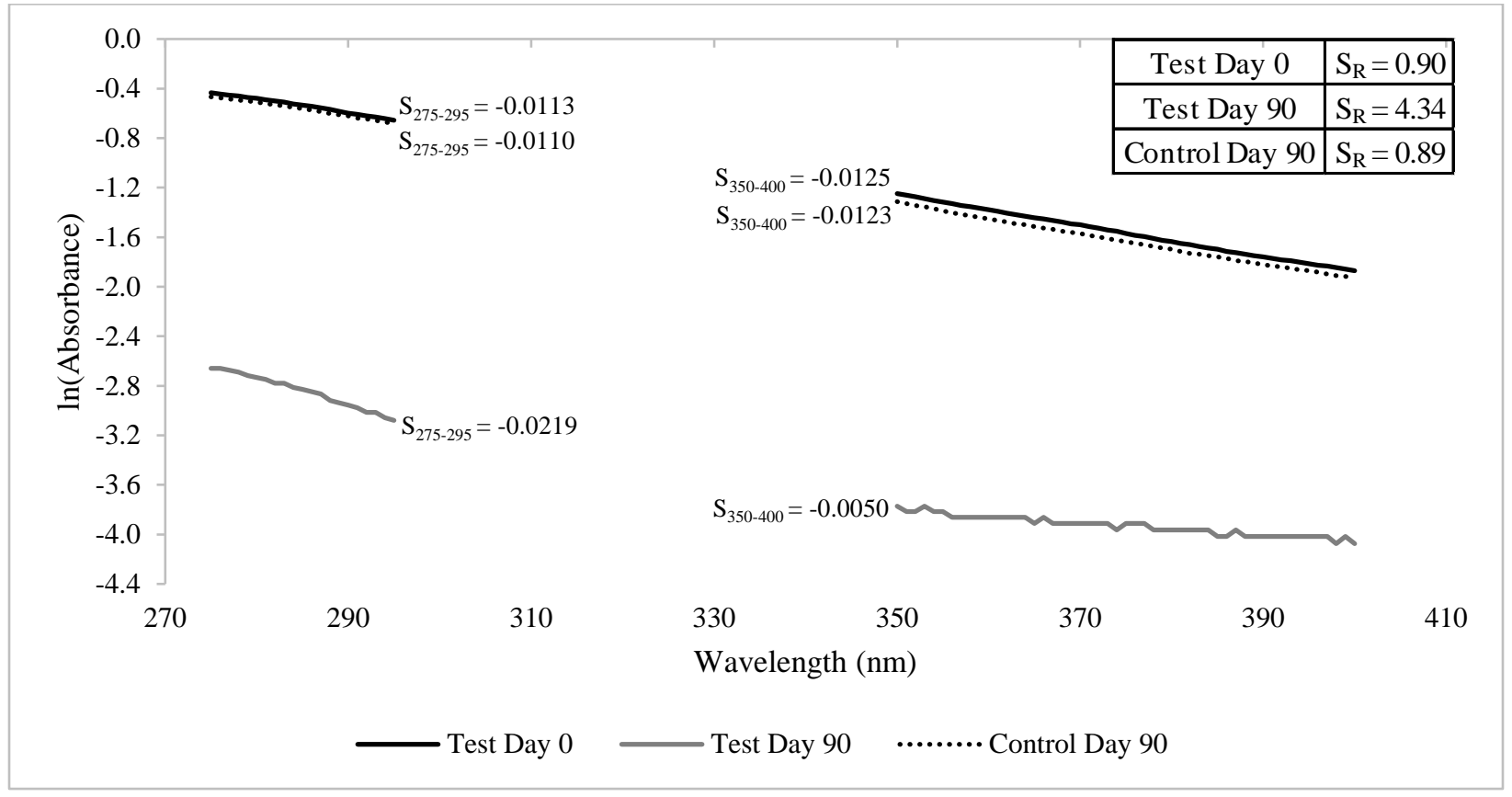

Figure E-16: Leachate F 1:40 Dilution Day 0 and Day 90 Slope Ratios 


\section{Leachate $\mathrm{G}$}

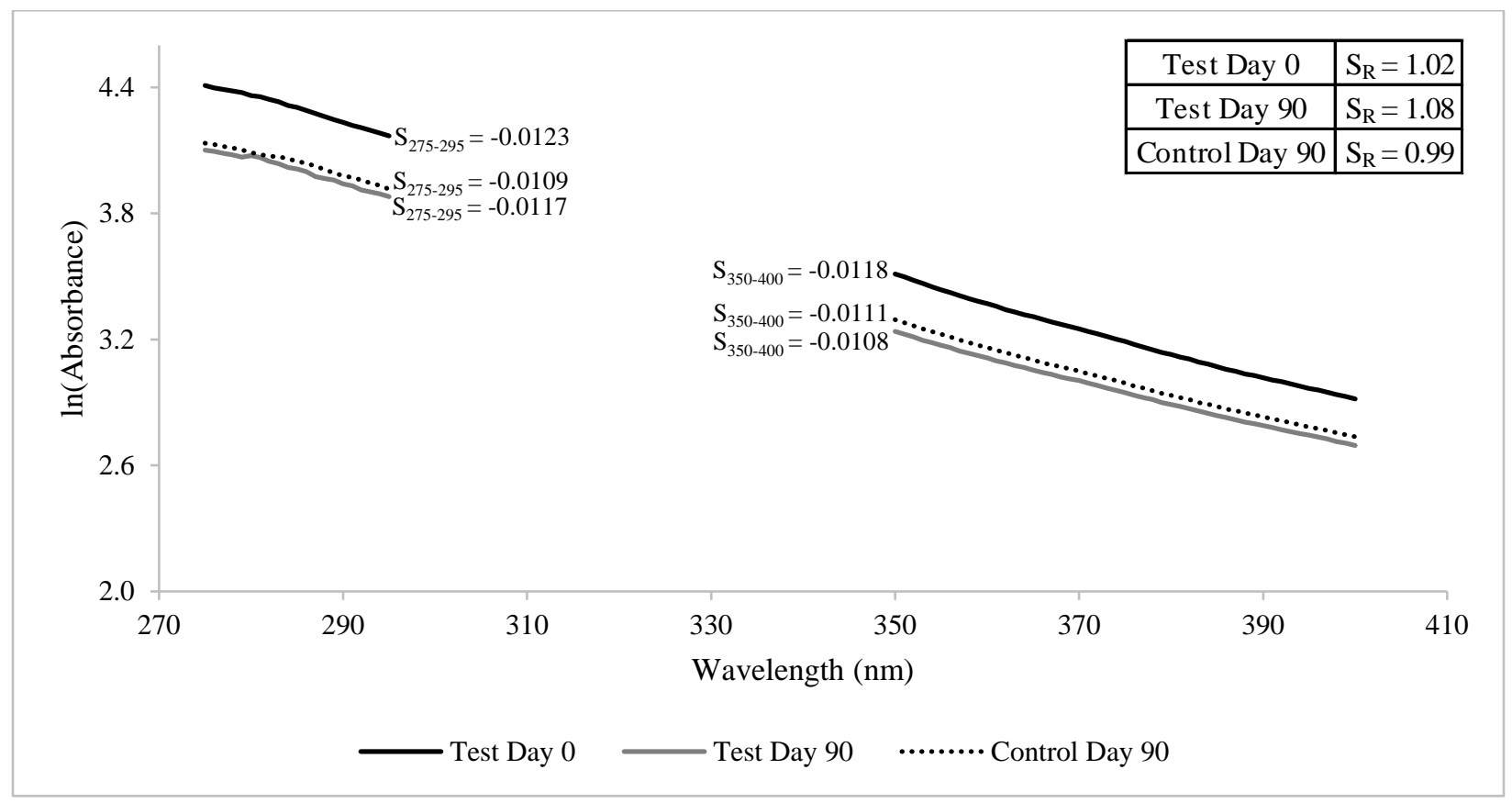

Figure E-17: Leachate G No Dilution Day 0 and Day 90 Slope Ratios

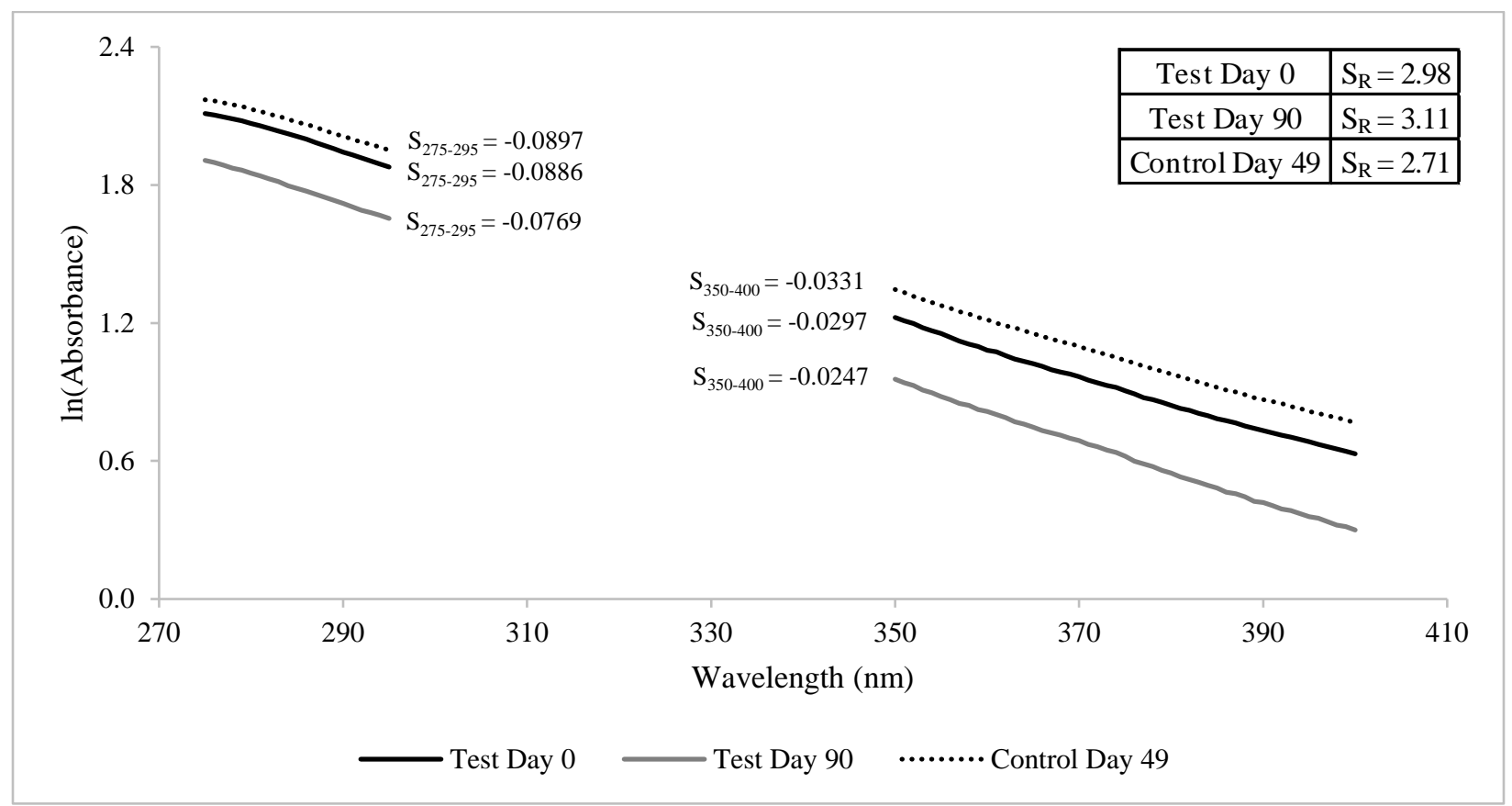

Figure E-18: Leachate G 1:10 No Dilution Day 0 and Day 90 Slope Ratios (*1:10 dilution control bag broke on day 49 of experimental test) 


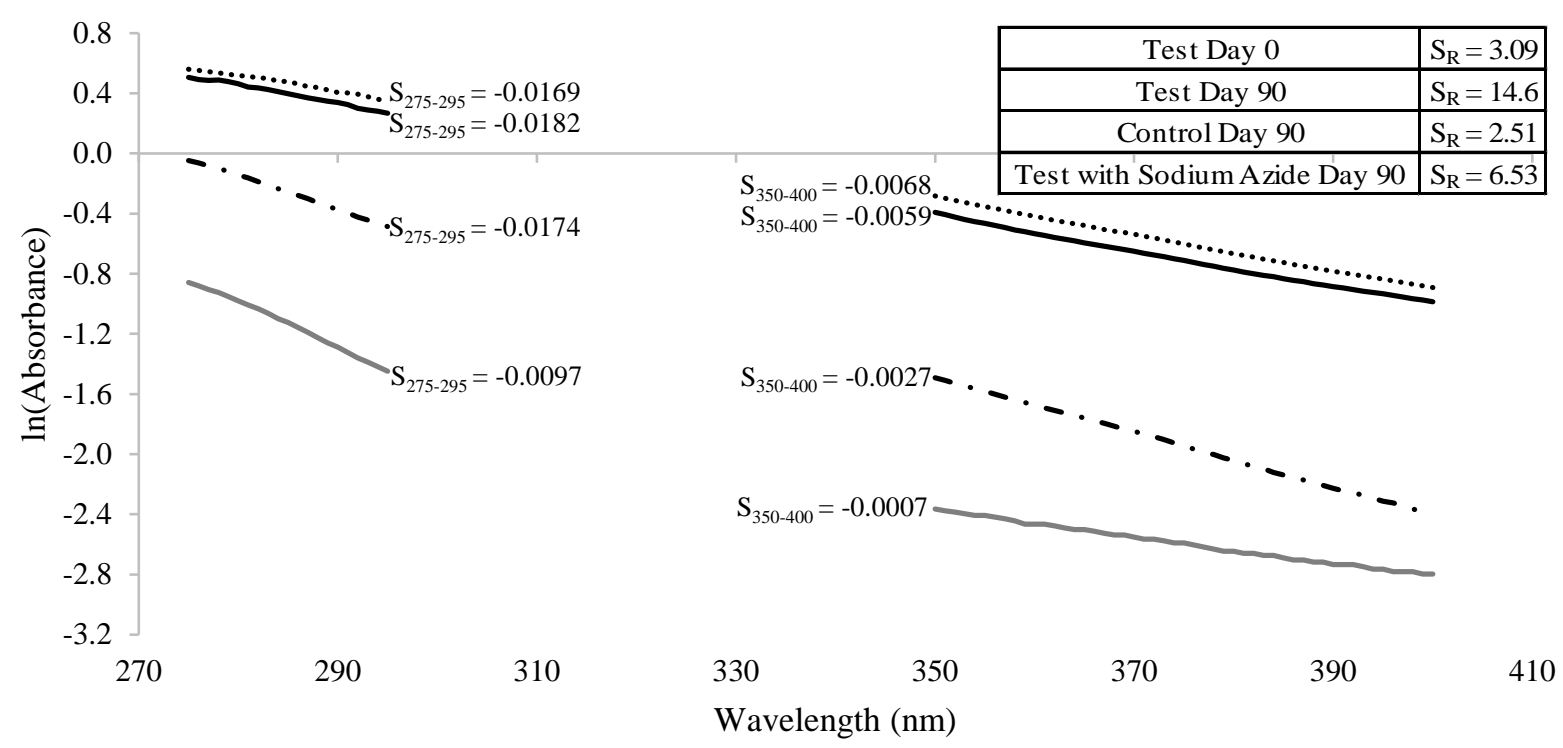

Test Day $0 \quad$ Test Day $90 \quad$ ….... Control Day $90 \quad \ldots$ - Test with Sodium Azide Day 90

Figure E-19: Leachate G 1:50 Dilution Day 0 and Day 90 Slope Ratios

Leachate $\mathrm{H}$

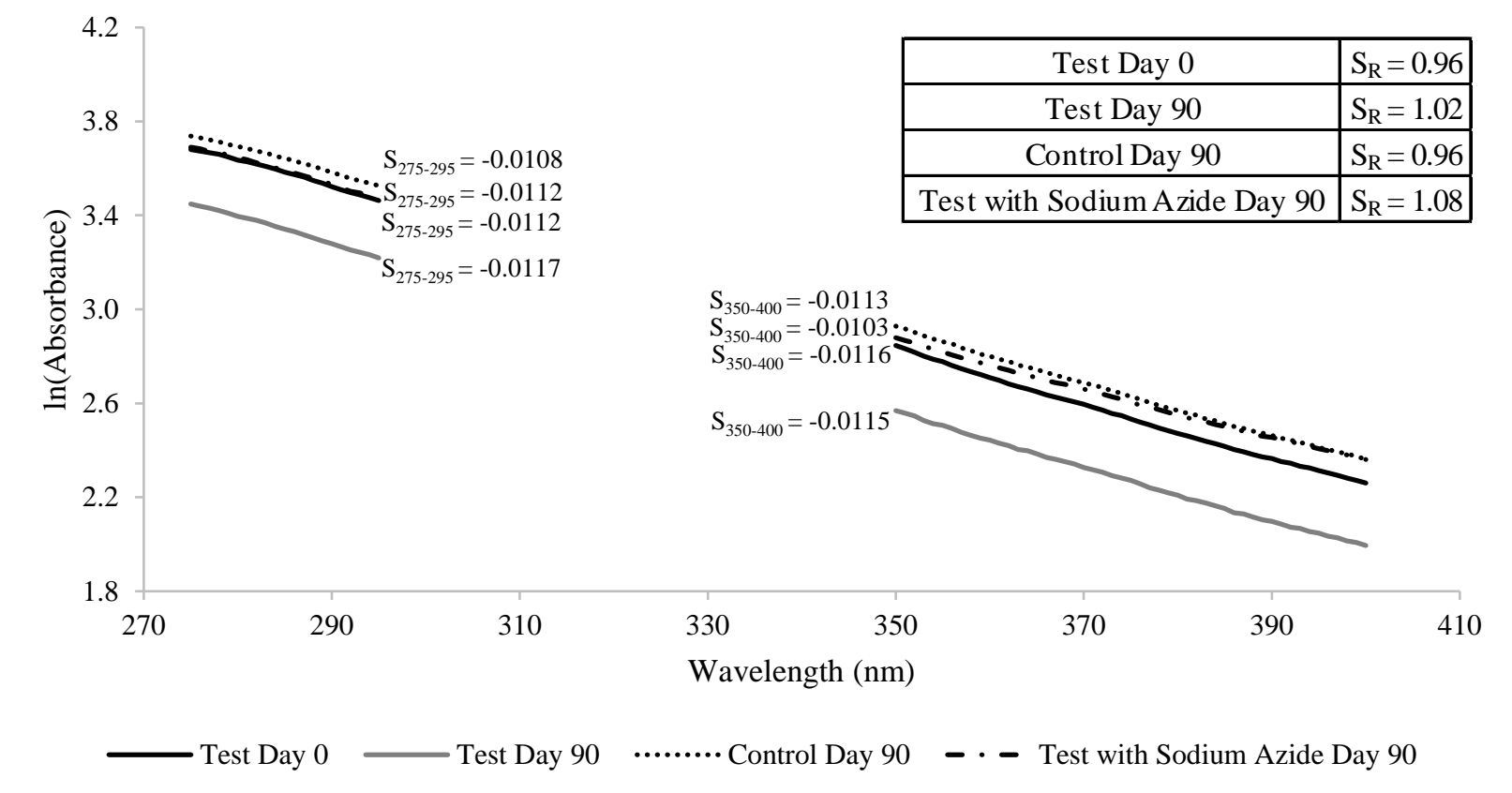

Figure E-20: Leachate H No Dilution Day 0 and Day 90 Slope Ratios 


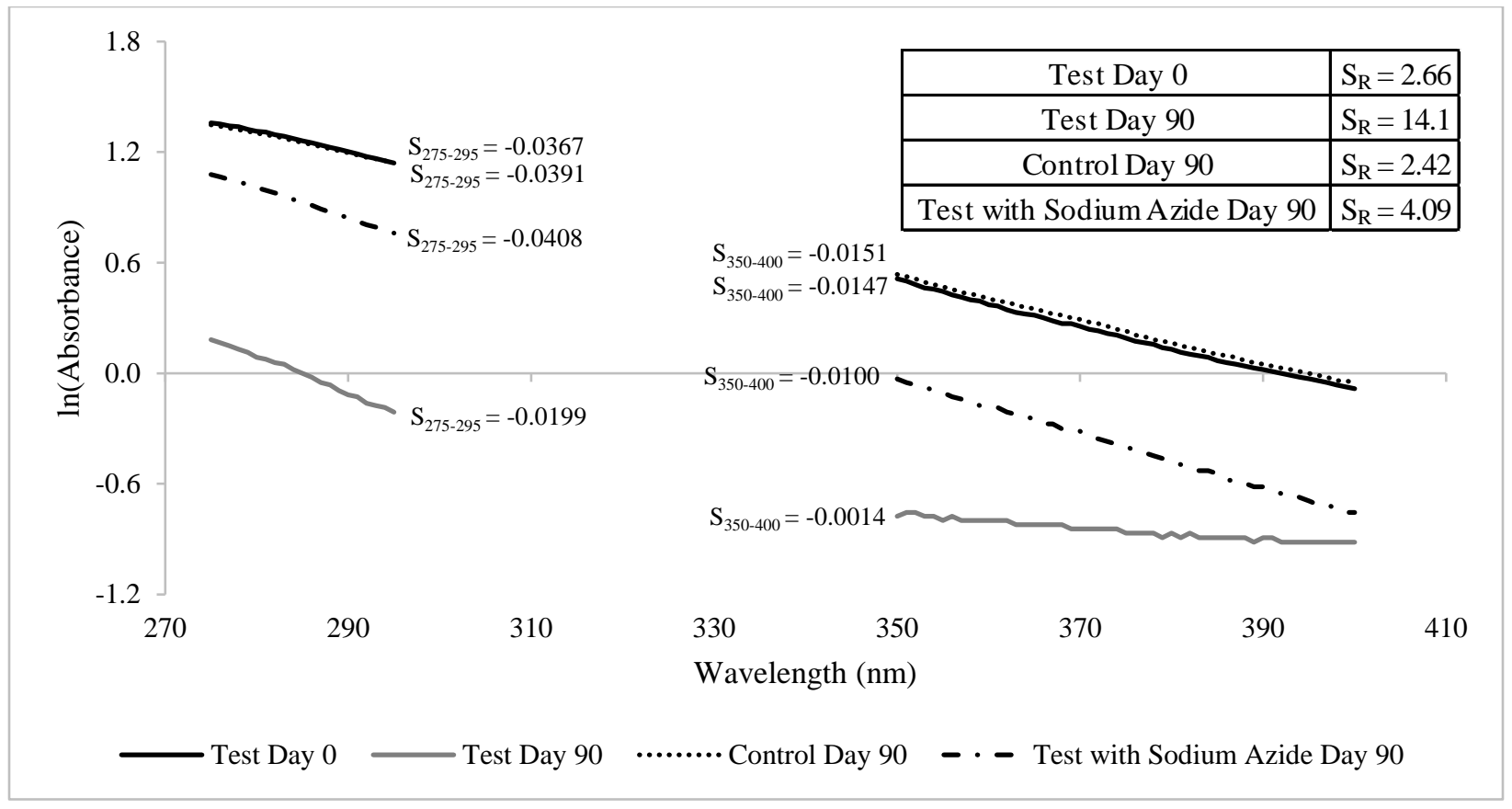

Figure E-21: Leachate H 1:10 Dilution Day 0 and Day 90 Slope Ratios

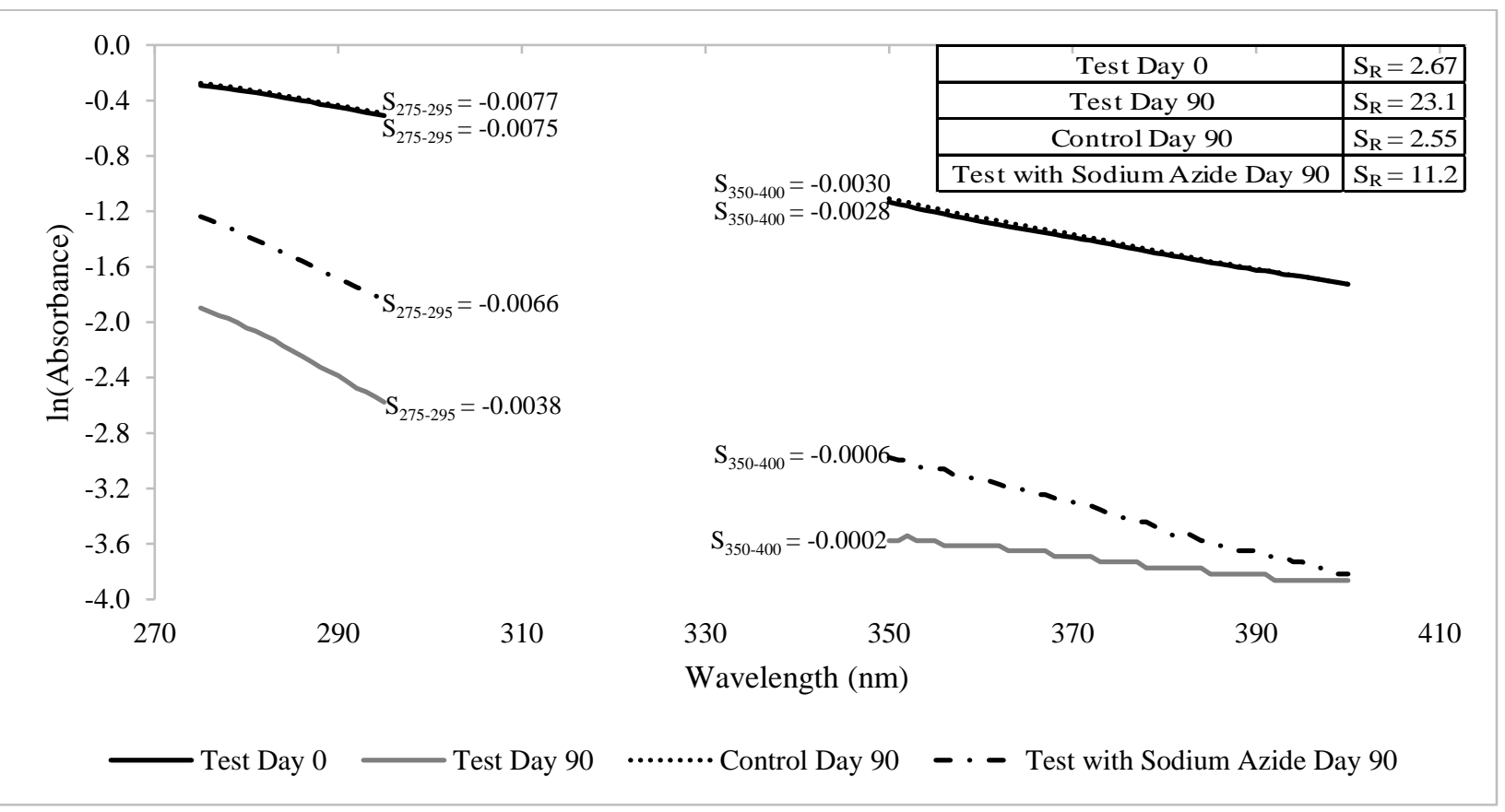

Figure E-22: Leachate H 1:50 Dilution Day 0 and Day 90 Slope Ratios 


\section{APPENDIX F: FLUORESCENCE EXCITATION EMISSION MATRIX SPECTROSCOPY DATA}


Leachate A

Table F-1: Leachate A Day 0 EEMs Data

\begin{tabular}{|c|c|c|c|c|c|c|c|c|c|c|c|}
\hline \multirow{2}{*}{ Sample } & \multicolumn{4}{|c|}{ Area Surface Integration } & \multicolumn{3}{c|}{ Percent of Total Area } & \multicolumn{3}{c|}{ Fluorescence Measurements } \\
\cline { 2 - 12 } & A & C & M & T & Sum & A & C & M & T & A:T Ratio & C:T Ratio \\
\hline No Dilution & 314,428 & 65,642 & 77,197 & 15,813 & 473,080 & $66 \%$ & $14 \%$ & $16 \%$ & $3 \%$ & 19.9 & 4.2 \\
\hline 1:10 Dilution & 273,395 & 56,220 & 65,906 & 13,766 & 409,287 & $67 \%$ & $14 \%$ & $16 \%$ & $3 \%$ & 19.9 & 4.1 \\
\hline 1:100 Dilution & 299,277 & 62,835 & 72,968 & 16,910 & 451,990 & $66 \%$ & $14 \%$ & $16 \%$ & $4 \%$ & 17.7 & 3.7 \\
\hline
\end{tabular}

Table F-2: Leachate A Day 90 EEMs Data

\begin{tabular}{|c|c|c|c|c|c|c|c|c|c|c|c|}
\hline \multirow{2}{*}{ Sample } & \multicolumn{4}{|c|}{ Area Surface Integration } & \multicolumn{3}{c|}{ Percent of Total Area } & \multicolumn{2}{c|}{ Fluorescence Measurements } \\
\cline { 2 - 12 } & A & C & M & T & Sum & A & C & M & T & A:T Ratio & C:T Ratio \\
\hline No Dilution & 332,528 & 62,536 & 76,708 & 19,949 & 491,721 & $68 \%$ & $13 \%$ & $16 \%$ & $4 \%$ & 16.7 & 3.1 \\
\hline No Dilution Control & 391,758 & 76,999 & 91,529 & 20,407 & 580,693 & $67 \%$ & $13 \%$ & $16 \%$ & $4 \%$ & 19.2 & 3.8 \\
\hline 1:10 Dilution & 43,987 & 7,848 & 9,570 & 3,696 & 65,101 & $68 \%$ & $12 \%$ & $15 \%$ & $6 \%$ & 11.9 & 2.1 \\
\hline 1:10 Dilution Control & 298,945 & 60,216 & 70,254 & 11,728 & 441,143 & $68 \%$ & $14 \%$ & $16 \%$ & $3 \%$ & 25.5 & 5.1 \\
\hline 1:100 Dilution & 9,986 & 1,904 & 3,150 & 6,470 & 21,510 & $46 \%$ & $9 \%$ & $15 \%$ & $30 \%$ & 1.5 & 0.3 \\
\hline 1:100 Dilution Control & 299,984 & 64,661 & 76,097 & 16,109 & 456,851 & $66 \%$ & $14 \%$ & $17 \%$ & $4 \%$ & 18.6 & 4.0 \\
\hline
\end{tabular}




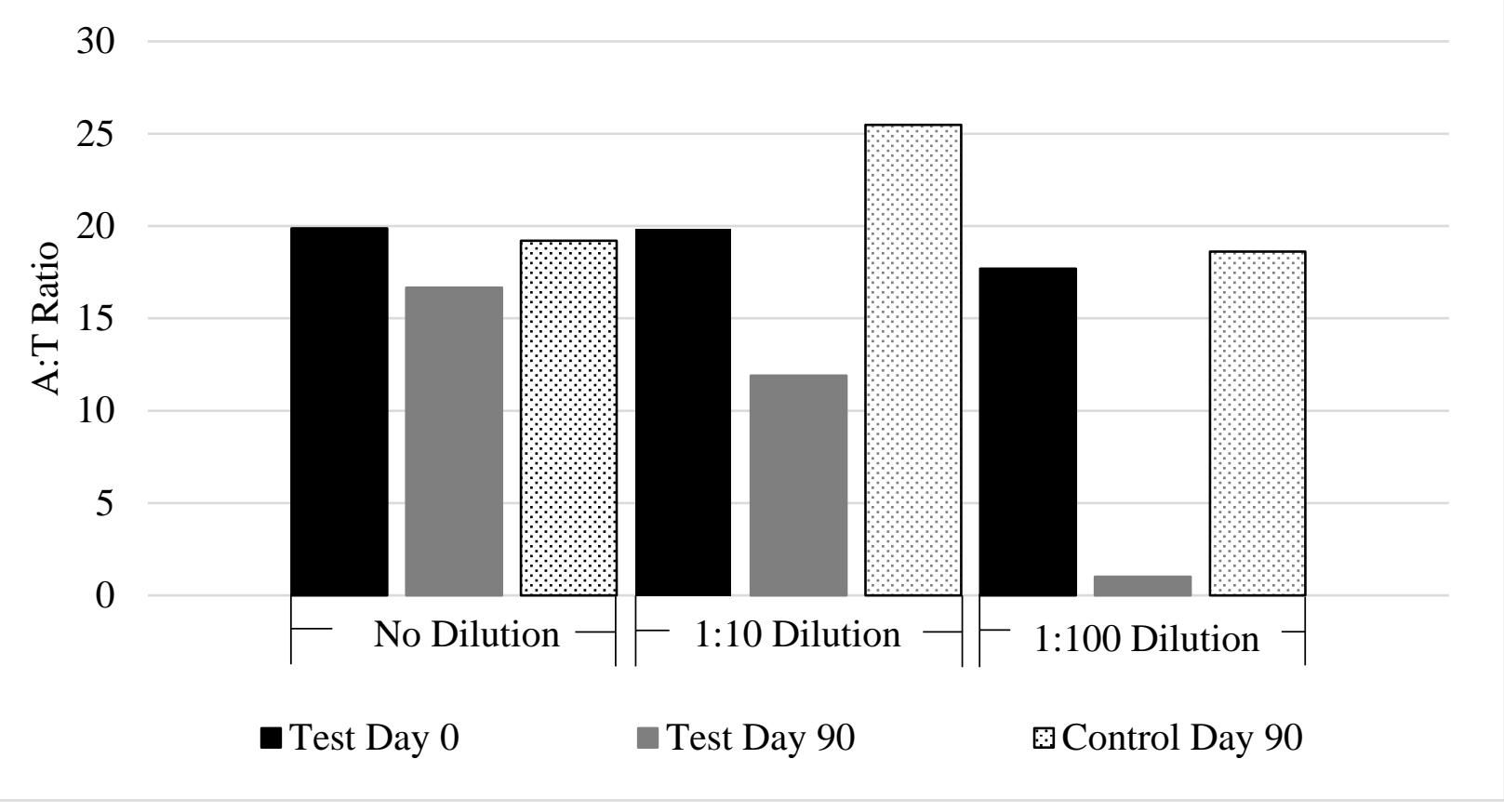

Figure F-1: Leachate A EEMs A:T Ratio

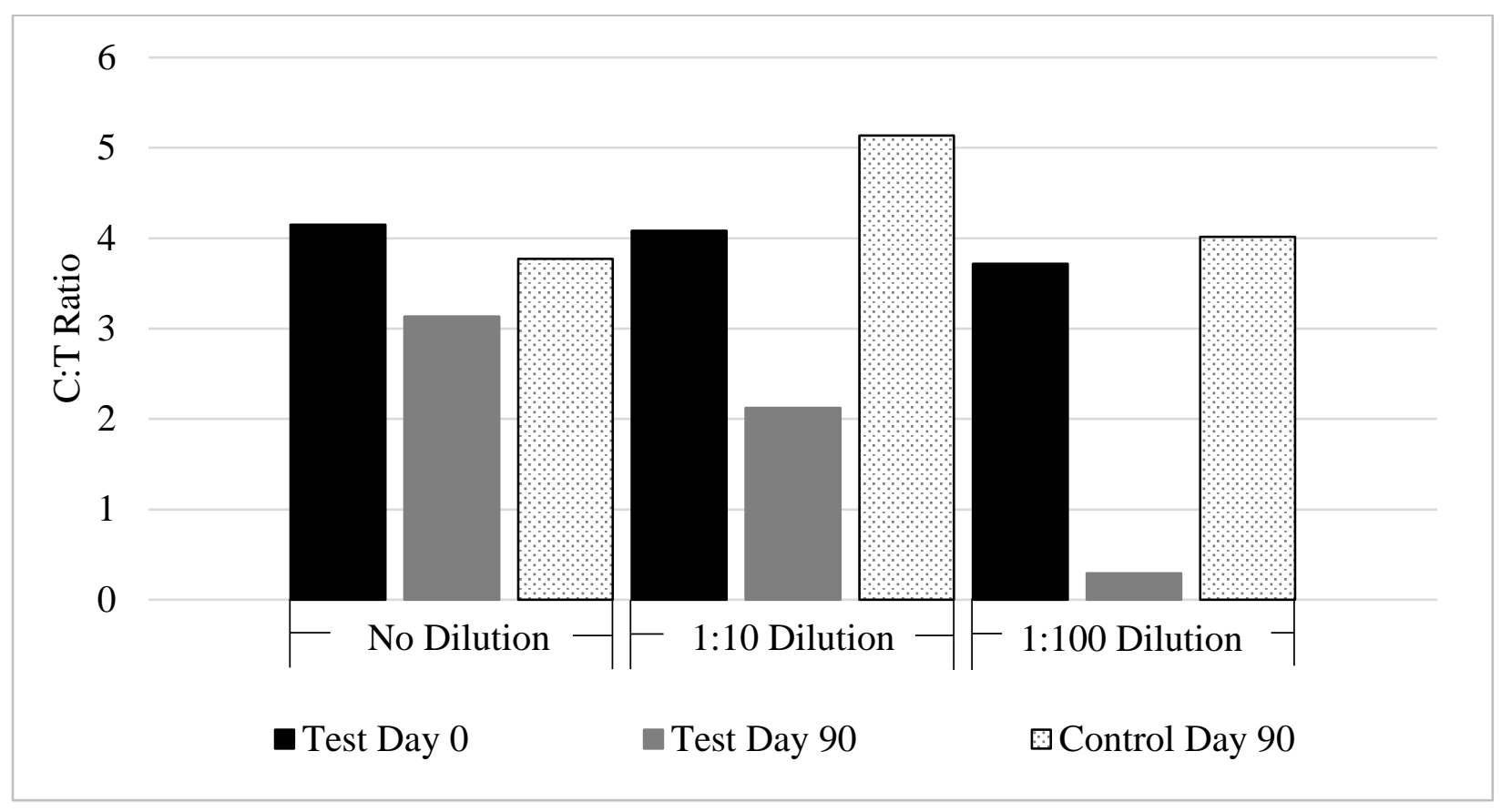

Figure F-2: Leachate A EEMs C:T Ratio 
$\underline{\text { Leachate B }}$

Table F-3: Leachate B Day 0 EEMs Data

\begin{tabular}{|c|c|c|c|c|c|c|c|c|c|c|c|}
\hline \multirow{2}{*}{ Sample } & \multicolumn{4}{|c|}{ Quinine Sulfate Equivalents } & \multicolumn{4}{c|}{ Percent of Total Area } & \multicolumn{2}{c|}{ Fluorescence Measurements } \\
\cline { 2 - 26 } & A & C & M & T & Sum & A & C & M & T & A:T Ratio & C:T Ratio \\
\hline No Dilution & 49 & 22 & 21 & 9 & 101 & $48 \%$ & $22 \%$ & $21 \%$ & $9 \%$ & 5.2 & 2.3 \\
\hline 1:10 Dilution & 5 & 2 & 2 & 1 & 10 & $48 \%$ & $22 \%$ & $21 \%$ & $9 \%$ & 5.2 & 2.3 \\
\hline 1:100 Dilution & 0.5 & 0.2 & 0.2 & 0.1 & 1.0 & $48 \%$ & $22 \%$ & $21 \%$ & $9 \%$ & 5.2 & 2.3 \\
\hline
\end{tabular}

Table F-4: Leachate B Day 90 EEMs Data

\begin{tabular}{|c|c|c|c|c|c|c|c|c|c|c|c|}
\hline \multirow{2}{*}{ Sample } & \multicolumn{4}{|c|}{ Area Surface Integration } & \multicolumn{3}{c|}{ Percent of Total Area } & Fluorescence Measurements \\
\cline { 2 - 12 } & A & C & M & T & Sum & A & C & M & T & A:T Ratio & C:T Ratio \\
\hline No Dilution & N/A & N/A & N/A & N/A & N/A & N/A & N/A & N/A & N/A & N/A & N/A \\
\hline No Dilution Control & N/A & N/A & N/A & N/A & N/A & N/A & N/A & N/A & N/A & N/A & N/A \\
\hline 1:10 Dilution & 334,978 & 60,603 & 173,024 & 25,838 & 594,443 & $56 \%$ & $10 \%$ & $29 \%$ & $4 \%$ & 13.0 & 2.3 \\
\hline 1:10 Dilution Control & 398,974 & 89,973 & 148,959 & 36,562 & 674,468 & $59 \%$ & $13 \%$ & $22 \%$ & $5 \%$ & 10.9 & 2.5 \\
\hline 1:100 Dilution & 23,415 & 3,902 & 5,465 & 5,151 & 37,933 & $62 \%$ & $10 \%$ & $14 \%$ & $14 \%$ & 4.5 & 0.8 \\
\hline 1:100 Dilution Control & 449,038 & 87,712 & 107,313 & 68,831 & 712,894 & $63 \%$ & $12 \%$ & $15 \%$ & $10 \%$ & 6.5 & 1.3 \\
\hline
\end{tabular}

(*1:100 dilution control bag broke on day 77 of experimental test, shown is day 77) 


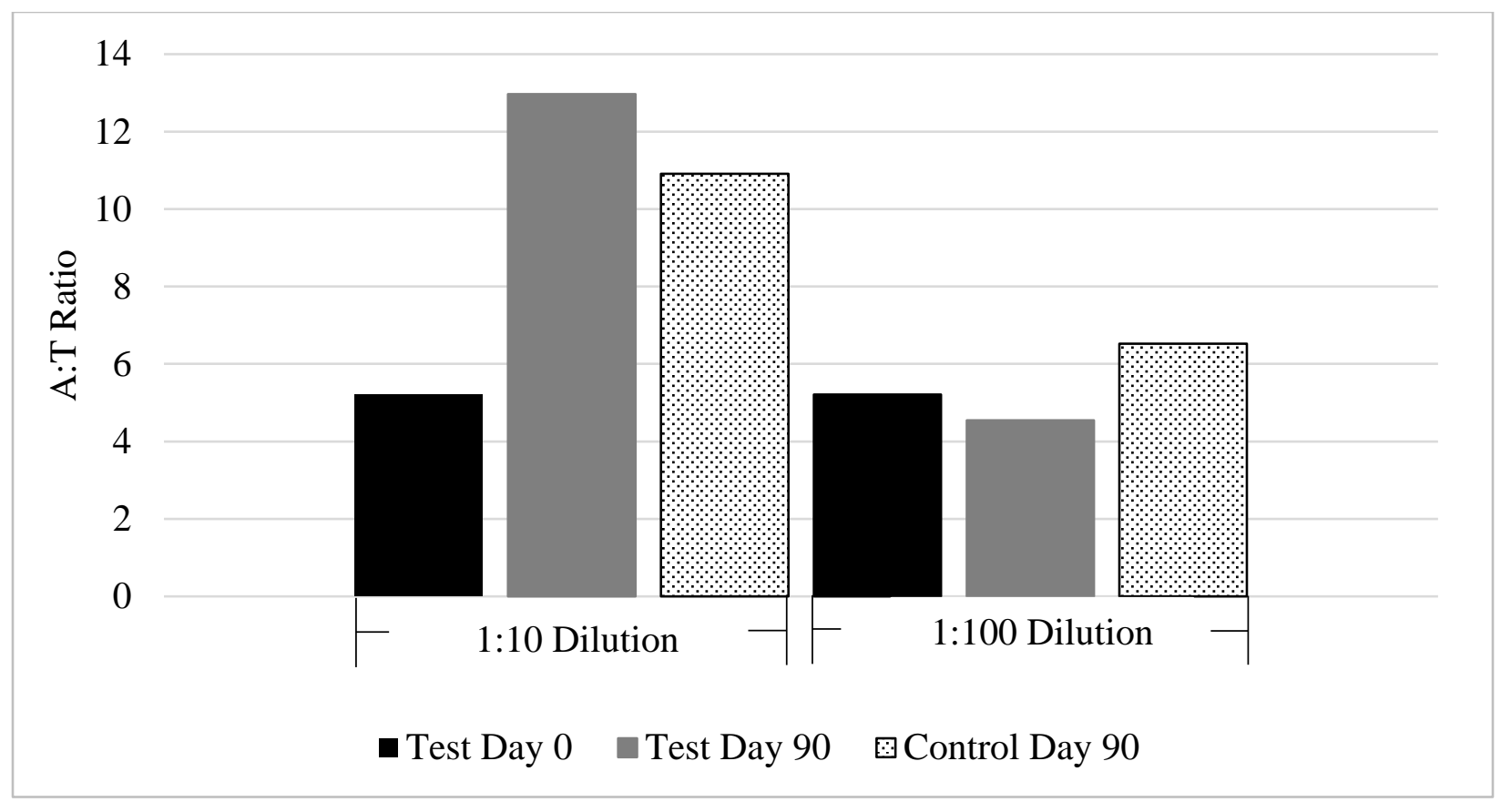

Figure F-3: Leachate B EEMs A:T Ratio

$(* 1: 100$ dilution control bag broke on day 77 of experimental test, shown is day 77)

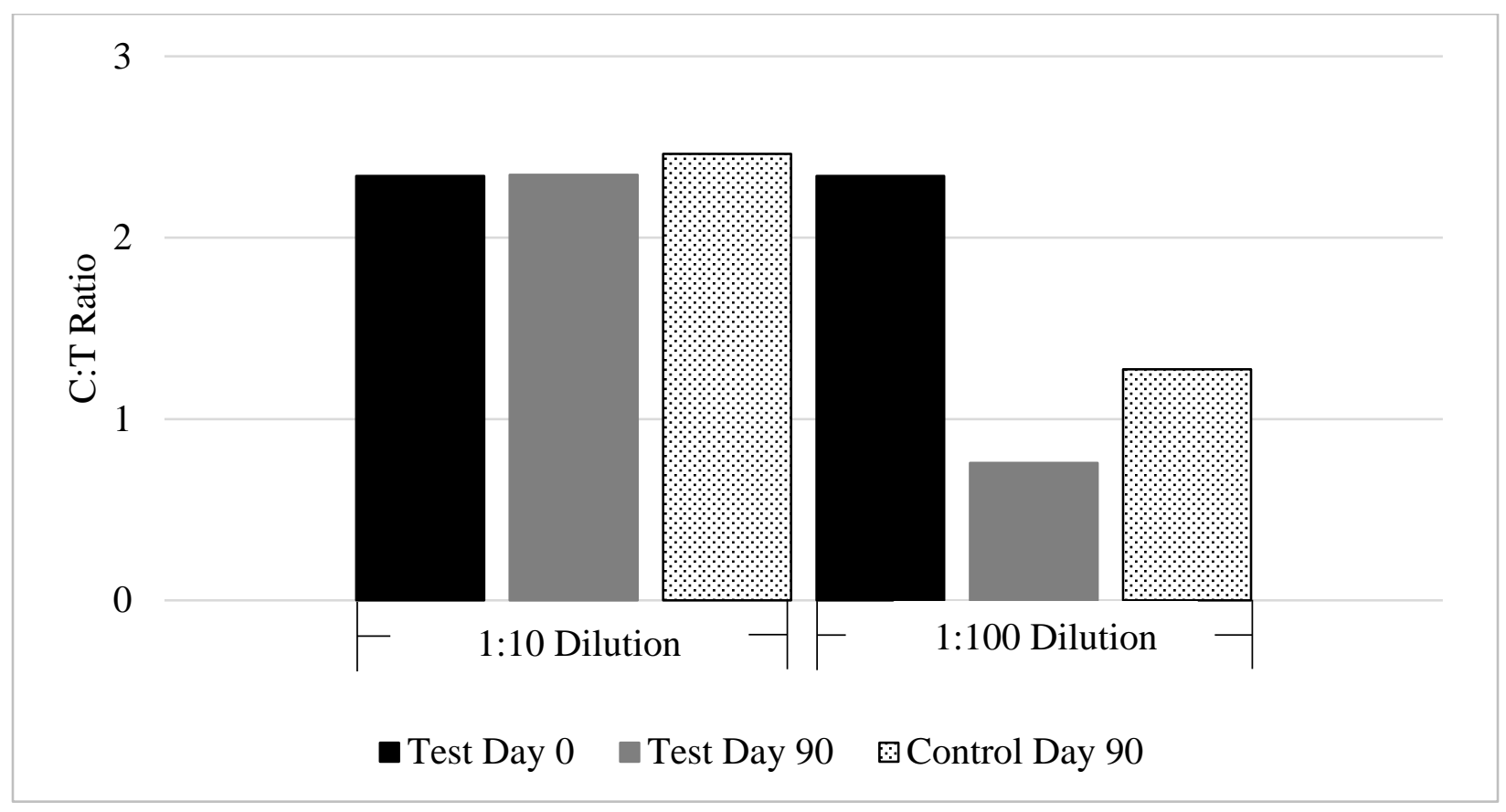

Figure F-4: Leachate B EEMs C:T Ratio

$(* 1: 100$ dilution control bag broke on day 77 of experimental test, shown is day 77) 
Leachate C

Table F-5: Leachate C Day 0 EEMs Data

\begin{tabular}{|c|c|c|c|c|c|c|c|c|c|c|c|}
\hline \multirow{2}{*}{ Sample } & \multicolumn{4}{|c|}{ Area Surface Integration } & \multicolumn{3}{c|}{ Percent of Total Area } & \multicolumn{3}{c|}{ Fluorescence Measurements } \\
\cline { 2 - 12 } & A & C & M & T & Sum & A & C & M & T & A:T Ratio & C:T Ratio \\
\hline 1:4.1 Dilution & 40,658 & 8,379 & 9,915 & 3,281 & 62,233 & $65 \%$ & $13 \%$ & $16 \%$ & $5 \%$ & 12.4 & 2.6 \\
\hline 1:31 Dilution & 59,721 & 12,322 & 14,945 & 4,580 & 91,568 & $65 \%$ & $13 \%$ & $16 \%$ & $5 \%$ & 13.0 & 2.7 \\
\hline
\end{tabular}

Table F-6: Leachate C Day 90 EEMs Data

\begin{tabular}{|c|c|c|c|c|c|c|c|c|c|c|c|}
\hline \multirow{2}{*}{ Sample } & \multicolumn{4}{|c|}{ Area Surface Integration } & \multicolumn{2}{c|}{ Percent of Total Area } & \multicolumn{2}{c|}{ Fluorescence Measurements } \\
\cline { 2 - 14 } & A & C & M & T & Sum & A & C & M & T & A:T Ratio & C:T Ratio \\
\hline 1:4.1 Dilution & 22,539 & 4,066 & 5,267 & 1,742 & 33,614 & $67 \%$ & $12 \%$ & $16 \%$ & $5 \%$ & 12.9 & 2.3 \\
\hline 1:4.1 Dilution Control & 47,902 & 9,797 & 11,820 & 3,159 & 72,678 & $66 \%$ & $13 \%$ & $16 \%$ & $4 \%$ & 15.2 & 3.1 \\
\hline 1:31 Dilution & 42,154 & 6,894 & 8,571 & 8,310 & 65,929 & $64 \%$ & $10 \%$ & $13 \%$ & $13 \%$ & 5.1 & 0.8 \\
\hline 1:31 Dilution Control & 54,534 & 11,480 & 12,854 & 2,769 & 81,637 & $67 \%$ & $14 \%$ & $16 \%$ & $3 \%$ & 19.7 & 4.1 \\
\hline
\end{tabular}




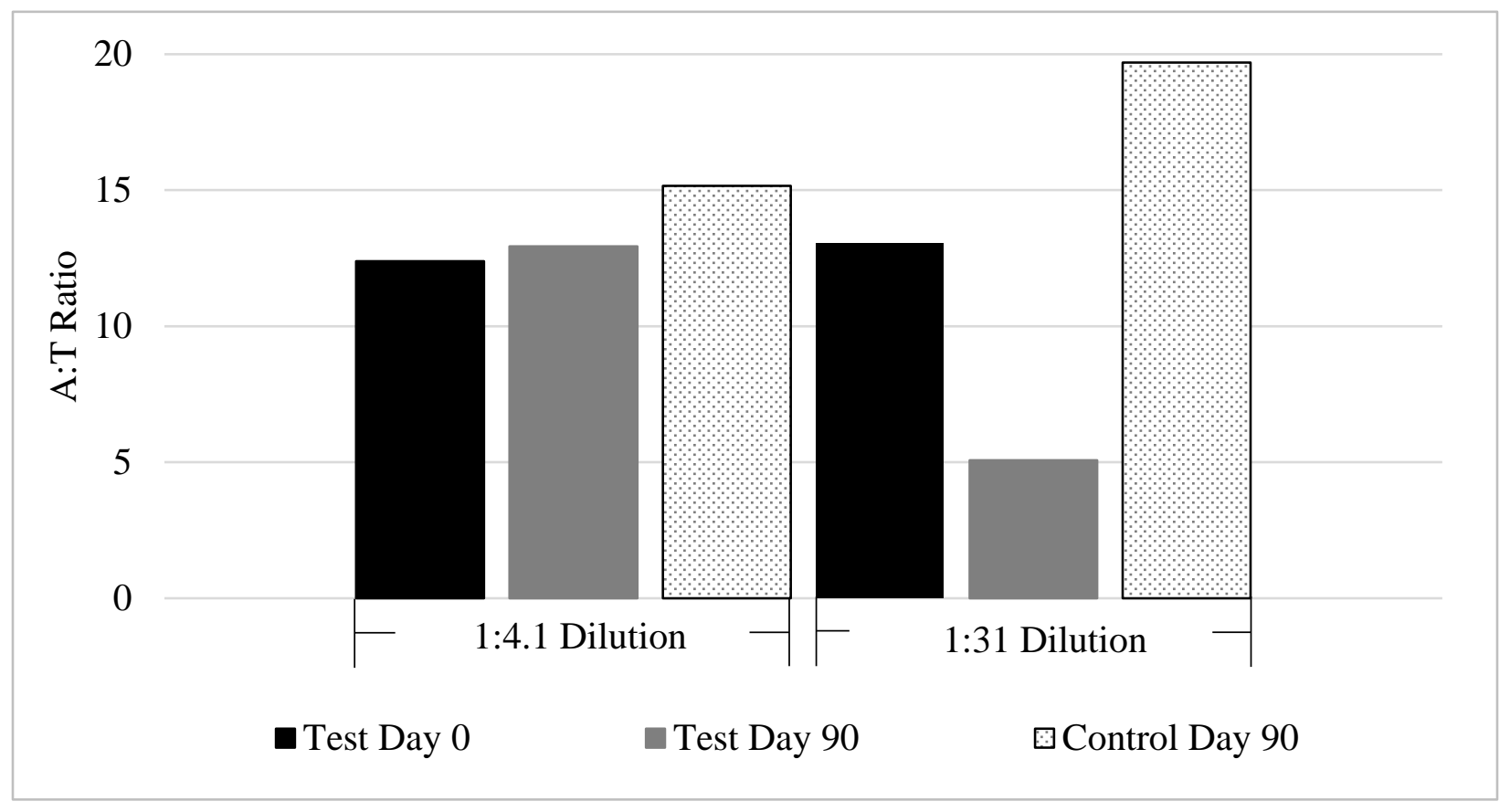

Figure F-5: Leachate C EEMs A:T Ratio

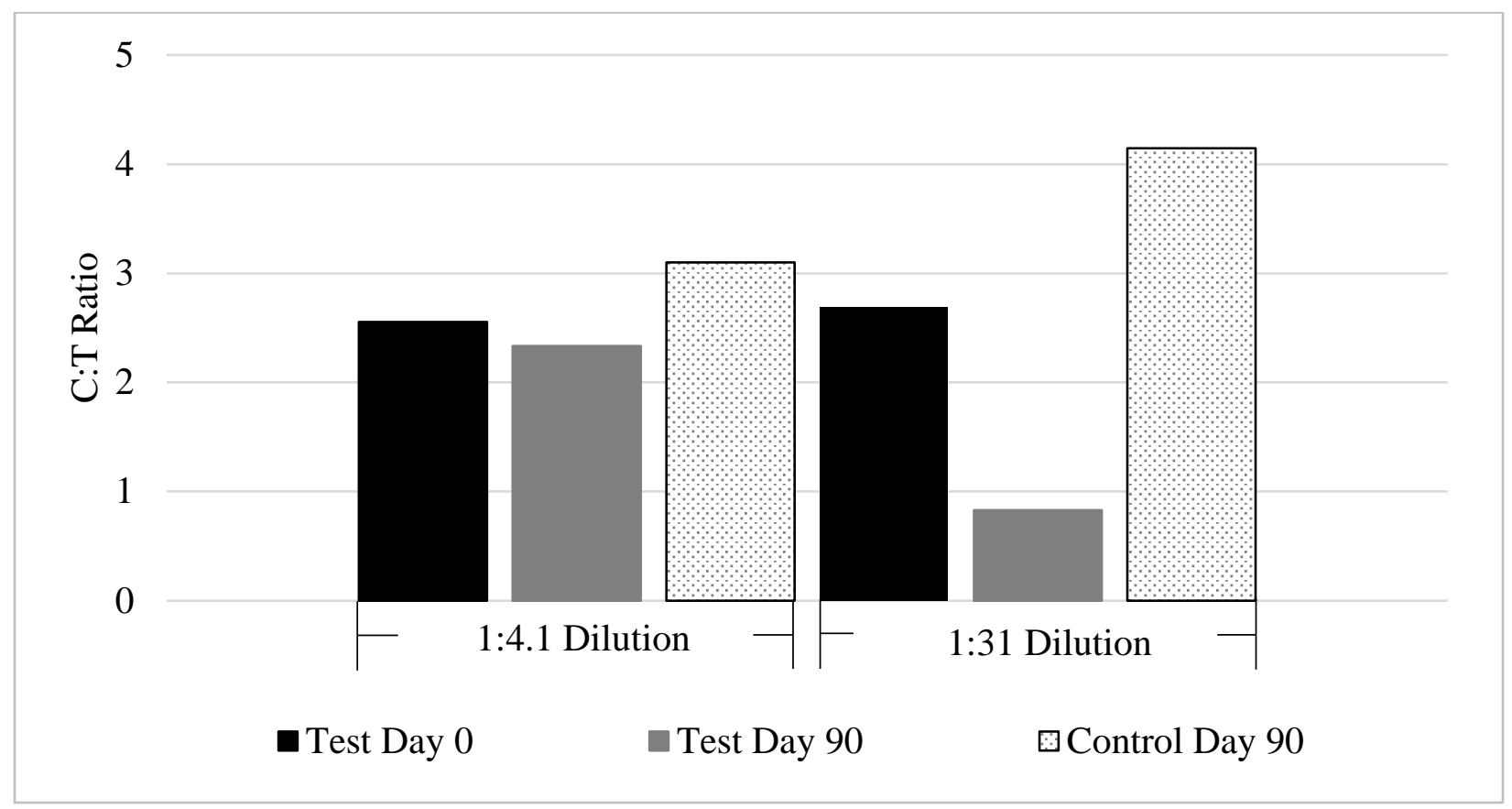

Figure F-6: Leachate C EEMs C:T Ratio 
$\underline{\text { Leachate D }}$

Table F-7: Leachate D Day 0 EEMs Data

\begin{tabular}{|c|c|c|c|c|c|c|c|c|c|c|c|}
\hline \multirow{2}{*}{ Sample } & \multicolumn{4}{|c|}{ Area Surface Integration } & \multicolumn{4}{c|}{ Percent of Total Area } & \multicolumn{3}{c|}{ Fluorescence Measurements } \\
\cline { 2 - 12 } & A & C & M & T & Sum & A & C & M & T & A:T Ratio & C:T Ratio \\
\hline 1:2.4 Dilution & 39,130 & 8,454 & 9,800 & 1,686 & 59,070 & $66 \%$ & $14 \%$ & $17 \%$ & $3 \%$ & 23.2 & 5.0 \\
\hline 1:16 Dilution & 54,833 & 11,901 & 13,315 & 2,455 & 82,504 & $66 \%$ & $14 \%$ & $16 \%$ & $3 \%$ & 22.3 & 4.8 \\
\hline
\end{tabular}

Table F-8: Leachate D Day 90 EEMs Data

\begin{tabular}{|c|c|c|c|c|c|c|c|c|c|c|c|}
\hline \multirow{2}{*}{ Sample } & \multicolumn{4}{|c|}{ Area Surface Integration } & \multicolumn{3}{c|}{ Percent of Total Area } & \multicolumn{2}{c|}{ Fluorescence Measurements } \\
\cline { 2 - 14 } & A & C & M & T & Sum & A & C & M & T & A:T Ratio & C:T Ratio \\
\hline 1:2.4 Dilution & 3,159 & 600 & 824 & 377 & 4,960 & $64 \%$ & $12 \%$ & $17 \%$ & $8 \%$ & 8.4 & 1.6 \\
\hline 1:2.4 Dilution Control & 39,055 & 7,638 & 8,458 & 1,167 & 56,318 & $69 \%$ & $14 \%$ & $15 \%$ & $2 \%$ & 33.5 & 6.5 \\
\hline 1:16 Dilution & 1,339 & 265 & 472 & 523 & 2,599 & $52 \%$ & $10 \%$ & $18 \%$ & $20 \%$ & 2.6 & 0.5 \\
\hline 1:16 Dilution Control & 105,195 & 21,030 & 23,878 & 4,874 & 154,977 & $68 \%$ & $14 \%$ & $15 \%$ & $3 \%$ & 21.6 & 4.3 \\
\hline
\end{tabular}




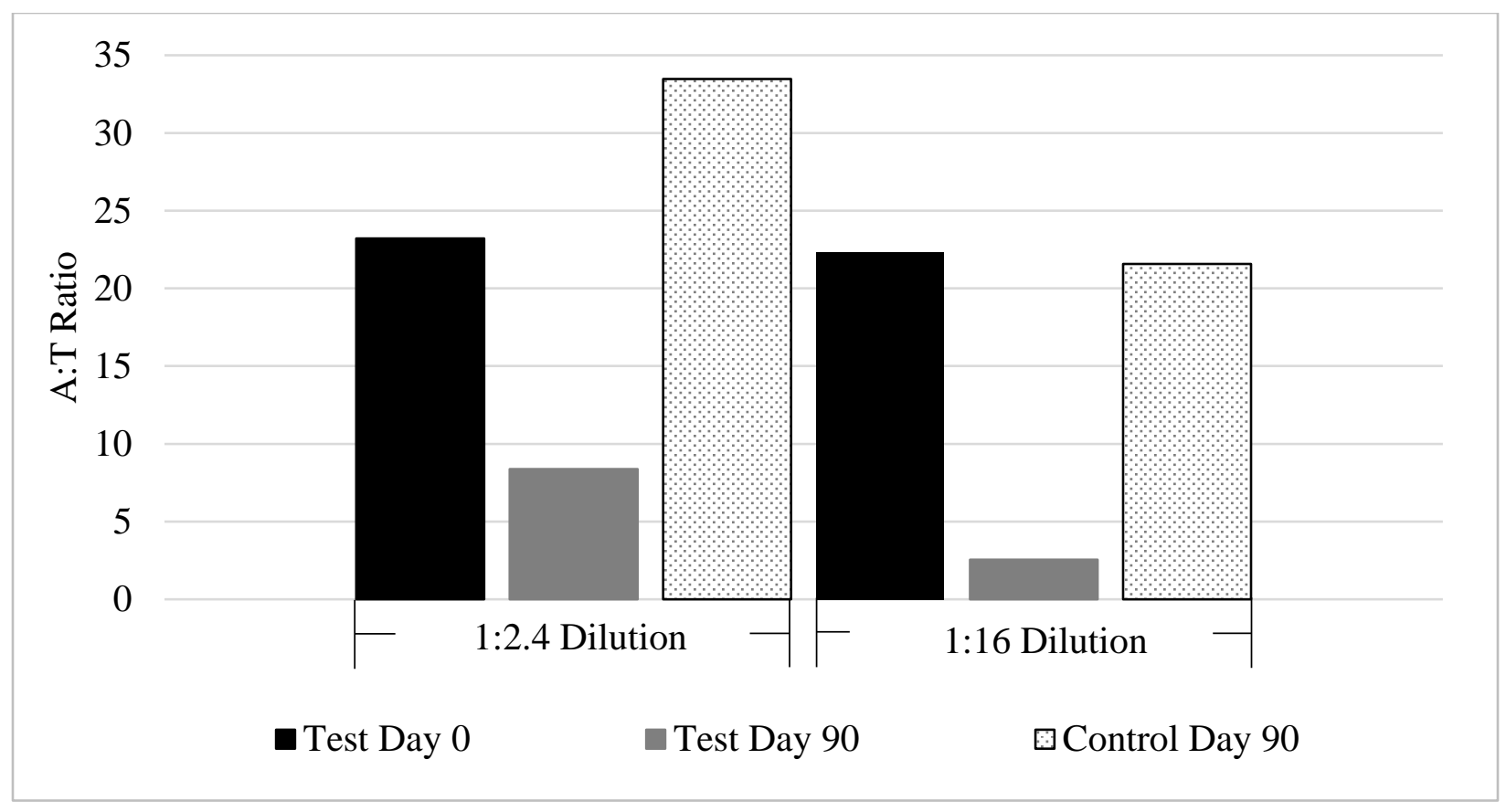

Figure F-7: Leachate D EEMs A:T Ratio

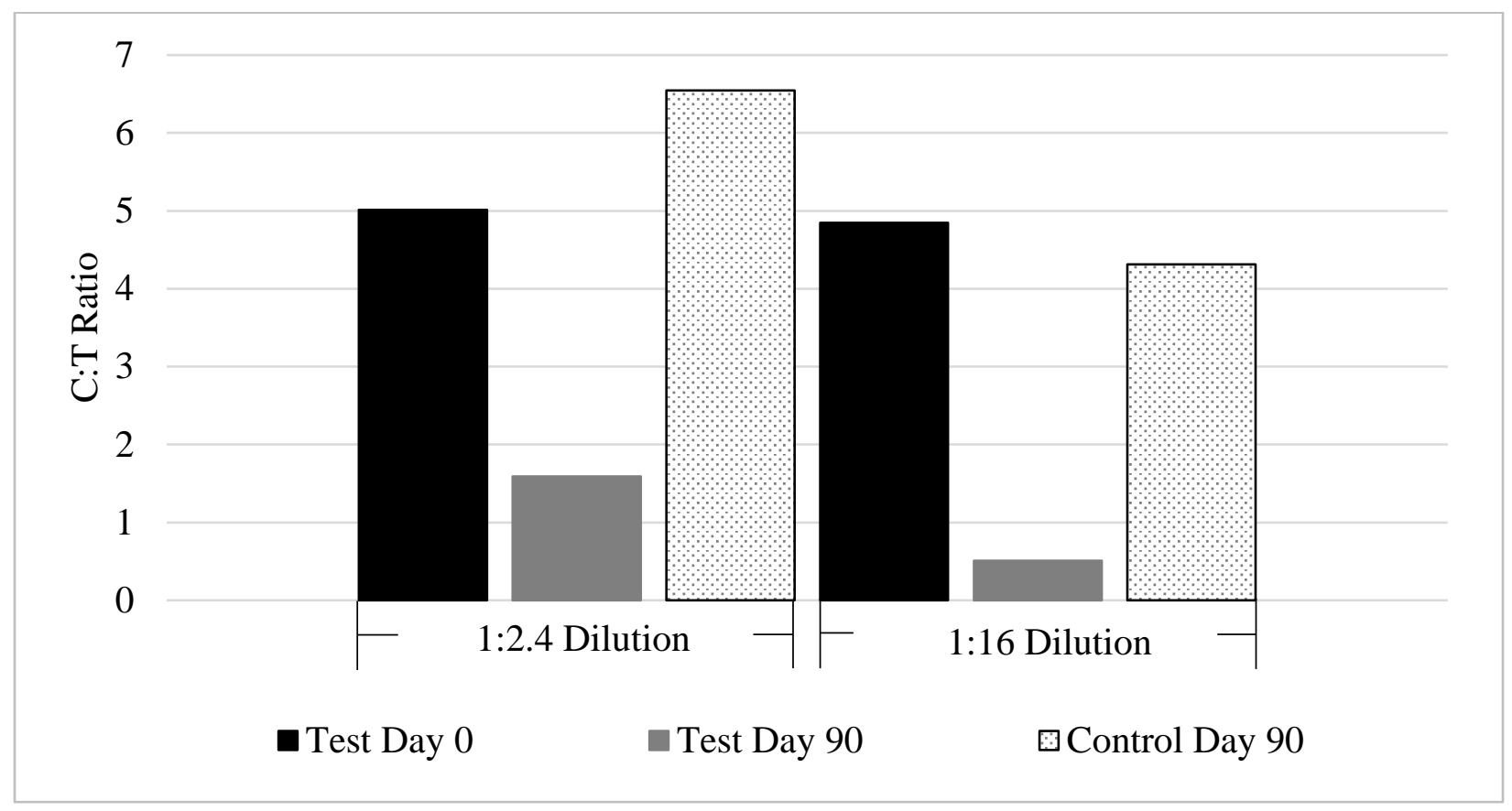

Figure F-8: Leachate D EEMs C:T Ratio 
Leachate E

Table F-9: Leachate E Day 0 EEMs Data

\begin{tabular}{|c|c|c|c|c|c|c|c|c|c|c|c|}
\hline \multirow{2}{*}{ Sample } & \multicolumn{6}{|c|}{ Quinine Sulfate Equivalents } & \multicolumn{3}{c|}{ Percent of Total Area } & \multicolumn{2}{c|}{ Fluorescence Measurements } \\
\cline { 2 - 12 } & A & C & M & T & Sum & A & C & M & T & A:T Ratio & C:T Ratio \\
\hline No Dilution & 43.2 & 19.6 & 17.7 & 6.5 & 87.0 & $50 \%$ & $23 \%$ & $20 \%$ & $7 \%$ & 6.6 & 3.0 \\
\hline 1:10 Dilution & 46.9 & 21.9 & 20.1 & 6.5 & 95.4 & $49 \%$ & $23 \%$ & $21 \%$ & $7 \%$ & 7.2 & 3.4 \\
\hline 1:40 Dilution & 10.7 & 5.5 & 5.1 & 1.8 & 23.0 & $46 \%$ & $24 \%$ & $22 \%$ & $8 \%$ & 5.9 & 3.0 \\
\hline
\end{tabular}

Table F-10: Leachate E Day 90 EEMs Data

\begin{tabular}{|c|c|c|c|c|c|c|c|c|c|c|c|}
\hline \multirow{2}{*}{ Sample } & \multicolumn{9}{|c|}{ Quinine Sulfate Equivalents } & \multicolumn{3}{c|}{ Percent of Total Area } & \multicolumn{3}{c|}{ Fluorescence Measurements } \\
\cline { 2 - 14 } & A & C & M & T & Sum & A & C & M & T & A:T Ratio & C:T Ratio \\
\hline No Dilution & 22.4 & 9.2 & 8.8 & 2.6 & 43.0 & $52 \%$ & $21 \%$ & $20 \%$ & $6 \%$ & 8.6 & 3.5 \\
\hline No Dilution Control & 41.5 & 20.2 & 18.7 & 6.2 & 86.6 & $49 \%$ & $23 \%$ & $21 \%$ & $7 \%$ & 6.9 & 3.2 \\
\hline 1:10 Dilution & 6.2 & 2.3 & 2.3 & 1.4 & 12.2 & $51 \%$ & $19 \%$ & $20 \%$ & $10 \%$ & 4.9 & 1.9 \\
\hline 1:10 Dilution Control & 35.9 & 18.1 & 16.3 & 4.2 & 74.5 & $48 \%$ & $24 \%$ & $22 \%$ & $6 \%$ & 8.5 & 4.3 \\
\hline 1:40 Dilution & 1.1 & 0.3 & 0.4 & 0.8 & 2.6 & $42 \%$ & $12 \%$ & $15 \%$ & $31 \%$ & 1.4 & 0.4 \\
\hline 1:40 Dilution Control & 6.4 & 4.2 & 4.0 & 1.1 & 15.7 & $41 \%$ & $27 \%$ & $25 \%$ & $7 \%$ & 5.8 & 3.8 \\
\hline
\end{tabular}




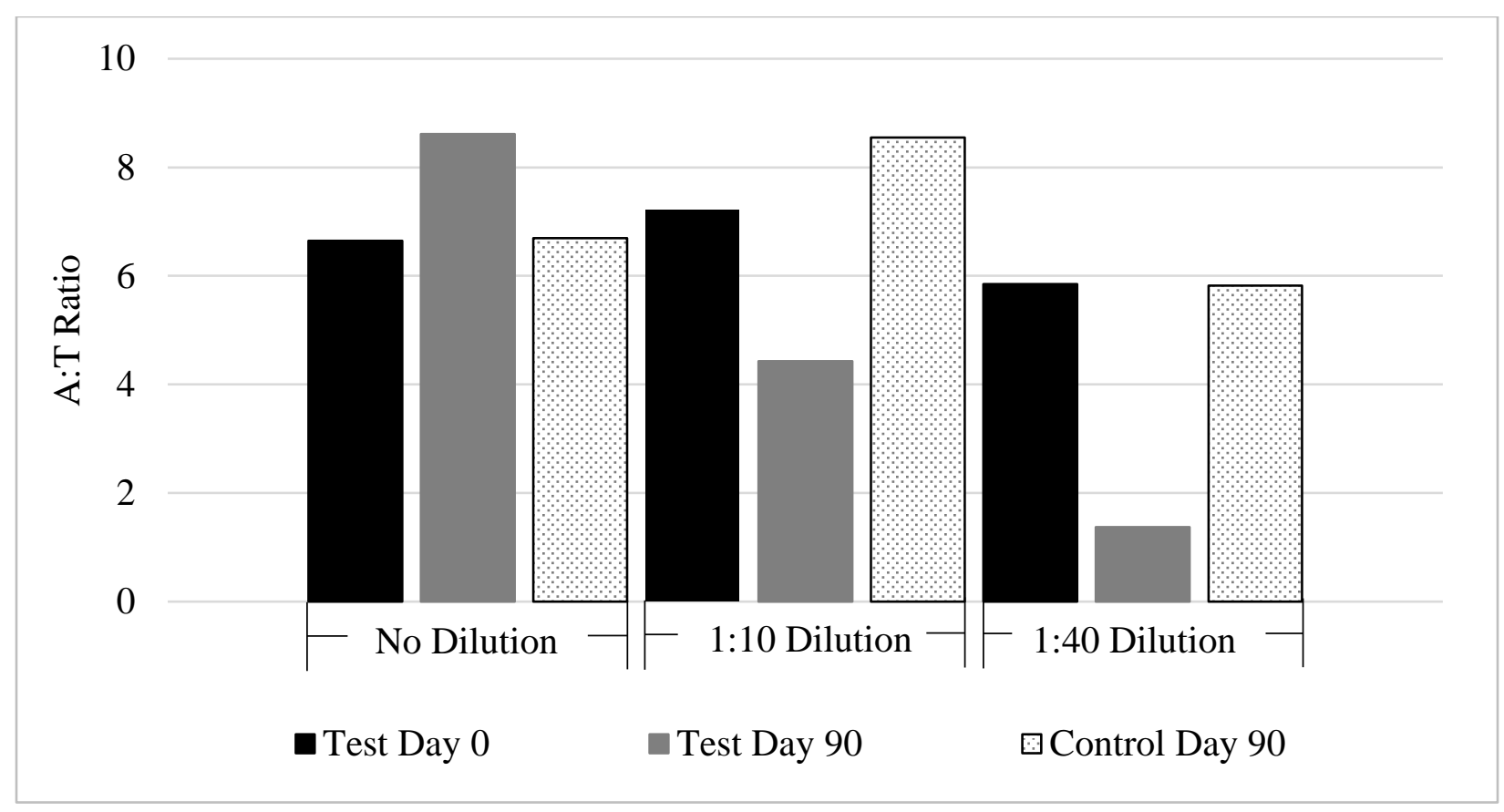

Figure F-9: Leachate E EEMs A:T Ratio

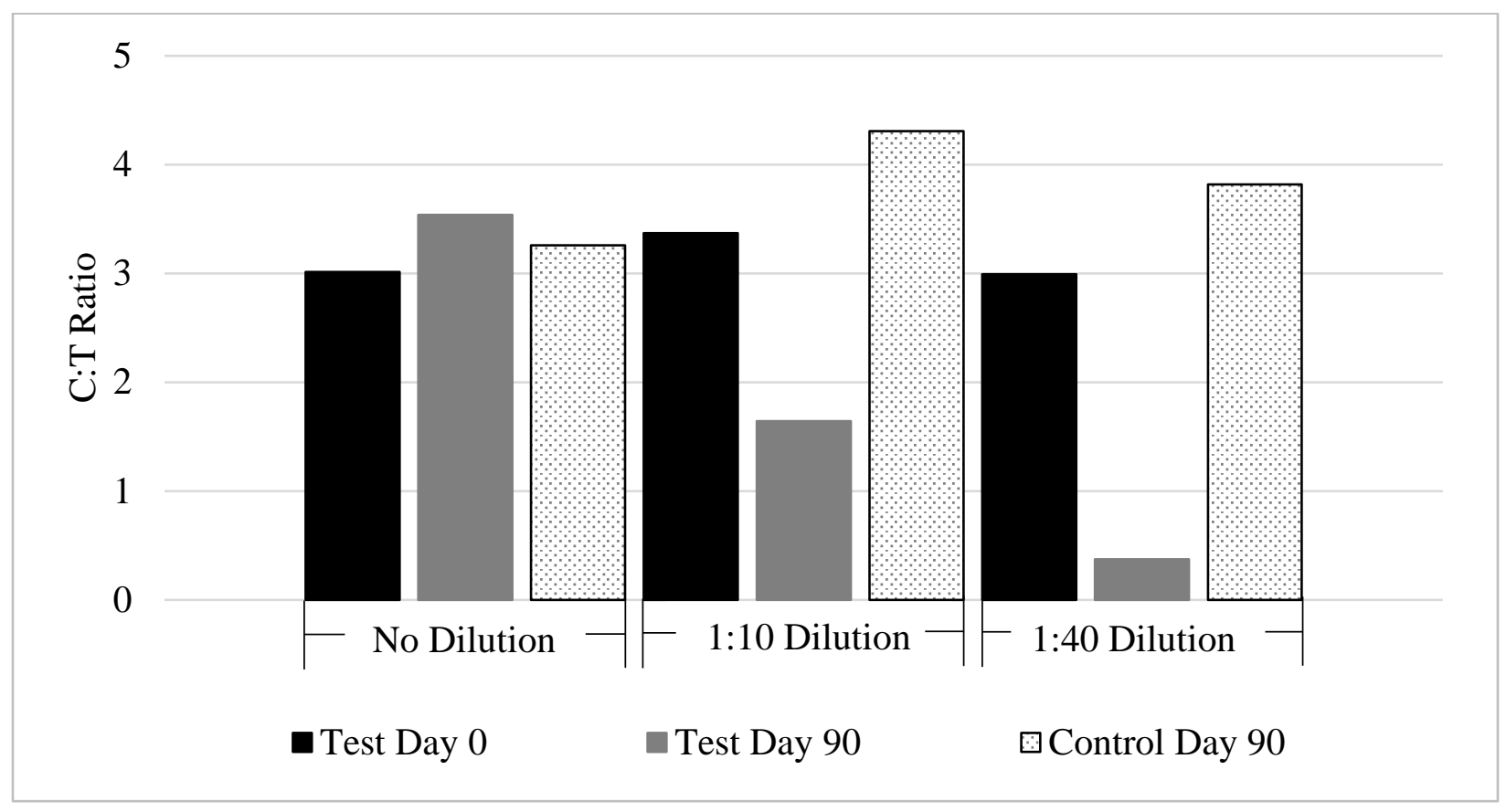

Figure F-10: Leachate E EEMs C:T Ratio 
$\underline{\text { Leachate F }}$

Table F-11: Leachate F Day 0 EEMs Data

\begin{tabular}{|c|c|c|c|c|c|c|c|c|c|c|c|}
\hline \multirow{2}{*}{ Sample } & \multicolumn{4}{|c|}{ Quinine Sulfate Equivalents } & \multicolumn{3}{c|}{ Percent of Total Area } & \multicolumn{2}{c|}{ Fluorescence Measurements } \\
\cline { 2 - 12 } & A & C & M & T & Sum & A & C & M & T & A:T Ratio & C:T Ratio \\
\hline No Dilution & 52.8 & 24.0 & 20.6 & 5.6 & 103.0 & $51 \%$ & $23 \%$ & $20 \%$ & $5 \%$ & 9.4 & 4.3 \\
\hline 1:10 Dilution & 24.9 & 12.5 & 11.1 & 3.3 & 51.8 & $48 \%$ & $24 \%$ & $21 \%$ & $6 \%$ & 7.5 & 3.8 \\
\hline 1:40 Dilution & 6.2 & 3.2 & 2.9 & 1.0 & 13.3 & $47 \%$ & $24 \%$ & $22 \%$ & $8 \%$ & 6.2 & 3.2 \\
\hline
\end{tabular}

Table F-12: Leachate F Day 90 EEMs Data

\begin{tabular}{|c|c|c|c|c|c|c|c|c|c|c|c|}
\hline \multirow{2}{*}{ Sample } & \multicolumn{5}{|c|}{ Quinine Sulfate Equivalents } & \multicolumn{4}{|c|}{ Percent of Total Area } & \multicolumn{2}{|c|}{ Fluorescence Measurements } \\
\hline & $\mathbf{A}$ & C & $\mathbf{M}$ & $\mathbf{T}$ & Sum & $\mathbf{A}$ & $\mathrm{C}$ & $\mathbf{M}$ & $\mathbf{T}$ & A:T Ratio & C:T Ratio \\
\hline No Dilution & 22.5 & 8.4 & 8.6 & 3.0 & 42.5 & $53 \%$ & $20 \%$ & $20 \%$ & $7 \%$ & 7.5 & 2.8 \\
\hline No Dilution Control & 37.0 & 17.6 & 16.2 & 5.2 & 76.0 & $50 \%$ & $25 \%$ & $21 \%$ & $5 \%$ & 9.9 & 5.0 \\
\hline 1:10 Dilution & 80.0 & 30.0 & 40.0 & 30.0 & 180.0 & $44 \%$ & $17 \%$ & $22 \%$ & $17 \%$ & 2.7 & 1.0 \\
\hline 1:10 Dilution Control & 23.1 & 11.6 & 9.7 & 2.7 & 47.1 & $49 \%$ & $25 \%$ & $21 \%$ & $6 \%$ & 8.6 & 4.3 \\
\hline 1:40 Dilution & 30.0 & 20.0 & 10.0 & 10.0 & 70.0 & $43 \%$ & $29 \%$ & $14 \%$ & $14 \%$ & 3.0 & 2.0 \\
\hline 1:40 Dilution Control & 7.0 & 4.0 & 4.0 & 1.0 & 16.0 & $44 \%$ & $25 \%$ & $25 \%$ & $6 \%$ & 7.0 & 4.0 \\
\hline
\end{tabular}




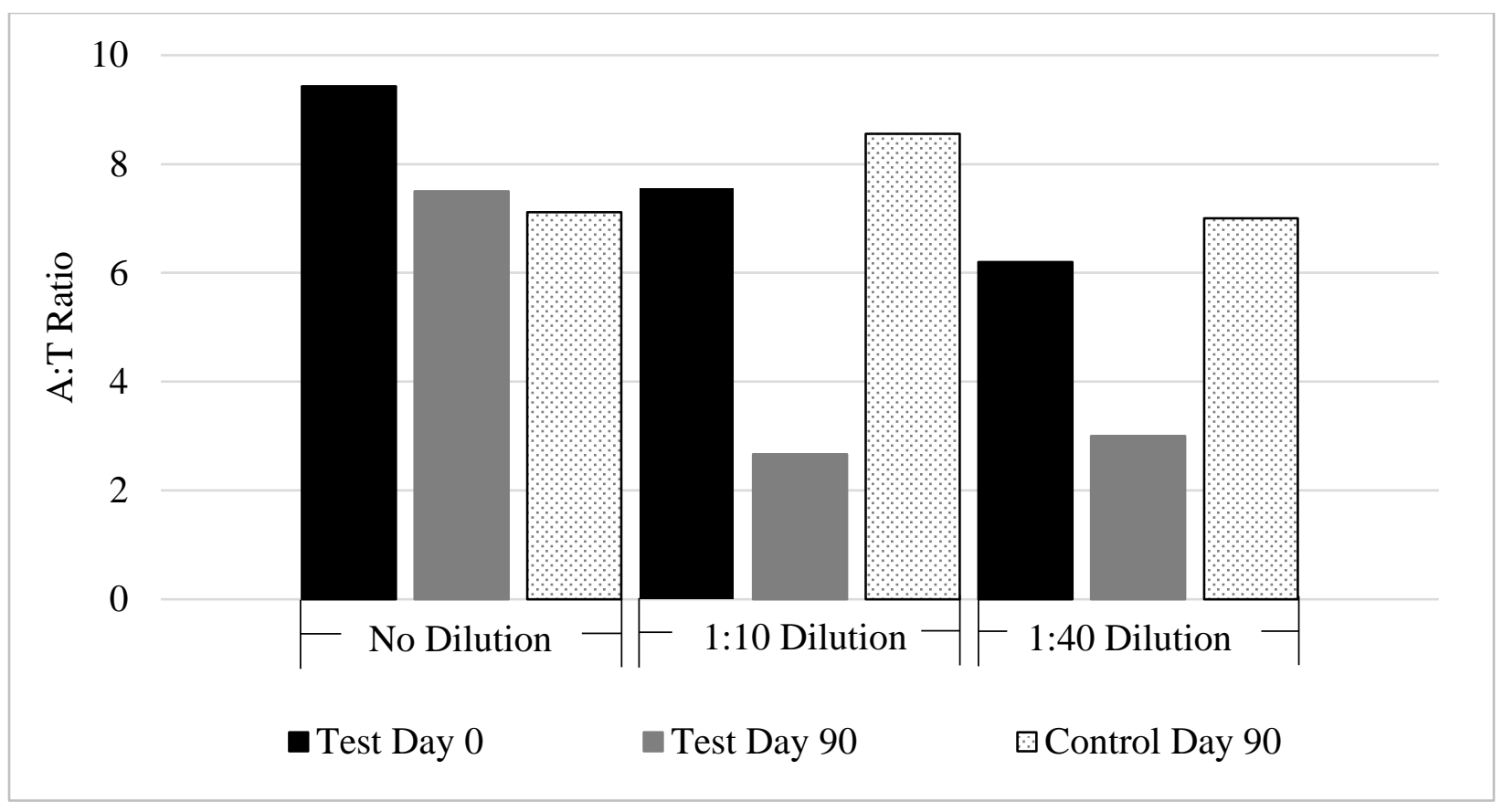

Figure F-11: Leachate F EEMs A:T Ratio

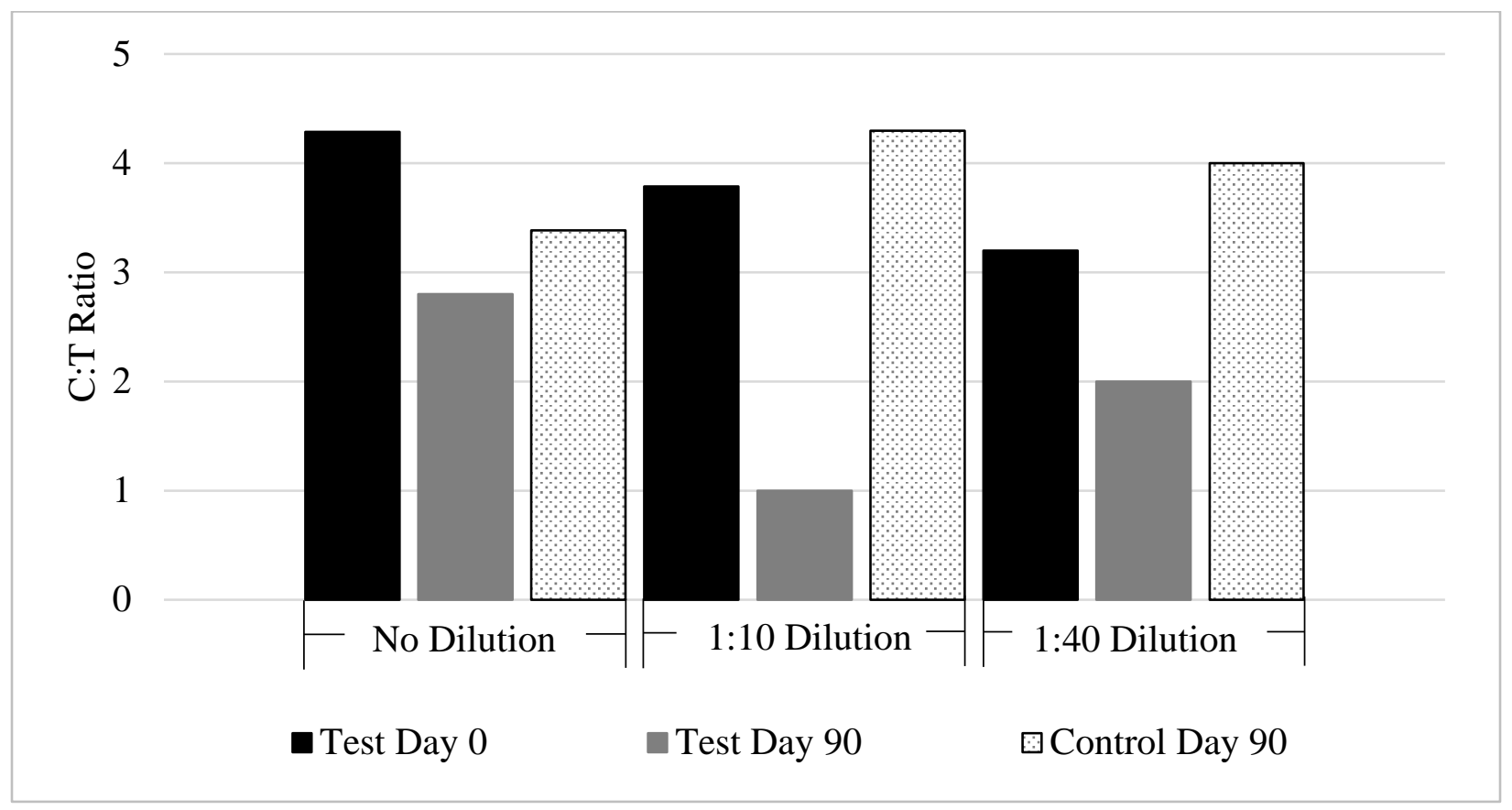

Figure F-12: Leachate F EEMs C:T Ratio 
Leachate G

Table F-13: Leachate G Day 0 EEMs Data

\begin{tabular}{|c|c|c|c|c|c|c|c|c|c|c|c|}
\hline \multirow{2}{*}{ Sample } & \multicolumn{1}{|c|}{ Quinine Sulfate Equivalents } & \multicolumn{3}{c|}{ Percent of Total Area } & \multicolumn{2}{c|}{ Fluorescence Measurements } \\
\cline { 2 - 12 } & A & C & M & T & Sum & A & C & M & T & A:T Ratio & C:T Ratio \\
\hline No Dilution & 47.7 & 22.8 & 20.7 & 7.6 & 99 & $48 \%$ & $23 \%$ & $21 \%$ & $8 \%$ & 6.3 & 3.0 \\
\hline 1:10 Dilution & 4.8 & 2.3 & 2.1 & 0.8 & 10 & $48 \%$ & $23 \%$ & $21 \%$ & $8 \%$ & 6.3 & 3.0 \\
\hline 1:50 Dilution & 1.0 & 0.5 & 0.4 & 0.2 & 2 & $48 \%$ & $23 \%$ & $21 \%$ & $8 \%$ & 6.3 & 3.0 \\
\hline
\end{tabular}

Table F-14: Leachate G Day 90 EEMs Data

\begin{tabular}{|c|c|c|c|c|c|c|c|c|c|c|c|}
\hline \multirow{2}{*}{ Sample } & \multicolumn{9}{|c|}{ Quinine Sulfate Equivalents } & \multicolumn{3}{c|}{ Percent of Total Area } & \multicolumn{2}{c|}{ Fluorescence Measurements } \\
\cline { 2 - 13 } & A & C & M & T & Sum & A & C & M & T & A:T Ratio & C:T Ratio \\
\hline No Dilution & 40.6 & 16.7 & 14.8 & 5.6 & 78 & $52 \%$ & $21 \%$ & $19 \%$ & $7 \%$ & 7.3 & 3.0 \\
\hline No Dilution Control & 43.7 & 19.1 & 18.1 & 6.7 & 88 & $50 \%$ & $22 \%$ & $21 \%$ & $8 \%$ & 6.5 & 2.9 \\
\hline 1:10 Dilution & 9.9 & 3.9 & 3.7 & 1.6 & 19 & $52 \%$ & $20 \%$ & $19 \%$ & $8 \%$ & 6.2 & 2.4 \\
\hline 1:10 Dilution Control & 19.8 & 9.0 & 8.4 & 2.6 & 40 & $50 \%$ & $23 \%$ & $21 \%$ & $7 \%$ & 7.6 & 3.5 \\
\hline 1:50 Dilution & 52.9 & 27.3 & 32.5 & 52.8 & 166 & $32 \%$ & $16 \%$ & $20 \%$ & $32 \%$ & 1.0 & 0.5 \\
\hline 1:50 Dilution Control & 14.0 & 7.9 & 7.0 & 2.4 & 31 & $45 \%$ & $25 \%$ & $22 \%$ & $8 \%$ & 5.8 & 3.3 \\
\hline 1:50 Dilution With Sodium Azide & 9.4 & 3.6 & 3.6 & 2.1 & 19 & $30 \%$ & $12 \%$ & $11 \%$ & $7 \%$ & 4.6 & 1.8 \\
\hline
\end{tabular}

$(* 1: 10$ dilution control bag broke on day 49 of experimental test, show in day 49$)$ 


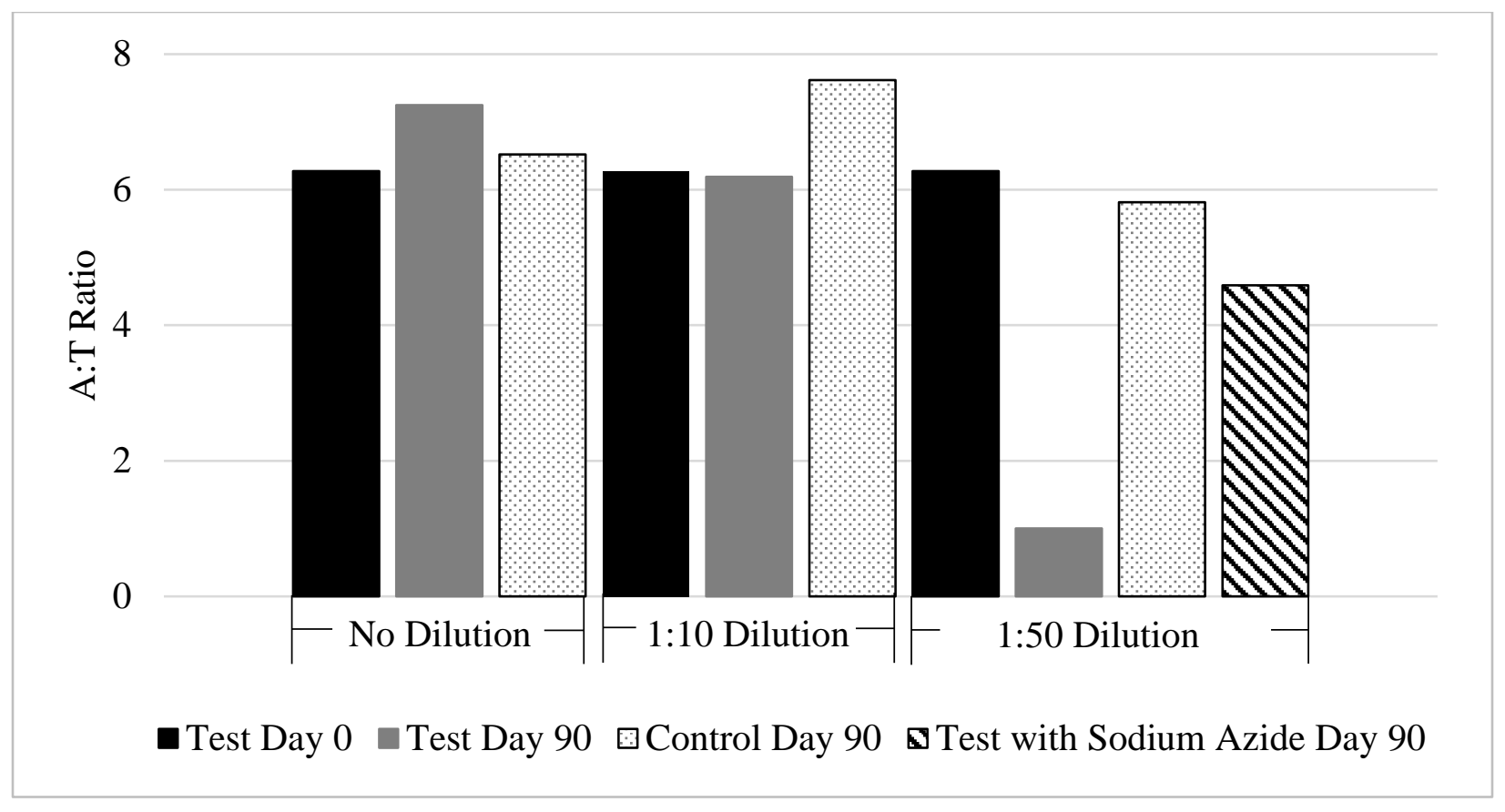

Figure F-13: Leachate G EEMs A:T Ratio

(*1:10 dilution control bag broke on day 49 of experimental test, show in day 49)

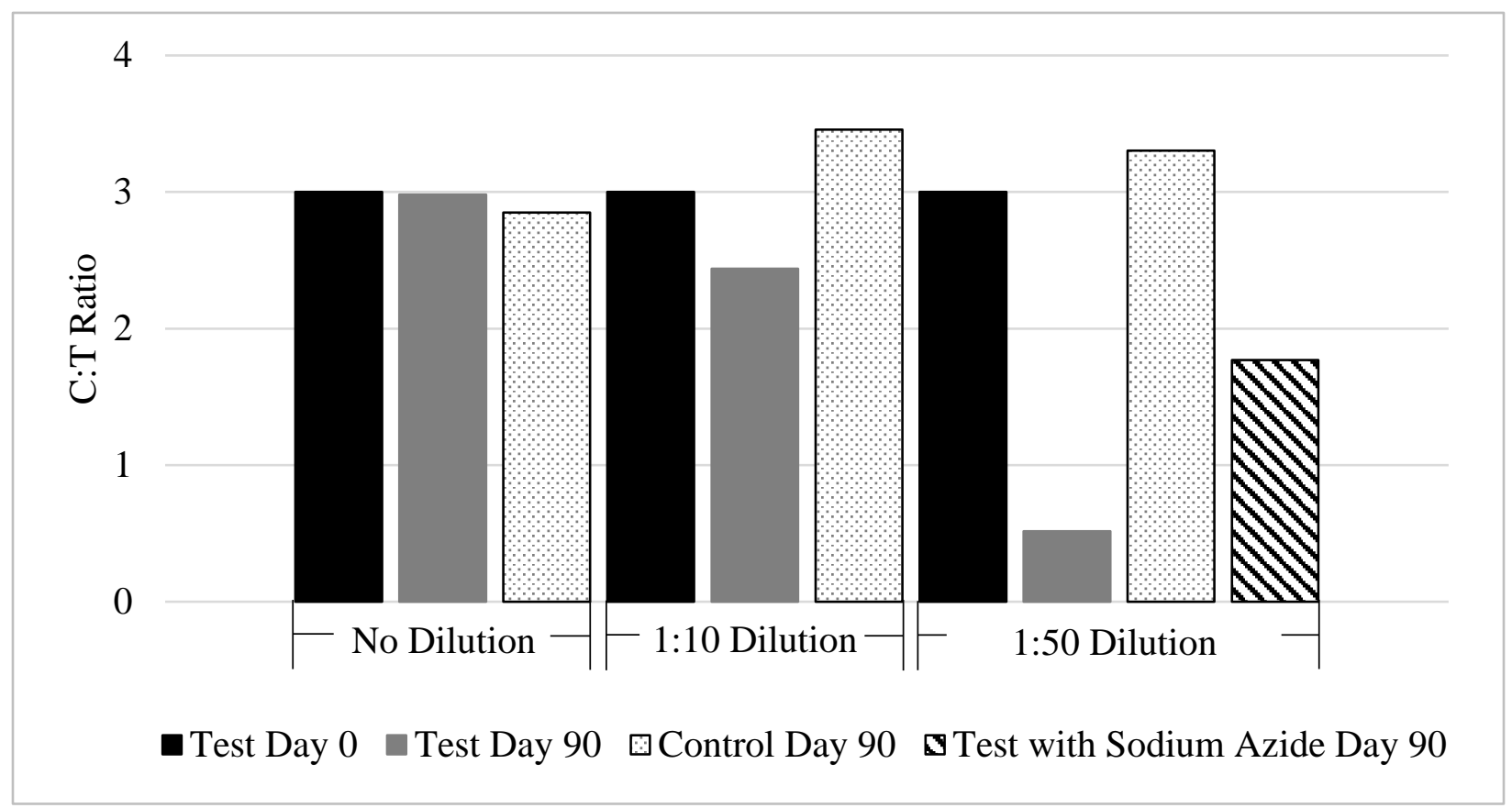

Figure F-14: Leachate G EEMs C:T Ratio

(*1:10 dilution control bag broke on day 49 of experimental test, show in day 49) 
$\underline{\text { Leachate } \mathrm{H}}$

Table F-15: Leachate H Day 0 EEMs Data

\begin{tabular}{|c|c|c|c|c|c|c|c|c|c|c|c|}
\hline \multirow{2}{*}{ Sample } & \multicolumn{4}{|c|}{ Quinine Sulfate Equivalents } & \multicolumn{3}{c|}{ Percent of Total Area } & \multicolumn{2}{c|}{ Fluorescence Measurements } \\
\cline { 2 - 30 } & A & C & M & T & Sum & A & C & M & T & A:T Ratio & C:T Ratio \\
\hline No Dilution & 19.99 & 9.56 & 8 & 2.69 & 40 & $50 \%$ & $24 \%$ & $20 \%$ & $7 \%$ & 7.4 & 3.6 \\
\hline 1:10 Dilution & 2.0 & 1.0 & 0.8 & 0.3 & 4 & $50 \%$ & $24 \%$ & $20 \%$ & $7 \%$ & 3.6 \\
\hline 1:50 Dilution & 0.4 & 0.2 & 0.2 & 0.1 & 1 & $50 \%$ & $24 \%$ & $20 \%$ & $7 \%$ & 7.4 & 3.6 \\
\hline
\end{tabular}

Table F-16: Leachate H Day 90 EEMs Data

\begin{tabular}{|c|c|c|c|c|c|c|c|c|c|c|c|}
\hline \multirow{2}{*}{ Sample } & \multicolumn{1}{|c|}{ Quinine Sulfate Equivalents } & \multicolumn{2}{c|}{ Percent of Total Area } & Fluorescence Measurements \\
\cline { 2 - 13 } & A & C & M & T & Sum & A & C & M & T & A:T Ratio & C:T Ratio \\
\hline No Dilution & 12.78 & 5.46 & 5.12 & 1.85 & 25 & $51 \%$ & $22 \%$ & $20 \%$ & $7 \%$ & 6.9 & 3.0 \\
\hline No Dilution Control & 20.68 & 8.89 & 7.93 & 2.81 & 40 & $51 \%$ & $22 \%$ & $20 \%$ & $7 \%$ & 7.4 & 3.2 \\
\hline No Dilution With Sodium Azide & 18.96 & 7.5 & 6.89 & 2.9 & 36 & $52 \%$ & $21 \%$ & $19 \%$ & $8 \%$ & 6.5 & 2.6 \\
\hline 1:10 Dilution & 12.13 & 4.48 & 4.72 & 5.47 & 27 & $45 \%$ & $17 \%$ & $18 \%$ & $20 \%$ & 2.2 & 0.8 \\
\hline 1:10 Dilution Control & 7.97 & 3.5 & 3.02 & 1.1 & 16 & $51 \%$ & $22 \%$ & $19 \%$ & $7 \%$ & 7.2 & 3.2 \\
\hline 1:10 Dilution With Sodium Azide & 4.78 & 1.92 & 2.04 & 1.78 & 11 & $45 \%$ & $18 \%$ & $19 \%$ & $17 \%$ & 2.7 & 1.1 \\
\hline 1:50 Dilution & 3.49 & 1.16 & 1.42 & 3.95 & 10 & $35 \%$ & $12 \%$ & $14 \%$ & $39 \%$ & 0.9 & 0.3 \\
\hline 1:50 Dilution Control & 16.4 & 7.51 & 6.27 & 5.4 & 36 & $46 \%$ & $21 \%$ & $18 \%$ & $15 \%$ & 3.0 & 1.4 \\
\hline 1:50 Dilution With Sodium Azide & 16.9 & 7.22 & 6.68 & 5.39 & 36 & $47 \%$ & $20 \%$ & $18 \%$ & $15 \%$ & 3.1 & 1.3 \\
\hline
\end{tabular}




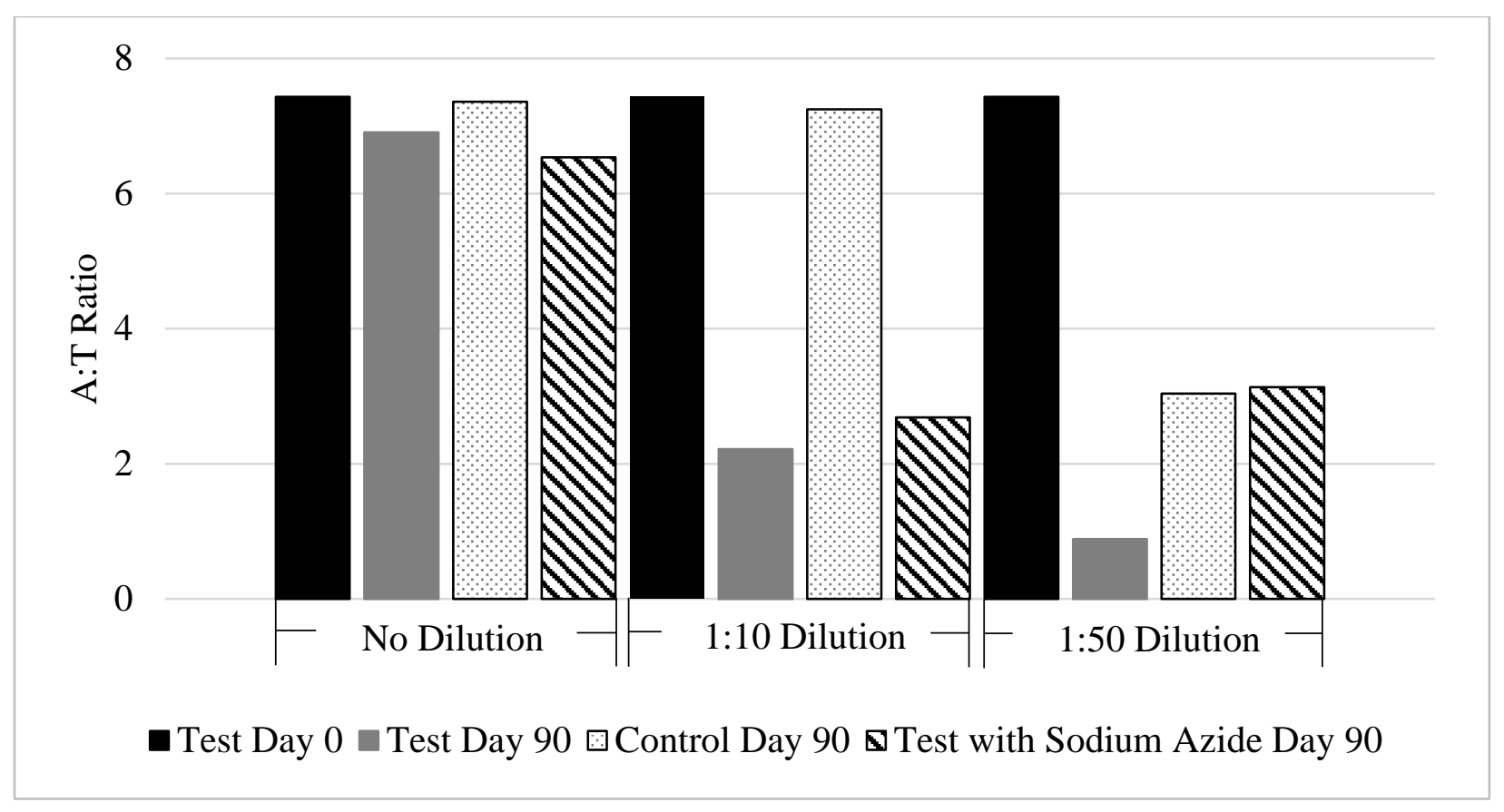

Figure F-15: Leachate H EEMs A:T Ratio

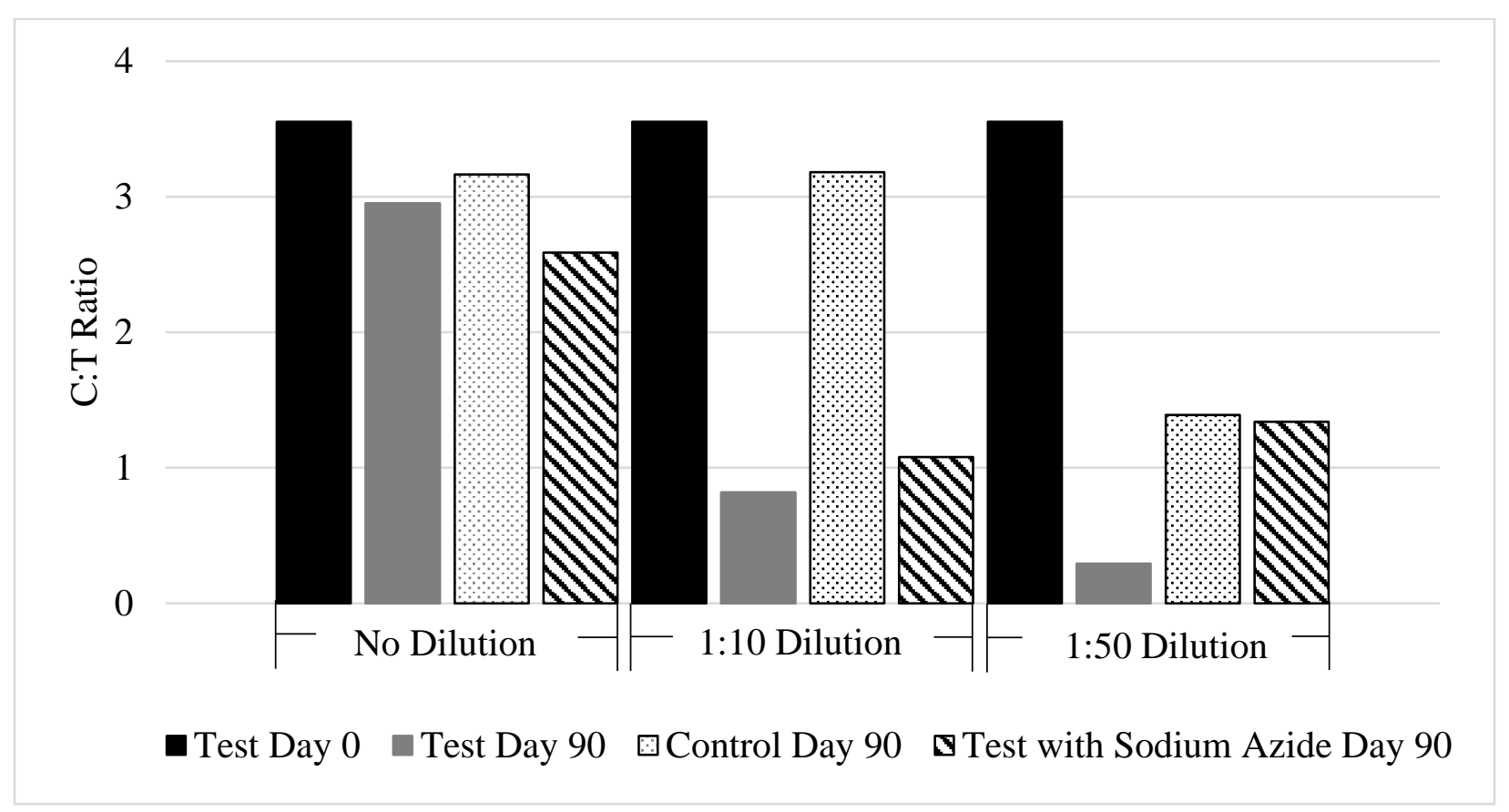

Figure F-16: Leachate H EEMs C:T Ratio 


\section{APPENDIX G: SIZE-EXCLUSION CHROMATOGRAPHY DATA}


Leachate A

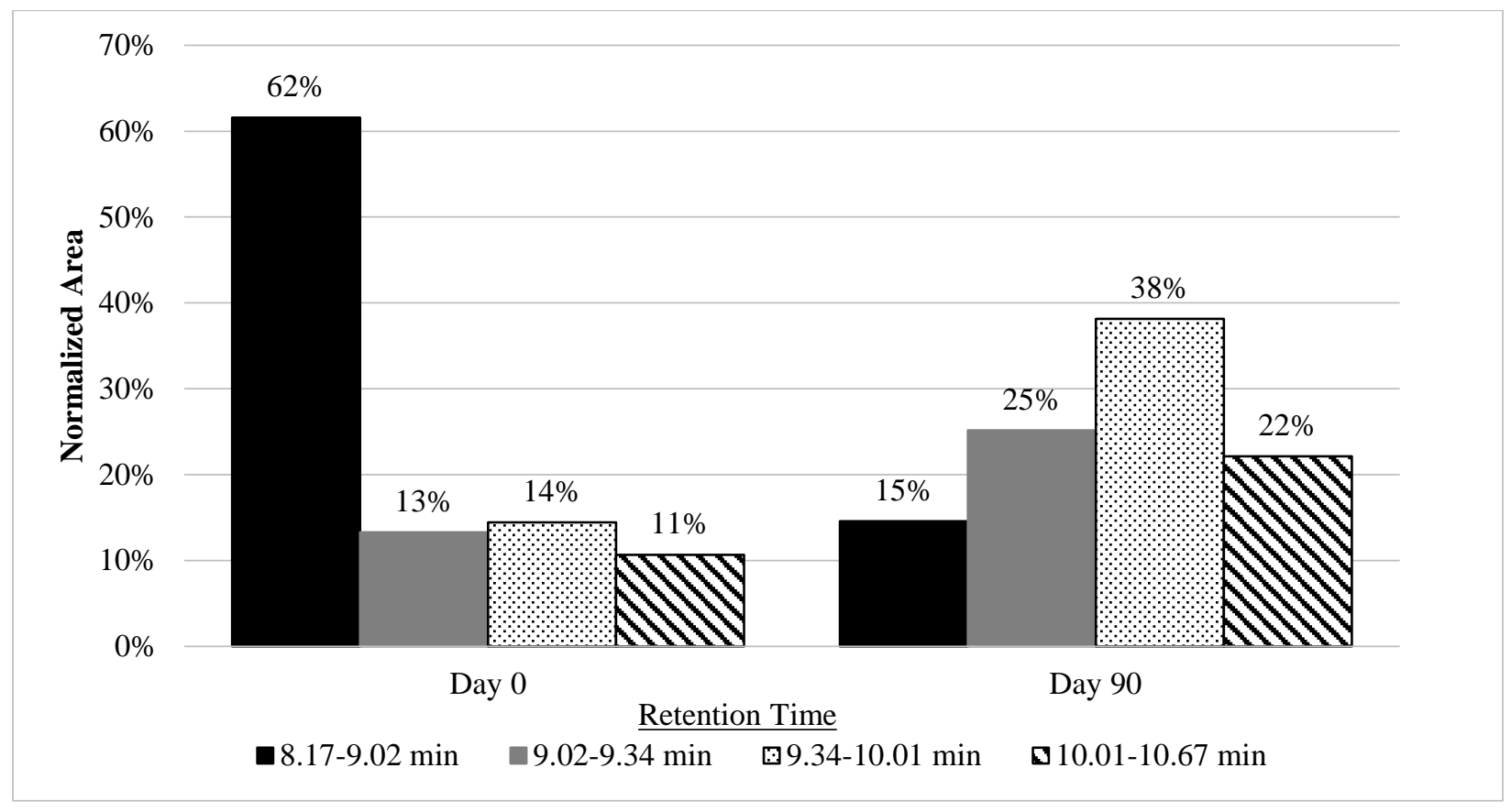

Figure G-1: Leachate A 1:100 Dilution SEC Normalized Peak Areas 


\section{Leachate C}

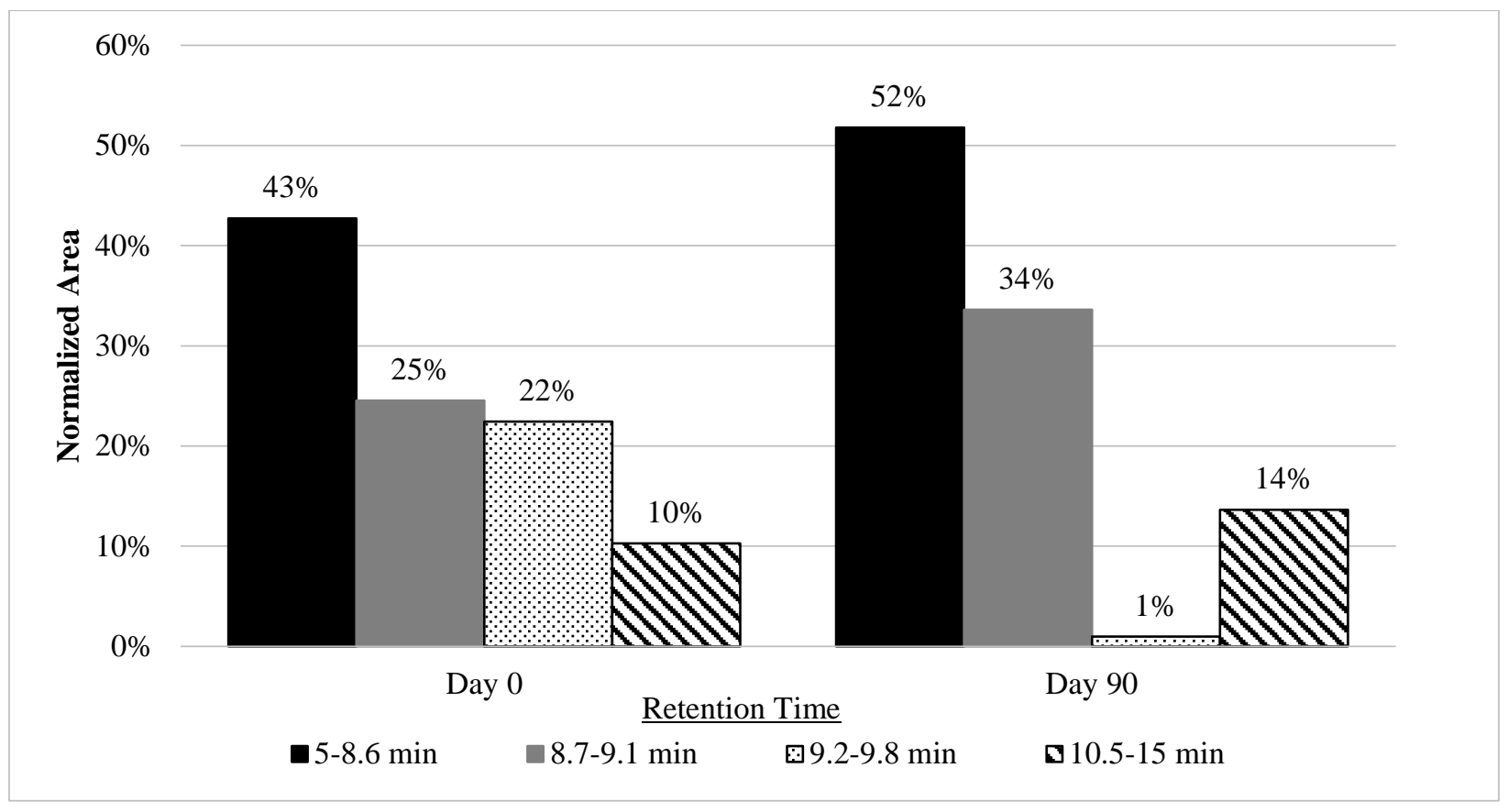

Figure G-2: Leachate C 1:4.1 Dilution SEC Normalized Peak Areas

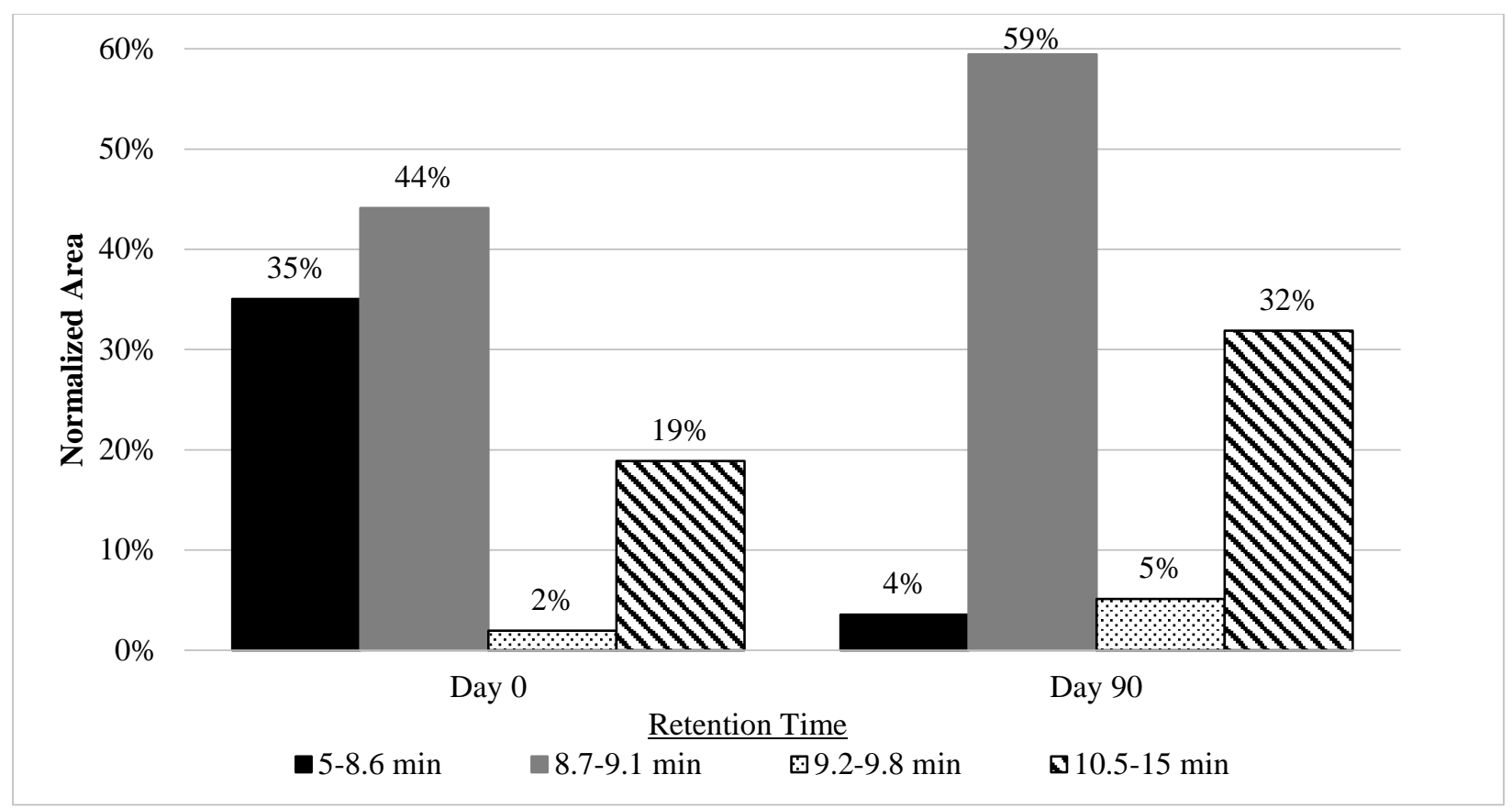

Figure G-3: Leachate C 1:31 Dilution SEC Normalized Peak Areas 
Leachate D

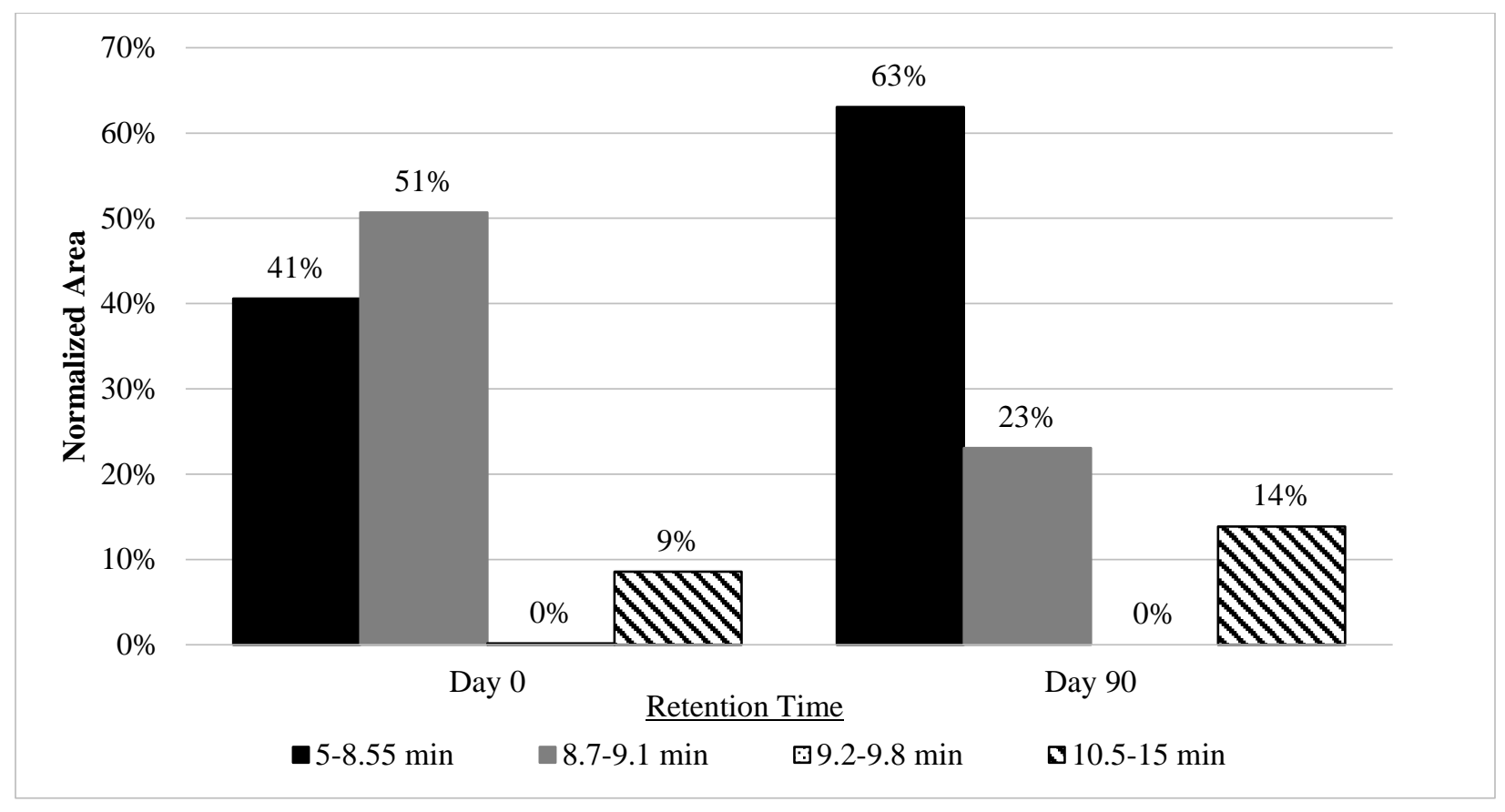

Figure G-4: Leachate D 1:2.4 Dilution SEC Normalized Peak Areas 


\section{Leachate E}

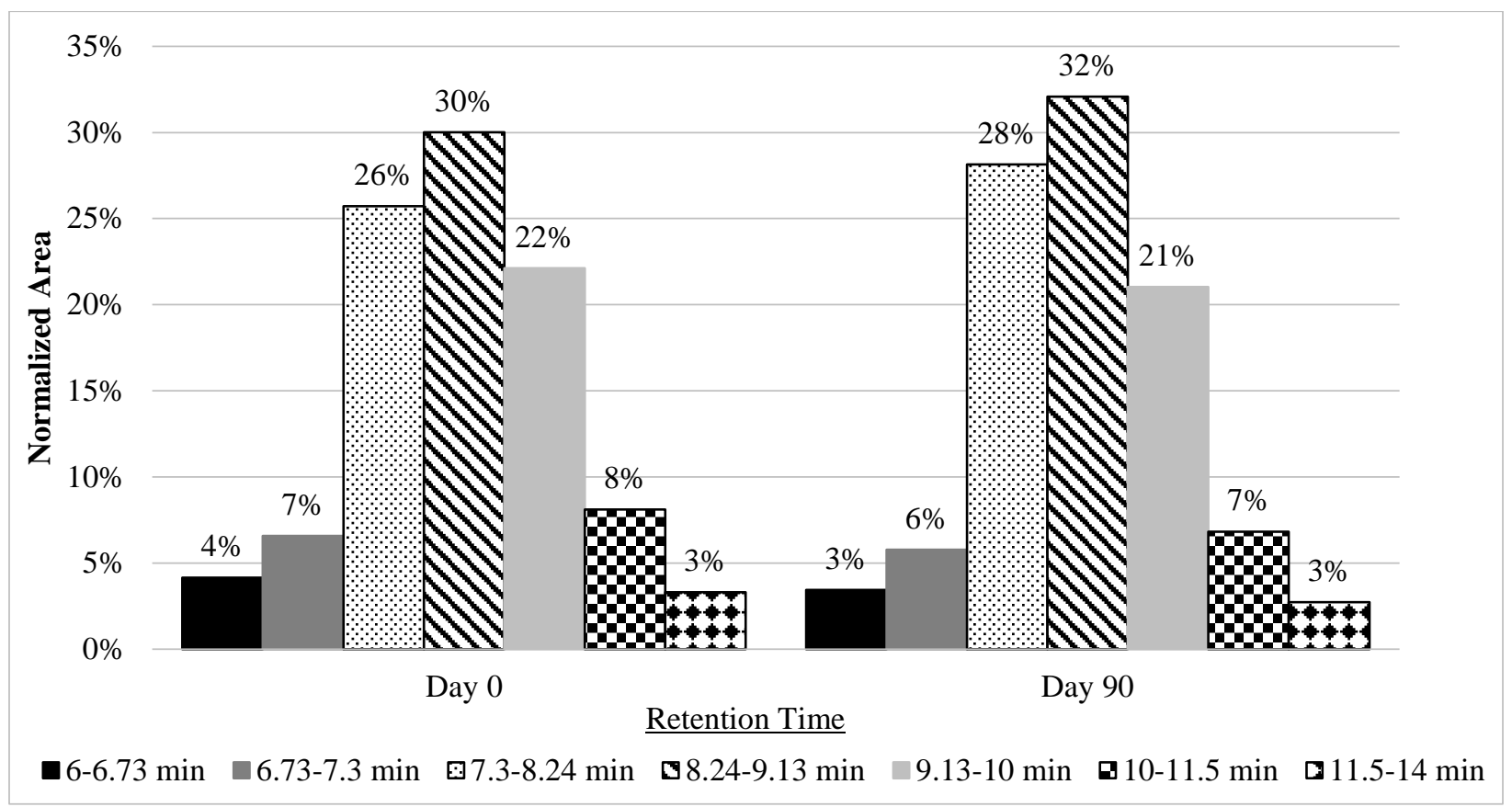

Figure G-5: Leachate E No Dilution SEC Normalized Peak Areas

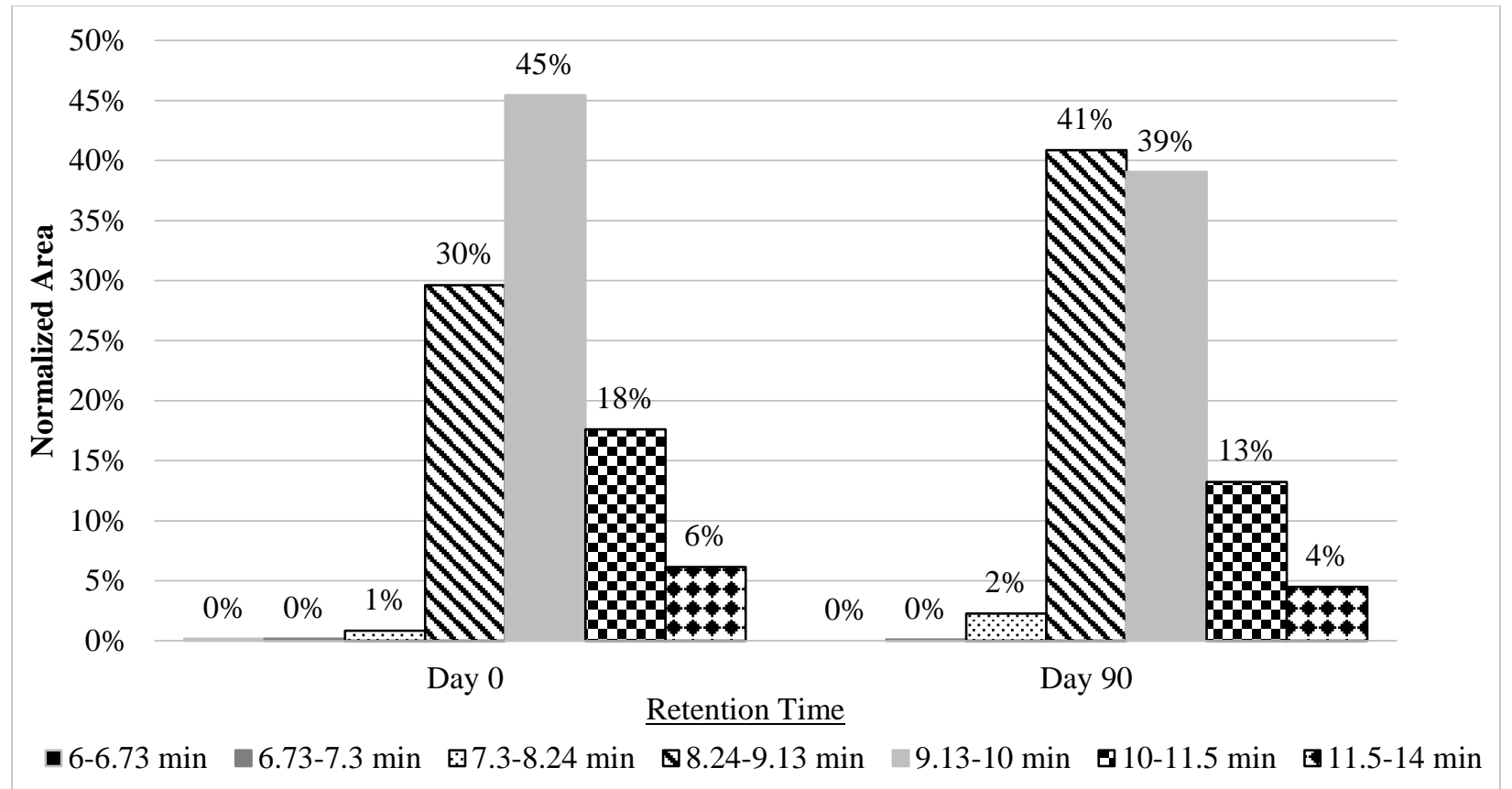

Figure G-6: Leachate E 1:10 Dilution SEC Normalized Peak Areas 


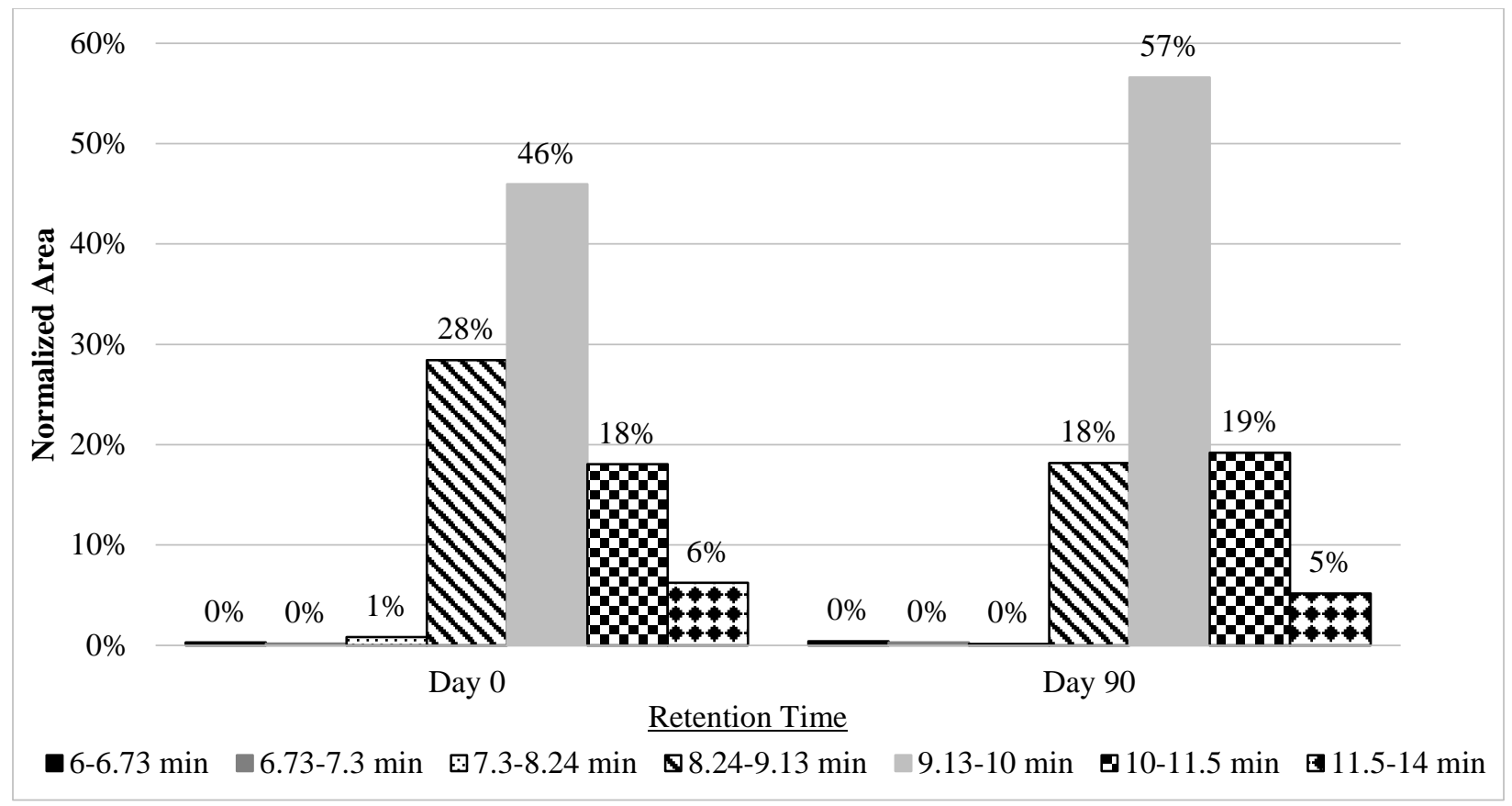

Figure G-7: Leachate E 1:40 Dilution SEC Normalized Peak Areas 


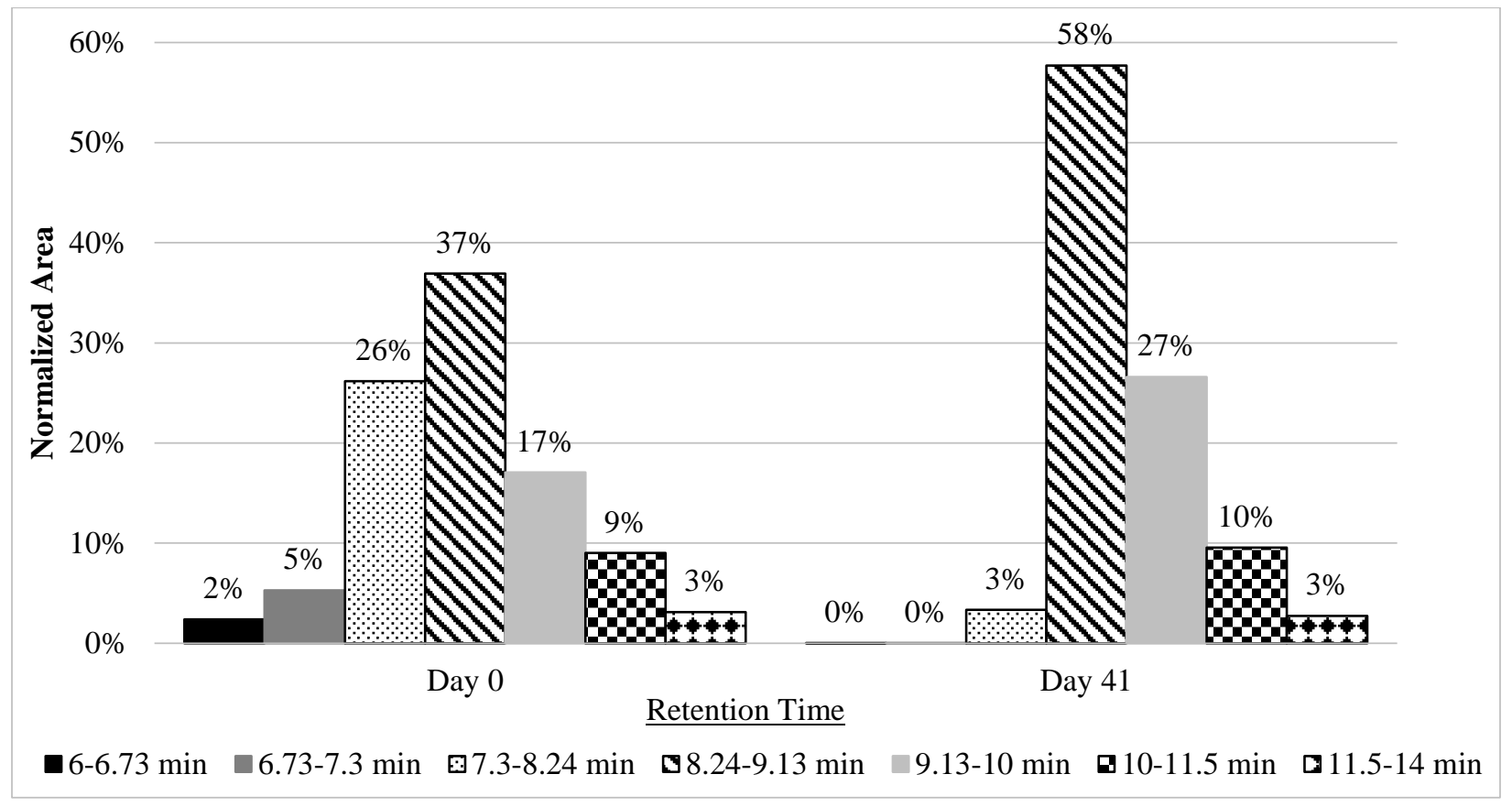

Figure G-8: Leachate F No Dilution SEC Normalized Peak Areas

*Shown is day 0 and day 41 of test. Concentrations at day 90 were below detectable limits

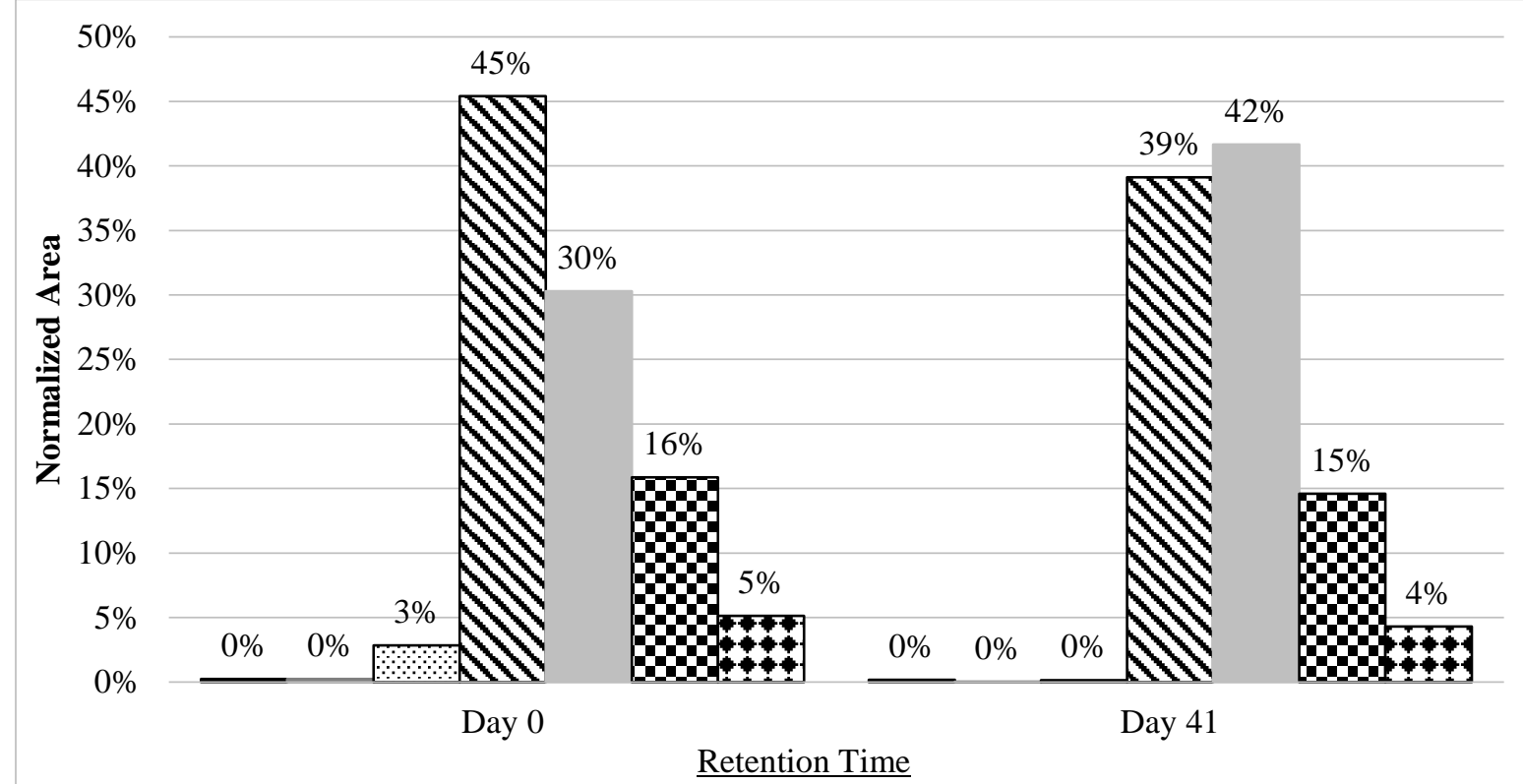

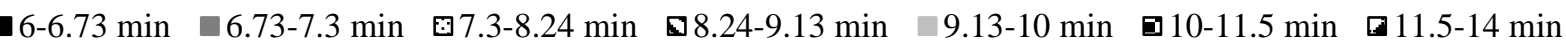

Figure G-9: Leachate F 1:10 Dilution SEC Normalized Peak Areas

*Shown is day 0 and day 41 of test. Concentrations at day 90 were below detectable limits 


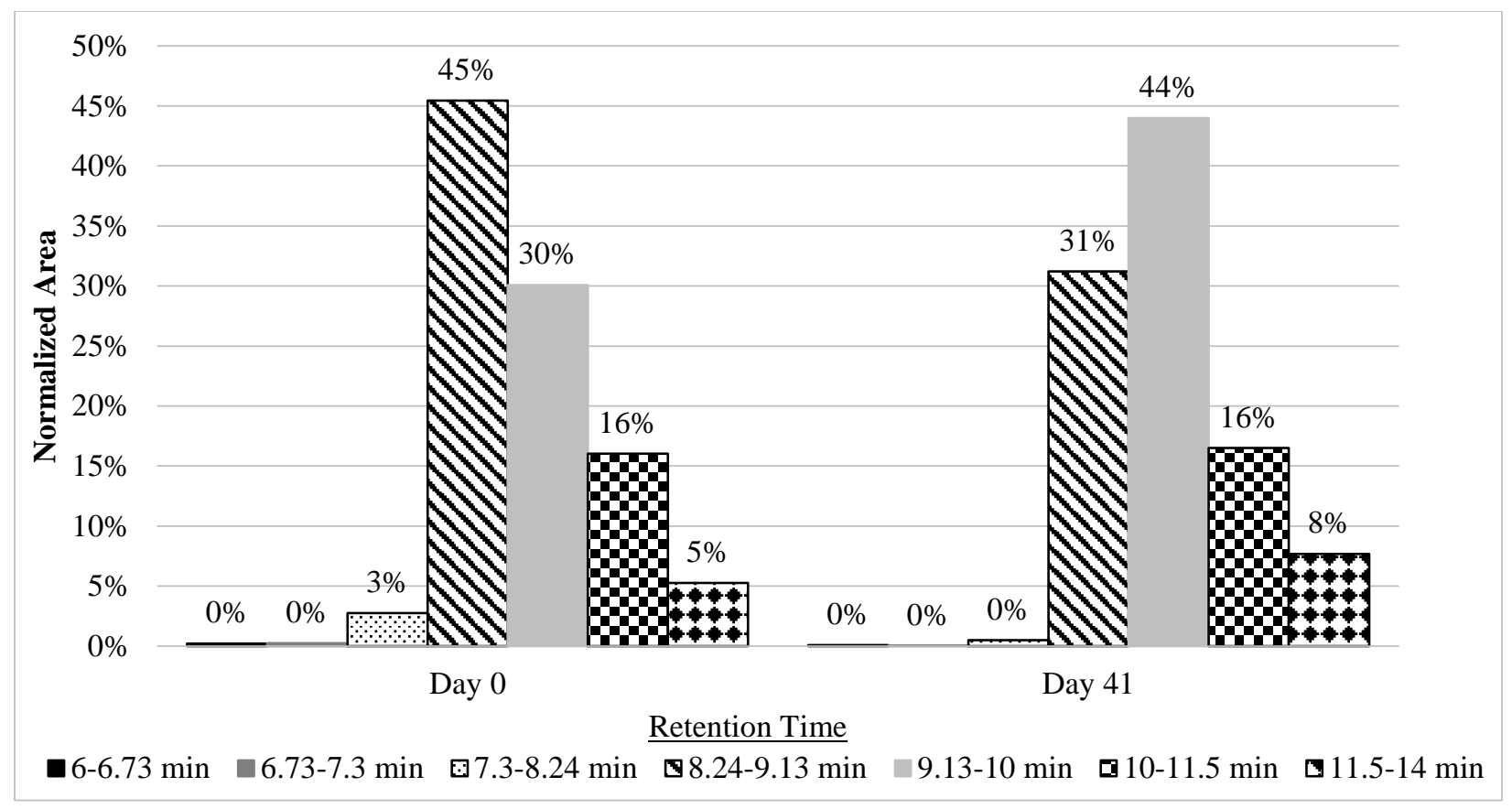

Figure G-10: Leachate F 1:40 Dilution SEC Normalized Peak Areas

*Shown is day 0 and day 41 of test. Concentrations at day 90 were below detectable limits 


\section{APPENDIX H: SOLAR IRRADIANCE DATA}




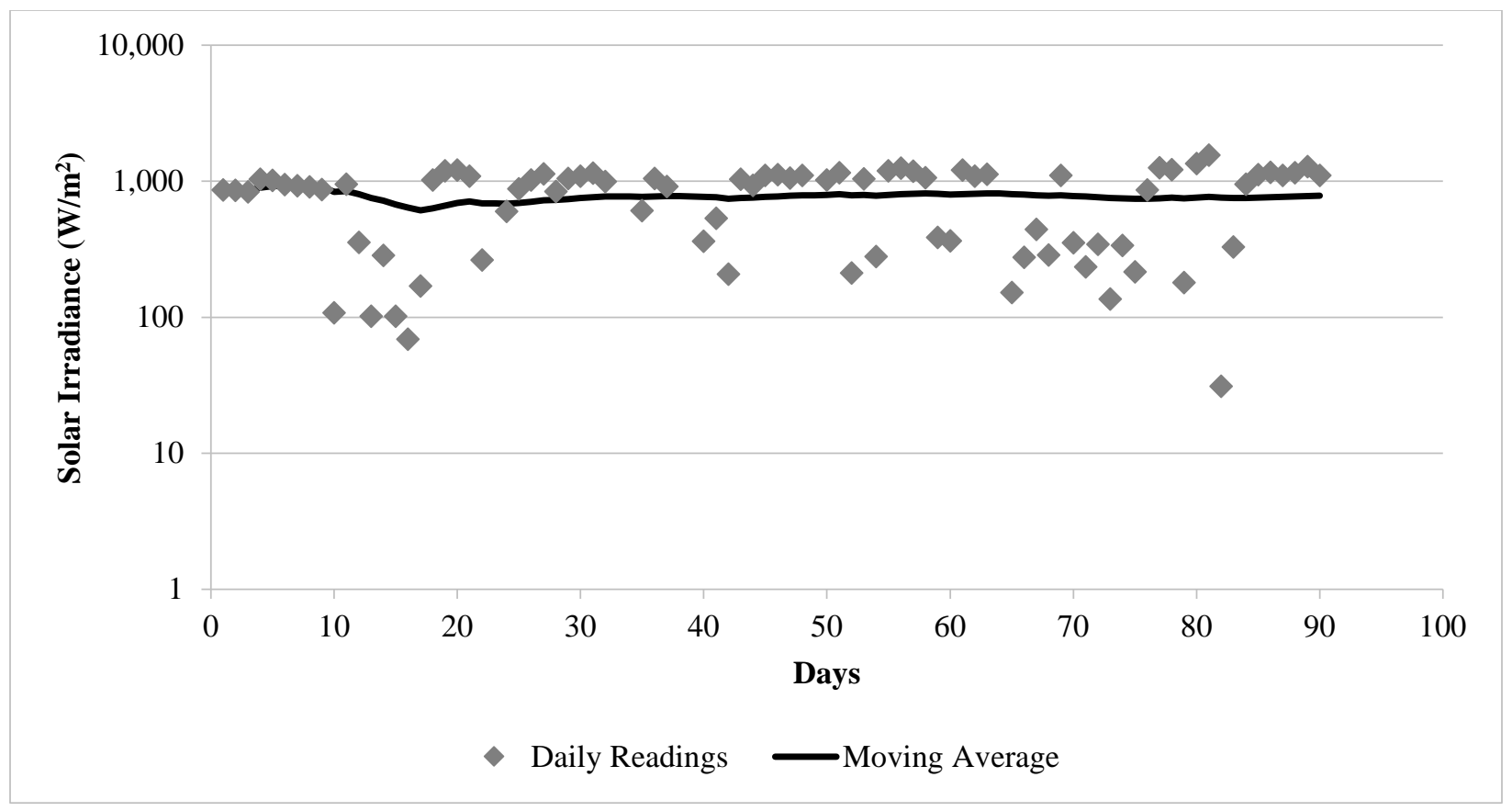

Figure H-1: Solar Irradiance Data from Batch Test 1 (Leachate A)

(start date: February 13, 2015; end date: May 14, 2015)

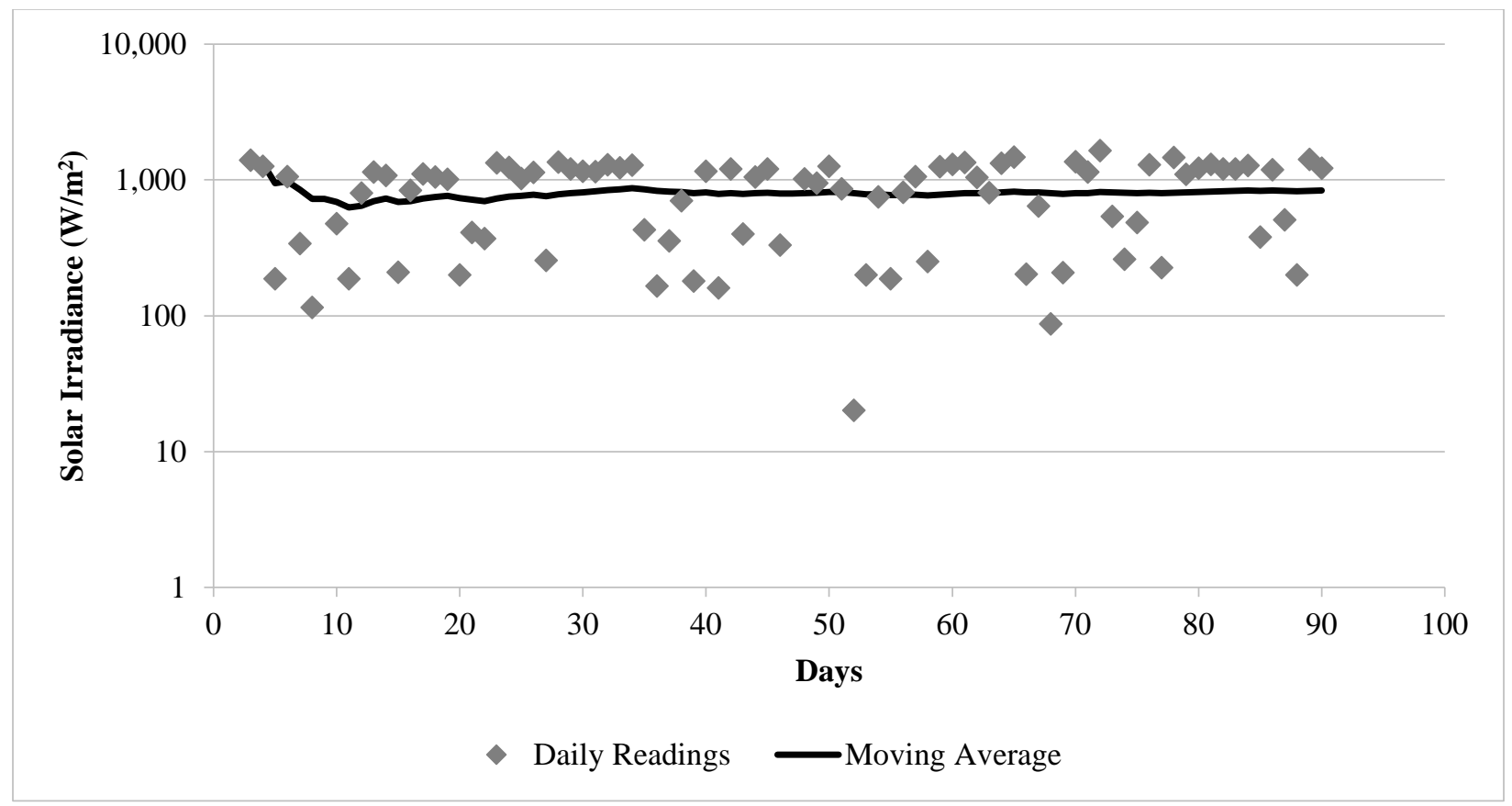

Figure H-2: Solar Irradiance Data from Batch Test 2 (Leachate B)

(start date: July 24, 2015; end date: October 22, 2015) 


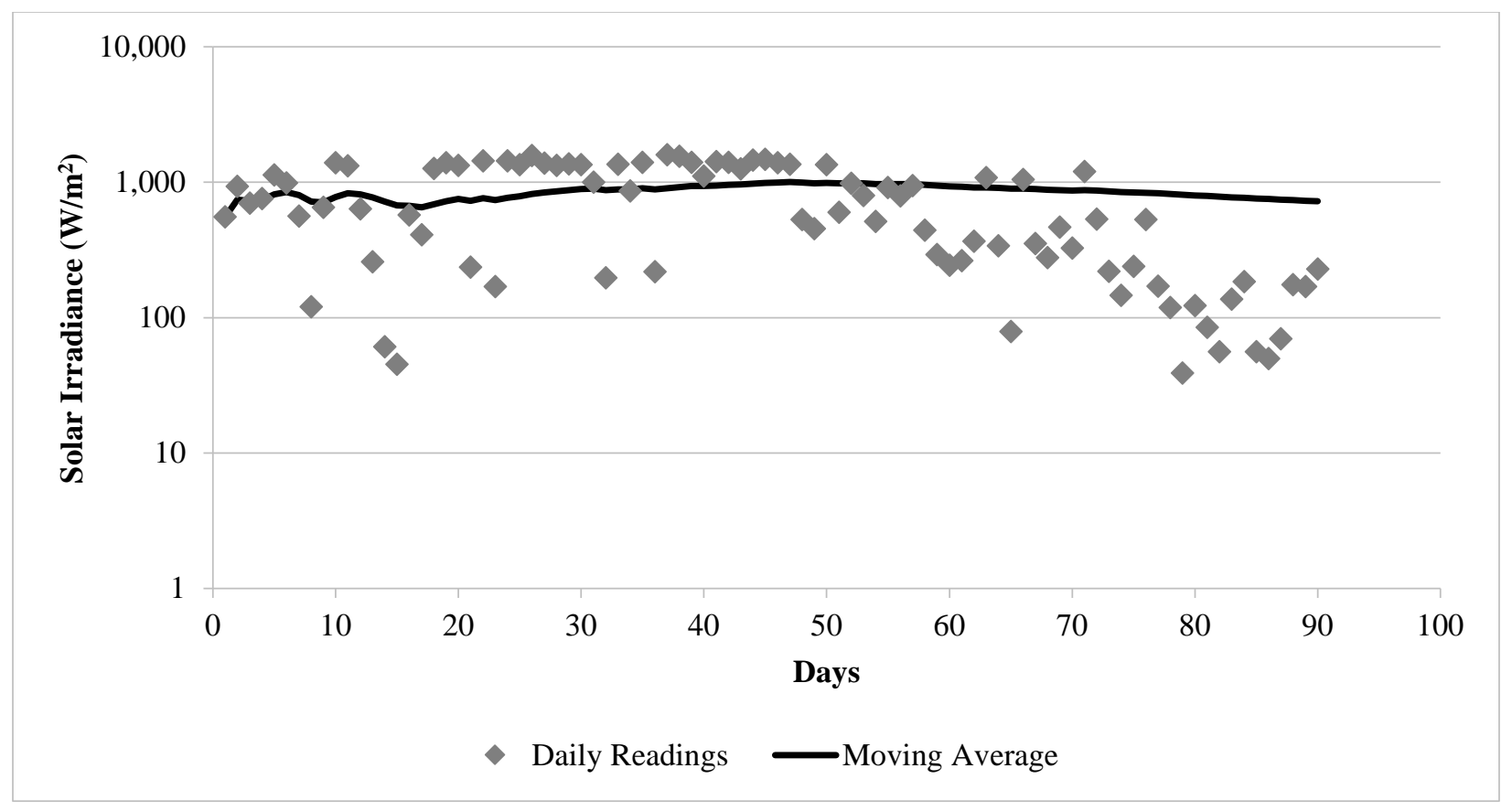

Figure H-3: Solar Irradiance Data from Batch Tests 3 and 4 (Leachates C \& D)

(start date: January 15, 2016; end date: April 14, 2016)

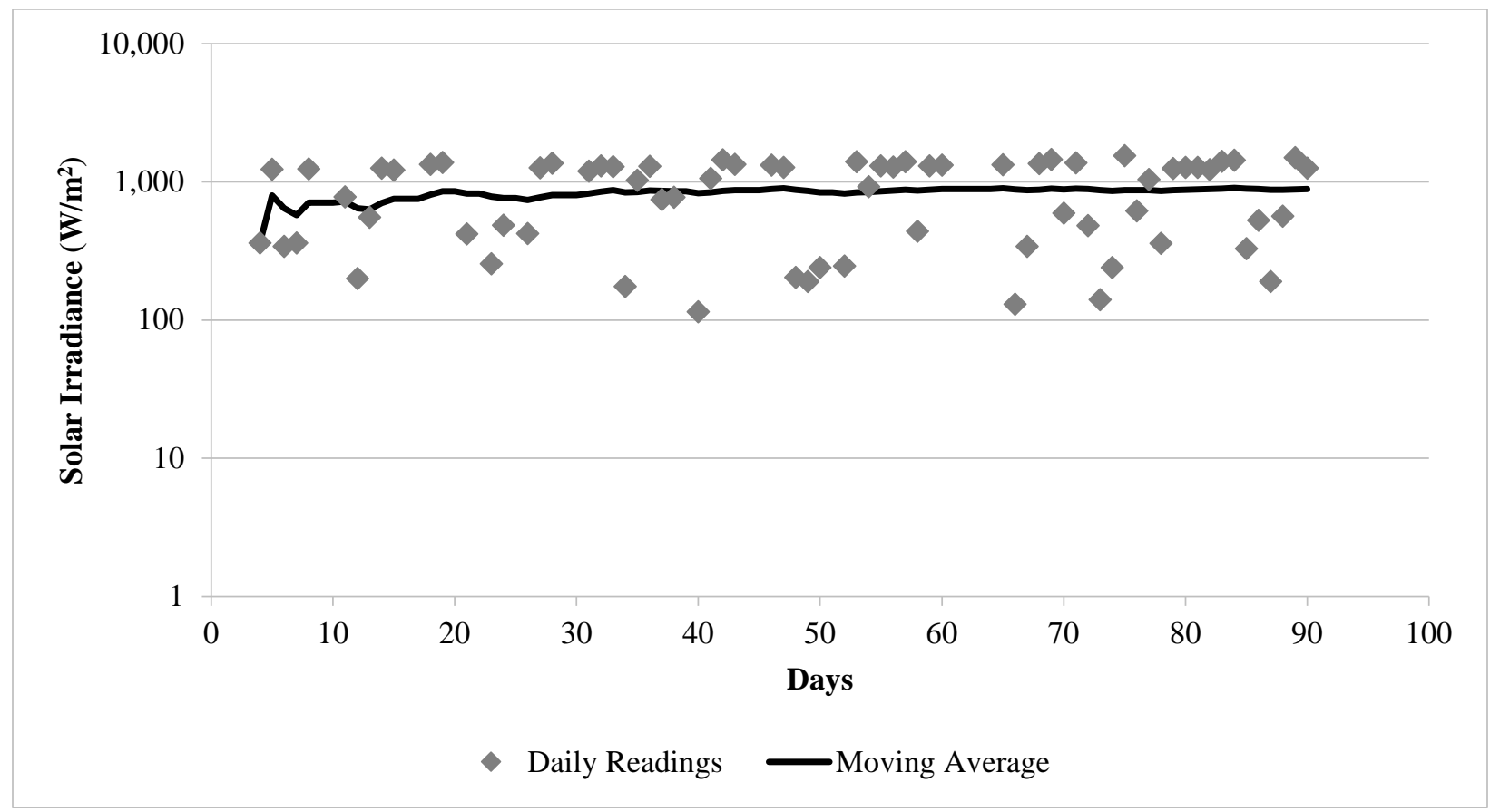

Figure H-4: Solar Irradiance Data from Batch Tests 5 and 6 (Leachates E \& F) (start date: November 3, 2016; end date: February 1, 2017) 


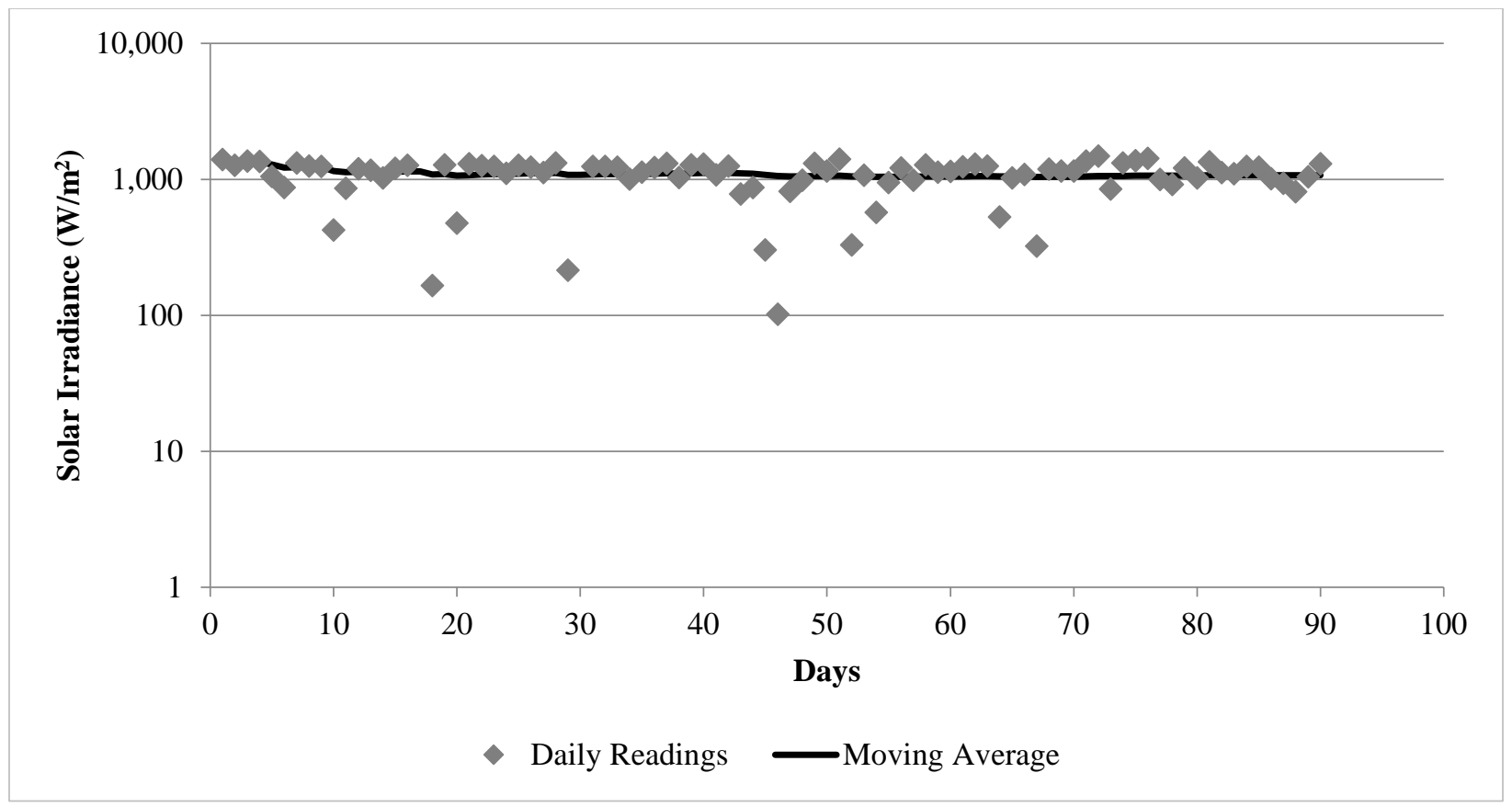

Figure H-5: Solar Irradiance Data from Batch Tests 7 and 8 (Leachates G \& H) (start date: July 13, 2017; end date: October 18, 2017 *Hurricane Irma delayed end date by 1 week) 


\section{REFERENCES}

Aiken, G. R., Heileen, H.-K., \& Ryan, J. N. (2011). Influence of Dissolved Organic Matter on the Environmental Fate of Metals, Nanoparticles, and Colloids. Environmental Science \& Technology, 45(8), 3196-3201. doi:10.1021/es103992s

Altmann, J., Massa, L., Sperlich, A., Gnirss, R., \& Jekel, M. (2016). UV254 absorbance as realtime monitoring and control parameter for micropollutant removal in advanced wastewater treatment with powdered activated carbon. Water Research, 94(Supplement C), 240-245. doi:https://doi.org/10.1016/j.watres.2016.03.001

American Public Health, A., Eaton, A. D., American Water Works, A., \& Water Environment, F. (2005). Standard methods for the examination of water and wastewater. Washington, D.C.: APHA-AWWA-WEF.

Barlaz, M. A., Rooker, A. P., Kjeldsen, P., Gabr, M. A., \& Borden, R. C. (2002). Critical Evaluation of Factors Required To Terminate the Postclosure Monitoring Period at Solid Waste Lnadfills. Environmental Science \& Technology, 36(16), 3457.

Barth, H. G., Jackson, C., \& Boyes, B. E. (1994). Size exclusion chromatography. Analytical chemistry, 66(12), 595-620.

Bolea, E., Gorriz, M. P., Bouby, M., Laborda, F., Castillo, J. R., \& Geckeis, H. (2006). Multielement characterization of metal-humic substances complexation by size exclusion chromatography, asymmetrical flow field-flow fractionation, ultrafiltration and inductively coupled plasma-mass spectrometry detection: A comparative approach. Journal of Chromatography A, 1129(2), 236-246. doi:https://doi.org/10.1016/j.chroma.2006.06.097

Bolyard, S. C., \& Reinhart, D. R. (2017). Evaluation of leachate dissolved organic nitrogen discharge effect on wastewater effluent quality. Waste Management, 65, 47-53. doi:http://dx.doi.org/10.1016/j.wasman.2017.03.025

Boyd, T. J., \& Osburn, C. L. (2004). Changes in CDOM fluorescence from allochthonous and autochthonous sources during tidal mixing and bacterial degradation in two coastal $\begin{array}{llll}\text { estuaries. } & \text { Marine } & \text { Chemistry, } & \text { 89(1), }\end{array}$ doi:https://doi.org/10.1016/j.marchem.2004.02.012

Brown, T. L. (2012). Chemistry : the central science. Boston: Prentice Hall.

Chen, W., Westerhoff, P., Leenheer, J. A., \& Booksh, K. (2003). Fluorescence excitationemission matrix regional integration to quantify spectra for dissolved organic matter. Environmental Science \& Technology, 37(24), 5701-5710. 
Chian, E. S., \& DeWalle, F. B. (1977). Characterization of soluble organic matter in leachate. Environmental Science \& Technology, 11(2), 158-163.

Chin, W.-C., Orellana, M. V., \& Verdugo, P. (1998). Spontaneous assembly of marine dissolved organic matter into polymer gels. Nature, 391(6667), 568.

Coble, P. G. (1996). Characterization of marine and terrestrial DOM in seawater using excitationemission matrix spectroscopy. Marine Chemistry, 51(4), 325-346. doi:https://doi.org/10.1016/0304-4203(95)00062-3

Comstock, S. E. H., Boyer, T. H., Graf, K. C., \& Townsend, T. G. (2010). Effect of landfill characteristics on leachate organic matter properties and coagulation treatability. Chemosphere, 81(7), 976-983. doi:http://dx.doi.org/10.1016/j.chemosphere.2010.07.030

Cottrell, B. A., Timko, S. A., Devera, L., Robinson, A. K., Gonsior, M., Vizenor, A. E., .. Cooper, W. J. (2013). Photochemistry of excited-state species in natural waters: A role for particulate organic matter. Water Research, 47(14), 5189-5199. doi:https://doi.org/10.1016/j.watres.2013.05.059

Crittenden, J. C., Trussell, R. R., Hand, D. W., Howe, K. J., \& Tchobanoglous, G. (2012). Chemical Oxidation and Reduction. In MWH's Water Treatment: Principles and Design, Third Edition (pp. 457-539): John Wiley \& Sons, Inc.

De Haan, H., \& De Boer, T. (1987). Applicability of light absorbance and fluorescence as measures of concentration and molecular size of dissolved organic carbon in humic Lake Tjeukemeer. Water Research, 21(6), 731-734. doi:https://doi.org/10.1016/00431354(87)90086-8

Dotson, A., Westerhoff, P., \& Krasner, S. W. (2009). Nitrogen enriched dissolved organic matter (DOM) isolates and their affinity to form emerging disinfection by-products. Water Science and Technology, 60(1), 135-143. doi:10.2166/wst.2009.333

Duntley, S. Q. (1963). Light in the sea. JOSA, 53(2), 214-233.

Fox, B. G., Thorn, R. M. S., Anesio, A. M., \& Reynolds, D. M. (2017). The in situ bacterial production of fluorescent organic matter; an investigation at a species level. Water Research, 125, 350-359. doi:https://doi.org/10.1016/j.watres.2017.08.040

Gao, H., \& Zepp, R. G. (1998). Factors Influencing Photoreactions of Dissolved Organic Matter in a Coastal River of the Southeastern United States. Environmental Science \& Technology, 32(19), 2940-2946. doi:10.1021/es9803660

Goldstone, J. V., Del Vecchio, R., Blough, N. V., \& Voelker, B. M. (2004). A multicomponent model of chromophoric dissolved organic matter photobleaching. Photochemistry and photobiology, 80(1), 52-60. 
Gonsior, M., Hertkorn, N., Conte, M. H., Cooper, W. J., Bastviken, D., Druffel, E., \& SchmittKopplin, P. (2014). Photochemical production of polyols arising from significant phototransformation of dissolved organic matter in the oligotrophic surface ocean. Marine Chemistry, 163, 10-18. doi:https://doi.org/10.1016/j.marchem.2014.04.002

Greedy, D. (2016). Landfilling and landfill mining. Waste Management \& Research: The Journal Of The International Solid Wastes And Public Cleansing Association, ISWA, 34(1), 1-2. doi:10.1177/0734242X15617878

Gu, B., Schmitt, J., Chen, Z., Liang, L., \& McCarthy, J. F. (1995). Adsorption and desorption of different organic matter fractions on iron oxide. Geochimica et Cosmochimica Acta, 59(2), 219-229.

Hansen, A. M., Kraus, T. E., Pellerin, B. A., Fleck, J. A., Downing, B. D., \& Bergamaschi, B. A. (2016). Optical properties of dissolved organic matter (DOM): effects of biological and photolytic degradation. Limnology and Oceanography, 61(3), 1015-1032.

Helms, J. R., Stubbins, A., Ritchie, J. D., Minor, E. C., Kieber, D. J., \& Mopper, K. (2008). Absorption Spectral Slopes and Slope Ratios as Indicators of Molecular Weight, Source, and Photobleaching of Chromophoric Dissolved Organic Matter. Limnology and Oceanography(3), 955.

Hou, W.-C., Henderson, W. M., Chowdhury, I., Goodwin, D. G., Chang, X., Martin, S., . . Zepp, R. G. (2016). The contribution of indirect photolysis to the degradation of graphene oxide in sunlight. Carbon, 110, 426-437. doi:https://doi.org/10.1016/j.carbon.2016.09.013

Huber, S. A., Balz, A., Abert, M., \& Pronk, W. (2011). Characterisation of aquatic humic and nonhumic matter with size-exclusion chromatography - organic carbon detection - organic nitrogen detection (LC-OCD-OND). Water Research, 45(2), 879-885. doi:https://doi.org/10.1016/j.watres.2010.09.023

Jiang, T., Liang, J., Zhang, M., Wang, D., Wei, S., \& Lu, S. (2016). Effect of Charge-Transfer Complex on Ultraviolet-Visible (UV-Vis) Absorption Property of Chromophoric Dissolved Organic Matter (CDOM) in Waters of Typical Water-Level Fluctuation Zones of the Three Gorges Reservoir Areas. Huan jing ke xue= Huanjing kexue, 37(2), 580-587.

Karen, L. B.-N., \& Mary Ann, M. (1999). Photochemical formation of biologically available nitrogen from dissolved humic substances in coastal marine systems. Aquatic Microbial Ecology, 18(3), 285-292.

Kerc, A., Bekbolet, M., \& Saatci, A. (2004). Effects of oxidative treatment techniques on molecular size distribution of humic acids. Water Science and Technology, 49(4), 7-12.

Kieber, R. J., Hydro, L. H., \& Seaton, P. J. (1997). Photooxidation of triglycerides and fatty acids in seawater: Implication toward the formation of marine humic substances. Limnology and Oceanography, 42(6), 1454-1462. 
Kjeldsen, P., Barlaz, M. A., Rooker, A. P., Baun, A., Ledin, A., \& Christensen, T. H. (2002). Present and long-term composition of MSW landfill leachate: A review. Critical Review in Environmental Science and Technology, 32(4).

Knudsen-Leerbeck, H., Mantikci, M., Bentzon-Tilia, M., Traving, S. J., Riemann, L., Hansen, J. L. S., \& Markager, S. (2017). Seasonal dynamics and bioavailability of dissolved organic matter in two contrasting temperate estuaries. Biogeochemistry, 134(1), 217-236. doi:10.1007/s10533-017-0357-2

Laborda, F., Bolea, E., Górriz, M. P., Martín-Ruiz, M. P., Ruiz-Beguería, S., \& Castillo, J. R. (2008). A speciation methodology to study the contributions of humic-like and fulvic-like acids to the mobilization of metals from compost using size exclusion chromatographyultraviolet absorption-inductively coupled plasma mass spectrometry and deconvolution $\begin{array}{lllll}\text { analysis. } & \text { Analytica } & \text { Chimica }\end{array}$ doi:https://doi.org/10.1016/j.aca.2007.10.048

Lakowicz, J. R. (2006). Principles of fluorescence spectroscopy. [electronic resource]: New York : Springer, c2006. 3rd ed.

Li, P., \& Hur, J. (2017). Utilization of UV-Vis spectroscopy and related data analyses for dissolved organic matter (DOM) studies: A review. Critical Reviews in Environmental Science \& Technology, 47(3), 131-154. doi:10.1080/10643389.2017.1309186

Liu, H., Jeong, J., Gray, H., Smith, S., \& Sedlak, D. L. (2011). Algal uptake of hydrophobic and hydrophilic dissolved organic nitrogen in effluent from biological nutrient removal municipal wastewater treatment systems. Environmental Science \& Technology, 46(2), 713-721.

Mack, J., \& Bolton, J. R. (1999). Photochemistry of nitrite and nitrate in aqueous solution: a review. Journal of Photochemistry and Photobiology A: Chemistry, 128(1), 1-13. doi:https://doi.org/10.1016/S1010-6030(99)00155-0

Miller, W. L., \& Moran, M. A. (1997). Interaction of Photochemical and Microbial Processes in the Degradation of Refractory Dissolved Organic Matter from a Coastal Marine Environment. Limnology and Oceanography(6), 1317.

Monje-Ramirez, I., \& Velásquez, M. T. O. d. (2004). Removal and transformation of recalcitrant organic matter from stabilized saline landfill leachates by coagulation-ozonation coupling processes. Water $\quad$ Research, 38(9), 2359-2367. doi:http://dx.doi.org/10.1016/j.watres.2004.02.011

Mopper, K., Zhou, X., Kieber, R. J., Kieber, D. J., Sikorski, R. J., \& Jones, R. D. (1991). Photochemical degradation of dissolved organic carbon and its impact on the oceanic carbon cycle. Nature, 353(6339), 60-62. 
Moran, M. A., \& Zepp, R. G. (1997). Role of Photoreactions in the Formation of Biologically Labile Compounds from Dissolved Organic Matter. Limnology and Oceanography(6), 1307.

Mori, S., \& Barth, H. G. (2013). Size exclusion chromatography: Springer Science \& Business Media.

Núñez, L., García-Hortal, J. A., \& Torrades, F. (2007). Study of kinetic parameters related to the decolourization and mineralization of reactive dyes from textile dyeing using Fenton and photo-Fenton processes. Dyes and Pigments, 75(3), 647-652. doi:https://doi.org/10.1016/j.dyepig.2006.07.014

Patel-Sorrentino, N., Mounier, S., Lucas, Y., \& Benaim, J. Y. (2004). Effects of UV-visible irradiation on natural organic matter from the Amazon basin. Science of The Total Environment, 321(1), 231-239. doi:http://dx.doi.org/10.1016/j.scitotenv.2003.08.017

Pernet-coudrier, B., Clouzot, L., Varrault, G., Tusseau-vuillemin, M.-H., Verger, A., \& Mouchel, J.-M. (2008). Dissolved organic matter from treated effluent of a major wastewater treatment plant: Characterization and influence on copper toxicity. Chemosphere, 73(4), 593-599. doi:http://dx.doi.org/10.1016/j.chemosphere.2008.05.064

Piccolo, A., Zaccheo, P., \& Genevini, P. G. (1992). Chemical characterization of humic substances extracted from organic-waste-amended soils. Bioresource Technology, 40(3), 275-282. doi:https://doi.org/10.1016/0960-8524(92)90154-P

Powell, J. T., Pons, J. C., \& Chertow, M. (2016). Waste Informatics: Establishing Characteristics of Contemporary U.S. Landfill Quantities and Practices. Environmental Science \& Technology, 50(20), 10877-10884. doi:10.1021/acs.est.6b02848

Roberts, P. V., Summers, R. S., \& Cornel, P. K. (1987). Molecular size distribution and spectroscopic characterization of humic substances. Science of the Total Environment, 62(1-3), 27.

Salonen, K., Kairesalo, T., \& Jones, R. (2012). Dissolved organic matter in lacustrine ecosystems: energy source and system regulator (Vol. 73): Springer Science \& Business Media.

Sanchez, N. P., Skeriotis, A. T., \& Miller, C. M. (2013). Assessment of dissolved organic matter fluorescence PARAFAC components before and after coagulation-filtration in a full scale water treatment plant. Water Research, 47(4), 1679-1690. doi:https://doi.org/10.1016/j.watres.2012.12.032

Schwarzenbach, R. P., Gschwend, P. M., \& Imboden, D. M. (2005). Direct Photolysis. In Environmental Organic Chemistry (pp. 611-654): John Wiley \& Sons, Inc.

Seligman, P. F., Valkirs, A. O., \& Lee, R. F. (1986). Degradation of tributyltin in San Diego bay, california, waters. Environmental Science \& Technology, 20(12), 1229-1235. 
Stedmon, C. A., Markager, S., \& Bro, R. (2003). Tracing dissolved organic matter in aquatic environments using a new approach to fluorescence spectroscopy. Marine Chemistry, 82(3), 239-254. doi:https://doi.org/10.1016/S0304-4203(03)00072-0

Stibinger, J. (2017). Approximation of clogging in a leachate collection system in municipal solid waste landfill in Osecna (Northern Bohemia, Czech Republic). Waste Management, 63, 131-142. doi:http://dx.doi.org/10.1016/j.wasman.2016.08.034

Stiig Markager, a., \& Warwick F. Vincent, a. (2000). Spectral Light Attenuation and the Absorption of UV and Blue Light in Natural Waters. Limnology and Oceanography(3), 642.

Stubbins, A., Spencer, R. G. M., Chen, H., Hatcher, P. G., Mopper, K., Hernes, P. J., . . Six, J. (2010). Illuminated darkness: Molecular signatures of Congo River dissolved organic matter and its photochemical alteration as revealed by ultrahigh precision mass spectrometry. Limnology and Oceanography, 55(4), 1467-1477. doi:10.4319/lo.2010.55.4.1467

Sulzberger, B., \& Durisch-Kaiser, E. (2009). Chemical characterization of dissolved organic matter (DOM): a prerequisite for understanding UV-induced changes of DOM absorption properties and bioavailability. Aquatic sciences, 71(2), 104-126.

Tarr, M. A., Wang, W., Bianchi, T. S., \& Engelhaupt, E. (2001). Mechanisms of ammonia and amino acid photoproduction from aquatic humic and colloidal matter. Water Research, 35(15), 3688-3696.

Timko, S. A., Gonsior, M., \& Cooper, W. J. (2015). Influence of pH on fluorescent dissolved organic matter photo-degradation. Water Research, 85, 266-274.

Tranvik, L. J., \& Bertilsson, S. (2001). Contrasting effects of solar UV radiation on dissolved organic sources for bacterial growth. Ecology Letters, 4(5), 458-463. doi:10.1046/j.14610248.2001.00245.x

Uyguner, C. S., \& Bekbolet, M. (2005). Evaluation of humic acid photocatalytic degradation by UV-vis and fluorescence spectroscopy. Catalysis Today, 101(3), 267-274. doi:https://doi.org/10.1016/j.cattod.2005.03.011

Vähätalo, A. V., \& Järvinen, M. (2007). Photochemically produced bioavailable nitrogen from biologically recalcitrant dissolved organic matter stimulates production of a nitrogenlimited microbial food web in the Baltic Sea. Limnology and Oceanography, 52(1), 132143.

Zairi, M., Aydi, A., \& Dhia, H. B. (2014). Leachate generation and biogas energy recovery in the Jebel Chakir municipal solid waste landfill, Tunisia. Journal of Material Cycles and Waste Management, 16(1), 141-150. doi:10.1007/s10163-013-0164-3 
Zepp, R. G., \& Cline, D. M. (1977). Rates of direct photolysis in aquatic environment. Environmental Science \& Technology, 11(4), 359-366. doi:10.1021/es60127a013

Zhang, C., Wang, Y., \& Qi, S. (2008). Identification and significance of sterols in MSW landfill leachate. Journal of Chromatography B, 874(1), 1-6. doi:https://doi.org/10.1016/j.jchromb.2008.08.014 